\title{
Influence of genetic variability and external regulating factors on amyloid-beta peptide aggregation
}

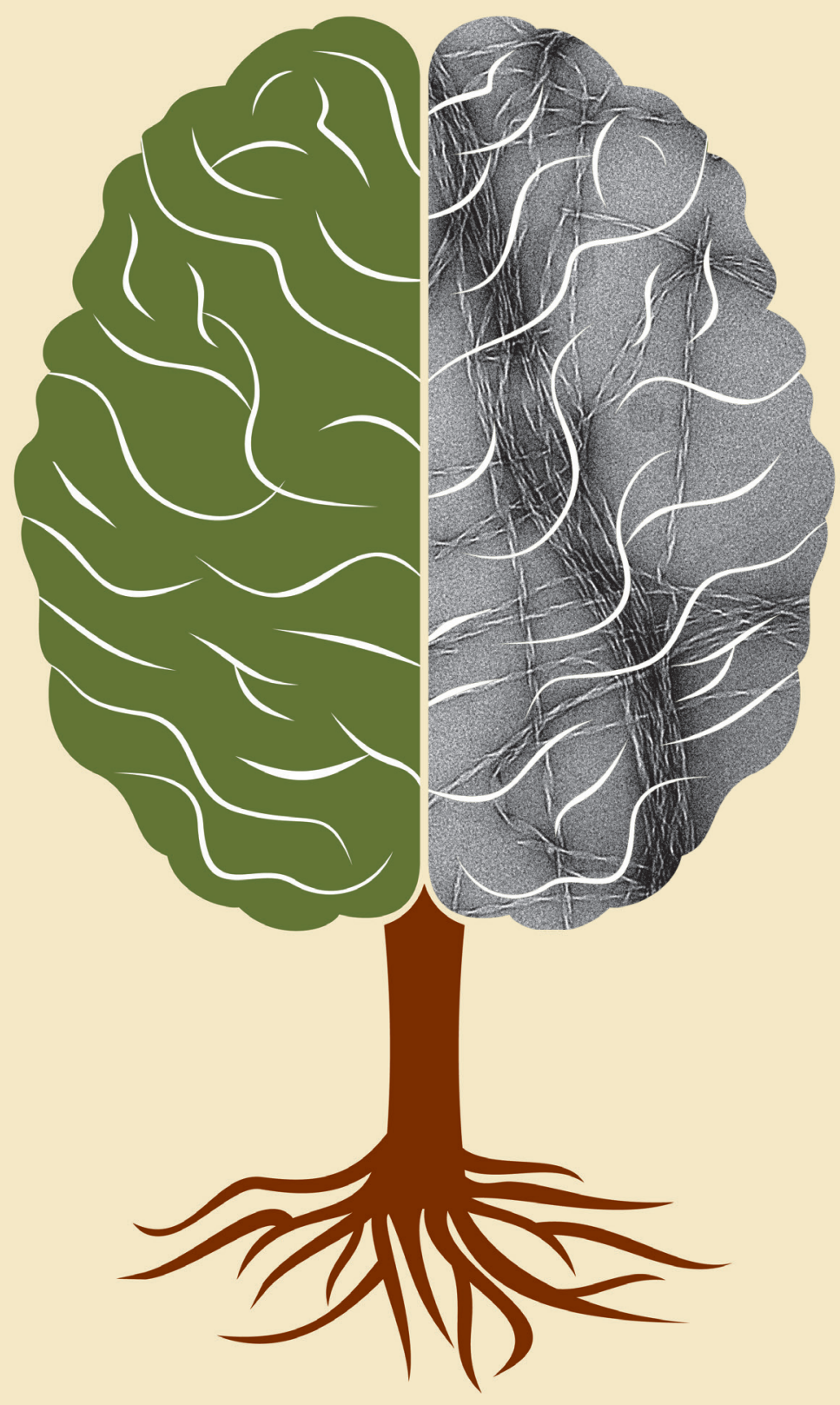

Ellen Hubin 



\section{INFLUENCE OF GENETIC VARIABILITY \\ AND EXTERNAL REGULATING FACTORS ON AMYLOID-BETA PEPTIDE AGGREGATION}

Thesis in fulfilment of the requirements for the degree of Doctor (Universiteit Twente) and Doctor in Bioengineering Sciences (Vrije Universiteit Brussel)

ir. Ellen Hubin 
Graduation committee members:

Prof. dr. ir. N. van Nuland Vrije Universiteit Brussel

(promotor)

Prof. dr. V. Subramaniam

Universiteit Twente

(promotor)

Prof. dr. K. Broersen

Universiteit Twente

(assistant-promotor)

Prof. dr. P. Tompa

Vrije Universiteit Brussel

Prof. dr. S. Ballet

Vrije Universiteit Brussel

Prof. dr. ir. M. van Putten

Universiteit Twente

Prof. dr. J. Cornelissen

Universiteit Twente

Prof. dr. V. Raussens

Université Libre de Bruxelles

Prof. dr. U.L.M. Eisel

Rijksuniversiteit Groningen

Prof. dr. ir. C. Kaminski University of Cambridge

The work described in this dissertation was performed at:

Molecular Recognition group

Structural Biology Research Center/VIB Department of Structural Biology

Vrije Universiteit Brussel, Belgium

Nanobiophysics group

MESA+ institute for nanotechnology,

MIRA institute for biotechnology and technical medicine,

Universiteit Twente, The Netherlands

This research was financially supported by the Fund for Scientific Research Flanders (FWOVlaanderen).

Copyright (C) 2014 by Ellen Hubin

cover design by Ellen Hubin and Gildeprint

All rights reserved. Apart from any fair dealing for the purposes of research or private study or criticism or review, this publication may not be reproduced, stored in a retrieval system, or transmitted, in any form or by any means (electronic, mechanical, photocopying, recording, scanning, or otherwise) without prior written permission of the author.

This dissertation was printed by Gildeprint, Enschede and can be downloaded from: http://dx.doi.org/10.3990/1.9789036537643

The production costs of this dissertation were co-funded by:

Alzheimer Nederland

Internationale Stichting Alzheimer Onderzoek
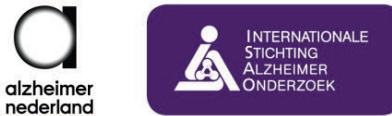

ISBN

978-90-365-3764-3

DOI

$10.3990 / 1.9789036537643$ 


\title{
INFLUENCE OF GENETIC VARIABILITY \\ AND EXTERNAL REGULATING FACTORS \\ ON AMYLOID-BETA PEPTIDE AGGREGATION
}

\author{
DISSERTATION
}

to obtain

the degree of doctor at the University of Twente, on the authority of the rector magnificus

Prof. dr. H. Brinksma

on account of the decision of the graduation committee,

to be publicly defended

on Friday the $24^{\text {th }}$ of October 2014 at 16:45

by

Ellen Sofie Hubin

born on the $31^{\text {st }}$ of July, 1987

in Antwerp, Belgium 
This dissertation has been approved by:

Prof. dr. ir. Nico van Nuland

(promotor)

Prof. dr. Vinod Subramaniam

(promotor)

Prof. dr. Kerensa Broersen

(assistant-promotor) 
Twenty years from now you will be more disappointed by the things that you didn't do than by the ones you did do, so throw off the bowlines, sail away from safe harbour, and catch the trade winds in your sails.

Explore. Dream. Discover.

Mark Twain 



\section{Acknowledgements}

It is not the critic who counts, not the man who points out how the strong man stumbles, or where the doer of deeds could have done them better. The credit belongs to the man who is actually in the arena, whose face is marred by dust and sweat and blood, who strives valiantly, who errs, who comes short again and again, because there is no effort without error and shortcoming; but who does actually strive to do the deeds, who knows great enthusiasms, the great devotions, who spends himself in a worthy cause, who at the best knows in the end the great triumph of high achievement, and who at the worst, if he fails, at least fails while daring greatly, so that his place shall never be with those cold and timid souls who neither know victory nor defeat.

Theodore Roosevelt

Four years in the amyloid arena have resulted in the work presented in this $\mathrm{PhD}$ thesis.

However, I did not stand alone.

Others have strived with me, and to them I owe a debt of gratitude, as the great triumph I feel today is for a big part ascribed to their support.

Kerensa, it was your enthusiasm that inspired me to start this journey with you. You have guided me to become an independent researcher, always there when needed, but allowing me to pave my own way. You have challenged me, motivated me, always optimistic, confident that our goals would be reached. You have created countless opportunities for me to meet and exchange my ideas with people from all over the world, at scientific meetings and conferences, and during research stays in other laboratories. In other words, I would not be standing here today if it wasn't for you. And however frightening it was to hear that you would move to The Netherlands in the very beginning of my $\mathrm{PhD}$, I now believe this experience has made the journey even more interesting, not only in terms of science, but also for my personal enrichment.

Nico, it is not an obvious choice to engage yourself as a promotor for someone working on a topic with which you are not familiar. Nevertheless, you have welcomed me in the MoRe group and gradually became more involved in my project. You followed my progress and always encouraged me along the way. Vinod, thank you for providing me with the opportunity to be a part of NBP, making me feel welcome at the UT, and critically reviewing my thesis in the final stage.

Rabia and Kris, you have both inspired me with your passion for science and learned me a great deal these past few years. Rabia, you have been a solid support during my thesis, always willing to help and share ideas, tackling problems with endless enthusiasm. Thank you for your friendship and for being such an energetic and motivating personality. Kris, you truly 
made me think out-of-the-box when reaching out to the field of ecosystem biology in an attempt to approach Alzheimer's disease from a different angle. This is what makes science so fun and challenging, and I have really enjoyed all our scientific and philosophical discussions.

Vincent, thank you for making our collaboration possible and for welcoming me in your group. As I was the only one studying $A \beta$ and $A p o E$ in the VUB research lab at a certain point, this was invaluable for me and is very much appreciated.

Annelies, my fellow comrade in the study of the A $\beta$ peptide, thank you for sharing your knowledge and for guiding me in the lab in the beginning of my $\mathrm{PhD}$, I have learned a lot from you. We had our laughs, especially when first encountering the habits of our northern neighbours: (butter)milk during lunch meetings, broodje kroket (uit de muur), ...

A big thanks also goes to:

The members of my examination committee, for the critical reading of my thesis that has greatly improved the quality of this document.

Clemens, for his inspiring talks in Leuven and Spetses. Thank you for inviting me for a research stay in your group, I had the most wonderful time in Cambridge. Also Gabi, Dora, and Laurie, thank you for your help with the experimental work, and for making me feel welcome in your group.

Harry and Coen, for your assistance during the inflammation experiments. Although the experiments didn't go as planned and Coen, your magic wand apparently didn't work, I really enjoyed the time spent in your lab.

Bram and Nico, for rising to the challenge to bridge the gap between our two disciplines, and for sharing your ideas and insights from ecology and ecosystem management; Jef, for introducing me into the world of mass spectrometry; Stéph, for your expertise in mass spectrometry and for your critical reviewing of our manuscript; Nicolas, for teaching me how to produce and purify ApoE; Philip, for teaching us the ApoE lipidation procedure and for your critical reviewing of our manuscript.

The ladies of the secretaries of both SBB and NBP, for your help with all the administration, which tends to double when doing a joint $\mathrm{PhD}$; and Bruno, for your help in the lab.

To all the people of both research groups, MoRe and NBP, for creating a nice working environment, for the scientific discussions, the chats, the laughs, the ventilations of frustration, the flying fish, the swimming breaks, the after work drinks. A special thanks to my paranymphs Anneleen and Karen for being the best of friends, to Steven for being his crazy and funny self and sharing my interest in epic fantasy novels, to Yann, for all the encouragement along the way, to Niels, for his hospitality during my first stays in Enschede, and to Sarah, Alexandra, Alex, Sophie, Radu, MA, Lucia, Mike, Katty, Wim, ... 
And last, but definitely not least, I would like to thank:

my friends, for being awesome and for making life wonderful,

my family, for their love, advice, and unconditional support, and for providing me with a warm nest to come home to,

in particular my brother, for making me put everything in perspective once in a while,

and my parents, who have provided me with so many opportunities in life, and have always encouraged me to undertake, discover, and go beyond my comfort zone,

and finally, Timo, for always being there with me in the arena, in times of failure and success. Thank you for your love, care, patience, encouragement, support, and for making me smile every day. I love you! 



\section{$\underline{\text { Table of contents }}$}

\section{INTRODUCTION}

CHAPTER 1:

Protein aggregation, Alzheimer's disease, and the amyloid-beta peptide

CHAPTER 2:

A comparative analysis of the aggregation behaviour of $\mathrm{A} \beta$ peptide variants

CHAPTER 3:

Distinct $\beta$-sheet structures in wild type and Italian-mutant $A \beta$ fibrils:

a possible link to different clinical phenotypes

CHAPTER 4:

ApoE associated with reconstituted HDL-like particles is protected from aggregation

CHAPTER 5:

Insights into insulin-degrading enzyme-mediated cleavage of the $A \beta$ peptide

CHAPTER 6:

New peptidomimetic inhibitors of $A \beta$ aggregation:

molecular guidance for rational drug design

CHAPTER 7:

Can ecosystem management provide a framework for Alzheimer's disease therapy?

CONCLUDING REMARKS AND PERSPECTIVES

SUMMARY 


\section{List of abbreviations}

$\mathrm{A} \beta$

AD

AFM

AICD

ANS

ApoE

APP

ATR

BBB

CAA

CD

CNS

$\mathrm{CSF}$

CTF

DLS

DMSO

EDTA

EPR

ESI

FAD

FDG

FFF

FLIM

FTIR

FWHH

GSI

HDL

HDX

HFIP

HRP

HSQC

IDE

IDP

LC

LDL

LPS

LRP

MALDI-TOF

MALS

MD

MM/GBSA

MRI amyloid-beta

Alzheimer's disease

atomic force microscopy

amyloid precursor protein intracellular domain

1-anilinoaphthalene 8-sulfonate

Apolipoprotein E

amyloid precursor protein

attenuated total reflectance

blood brain barrier

cerebral amyloid angiopathy

circular dichroism

central nervous system

cerebrospinal fluid

C-terminal fragment

dynamic light scattering

dimethyl sulfoxide

ethylenediaminetetraacetic acid

electron paramagnetic resonance

electrospray ionization

familial Alzheimer's disease

fluoro-deoxy-D-glucose

field flow fractionation

fluorescence lifetime imaging spectroscopy

Fourier transform infrared spectroscopy

full width at half height

$\gamma$-secretase inhibitors

high density lipoprotein

hydrogen-deuterium exchange

hexafluoroisopropanol

horseradish peroxidase

heteronuclear single quantum correlation spectroscopy

insulin-degrading enzyme

intrinsically disordered protein

liquid chromatography

low density lipoprotein

lipopolysaccharide

low density lipoprotein receptor-related protein

matrix-assisted laser desorption ionization-time of flight

multi-angle light scattering

molecular dynamics

molecular mechanics/generalized born surface area

magnetic resonance imaging 
mass spectrometry

NEP

neprilysin

NFT

neurofibrillary tangles

NMDA

N-methyl-D-aspartate

NMR

nuclear magnetic resonance

NTF

$\mathrm{N}$-terminal fragment

PAGE

PBS

polyacrylamide gel electrophoresis

PET

phosphate-buffered saline

POPC

positron emission tomography

PSEN

1-palmitoyl-2-oleoyl-sn-glycero-3-phosphocholine

RAGE

ROS

presenilin

receptor for advanced glycation end products

RT

reactive oxygen species

RT-qPCR

reverse transcriptase

SEC

real-time quantitative polymerase chain reaction

TBS

size exclusion chromatography

TEM

tris-buffered saline

ThT

transmission electron microscopy

UV

thioflavin $\mathrm{T}$

VLDL

ultraviolet

WT

very low density lipoprotein

wild type

$\mathrm{A} \beta$ sequence of the 42-amino acid long peptide, and mutations studied in this thesis:

\section{DAEFRHDSGYEVHHQKLVFFAEDVGSNKGAIIGLMVGGVVIA}

D7N

A21G

E22G

$\mathrm{E} 22 \mathrm{~K}$

E22Q

$\mathrm{D} 23 \mathrm{~N}$
Tottori mutation: aspartic acid at position 7 to asparagine

Flemish mutation: alanine at position 21 to glycine

Arctic mutation: glutamic acid at position 22 to glycine

Italian mutation: glutamic acid at position 22 to lysine

Dutch mutation: glutamic acid at position 22 to glutamine

Iowa mutation: aspartic acid at position 23 to asparagine 


\section{Introduction}

Alzheimer's disease (AD) is a progressive form of neurodegeneration known as dementia, affecting millions of people worldwide (1). The earliest disease symptom of AD is a decline in memory capabilities, but as $\mathrm{AD}$ pathology spreads throughout the brain, patients experience behavioural problems, personality changes, and gradually lose their ability to communicate and recognize others. Eventually AD patients become bedridden and depend entirely on others for care. In the final disease stage, AD is fatal (2).

\section{The amyloid-beta peptide: a major player in Alzheimer's disease}

The general paradigm states that the primary driver of AD pathology is the amyloid-beta $(\mathrm{A} \beta)$ peptide (3). A $\beta$ is cleaved from the transmembrane amyloid precursor protein (APP) by $\beta$ and $\gamma$-secretase and is released in the extracellular space of the brain as an intrinsically disordered monomer. In the $\mathrm{AD}$ brain, the $\mathrm{A} \beta$ monomer aggregates to oligomers and fibrils that deposit in amyloid plaques (4). Considerable research has been conducted to understand the $A \beta$ aggregation mechanism and characterize the intermediate species that occur along the aggregation pathway and their dynamic interplay. The current amyloid cascade hypothesis suggests that soluble $\mathrm{A} \beta$ oligomers are the main toxic agents in $\mathrm{AD}$, causing synapto- and neurotoxicity that eventually progress in brain deterioration and the associated disease symptoms (5). However, the dynamic behaviour of $A \beta$ might provide an additional source for toxicity, as the ongoing aggregation process has also been suggested to be responsible for $\mathrm{AD}$ pathology (6). Nevertheless, although $\mathrm{A} \beta$ has been the main target of many therapeutic strategies (7), AD treatment interventions have not yet been successful in halting or reverting disease progression, and an effective AD therapy remains to be discovered.

\section{Research objective: studying the dynamic nature of the amyloid-beta peptide}

AD therapy development is hampered by the highly dynamic nature of $A \beta$, in terms of (i) the intrinsic molecular flexibility of the peptide, (ii) the behaviour of the various $A \beta$ peptides, and (iii) the dynamics of interactions, as reviewed in chapter 1 (8). First, the A $\beta$ peptide is characterized by intrinsic disorder or polypeptide backbone flexibility (intramolecular dynamics). This intrinsic disorder is present in the isolated monomeric peptide, but also in $\mathrm{A} \beta$ aggregation states. Moreover, the in vivo $\mathrm{A} \beta$ peptide pool is highly dynamic containing different $A \beta$ peptides that interact and influence each other's aggregation and toxic behaviour. These A $\beta$ peptides vary in length due to heterogeneous $\gamma$-secretase cleavage, or contain posttranslational modifications and/or mutations. Finally, the dynamic equilibrium that exists between different $A \beta$ aggregation species and the interplay with several external factors and interaction partners (e.g. lipids, membranes, metals, cofactors, enzymes) also contribute to A $\beta$ dynamics (intermolecular dynamics) and AD pathology.

Understanding $A \beta$ dynamics is crucial to comprehend the molecular mechanisms underlying the pathophysiology of $\mathrm{AD}$. This will allow a more rational design of therapeutic intervention strategies to halt the disease progress and neutralize the malignant action of $A \beta$ aggregation. Following these events in real-time in the human brain is difficult, if not impossible. Therefore, they are often mimicked in the test tube in research laboratories where information on $\mathrm{A} \beta$ behaviour can be followed in molecular detail using advanced biophysical and biochemical assays in the course of seconds to hours or days, whereas these processes happen in patients over a range of years. 
The aim of this doctoral thesis is to investigate the dynamic nature of the $A \beta$ peptide in the context of AD, by using a biophysical approach complemented with cell culture studies. The dynamic behaviour of the $A \beta$ peptide is illustrated and considered in all its facets as described in detail in chapter 1, from intra- to intermolecular dynamics. The research presented in this thesis provides insights into the effect of (i) genetic variability (chapters 2-4) and of (ii) external regulating factors (chapters 5-7) on $A \beta$ dynamics, mainly focusing on aggregation behaviour and structural properties of the $\mathrm{A} \beta$ peptide.

\section{Outline of this thesis}

Chapter 1, based on extensive literature review, introduces the concept of protein (dis)order and describes how protein aggregation can result in amyloid-related diseases such as AD. The second part of this chapter focuses on $\mathrm{AD}$ and illustrates the highly dynamic nature of $\mathrm{A} \beta$, and how this affects its structural and toxic properties in the context of AD.

The heterogeneity and dynamics of the $\mathrm{A} \beta$ peptide pool is illustrated in chapter 2 by a comparative study of the aggregation behaviour of a selection of $A \beta$ peptides occurring in the human brain (9). A $\beta$ variants included in the analysis were (i) $A \beta$ mutants associated with early-onset familial AD (FAD) arising from mutations within the $A \beta$-coding region of the $A P P$ gene, (ii) A $\beta$ peptide lengths originating from heterogeneous $\gamma$-secretase cleavage, and (iii) N-terminally truncated $\mathrm{A} \beta$ variants. In addition to naturally occurring peptides, the aggregation properties of (iv) biotinylated $\mathrm{A} \beta$ peptides were also examined. Biotinylation of $\mathrm{A} \beta$ is often used in vitro to facilitate its study, but a systematic verification that the labelling does not affect $A \beta$ properties has not yet been performed.

Chapter 3 elaborates on the intrinsic molecular flexibility of one of the early-onset FAD A $\beta$ mutants studied in the previous chapter: the Italian (E22K) A $\beta$ peptide, which is associated with cerebral amyloid angiopathy (CAA) (10). Wild type and Italian-mutant A $\beta$ aggregation were monitored and the structural and inflammatory properties of the corresponding fibrils were investigated in more detail.

Chapter 4 focuses on Apolipoprotein E (ApoE), as the ApoE $\varepsilon 4$ allele is one of the most important genetic risk factors for the development of late-onset AD (11). ApoE mainly occurs associated with lipids in vivo, but lipid-poor ApoE pools are present in the brain as well, and the ApoE lipidation status has been reported to influence ApoE functionality and its effect on A $\beta$ metabolism (12). Therefore, this chapter presents an extensive biophysical characterization of ApoE, in its lipid-free and lipid-bound form.

$\mathrm{A} \beta$ metabolism is also greatly influenced by $A \beta$-degrading enzymes that are capable of reducing the amyloid load, such as insulin-degrading enzyme (IDE) (13). Chapter 5 investigates the ability of IDE to cleave different $A \beta$ aggregation species, as these insights have consequences for protease-based $\mathrm{AD}$ therapies.

Next, novel mimetic peptide compounds were designed to inhibit $\mathrm{A} \beta$ aggregation using a structure-based virtual approach. Molecular simulations were conducted to provide insight into their potential mode of action, and biophysical assays assessed their predicted effect in vitro (Chapter 6). 
Finally, the parallel that exists between the complexity and dynamics of the "A $\beta$ network" within $\mathrm{AD}$ and the complex architecture of an ecosystem is described in chapter 7 , with the aim of providing a new framework for understanding $\mathrm{AD}$ mechanisms and designing more effective therapeutic strategies.

The closing chapter consists of concluding remarks and gives some perspectives on promising $\mathrm{AD}$ research avenues for the future. 


\section{$\underline{\text { References }}$}

1. Thies W, Bleiler L, \& Association As (2013) 2013 Alzheimer's disease facts and figures. Alzheimers Dement 9(2):208-245.

2. ADEAR (2008) Alzheimer's disease: unraveling the mystery. (NIH publication no. 08- 3782).

3. Hardy J \& Allsop D (1991) Amyloid deposition as the central event in the aetiology of Alzheimer's disease. Trends Pharmacol Sci 12(10):383-388.

4. Masters CL \& Selkoe DJ (2012) Biochemistry of amyloid $\beta$-protein and amyloid deposits in Alzheimer disease. Cold Spring Harb Perspect Med 2(6):a006262.

5. Haass C \& Selkoe DJ (2007) Soluble protein oligomers in neurodegeneration: lessons from the Alzheimer's amyloid $\beta$-peptide. Nat Rev Mol Cell Biol 8(2):101-112.

6. Jan A, et al. (2011) A $\beta 42$ neurotoxicity is mediated by ongoing nucleated polymerization process rather than by discrete A $\beta 42$ species. J Biol Chem 286(10):8585-8596.

7. Karran E, Mercken M, \& De Strooper B (2011) The amyloid cascade hypothesis for Alzheimer's disease: an appraisal for the development of therapeutics. Nat Rev Drug Discov 10(9):698-712.

8. Hubin E, van Nuland NA, Broersen K, \& Pauwels K (2014) Transient dynamics of A $\beta$ contribute to toxicity in Alzheimer's disease. Cell Mol Life Sci. 71(18), 3507-3521.

9. Vandersteen A, et al. (2012) A comparative analysis of the aggregation behavior of amyloid- $\beta$ peptide variants. FEBS Lett 586(23):4088-4093.

10. Bugiani O, et al. (2010) Hereditary cerebral hemorrhage with amyloidosis associated with the E693K mutation of APP. Arch Neurol 67(8):987-995.

11. Spinney L (2014) Alzheimer's disease: The forgetting gene. Nature 510(7503):26-28.

12. Hauser PS, Narayanaswami V, \& Ryan RO (2011) Apolipoprotein E: from lipid transport to neurobiology. Prog Lipid Res 50(1):62-74.

13. Saido T \& Leissring MA (2012) Proteolytic degradation of amyloid $\beta$-protein. Cold Spring Harb Perspect Med 2(6):a006379. 


\section{Chapter 1}

\section{Protein aggregation, Alzheimer's disease, and the amyloid-beta peptide}

Parts of this chapter have been published as:

Hubin E, van Nuland N, Broersen K, and Pauwels K (2014).

Transient dynamics of $\mathrm{A} \beta$ contribute to toxicity in Alzheimer's disease.

Cellular and Molecular Life Sciences 71(18), 3507-3521.

Proteins are essential in life as they exert a wide range of vital functions in the cell. Although most proteins need to adopt a defined three-dimensional structure to perform their function, growing recognition has emerged in the past decade that (partly) intrinsically disordered proteins have significant functional roles. Proteins are subject to cellular quality control processes, and failure of these mechanisms can result in misfolding and protein aggregation, leading to malfunctioning and human diseases. One major human disorder associated with protein aggregation is Alzheimer's disease (AD), which is the leading cause of dementia and affects millions of people worldwide. The amyloid-beta (A $\beta$ ) peptide has been suggested to be the primary driver of the development and pathogenesis of $\mathrm{AD}$, and converts from an apparently harmless intrinsically disordered monomer into more ordered and toxic aggregates. The lack of a cure for $\mathrm{AD}$ and the predicted increase in disease prevalence, as a result of its strong association with increasing age, emphasize the need for the development of an effective therapy. Gaining more and novel insights into the role of $\mathrm{A} \beta$ in $\mathrm{AD}$ pathology is essential for devising more effective strategies to halt or reverse disease progression.

This chapter introduces the concept of protein (dis)order, describes how protein aggregation can result in amyloid-related diseases, and then focuses on AD. The highly dynamic nature of the $A \beta$ peptide is illustrated, and how this affects its structural and toxic properties in the context of AD. 


\section{Contents}

\subsection{The remarkable properties of protein (dis)order}

1.1.1. The classical structure-function paradigm

1.1.2. Intrinsically disordered proteins: highly abundant in nature

\subsection{Protein misfolding, aggregation, and amyloid-related diseases}

1.2.1. Protein misfolding and aggregation

1.2.2. Tight regulation of intrinsically disordered proteins

1.2.3. When protein quality control fails: amyloid-related diseases

\subsection{Alzheimer's disease: a progressive neurodegenerative brain disorder}

1.3.1. Impact of AD

1.3.2. Major histopathological hallmarks of AD

1.3.3. AD risk factors

1.3.4. Diagnosis and treatment of $\mathrm{AD}$

1.3.4.1. AD diagnosis: a combined effort

1.3.4.2. Current AD drugs temporarily reduce disease symptoms

\subsection{The amyloid-beta peptide: the primary driver of AD pathogenesis}

\subsubsection{Intramolecular $A \beta$ dynamics}

1.4.1.1. The intrinsically disordered $A \beta$ monomer

1.4.1.2. Intrinsic fibril flexibility might underlie disease progression and phenotype

1.4.1.3. A $\beta$ oligomers: a mishmash of conformations and sizes

1.4.2. Intermolecular $A \beta$ dynamics

1.4.2.1. The in vivo $\mathrm{A} \beta$ peptide pool: a cocktail of different interacting species

1.4.2.2. The interactions between different species present during $A \beta$ aggregation

1.4.2.3. The dynamic equilibrium potentially contributes to $A \beta$ toxicity

1.4.3. Other players in the game

1.4.3.1. Receptor-mediated $\mathrm{A} \beta$ clearance and proteolytic $\mathrm{A} \beta$ degradation

1.4.3.2. Metals

1.4.3.3. Lipids and membranes

1.4.3.4. Chaperones

1.4.3.5. Lifestyle

1.4.4. AD therapy development

\subsection{References}




\subsection{The remarkable properties of protein (dis)order}

Proteins are the workhorses of life and carry out a variety of tasks ranging from structural support of cells, to catalysis of biochemical reactions and modulation of communication and cell signalling (1). Although it was initially thought that proteins must fold into a unique three-dimensional (3D) structure to perform their function, it has now been recognized that intrinsically disordered proteins (IDPs), lacking a stable structure in a specific region or across the entire primary sequence, can also have important functions. Whereas enzymatic and ligand-binding activities usually require a well-defined 3D structure, disorder is enriched in proteins exerting key regulatory functions such as signalling, control, and regulation (2-5).

\subsubsection{The classical structure-function paradigm}

Despite the wide variety of protein structures, they are composed of a subset of 20 building blocks (amino acids). The linear chain of amino acids, called the protein primary sequence, is encoded in the deoxyribonucleic acid (DNA) and makes up the primary structure of the protein. In 1961, Anfinsen and co-workers stated that the protein sequence contains all the information to fold into a native structure (6). Transition of the primary to the secondary structure involves the formation of stretches with distinct conformations that depend on the hydrogen (H)-bonding pattern of backbone amide and carboxyl groups (e.g. $\alpha$-helix, $\beta$-sheet, random coil, turn). Subsequent folding gives rise to the tertiary structure, the $3 \mathrm{D}$ shape of the protein that is defined by its atomic coordinates. During this process, hydrophobic side chains tend to be buried in the protein core, while hydrophilic residues are exposed to the aqueous medium. Moreover, several stabilizing interactions are formed such as disulphide bridges, salt bridges, and side chain H-bonds. The assembly of multiple protein subunits into one integral structure is called the quaternary structure (7).

\subsubsection{Intrinsically disordered proteins: highly abundant in nature}

Although long neglected in the protein field, it has now been recognized that many protein regions and even entire proteins lack stable secondary and/or tertiary structure in solution, and exist as highly dynamic ensembles of interconverting conformations. Despite their lack of stable structure, IDPs exert specific functions. Hence, a reassessment of the classical structure-function paradigm was necessary to include the phenomenon of intrinsic disorder (2). Predictors revealed that intrinsic disorder is abundant in nature and increases from bacteria to archaea to eukaryotes, with $10-45 \%$ of eukaryotic proteins containing significant disorder (regions of at least 30 residues in length) $(8,9)$.

Intrinsic disorder is enriched in biological processes such as transcription (regulation), signal transduction, cell cycle regulation, biogenesis and functioning of organelles (e.g. ribosome, chromatin), messenger ribonucleic acid (mRNA) processing, and organization and biogenesis of the cytoskeleton (3-5). The high flexibility of IDPs allows them to interact with different partners with high specificity and low affinity, and thus to exert multiple functions (10).

Given the crucial roles of IDPs in numerous biological processes, a significant enrichment of structural disorder was also found in various diseases, including cancer, diabetes, and cardiovascular diseases (11). Moreover, the open and exposed conformation of IDPs makes them vulnerable to aggregation. Therefore, many IDPs have been associated with amyloidrelated and neurodegenerative diseases (12). 


\subsection{Protein misfolding, aggregation, and amyloid-related diseases}

\subsubsection{Protein misfolding and aggregation}

Some proteins may convert into a structure that differs from their native conformational state, which is either characterized by a well-defined structure or is (partly) intrinsically disordered, by acquiring a substantial amount of non-native interactions that affects their overall architecture and biological function. This is referred to as misfolding (13). Misfolded conformers typically expose unfolded segments or hydrophobic residues that are normally shielded in the native conformation. Such patches are prone to aggregation and this can lead to undesirable interactions with other molecules in the complex and crowded cellular environment (14). Protein misfolding and aggregation can be induced by stress conditions (heat, oxidative stress), translational errors, protein mutations, or ageing $(15,16)$.

\subsubsection{Tight regulation of intrinsically disordered proteins}

Cells possess quality control machineries (e.g. chaperones, the unfolded protein response) that monitor and maintain protein homeostasis $(15,17-19)$. In the case of IDPs, their disordered nature, high conformational dynamics and flexibility, and sticky binding elements, require mechanisms to prevent them from aggregation or unwanted interactions with non-native partners. To prevent aggregation, IDPs are usually characterized by low hydrophobic residue content, a high net charge, and a low amount of aggregation-promoting regions $(20,21)$. Aggregation can also be averted by induced folding of IDPs upon binding to target molecules or upon interaction with membranes (22). Furthermore, functional misfolding has been proposed to sequester sticky and interaction-prone elements in IDPs through non-native intramolecular interactions inside a cage-like structure, that is not, or less, interactive (23). Finally, the availability of IDPs, i.e. their abundance and residing time in cells, is tightly regulated through a plethora of mechanisms modulating transcription, translation, degradation, and post-translational modification of IDPs (24).

\subsubsection{When protein quality control fails: amyloid-related diseases}

Failure of protein quality control mechanisms, due to their reduced capacity upon ageing or due to an overwhelming amount of aberrantly folded proteins, can result in disturbance of protein homeostasis. This can then lead to the accumulation of misfolded or unfolded proteins, and subsequent protein aggregation (25). Misfolding and protein aggregation are tightly associated with malfunctioning and diseases (26). Even small impairments in the quality control mechanisms that regulate protein concentration and solubility in the cell can lead to disease (27).

Protein aggregation involves the conversion and self-assembly of monomeric proteins into larger aggregates, that are either amorphous, partly structured, or highly ordered and insoluble, such as amyloid fibrils (Fig. 1.1) (28). The defining molecular unit of an amyloid fibril is the cross- $\beta$ spine that originates from extending $\beta$-sheets composed of $\beta$-strands that are arranged perpendicular to the fibre axis (29). Other criteria to define amyloid fibrils include binding to amyloid-specific dyes such as thioflavin T (ThT), green birefringence upon binding to Congo red, and their thread-like appearance of a few nanometres in diameter as observed by transmission electron microscopy (TEM) or atomic force microscopy (AFM) (30). 
A.

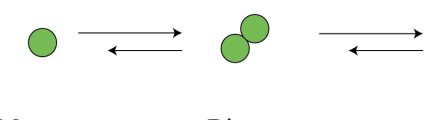

Monomer

Dimer

Oligomer
Protofibrils
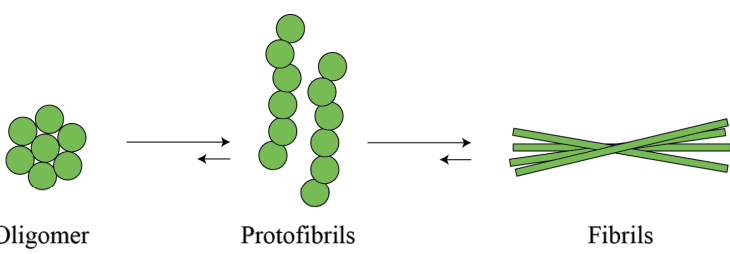

C.
C.

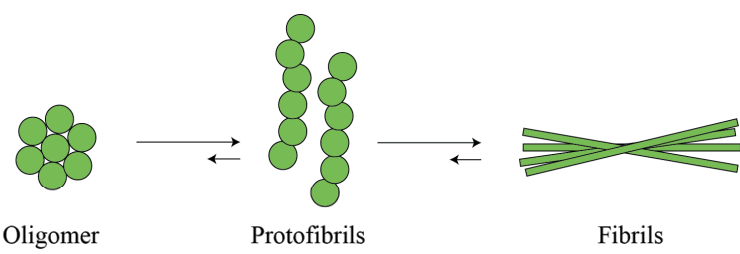

B.

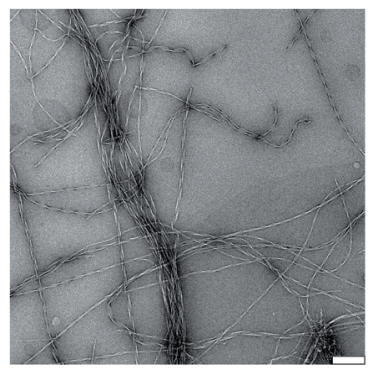

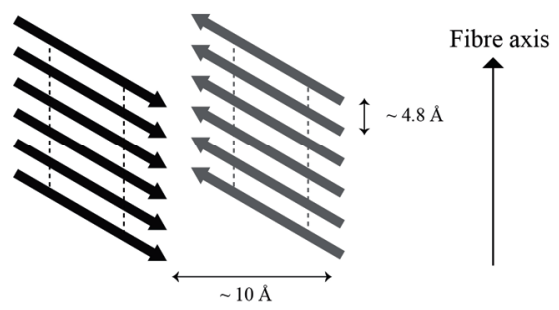

Figure 1.1: Schematic representation of the formation of amyloid fibrils and their associated morphology/structure. (A) A simplified scheme of the process of protein aggregation, in which a monomeric peptide/protein is converted into oligomers and highly ordered amyloid fibrils. A dynamic equilibrium exists between the different aggregation species. (B) TEM image of fibrils composed of the amyloid- $\beta$ peptide. Fibrils are typically $\sim 10 \mathrm{~nm}$ in diameter. The scale bar represents $200 \mathrm{~nm}$. (C) The cross- $\beta$ spine of amyloid fibrils consists of $\beta$-strands stacked perpendicular to the fibre axis, separated by $\sim 4.8 \AA$, and stabilized by H-bonds (indicated by dashed lines). The $\beta$-strands are organized in $\beta$-sheets that are separated by $\sim 10 \AA$ and run parallel to the fibre axis. The $\beta$-sheets can be either parallel (as depicted here) or antiparallel, i.e. containing adjacent $\mathrm{H}$ bonded $\beta$-strands running in the same or opposite direction, respectively.

Intra- or extracellular accumulation of protein aggregates can lead to the onset and development of amyloid-related diseases that are classified in two groups: non-neuropathic amyloidoses and neurodegenerative diseases (Table 1.1) (31). In the first group, an overload of amyloid deposition in organs or joints, either in a single organ or joint (localized) or in multiple tissues (systemic), leads to disease symptoms (32). In neurodegenerative diseases, soluble prefibrillar aggregates, rather than the amyloid deposits, are most likely the main cause of toxicity and disease pathology (33).

Table 1.1: A subset of human diseases associated with the accumulation of intracellular or extracellular amyloid deposits, adapted from (31).

\begin{tabular}{ll}
\hline \hline Human disease & Aggregating peptide or protein \\
\hline \hline Neurodegenerative diseases & Amyloid- $\beta$ peptide \\
Alzheimer's disease & $\alpha$-synuclein \\
Parkinson's disease & Prion protein or fragments \\
Spongiform encephalopathies & Huntingtin with polyQ expansion \\
Huntington's disease & $\alpha$-synuclein \\
Dementia with Lewy bodies & Tau \\
Frontotemporal dementia & \\
Systemic non-neuropathic amyloidoses & Immunoglobulin light chains or fragments \\
Amyloid Light-chain amyloidosis & Fragments of serum amyloid A protein \\
AA amyloidosis & Transthyretin \\
Senile systemic amyloidosis & $\beta 2$-microglobulin \\
Hemodialysis-related amyloidosis & \\
Localized non-neuropathic amyloidoses & amylin \\
Type II diabetes & $\gamma$-crystallin \\
Cataract & \\
\hline \hline
\end{tabular}


In contrast, amyloid formation can also be beneficial, and functional amyloids are found in all domains of life. They serve many functions ranging from biofilm formation, structural support, and host attachment, to scaffolding and sequestration of toxic intermediates (34). However, this chapter will only focus on disease-related amyloid formation.

\subsection{Alzheimer's disease: a progressive neurodegenerative brain disorder}

Of all known neurodegenerative diseases, Alzheimer's disease (AD) is by far the most prevalent one with a high impact on society. In the following section, several aspects of $A D$ will be discussed: the disease burden, the major pathological hallmarks and risk factors, and the current means of diagnosing and treating this disease.

\subsubsection{Impact of $\mathrm{AD}$}

$\mathrm{AD}$ is a progressive neurodegenerative brain disorder and the most common type of dementia, accounting for approximately $60-80 \%$ of all dementia cases. As dementia has been estimated to affect 36 million people worldwide (35), AD dramatically influences the lives of millions of patients and their families, but also imposes an enormous global burden in terms of health care costs and hospice. Considering the ageing global population and that there is no cure or prevention available yet, AD incidence has been predicted to nearly triple by 2050 (36).

Dementia is a general term that describes a range of disease symptoms associated with a decrease in mental ability due to brain dysfunction, severe enough to interfere with daily life. The most common early symptom associated with $\mathrm{AD}$ is the difficulty to remember newly learned information, as the first brain region to be damaged is the hippocampus, which is the brain centre responsible for memory and learning. Symptoms increase and aggravate in time and include memory loss, a decrease of thinking and learning capabilities, personality and behavioural changes, disorientation, and confusion. In severe or late-stage AD, patients lose their ability to respond to the environment, to control movement, and several body functions (e.g. swallowing, reflexes) are impaired. Eventually, AD patients lose their personal identity and ability to connect to others, and in the final stage AD is fatal (37).

\subsubsection{Major histopathological hallmarks of AD}

AD targets the brain, which contains a heterogeneous network of an estimated 86 billion neuronal cells $(38,39)$. Research is ongoing to create a 3D map of the human brain to fully understand its structure, processes, and complexity (40). Communication between neurons is crucial for normal brain functioning. AD causes damage to neurons and subsequent cell death, disrupting the underlying communication pathways between neurons and leading to brain atrophy and shrinkage. Processes involved in neuronal cell death include synapto- and neurotoxicity, inflammation, disruption of calcium homeostasis, and depletion of energy and growth factors. $\mathrm{AD}$ symptoms emerge as a consequence of dying neurons and perturbed nerve cell communication and depend on the brain region that is affected (41).

Post-mortem examination of $\mathrm{AD}$ brains revealed two primary histopathological disease hallmarks: intracellular neurofibrillary tangles (NFT) and extracellular amyloid plaques (42). NFTs are composed of hyperphosphorylated tau protein that is misfolded and builds up within neurons (43), and amyloid plaques mainly consist of the amyloid-beta $(\mathrm{A} \beta$ ) peptide (44). In healthy brains, tau and $A \beta$ are produced normally and exist as soluble IDPs (12). Whereas tau is found in axons and regulates the assembly and stability of microtubules (45), the A $\beta$ monomer has been suggested to act as a modulator of synaptic activity with neuroprotective functions $(46,47)$. This physiological role of $A \beta$ has however not yet been confirmed. In AD 
brains, an imbalance of the activities of protein kinases and phosphatases results in abnormal hyperphosphorylation of tau, which leads to microtubule disassembly. Free tau molecules then aggregate and form paired helical filaments (43). On the other hand, imbalance between $\mathrm{A} \beta$ production and clearance leads to abnormal $A \beta$ accumulation and onset of aggregation (44). The biochemistry of the $\mathrm{A} \beta$ peptide and its association with $\mathrm{AD}$ pathology will be discussed in more detail in section 1.4 of this chapter.

Numerous debates have dealt with the question what the primary causative factor is of AD pathology: tau or $A \beta$ ? Thirty years ago, the amyloid cascade hypothesis was launched and stated that $A \beta$ accumulation is the primary driver of $A D$ pathogenesis and that NFTs deposit after initial changes in $A \beta$ metabolism and plaque formation (48). Although the initial hypothesis has been re-evaluated several times during the past decades $(49,50)$, it remains the leading hypothesis to explain the pathophysiology of AD (Fig. 1.2). Nevertheless, one of the alternative views considers tau as the main driving force of $\mathrm{AD}$, as mutations in the gene encoding tau cause frontotemporal dementia in the absence of $\mathrm{A} \beta$ deposition (51). Moreover, abnormal levels of hyperphosphorylated tau are causative of a group of neurodegenerative disorders referred to as tauopathies (52). Therefore, tau is also targeted in therapeutic development for $\mathrm{AD}(53)$, albeit considerably less than $\mathrm{A} \beta$. Another alternative view deems that several AD pathogenic features can be interpreted as amyloid-independent alterations of synaptic plasticity, endolysosomal trafficking, cell cycle regulation, and neuronal survival (54).

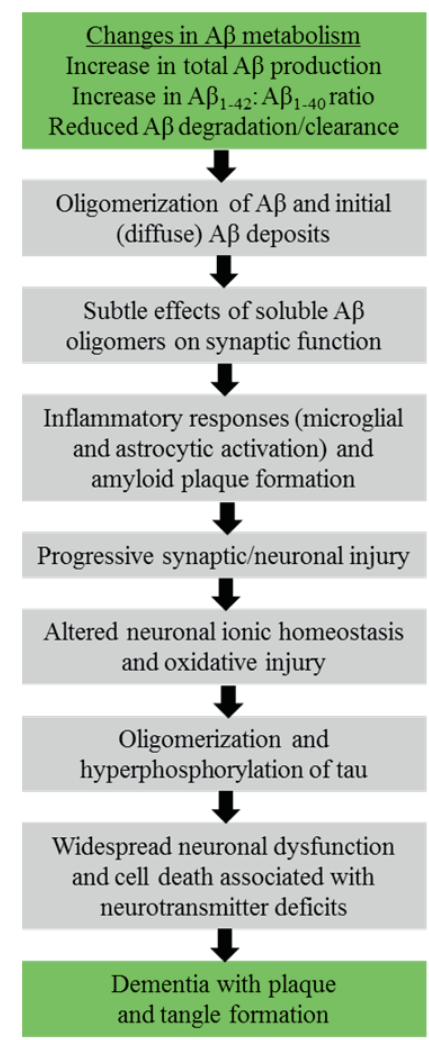

Figure 1.2: Amyloid cascade hypothesis. Gradual changes in the metabolism of A $\beta$ are thought to initiate the amyloid cascade, leading to dementia with plaque and tangle formation, i.e. AD. Adapted from (55). 


\subsubsection{AD risk factors}

Ageing is the most important risk factor for AD. In most cases, the first clinical symptoms do not appear before the age of 65. In the USA, an estimated one in nine people of the age of 65 years and older have $\mathrm{AD}$, and this prevalence increases to about one-third when the age of 85 is reached (36). Healthy non-demented individuals undergo several cognitive changes during ageing (e.g. decreased speed of mental processing and reaction, some decline in verbal fluency and difficulty with naming), but these are benign and static in comparison with the progressive and functionally significant changes in $\mathrm{AD}$ (56). The contribution of ageing to $\mathrm{AD}$ is not yet fully understood, but involves translational errors leading to defective protein synthesis, less efficient protein quality control machineries, cumulative oxidative damage to proteins and membranes, and age-related alterations of $\mathrm{A} \beta$ metabolism (57).

Family history is the second greatest risk for $\mathrm{AD}$ and studies have indicated that genetic factors are estimated to play a role in at least $80 \%$ of $\mathrm{AD}$ cases (58). A few rare mutations guarantee development of early-onset familial AD (FAD) $(<65$ years old). These gene mutations are transmitted through Mendelian inheritance and are localized in genes encoding for proteins involved in the production of $\mathrm{A} \beta$ : the amyloid precursor protein $(A P P)$, presenilin-1 (PSEN1), and presenilin-2 (PSEN2). Early-onset FAD however only accounts for less than $2 \%$ of AD cases (58). The current paradigm states that the majority of AD cases, referred to as late-onset $\mathrm{AD}$ ( $\geq 65$ years old), is the result of the complex interplay among susceptibility genes, environmental factors, and lifestyle contributors, as depicted in fig. 1.3 (59).

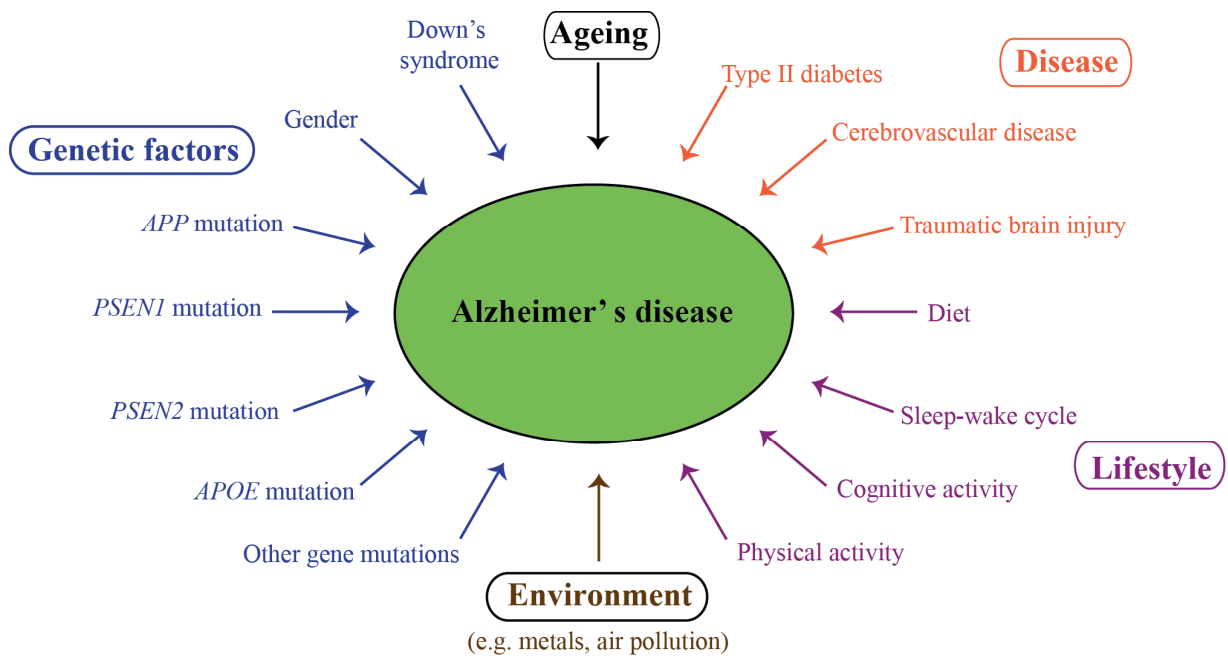

Figure 1.3: A non-exhaustive list of factors that have been identified or suggested to modulate AD risk. Ageing and several gene mutations are the most important risk factors for $\mathrm{AD}$. However, the majority of $\mathrm{AD}$ cases are most likely also influenced by environmental factors, lifestyle, and/or other diseases.

The only gene variant considered to be an established late-onset $\mathrm{AD}$ risk factor is $A P O E$ encoding for the lipid carrier Apolipoprotein E (ApoE). ApoE exists as three isoforms (ApoE2, ApoE3, and ApoE4) and individuals carrying one or two APOE $\varepsilon 4$ alleles have an increased risk of respectively three- and twelvefold of developing $\mathrm{AD}$, compared to non$A P O E \& 4$ carriers (60). ApoE4 contributes to $\mathrm{AD}$ pathogenesis by affecting $\mathrm{A} \beta$ aggregation and clearance, but also by modulating brain lipid metabolism, synaptic functioning through 
ApoE receptors, neuroinflammation, and via the generation of neurotoxic ApoE fragments, impairment of mitochondrial function, and disruption of the cytoskeleton through stimulation of tau phosphorylation (61-66). However, several other candidate risk genes have been identified by genome-wide association studies over the past years and await further validation by functional studies (Table 1.2) (58).

Table 1.2: Early-onset FAD genes, predicted late-onset AD risk genes, and their associated molecular pathways, adapted from (58).

\begin{tabular}{lll}
\hline \hline Gene & Protein & Associated molecular pathway \\
\hline \hline$A P P$ & Amyloid precursor protein & $\mathrm{A} \beta$ production \\
PSEN1 & Presenilin-1 & $\mathrm{A} \beta$ production \\
PSEN2 & Presenilin-2 & $\mathrm{A} \beta$ production \\
APOE & Apolipoprotein E & $\mathrm{A} \beta$ clearance, lipid metabolism \\
$C D 33$ & CD33 (Siglec 3) & Innate immunity, A $\beta$ degradation \\
$C L U$ & Clusterin & $\mathrm{A} \beta$ clearance, innate immunity \\
CR1 & Complement component (3b/4b) & $\mathrm{A} \beta$ clearance, innate immunity \\
& receptor 1 & \\
PICALM & Phosphatidylinositol binding clathrin & $\mathrm{A} \beta$ production and clearance, \\
& assembly molecule & cellular signalling \\
BIN1 & Bridging integrator 1 & A $\beta$ production and clearance, \\
& & cellular signalling \\
ABCA7 & ATP-binding cassette subfamily A & Lipid metabolism, cellular signalling \\
& member 7 & \\
EPHA $2 A P$ & CD2-associated protein & Cellular signalling \\
$M S 4 A 6 A / M S 4 A 4 E$ & EPH receptor A1 & Cellular signalling, innate immunity \\
ATXN1 & sembrane-spanning 4-domains, & Cellular signalling \\
\hline \hline
\end{tabular}

\subsubsection{Diagnosis and treatment of $A D$}

\subsubsection{AD diagnosis: a combined effort}

In addition to a post-mortem analysis of the brain, AD can be diagnosed with a high certainty during life by combining the knowledge of the family medical history, a neurological and physical examination, a mental test, and brain imaging (67).

Brain imaging is used for a variety of roles in AD studies. First, magnetic resonance imaging (MRI) visualizes the progression of brain atrophy (structural MRI) (68) and probes the functional integrity of the brain by measuring neuronal activity (functional MRI) (69). Second, as glucose is the main energy source of the brain, uptake of the glucose analogue fluoro-deoxy-D-glucose (FDG) is used as a biomarker for impaired brain metabolism and synaptic activity in AD patients. The fluorine-18 label allows for detection of FDG uptake with positron emission tomography (PET) (70). Third, PET can quantify brain amyloid load using Pittsburgh compound-B, a radiotracer specific for fibrillar $\mathrm{A} \beta(70,71)$. Brain imaging is thus used to facilitate $\mathrm{AD}$ diagnosis, determine disease progression, rule out other dementia causes, and assess the effectiveness of disease-modifying therapies (72).

Another hot topic in the $\mathrm{AD}$ research field is the identification of biomarkers in the plasma and cerebrospinal fluid (CSF) that are capable of diagnosing AD or detecting brain alterations in an early disease stage, as clinical symptoms only appear on average 10-15 years after disease onset (73). Low CSF levels of $A \beta_{1-42}$, the $A \beta$ peptide consisting of 42 amino acids, in combination with high levels of total tau and phosphorylated tau, are highly predictive biomarkers for $\mathrm{AD}$ (74). Other candidate biomarkers are now under study and are related to 
A $\beta$ metabolism, neuronal and synaptic degeneration, inflammation, and oxidative stress (73). The relevance of an early diagnosis relies on the prospect that pharmacologic interventions will likely be more effective in generating clinical benefits if started early in AD progression, before neurodegeneration is already too advanced. Moreover, biomarkers can provide insights into early disease mechanisms, which will benefit the development of an effective AD therapy (73).

\subsubsection{Current $\mathrm{AD}$ drugs temporarily reduce disease symptoms}

Current AD treatment is purely symptomatic and aimed at improving the life quality of a patient. Therapy consists mainly of treating cognitive decline and behavioural symptoms. Five cholinesterase inhibitors and one N-methyl-D-aspartate (NMDA) receptor antagonist (memantine) have been approved by the US Food and Drug Administration (FDA) for treatment of cognitive decline (75). Acetylcholinesterase inhibitors are thought to improve functioning of the cholinergic system in $\mathrm{AD}$ patients by binding to acetylcholinesterase in the synaptic cleft, preventing it to break down acetylcholine, a neurotransmitter involved in learning and memory (76). On the other hand, memantine addresses dysfunction in glutamatergic transmission and reduces calcium-stimulated apoptotic cell death cascades (76). Behavioural symptoms are most commonly treated with antipsychotics and antidepressants, although they have not been approved by the FDA for AD treatment (77). The marginal benefits of current treatment however emphasize the need for the development of a more effective AD therapy.

\subsection{The amyloid-beta peptide: the primary driver of $\mathrm{AD}$ pathogenesis}

Experimental studies and clinical trials are ongoing in the search for an effective prevention or treatment of $\mathrm{AD}(78-80)$. These studies and trials often target $\mathrm{A} \beta$, which plays a major role in $\mathrm{AD}$ pathogenesis (48). Effective drug development targeting $\mathrm{A} \beta$ has however remained without success and one of the underlying reasons for this is that $\mathrm{A} \beta$ can appear in many different shapes that can interconvert within a dynamic interplay. This finding triggered a vast exploration of the many conformations the peptide can adopt, as well as the aim to precisely pinpoint which of these conformations can be claimed as "the toxic species", such that specific drug targeting can be employed. To complicate matters even more, a heterogeneous pool of monomeric $A \beta$ varying in length from 37 to 49 amino acids is produced by proteolytic cleavage from the transmembrane amyloid precursor protein APP by $\beta$ - and $\gamma$-secretase (81, 82) (Fig. 1.4). Research effort has been mainly focused on the most abundant forms $A \beta_{1-40 \text {, }}$ which comprises 40 amino acids, and the longer $A \beta_{1-42}$, which is C-terminally extended by two hydrophobic residues and has been found to be more aggregation-prone (83). Nonetheless, it has recently been discovered that the co-occurrence of peptides varying in length can affect the neurotoxic and aggregation potential of the total $A \beta$ pool (84-90). It has also been recognized that particularly small aggregated forms of $A \beta$ are potently toxic, rather than the mature amyloid fibrils as observed in the brains of AD patients. Therefore, a lot of research has aimed at understanding the $\mathrm{A} \beta$ aggregation mechanism and identifying the intermediate species that occur along the aggregation pathway $(91,92)$. The current amyloid cascade hypothesis suggests that AD-related synapto- and neurotoxicity might be mediated by soluble $A \beta$ oligomers $(55,93)$, which have proven notoriously difficult to study in detail in vivo with the currently available technology. The dynamics, stability, and transient lifetime of potentially toxic species further hamper the possibility to precisely pinpoint the structural aspects of toxic A $\beta$ aggregates. Moreover, the dynamic behaviour of aggregation intermediates may actually provide an important source for toxicity of $A \beta$ as the ongoing aggregation process has also been suggested to be a culprit for toxicity $(86,94,95)$. 

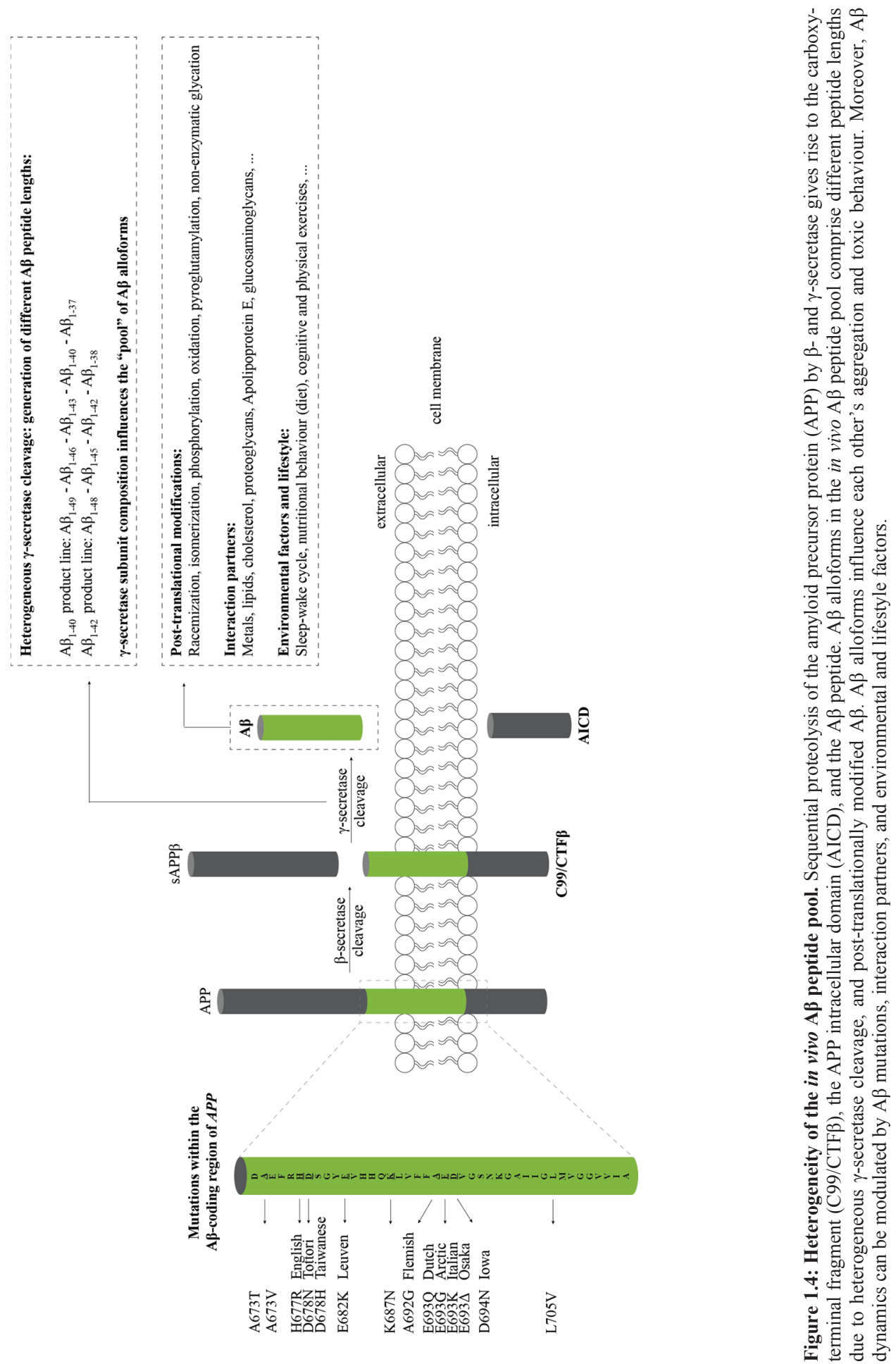
The following section describes $\mathrm{A} \beta$ peptide dynamics and illustrates how the dynamic nature of $A \beta$ can influence and contribute to its toxicity. $A \beta$ dynamics are mainly considered on two levels. First, intramolecular dynamics of $\mathrm{A} \beta$ are defined as the intrinsic disorder and polypeptide backbone flexibility that are present in isolated $A \beta$ monomeric peptides or aggregation states (section 1.4.1). Second, intermolecular dynamics comprise (i) the interplay between different $\mathrm{A} \beta$ alloforms present in the in vivo $\mathrm{A} \beta$ pool and (ii) the dynamic equilibrium that exists between different $A \beta$ species (section 1.4.2). The term alloform refers to a distinct form of the $A \beta$ peptide that is commonly treated as a single kind of peptide species, like $A \beta$ length variants or side chain modifications. Next, several external factors and interaction partners that can influence $A \beta$ dynamics are addressed in section 1.4.3. Finally, promising $\mathrm{AD}$ therapeutic strategies that target $\mathrm{A} \beta$ are presented in section 1.4.4.

\subsubsection{Intramolecular $A \beta$ dynamics}

The A $\beta$ monomer has a high tendency to self-assemble into large aggregates and fibrils. It is increasingly recognized that despite the highly packed and ordered state of these aggregates, they often still contain a significant portion of flexible and intrinsically disordered regions (96). The intrinsically disordered nature of the $A \beta$ monomer is fairly well documented, but revealing the intrinsic disorder in oligomers and fibrils has proven more challenging due to the difficulties in studying this phenomenon. This section reviews the intrinsic disorder that is present in every $A \beta$ aggregation state, and how it contributes to $A \beta$-induced toxicity.

\subsubsection{The intrinsically disordered $A \beta$ monomer}

Although one of the pathological hallmarks of $\mathrm{AD}$ comprises insoluble $\mathrm{A} \beta$ deposits in neuritic plaques in the brain of $\mathrm{AD}$ patients, monomeric $\mathrm{A} \beta$ peptides have also been purified and characterized from brain tissue (97-100). Size exclusion chromatography (SEC) experiments suggested that the freshly dissolved $A \beta$ peptide eluted as a single low molecular weight species, consistent with a monomer or dimer (101-103). These low molecular weight A $\beta$ species were competent to deposit onto pre-existing amyloid in preparations of AD cortex (102). Translational diffusion measurements by nuclear magnetic resonance (NMR) techniques conclusively demonstrated that the form of the peptide active in plaque deposition is a monomer (102). Further NMR data revealed that monomeric A $\beta$ exists in solution as disordered coils that lack regular $\alpha$-helical or $\beta$-stranded structure (104-106). Despite the challenging task because of its disordered and amyloidogenic nature, the $A \beta$ monomer is now well recognized as an IDP (12). This implies that the monomeric A $\beta$ peptide does not display a unique fold, as would be the case for a typical well-folded protein, but rather comprises a mixture of rapidly interconverting conformations whereby the polypeptide backbone can sample the conformational space without any stable and well-defined conformational ensemble (Fig. 1.5A). Yet, it is possible to bias the ensemble toward distinct secondary structure elements by changing solution conditions and/or the oxidation state of $\mathrm{Met}_{35}$ within the $\mathrm{A} \beta$ sequence (106-109) (Fig. 1.5B).

Some experimental studies however suggest that A $\beta$ is not entirely a "random coil". Ion mobility mass spectrometry (MS) combined with theoretical modelling showed that $A \beta_{1-42}$ in aqueous solution adopts both extended chain as well as collapsed coil structures (110). Limited proteolysis successfully identified structured and disordered regions within $A \beta$. This approach revealed a proteolytically resistant decapeptide, $\mathrm{Ala}_{21}-\mathrm{Ala}_{30}$, that was found in NMR studies to form a turn-like structure (111). When the dynamic nature of monomeric $A \beta_{1-40}$ in solution was studied using ${ }^{15} \mathrm{~N}$-relaxation experiments, the results revealed structural propensities that correlated well with the secondary structure segments of the peptide that are 
present in the fibrils, and with the $\alpha$-helical structure in membrane-mimicking systems $(108$, 112). NMR studies further revealed subtle differences between $A \beta_{1-40}$ and $A \beta_{1-42}$ monomers with a modest increase in C-terminal rigidity for $A \beta_{1-42}$ versus $A \beta_{1-40}$ (113). Various molecular dynamics (MD) simulations also hinted that intramolecular interaction patterns occur in $A \beta_{1-42}(104,114,115)$ and that subtle differences exist between the dynamic behaviours of $A \beta_{1-40}$ and $A \beta_{1-42}(116,117)$.

Experimental results in combination with computational simulations have thus proven very powerful to shed light on the conformational landscape of IDPs. The emerging picture of A $\beta$ comprises an IDP that can adapt a variety of collapsed and extended monomeric conformations and transiently samples long-range intramolecular interactions without exclusively stabilizing a specific globular fold.

A
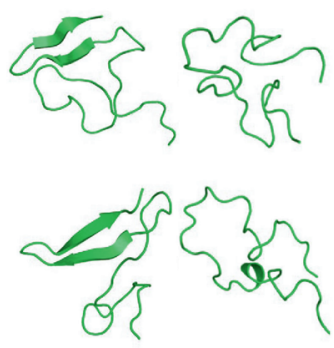

B.
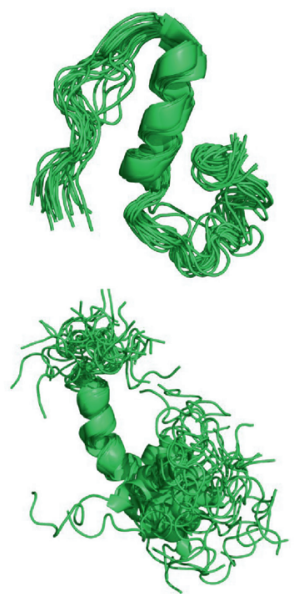
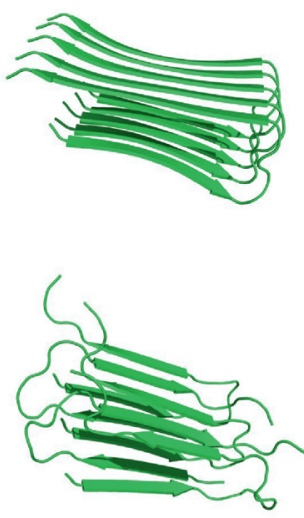

D.
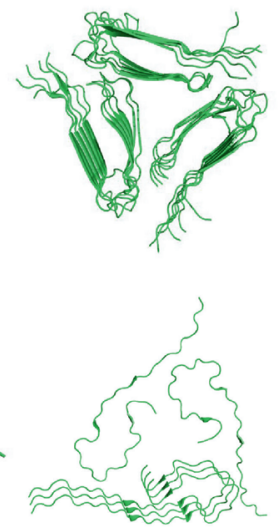

Figure 1.5: Various structures of $A \beta$ that correspond to different experimental conditions and phases in the aggregation landscape. (A) Four representatives of the structural ensemble of monomeric $A \beta_{1-42}$ under aqueous conditions as derived from a combined MD/NMR approach (114). Extended as well as collapsed coil conformations with secondary structural elements can be observed. (B) $\mathrm{A} \beta_{1-40}$ in presence of $20 \mathrm{mM}$ potassium phosphate buffer containing $50 \mathrm{mM} \mathrm{NaCl}$ at $15{ }^{\circ} \mathrm{C}$ (top) (109) and $\mathrm{A} \beta_{1-42}$ in presence of $30 \%$ hexafluoroisopropanol at $25{ }^{\circ} \mathrm{C}$ (bottom) (108) contain an $\alpha$-helical segment. (C) Fibril polymorphism illustrated by the structural differences between fibrillar $A \beta_{1-42}$ (118), D23N A $\beta_{1-40}$ (119), and (D) the ultrastructure of $A \beta_{1 \text { - }}$ 40 (120) and brain-derived $\mathrm{A} \beta_{1-40}(121)$.

Even though the physiological function of the $A \beta$ monomer remains obscure, its intrinsic structural flexibility offers certain advantages: high specificity and low affinity in binding (mostly exploited in signalling pathways), and high binding promiscuity that is frequently used by hub proteins in large interaction networks (122). There is a well-established link between intrinsic polypeptide disorder and functional promiscuity. Protein moonlighting, the phenomenon of proteins exhibiting more than one unique biological function, is typically mediated by intrinsically disordered regions in polypeptides (10). As a consequence, as IDPs can play a role in numerous biological processes, it is not surprising to find some of them involved in human diseases.

In the case of $A \beta$, its IDP nature facilitates its interaction with many different binding partners, including identical and other $\mathrm{A} \beta$ alloforms (sections 1.4.2 and 1.4.3). In addition, the 
intrinsic disorder of $\mathrm{A} \beta$ also simplifies post-translational modifications because the involved side chains are readily accessible (section 1.4.2).

\subsubsection{Intrinsic fibril flexibility might underlie disease progression and phenotype}

$\mathrm{A} \beta$ fibrils contain high order and rigidity compared to $\mathrm{A} \beta$ monomers, but still retain a considerable amount of disorder in the N-terminal segment (123-126) and are often polymorphous (127). The inherent disorder of $A \beta$ fibrils and the associated fibril polymorphism could underlie time-dependent structural changes during ageing in AD (128, $129)$ and differences in disease progression and phenotype (121).

\section{The dynamic nature of $A \beta$ fibrils}

Even though the amyloid fibril state of $A \beta$ has traditionally been viewed as a rigid or semirigid state characterized by the cross- $\beta$ spine $(130,131)$, part of the peptide in the fibril conformation is still flexible. This flexibility has been illustrated by solid state and solution NMR (118, 132-136), electron paramagnetic resonance (EPR) (123), site-directed mutagenesis (137), limited proteolysis, hydrogen-deuterium exchange (HDX) evaluated by MS (124-126, 138), and X-ray crystallography (139). These studies suggest a hairpin-like arrangement of each $A \beta$ monomer stacked within the fibril, consisting of two semi-rigid organized $\beta$-strands linked by a flexible connecting region (Fig. 1.5C and 1.6).

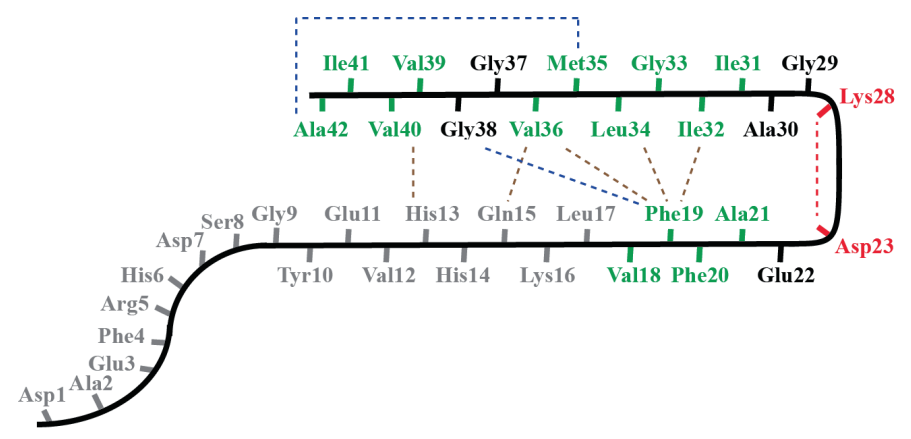

Figure 1.6: Suggested structure of the A $\boldsymbol{\beta}$ monomeric unit in fibrils. The $A \beta$ monomer in fibrils has been proposed to form a hairpin, consisting of a flexible N-terminal region (grey residues), and two $\beta$-strands connected by a turn region. A stabilizing salt bridge has been suggested to be present in both $A \beta_{1-40}$ and $A \beta_{1-42}$ (red dashed line), and the hairpin conformation is further stabilized by hydrophobic interactions (green residues). Several additional intramolecular contacts have been reported for $A \beta_{1-40}$ (brown dashed lines) and $A \beta_{1-42}$ (blue dashed lines). Adapted from (136).

The hydrophobic C-terminus of $A \beta_{1-42}$ in fibrils is highly resistant to HDX and forms the fibril core $(118,135)$, whereas the $\mathrm{C}$-terminus of $\mathrm{A} \beta_{1-40}$ in fibrils contains slightly more disorder $(120,134,138,140-142)$. In contrast, the N-terminal segment, which can range from the first nine to 19 residues depending on the study, remains intrinsically disordered for both $\mathrm{A} \beta_{1-40}$ and $A \beta_{1-42}$ fibrils (Table 1.3). This relatively hydrophilic part of the polypeptide chain is excluded from the $\mathrm{H}$-bonded $\beta$-sheet fibril core and remains exposed to the solvent $(118$, $120,123-126,134,135,140-142)$.

Recently, differential scanning calorimetry suggested that thermal denaturation of amyloid fibrils can occur and that this process can be considered as a reversible equilibrium under certain experimental conditions, highlighting the dynamic nature of fibrils (143). These observations illustrate the impact of the various dynamics within the $A \beta$ system. 
Table 1.3: Overview of the variability in secondary structure assignments of $A \beta$ fibrils between different studies.

\begin{tabular}{|c|c|c|c|c|}
\hline Peptide* & $\begin{array}{l}\text { Flexible regions } \\
\text { (solvent-exposed) }\end{array}$ & $\begin{array}{l}\begin{array}{l}\beta \text {-structured regions } \\
\text { (non-exposed) }\end{array} \\
\end{array}$ & Method & Ref. \\
\hline$\overline{\mathrm{A}} \beta_{1-40}$ & $\begin{array}{l}\text { N-terminus }\left(\mathrm{Asp}_{1}-\mathrm{Gly}_{9}\right) \\
\text { Bend/loop }\left(\mathrm{Asp}_{23}-\mathrm{Gly}_{29}\right)\end{array}$ & $\begin{array}{l}\mathrm{Tyr}_{10}-\mathrm{Glu}_{22} \\
\text { C-terminus }\left(\mathrm{Ala}_{30}-\mathrm{Val}_{40}\right)\end{array}$ & "Solid state NMR & (120) \\
\hline $\mathrm{A} \beta_{1-40}$ & $\begin{array}{l}\text { N-terminus }\left(\mathrm{Asp}_{1}-\mathrm{Tyr}_{10}\right) \\
\text { Bend }\left(\mathrm{Gly}_{25}-\mathrm{Gly}_{29}\right)\end{array}$ & $\begin{array}{l}\mathrm{Val}_{12}-\mathrm{Val}_{24} \\
\text { C-terminus }\left(\mathrm{Ala}_{30}-\mathrm{Val}_{40}\right)\end{array}$ & Solid state NMR & $(132)$ \\
\hline $\mathrm{A} \beta_{1-40}$ & $\begin{array}{l}\text { N-terminus }\left(\mathrm{Asp}_{1}-\mathrm{His}_{14}\right) \\
\text { C-terminus }\left(\mathrm{Gly}_{37}-\mathrm{Val}_{39}\right) \\
\text { Turn }\left(\mathrm{Ser}_{26}-\mathrm{Asn}_{27}\right)\end{array}$ & $\begin{array}{l}\mathrm{Gln}_{15}-\mathrm{Asp}_{23} \\
\text { Lys }_{28}-\mathrm{Met}_{35}\end{array}$ & HDX - solution NMR & (134) \\
\hline $\bar{A} \beta_{1-40}$ & $\begin{array}{l}\text { N-terminus }\left(\mathrm{Asp}_{1}-\mathrm{His}_{14}\right) \\
\text { C-terminus }\left(\mathrm{Gly}_{37}-\mathrm{Val}_{40}\right) \\
\text { Turns }\left(\mathrm{Glu}_{22}-\mathrm{Asp}_{23}, \mathrm{Gly}_{29}-\mathrm{Ala}_{30}\right)\end{array}$ & $\begin{array}{l}\mathrm{Gln}_{15}-\mathrm{Ala}_{21} \\
\mathrm{Val}_{24}-\mathrm{Lys}_{28} \\
\mathrm{Ile}_{31}-\mathrm{Val}_{36} \\
\end{array}$ & $\begin{array}{l}\text { Scanning proline } \\
\text { mutagenesis }\end{array}$ & $(140)$ \\
\hline $\mathrm{A} \beta_{1-40}$ & $\begin{array}{l}\text { N-terminus }\left(\mathrm{Asp}_{1}-\mathrm{Phe}_{19}\right) \\
\text { C-terminus }\left(\mathrm{Met}_{35^{-}}-\mathrm{Val}_{40}\right)\end{array}$ & $\mathrm{Phe}_{20}-\mathrm{Leu}_{34}$ & $\begin{array}{l}\text { HDX - MS with online } \\
\text { proteolysis }\end{array}$ & (144) \\
\hline $\begin{array}{l}\mathrm{A} \beta_{1-40} \\
\mathrm{~A} \beta_{1-42}\end{array}$ & $\begin{array}{l}\text { N-terminus }\left(\mathrm{Asp}_{1}-\mathrm{Tyr}_{10}\right) \\
\text { C-terminus }\left(\mathrm{Val}_{40}-\mathrm{Ala}_{42}\right) \\
\text { Turn/bend }\left(\mathrm{Asp}_{23}-\mathrm{Gly}_{29}\right)\end{array}$ & $\mathrm{His}_{14}-\mathrm{Gly}_{38}$ & $\begin{array}{l}\text { Site-directed spin } \\
\text { labelling - EPR }\end{array}$ & $(123)$ \\
\hline $\mathrm{A} \beta_{1-42}$ & $\begin{array}{l}\text { N-terminus }\left(\mathrm{Asp}_{1}-\mathrm{Leu}_{17}\right) \\
\text { Turn }\left(\mathrm{Asn}_{27}-\mathrm{Ala}_{30}\right)\end{array}$ & $\begin{array}{l}\mathrm{Val}_{18}-\mathrm{Ser}_{26} \\
\text { C-terminus }\left(\mathrm{Ile}_{31}-\mathrm{Ala}_{42}\right)\end{array}$ & HDX - solution NMR & (118) \\
\hline $\bar{A} \beta_{1-42}$ & $\begin{array}{l}\text { N-terminus }\left(\mathrm{Asp}_{1}-\mathrm{Tyr}_{10}\right) \\
\text { Bend }\left(\operatorname{Ser}_{26}-\mathrm{Asn}_{27}\right)\end{array}$ & $\begin{array}{l}\mathrm{Glu}_{11}-\mathrm{Gly}_{25} \\
\text { C-terminus }\left(\mathrm{Lys}_{28}-\mathrm{Ala}_{42}\right)\end{array}$ & HDX - solution NMR & $(135)$ \\
\hline
\end{tabular}

* A $\beta$ fibril structures deposited in the Protein Data Bank: synthetic A $\beta_{1-40}(2 \mathrm{LMN}, 2 \mathrm{LMO}, 2 \mathrm{LMP}, 2 \mathrm{LMQ})$, brain-derived $\mathrm{A} \beta_{1-40}(2 \mathrm{M} 4 \mathrm{~J})$, synthetic D23N A $\beta_{1-40}(2 \mathrm{LNQ})$, recombinant $\mathrm{A} \beta_{1-42}(2 \mathrm{BEG})$.

The inherent flexibility of $A \beta$ fibrils also allows the internal fibril structure to evolve in time. Multidimensional infrared spectroscopy revealed that fresh and 4-year-old fibrils were structurally heterogeneous due to trapped water molecules that perturbed the H-bonding pattern in time (128). Recently, Nilsson and co-workers revealed conformational rearrangements during ageing in plaques in the brains of $\mathrm{AD}$ mouse models using luminescent conjugated polythiophenes (129).

Although ignored for a long time, structural disorder in fibrils seems to occur in various amyloidogenic proteins (e.g. $\alpha$-synuclein, tau, and multiple prions). Structural disorder in fibrils has been suggested to stabilize fibril formation by accommodating destabilizing residues and by limiting the unfavourable entropy associated with the formation of the highly ordered cross- $\beta$ spine (96).

\section{A $\beta$ fibrils are polymorphic entities}

Overall fibril topology has been studied using cryo-electron microscopy and 3D reconstruction. In general, $\mathrm{A} \beta$ fibrils exhibit multiple distinct morphologies that can differ in fibril symmetry, width, twist period, and curvature (Fig. 1.5C and D) $(127,145)$. This structural diversity is not limited to fibrils composed of the $\mathrm{A} \beta$ peptide, but appears to be a fundamental property of amyloid fibrils (146-148). Inter-sample polymorphism commonly occurs in vitro in different fibril growth conditions and is subject to $\mathrm{pH}$, temperature, agitation, and salt-conditions $(149,150)$. A Darwinian-type "survival of the fittest" competition allows the type of fibril that is kinetically the most accessible in a given environment to be the most populated (151). However, $A \beta_{1-40}$ can also form at least 12 structurally distinct polymorphs under the same solution conditions (intra-sample polymorphism), indicating that this polymorphism arises from an intrinsic structural variability (152). Interconversion between fibril polymorphs coexisting in solution can occur, resulting in the thermodynamically more stable polymorph, as was monitored by solid state NMR over a period of several weeks for $A \beta_{1-40}(119,153)$. 
Amyloid polymorphism can have several molecular origins that are not mutually exclusive (154-157). First, mass-per-length values obtained from scanning TEM indicate that fibrils can be composed of one to five protofilaments (the minimal fibrillar entities) $(158,159)$. Second, distinct orientations and modes of lateral association of protofilaments and patterns of interresidue interactions determine if protofilaments are oriented side-by-side $(132,160)$, offset from one another $(154,155)$, or wound around a hollow core (157). Third, solid state NMR demonstrated that agitated (striated) and quiescent (twisted) fibrils differ in the residues participating in their $\beta$-strands and that such variations in the underlying protofilament substructure can contribute to fibril polymorphism $(120,161)$. Surprisingly, the Iowa D23N $\mathrm{A} \beta_{1-40}$ mutant was recently found to form metastable fibrils with an antiparallel $\beta$-sheet arrangement, as opposed to parallel $\beta$-sheet wild type fibrils, indicating that a FAD mutation can have profound effects on fibril structure (Fig. 1.5C) (119).

Hence, although the cross- $\beta$ spine of $A \beta$ fibrils is a common structural feature, fibrils show a great variety of structural complexity that appears to be inherent to the dynamic nature of the A $\beta$ peptide.

\section{Fibril polymorphism might underlie different pathological outcomes}

Fibrils can initiate inflammation in brain tissues and microglia and astrocytes in cell culture. Fibril-induced inflammation leads to the secretion of pro-inflammatory cytokines and the production of reactive oxygen species (ROS) causing oxidative damage (Fig. 1.7A) (162, 163). Substantial evidence has demonstrated that different fibril morphologies exert different toxicities in vitro $(118,120,164-166)$, although toxic activity of oligomeric A $\beta$ was reported to exceed that of the fibrillar form multiple times and oligomeric $A \beta$ correlated more strongly to cognitive impairment as compared to fibrillar $A \beta$ of amyloid plaques $(164,165)$.

\section{A. Ap fibril-induced toxicity}

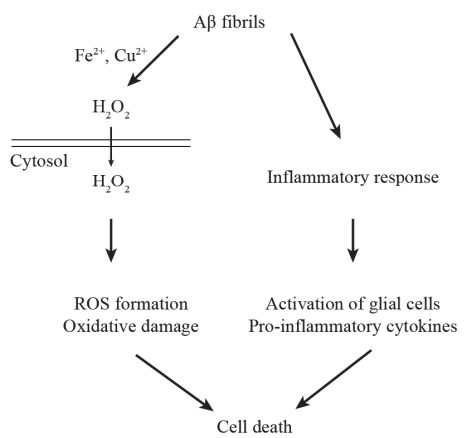

B. A $\beta$ oligomer-induced toxicity

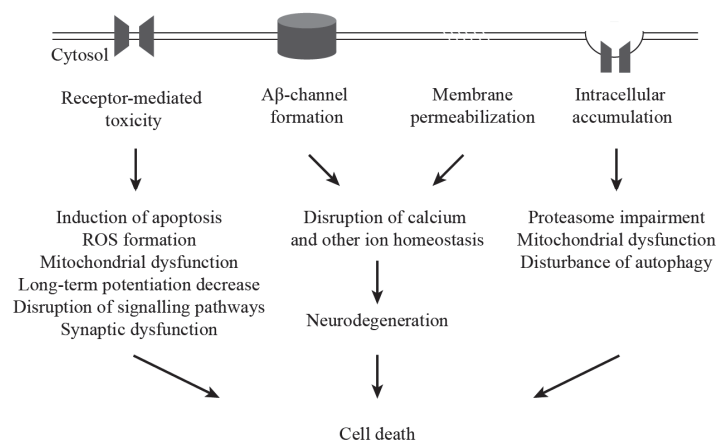

Figure 1.7: A schematic view of the molecular mechanisms suggested for the toxic effect of $A \beta$ fibrils and oligomers. (A) A $\beta$ fibrils induce oxidative stress and elicit inflammatory reactions. (B) A $\beta$ oligomers have been suggested to cause cell death via receptor-mediated toxicity, pore formation in cell membranes, membrane permeabilization, and intracellular $\mathrm{A} \beta$ accumulation. Adapted from (167).

Fibril polymorphism could explain why some studies report significant toxicity for A $\beta$ fibrils whereas others do not, but could also underlie the weak correlation between plaque load and cognitive impairment. If plaques comprise different fibril polymorphs, different levels of toxicity could be associated to these amyloid deposits. In this case, the structural diversity of fibrils may account for differences in disease progression and phenotype as has been suggested by Tycko and co-workers (121). They reported that A $\beta$ fibrils seeded from human 
brain extracts differed between patients with a different clinical history and neuropathology (121). Moreover, fibril polymorphism has been linked previously to different phenotypes for hereditary transthyretin amyloidosis (168). In this regard, the different architectures of wild type and Iowa D23N A $\beta$ fibrils, composed of parallel and antiparallel $\beta$-sheet structure respectively, could underlie their different pathological outcomes: late-onset $A D$ characterized by plaques versus early-onset $\mathrm{AD}$ associated with cerebral amyloid angiopathy (CAA).

\subsubsection{A $\beta$ oligomers: a mishmash of conformations and sizes}

Since A $\beta$ plaque load and AD severity could not be correlated $(164,165)$, increasing evidence suggests that soluble oligomers play a primary role in AD pathology. Soluble oligomers have commonly been associated with disease severity, the loss of synapses, and neuronal damage (55). The low abundance, heterogeneity, and transient nature of $A \beta$ oligomers have hindered high resolution structural studies. However, it now becomes clear that $\mathrm{A} \beta$ oligomers exist in a broad range of interconverting assemblies varying in size, conformation, and associated toxicity $(169,170)$.

A $\beta$ oligomers can cause toxicity by a variety of mechanisms (Fig. 1.7B) (167). To enable AD drug design, it is essential to establish the key determinants of oligomer toxicity. Several studies report that neurotoxic activity varies with $A \beta$ oligomer size, with small oligomers, consisting of less than 14 monomers, being most toxic $(171,172)$. However, oligomer size is not sufficient to define toxicity as $A \beta$ oligomers with similar size have been shown to exert different toxicities (173-175). The underlying peptide conformation also needs to be taken into account as the interplay between $A \beta$ oligomer size and conformation plays an important role in toxicity (170). Different $A \beta$ oligomer conformations have been shown to induce neurotoxicity by distinct mechanisms in human cortical neurons (176). The design of a wellcontrolled study to investigate size and conformational impact on toxicity is notoriously difficult as different oligomer conformations and sizes are in continuous exchange. However, studies in which different conformations or sizes have been enriched or stabilized by means of crosslinking have been performed and careful conclusions can be drawn from such studies. One possibility to classify oligomers according to their underlying structure is based on recognition by conformation-dependent antibodies (177-180). Surprisingly, soluble oligomers of a wide variety of amyloidogenic polypeptides $(\mathrm{A} \beta, \alpha$-synuclein, islet amyloid polypeptide, polyglutamine, lysozyme, human insulin and prion peptide) react with the oligomer-specific A11 antibody developed by Glabe and co-workers, suggesting that there has to be a common structural denominator to their toxic origin. Interestingly, pre-incubation of mouse hippocampal neurons with the A11 antibody, before treatment with $\mathrm{A} \beta$, rescues them from the neurotoxic effects induced by $A \beta(88)$. It has been suggested that A11-positive oligomers are composed of antiparallel $\beta$-sheets, based on Fourier transform infrared spectroscopy (FTIR). This antiparallel $\beta$-sheet signature might represent a critical step in perturbation or permeabilization of cell membranes leading to cell toxicity (181). Later studies using FTIR, EPR, and X-ray crystallography have also demonstrated that oligomeric species can be characterized by an antiparallel $\beta$-sheet arrangement, while most amyloid fibrils consist of inregister, parallel $\beta$-sheets (182-186).

In addition to size and peptide conformation, the intrinsic flexibility of the $A \beta$ oligomer might also contribute to $A \beta$-induced toxicity. Several studies have shown that the $N$-terminus of $A \beta$ retains a degree of flexibility upon oligomerization and is exposed to the solvent $(117,136$, $186,187)$. Ahmed and co-workers reported solution NMR measurements of $A \beta_{1-42}$ pentamers (136). The authors reported that the loosely packed $N$-terminal segment of $A \beta$ was defined by 
HDX ratios approaching 1 for residues $\mathrm{Asp}_{1}-\mathrm{Gly}_{9}$, indicating high solvent accessibility and nearly complete exchange within the acquisition time $(<1.5 \mathrm{~h})$. In contrast, the C-terminal region $\mathrm{Val}_{40}-\mathrm{Ala}_{42}$ was less solvent accessible and most likely buried within the centre of the oligomer. Similar results were obtained for packing of the $A \beta$ peptide within $A \beta_{1-42}$ dodecamers. Site-directed spin labelling of $A \beta_{1-42}$ combined with EPR spectroscopy showed that the N-terminus was loosely packed within the dodecamer, while residues $\mathrm{Ile}_{32}$-Val $\mathrm{Va}_{40}$ formed a tight core (186). High intrinsic disorder and solvent exposure of hydrophobic segments have been suggested to be a common feature of highly toxic and soluble aggregates (173-175, 188). Recent work has shown that the most cytotoxic, oligomeric species of the Arctic E22G A $\beta_{1-42}$ mutant interacted more strongly with 1-anilinoaphthalene 8-sulfonate (ANS), a dye sensitive to exposed hydrophobic patches (188). A higher degree of solventexposed, hydrophobic regions was further shown to lead to a disturbed cellular calcium homeostasis, likely due to disruption of the cell membrane (175). Moreover, antiparallel $\beta$ sheet oligomers display faster HDX kinetics compared to fibrils, suggesting a higher intrinsic disorder/flexibility (181). Oligomers have also been shown to bind with higher affinity and cause more disruption of synthetic membranes compared to the higher ordered fibrils (189). These data emphasize the importance of intrinsic disorder and molecular flexibility of $A \beta$ oligomers to exert their toxic effect.

In conclusion, a re-evaluation of the amyloid cascade hypothesis is required (190). Whereas earlier hypotheses held one particular oligomer of a predefined size responsible for $\mathrm{A} \beta$ toxicity $(99,191)$, it is now obvious that a diverse "A $\beta$ oligomeric soup" exists, consisting of a large variety of rapidly exchangeable polymorphs that differ in size, conformation, hydrophobicity, solvent exposure, intrinsic disorder (or internal flexibility), and toxicity. The amyloid cascade hypothesis should take into account that it is possible that the entire dynamic $\mathrm{A} \beta$ oligomeric soup contributes to the heterogeneity of $\mathrm{AD}$ progression and phenotype, via various toxic mechanisms.

\subsubsection{Intermolecular $A \beta$ dynamics}

As the in vivo $\mathrm{A} \beta$ peptide pool is a mix of species influencing one another, one must consider the dynamics between different $A \beta$ species when regarding $A \beta$-related toxicity. This mix comprises various $A \beta$ alloforms, but also contains different $A \beta$ aggregation states that are in dynamic equilibrium. Studying the behaviour of $A \beta$ peptide mixtures and revealing the dynamics of interconversion among different aggregate species is crucial in understanding the toxic effects of $\mathrm{A} \beta$ in $\mathrm{AD}$.

\subsubsection{The in vivo $\mathrm{A} \beta$ peptide pool: a cocktail of different interacting species}

The large majority of biophysical and cell biological studies investigating the role of $A \beta$ in $\mathrm{AD}$ have focused either on pure $\mathrm{A} \beta_{1-40}$ or $\mathrm{A} \beta_{1-42}$, the two predominant $\mathrm{A} \beta$ alloforms present in the brain $(44,83)$. However, trace amounts of peptides ranging in length from 37 to 49 amino acids are also present (192-194) due to the heterogeneous cleavage pattern of APP by $\gamma$ secretase $(81,82)$. The in vivo $\mathrm{A} \beta$ peptide pool not only contains different $\mathrm{A} \beta$ peptide lengths, but also comprises post-translationally modified $\mathrm{A} \beta$ (195) (Fig. 1.4). A $\beta$ peptides can undergo racemization $(196,197)$, isomerization (198), phosphorylation $(199,200)$, oxidation $(201$, 202), non-enzymatic glycation (203), and pyroglutamylation (204). Post-translational oxidation of Met $_{35}$ affects fibril flexibility within $A \beta$ plaques (202). Met $_{35}$ oxidation has also been shown to impede the rate of $\mathrm{A} \beta$ aggregation in vitro (106), possibly by decreasing the $\beta$ strand content of the C-terminal region (205). Furthermore, proteins can become modified by non-enzymatic glycation upon ageing. Advanced glycation end products (AGEs), found in A $\beta$ 
plaques and in neurons, and their receptor, the receptor for advanced glycation end products (RAGE), play an important role in $\mathrm{AD}$ by contributing to oxidative stress and by triggering inflammation signalling pathways $(203,206)$. For other modifications, it remains largely unknown how they can affect $\mathrm{A} \beta$ aggregation dynamics.

Various forms of $A \beta$ co-exist and co-deposit in amyloid fibrils and plaques $(99,203)$. It has become clear that biologically relevant mixtures of $A \beta$ alloforms behave in a more complex manner in vitro than anticipated from their behaviour in isolation, in terms of aggregation properties and toxicity $(84,85,88-90)$. For example, $A \beta_{1-38}$ and $A \beta_{1-40}$ exerted little toxicity in isolation, but were highly toxic to a neuroblastoma cell line when tested in a mixture, whereas addition of $A \beta_{1-38}$ to $A \beta_{1-42}$ had a cytoprotective effect (90).

\subsubsection{The interactions between different species present during $A \beta$ aggregation}

NMR relaxation measurements showed that monomers are constantly binding to and being released from oligomers and protofibrils in vitro. Estimates showed that approximately $3 \%$ of the peptide within the oligomer undergoes exchange with free monomer in pseudoequilibrium conditions (207-209).

Mature fibrils can thermodynamically be considered as the most stable aggregation state due to the high density of intermolecular H-bonding and steric zipper interactions (17). However, fibrils are not static and irreversible end species, as was the traditional view, but were shown to continuously dissociate and reassociate through both fibril ends. $A \beta_{1-40}$ fibrils recycle to a greater extent than $A \beta_{1-42}$ fibrils, which could be attributed to a difference in fibril dissolution rate (210). These findings are consistent with a dynamic model for interpreting plaque morphology, in which aggregation and disaggregation were proposed to be in steady-state equilibrium (211). The species involved in the fibril recycling process are however still a matter of debate. Differential solution NMR isotope labelling experiments revealed that $\mathrm{A} \beta_{1-40}$ monomers can replace $A \beta_{1-42}$ on $A \beta_{1-42}$ aggregates, recycling $A \beta_{1-42}$ monomers back into solution (87). Later reports confirmed the constant recycling of $A \beta_{1-40}$ and $A \beta_{1-42}$ monomers and competition of binding for the ends of protofibrillar and fibrillar aggregates (86). However, the accumulation of fibrils might also be associated with the generation of diffusible lower molecular weight aggregates. This hypothesis is consistent with the observation of a halo of oligomeric $A \beta$ surrounding senile plaques when analysed by array tomography (212). Recently, Knowles and co-workers demonstrated that the secondary nucleation pathway can be a major source of oligomers once the critical concentration of amyloid fibrils (in the order of $10 \mathrm{nM}$ ) has formed (213). Hereby, the surfaces of existing fibrils catalyse the nucleation of new aggregates from the monomeric state, with a rate dependent on both the concentration of the monomers and that of the existing fibrils. As the critical fibril concentration is lower than the aggregate loads present in brains of AD patients, it is possible that this pathway is active in the brain (213).

\subsubsection{The dynamic equilibrium potentially contributes to $\mathrm{A} \beta$ toxicity}

The co-existence of different $A \beta$ aggregate species should be taken into account when analysing $A \beta$ toxicity studies. For example, fibrils might act as a reservoir of soluble aggregates that can diffuse and induce toxic effects. The halo of oligomers surrounding senile plaques co-localized with the loss of excitatory synapses and spine collapse (212), and the disruption of dendritic spines in the vicinity of plaques is dependent on their distance from these plaques (214). Moreover, fibrils have been suggested to be destabilized by brain lipids, reverting into neurotoxic soluble protofibrils (215). Amyloid fibrils can thus be toxic per se (section 1.4.1.2) or can function as a potential source of neurotoxic oligomeric species (216, 
217). Alternatively, it has also been suggested that the ongoing polymerization process, rather than a specific and stable aggregate, is responsible for $A \beta$-related toxicity $(94,95)$. In accordance with this hypothesis, crude $A \beta_{1-42}$ preparations containing a monomeric and heterogeneous mixture of $A \beta_{1-42}$ oligomers and protofibrils were more toxic than purified monomers, protofibrillar fractions, or fibrils. The toxicity of protofibrils was directly linked to their interaction with monomeric $A \beta_{1-42}$ and strongly dependent on their ability to convert into fibrils. Moreover, the ongoing $A \beta$ aggregation process, rather than distinct aggregation states, elicited alterations in astrocyte metabolic phenotypes (94). Therefore, we postulate that insights into the dynamic equilibrium between $A \beta$ aggregation species are required to fully understand $\mathrm{A} \beta$ toxicity.

\subsubsection{Other players in the game}

The dynamic nature of the $\mathrm{A} \beta$ peptide allows it to act as a hub protein and interact with many different partners and environmental factors. Moreover, its properties are modulated by human lifestyle. In this section, a non-exhaustive list will be given of the interaction partners and influencing factors that have been studied most. The modulation of $A \beta$ production, aggregation, and degradation by these factors has been the focus of numerous studies, but less is known about their effect on $\mathrm{A} \beta$ dynamics.

\subsubsection{Receptor-mediated $\mathrm{A} \beta$ clearance and proteolytic $\mathrm{A} \beta$ degradation}

$\mathrm{A} \beta$ is cleared from the brain by two major pathways: receptor-mediated transport across the blood brain barrier (BBB) and proteolytic degradation (218). First, several multi-ligand cell surface receptors are responsible for $A \beta$ flux across the brain endothelium (219). A $\beta$ efflux to the blood stream is exerted by receptors from the low density lipoprotein (LDL) receptor family, such as the low density lipoprotein receptor-related protein 1 (LRP-1) (220). This A $\beta$ transfer occurs via direct interaction with receptors or via binding to other receptor ligands (e.g. ApoE and ApoJ in the case of LRP-1). The process of A $\beta$ influx is regulated by RAGE, a multi-ligand receptor of the immunoglobin superfamily (221). A $\beta$ interactions with RAGE amplify neuronal stress and $A \beta$ accumulation, and result in neuroinflammation by stimulating the expression and secretion of pro-inflammatory cytokines (222). Second, extensive in vitro and in vivo studies have identified a range of enzymes capable of degrading $A \beta$ (223-225), with neprilysin (NEP) (226) and insulin-degrading enzyme (IDE) (227) the best characterized $\mathrm{A} \beta$-degrading proteases (228). Finally, other clearance pathways include bulk flow drainage of CSF and cellular A $\beta$ uptake by microglia or astrocytes and subsequent degradation (229, 230).

\subsubsection{Metals}

Metals $(\mathrm{Cu}, \mathrm{Zn}, \mathrm{Fe}, \mathrm{Al})$ co-localize with $\mathrm{A} \beta$ plaques and induce $\mathrm{A} \beta$ toxicity through enhanced $\mathrm{A} \beta$ aggregation and ROS production. In AD brains, a disrupted homeostasis of metal ions contributes to the imbalance of the production and removal of $\operatorname{ROS}(231,232)$. Aluminium is known to increase the $A \beta$ brain burden and this might be due to a direct influence upon $A \beta$ anabolism or to direct or indirect effects on $A \beta$ catabolism (233). Metals have also been shown to affect $A \beta$ intramolecular dynamics. Binding of zinc to the $N$-terminus of the $A \beta$ monomer leads to a decrease in the intrinsic mobility of this region and the formation of a turn-like conformation in residues $\mathrm{Val}_{24}-\mathrm{Lys}_{28}$ promoting aggregation, as shown by ${ }^{15} \mathrm{~N}$ relaxation measurements (234). Copper can also bind to the $\mathrm{N}$-terminus, causing a structural ordering in this region (235). 


\subsubsection{Lipids and membranes}

There is evidence that membrane composition and properties play a role in A $\beta$ cytotoxicity (236-239). Interaction of $A \beta$ with membranes can modulate the peptide conformation and aggregation properties of $\mathrm{A} \beta(239,240)$. Moreover, cholesterol has been suggested to provide stability to membrane-adjacent lipid rafts and therefore facilitate A $\beta$ cleavage from APP (241). Proteoglycans, major components of the cell membrane and extracellular matrix in the central nervous system (CNS), co-localize with $A \beta$ plaques. Proteoglycans have been shown to directly interact with $\mathrm{A} \beta$, causing an increased aggregation propensity and fibril formation, and a decreased degradation by microglia (242).

\subsubsection{Chaperones}

Genetic evidence suggests a role for chaperones in AD (243) and the contribution of chaperones in the context of $\mathrm{AD}$ is reviewed in (244). Abundant chaperone levels block formation of $\mathrm{A} \beta$ aggregates as was demonstrated in a Caenorhabditis elegans disease model (245). In vitro results indicated that heat shock proteins were capable of suppressing the early stages of aggregation (246).

\subsubsection{Lifestyle}

Recently, the group of Holtzman suggested that sleep abnormalities in life might predispose an individual to AD (247). They discovered that $A \beta$ levels in the CSF undergo diurnal fluctuations in humans and that this cycle is disturbed following plaque formation before the appearance of any cognitive symptoms (248). Using AD mouse models, Holtzman and coworkers determined that $A \beta$ dynamics are affected by perturbation of the orexin signalling pathway and the sleep-wake cycle. Moreover, chronic sleep restriction lead to an enhancement of plaque formation (249). A relationship between sleep disturbances and disease development has also been suggested for Parkinson's and Huntington's disease (250).

Another important factor to consider is nutritional diet $(251,252)$. Several food components have been suggested to modulate AD risk, but the mechanistic details of their mode of action remain to be discovered. An increased $\mathrm{AD}$ risk has been linked to a diet rich in saturated fatty acids and a high calorie and alcohol intake. In contrast, flavonoids, fish, methionine-rich proteins, and vitamins have been suggested to have a beneficial effect in AD development and can act as antioxidants, anti-inflammatory molecules and metal chelators. Beneficial nutritional components that have extensively been studied include the polyphenols (-)epigallocatechine gallate (EGCC, green tea), grape seed polyphenolic extract (GSPE, grape seed), and resveratrol (red wine), and also curcumin and certain vitamins. Deficiency of vitamin B6 leads to an increased concentration of homocysteine, a risk factor implicated in vascular mechanisms leading to $\operatorname{AD}(251,252)$.

Furthermore, physical and cognitive exercises have a beneficial effect on AD development, although studies are required to understand the molecular basis for this phenomenon (253255). Recently, Selkoe and co-workers demonstrated that cognitive exercise induces a protective effect against $\mathrm{A} \beta$-oligomer induced synaptotoxicity in $\mathrm{AD}$ mouse models by activation of the $\beta 2$-adrenergic signalling pathway (256).

\subsubsection{AD therapy development}

As the $\mathrm{A} \beta$ peptide is central to $\mathrm{AD}$ pathogenesis, it has been the main target of many therapeutic strategies in the fight against $\mathrm{AD}$. In the following section, the most widely studied approaches are presented (Fig. 1.8). Concerns generally applicable to all approaches 
mentioned in this section are their efficacy in full-blown AD brains, which already possess a considerable amyloid load, and their potential undesirable side-effects.

Initially, numerous studies explored the possibility to lower $A \beta$ levels in the brain by inhibiting or modulating the activity of $\beta$ - and $\gamma$-secretase, the enzymes responsible for the generation of $\mathrm{A} \beta$ from its precursor APP. Initial studies were promising, as $\beta$-secretase and $\gamma$ secretase inhibitors (GSI) reduced $\mathrm{A} \beta$ deposition in transgenic APP mice brains. However, these inhibitors were associated with intolerable and toxic side-effects, due to the fact that both proteases have many other substrates that play roles in neuronal functioning, cell maintenance, development, and cell fate (e.g. Notch 1 in the case of y-secretase) $(257,258)$. Therefore, more selective inhibitors were developed that only targeted APP (e.g. Notchsparing APP selective GSIs), but these compounds were not effective in humans and did not result in reduced $A \beta$ levels in the brain (259). Modulators of $\gamma$-secretase activity, rather than inhibitors, are now under development. These modulators have the capability to selectively decrease $A \beta_{1-42}$ production with respect to $A \beta_{1-40}$, or shift the ratios of other $A \beta$ peptide lengths (260). Differential targeting of $\gamma$-secretase complexes, based on their subunit composition, might also be considered as a viable strategy (82).

Another option to reduce $A \beta$ levels in the brain is depletion of $A \beta$ by immunotherapy, either actively or passively (261). Active immunization involves administration of a vaccine containing antigens to induce an immune response that generates antibodies directed against $\mathrm{A} \beta$. It has the advantage of generating a prolonged antibody response by one or minimal numbers of administration, but the response can be variable among patients. Passive immunization consists of the repeated infusion of $A \beta$-directed antibodies that can be rapidly cleared if side-effects occur. $A \beta$ immunotherapy has the ability of targeting a variety of mechanisms and targets, and is considered one of the most promising AD therapeutic strategies. It remains to be determined which type of immunization gives the best results, active or passive, and which $\mathrm{A} \beta$ species need to be targeted. As soluble aggregates have been shown to correlate with disease severity and are more toxic than their fibrillar counterparts, most current strategies target soluble $\mathrm{A} \beta$ oligomers and protofibrillar species.

Inhibition of $A \beta$ aggregation is a third possible strategy that has resulted in the development and testing of numerous compounds $(262,263)$. The nature of these compounds is versatile and ranges from peptides and proteins (e.g. molecular chaperones and antibodies), to small chemical compounds such as polyphenols, anti-inflammatory agents, metal chelators, tetracyclines, and inorganic and organic nanoparticles. Some compounds interact with the A $\beta$ monomer and stabilize it in its native conformation, others target soluble and toxic oligomers, protofibrillar species, or prevent the overall aggregation propensity. Fundamental understanding of the mechanism of $\mathrm{A} \beta$ aggregation and its kinetics are essential for developing inhibiting compounds (264).

However, as A $\beta$-based drugs have not yet proven successful, alternative approaches are being explored that involve targeting other aspects of AD pathology, such as neuroinflammation $(265,266)$, oxidative stress $(267)$, and tau (268).

Moreover, as the multifactorial nature of $\mathrm{AD}$ is a complicating factor in drug development in addition to $A \beta$ dynamics, the attention in the field is shifting towards the development of combination therapies and multi-target directed ligands. Multi-target directed ligands (269) can simultaneously target and modulate various facets of AD pathology (270-273). These drugs may then serve as leads for further development as network medicines. Network medicine aims to understand "the big picture" and offers a platform to understand the complexity of a disease and all the molecular pathways involved, their interconnections, and 
identify potential treatment strategies. This strategy is not only under development for targeting $\mathrm{AD}$, but also serves as a framework for tackling other complex diseases, such as cancers $(274,275)$.

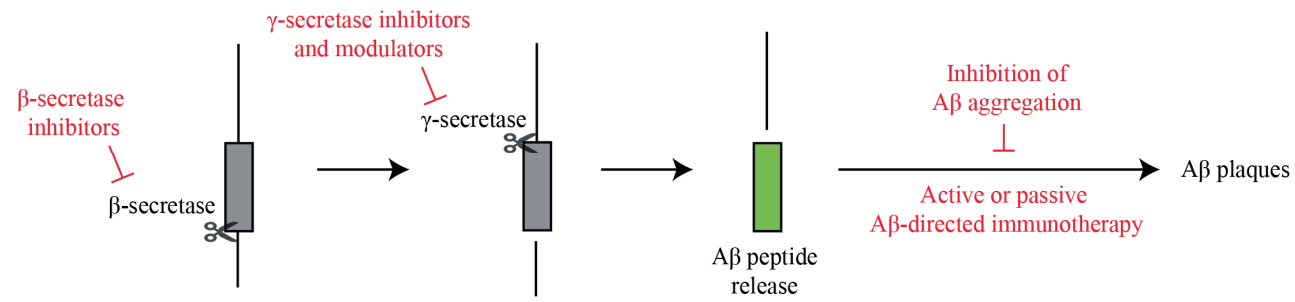

Figure 1.8: Schematic view of A $\boldsymbol{\beta}$-based strategies for AD treatment. Several approaches were or are under investigation to reduce $A \beta$ levels in the brain or shift the ratios of certain $A \beta$ alloforms (e.g. $A \beta_{1-42}$ : $A \beta_{1-40}$ ): (i) inhibition or modulation of the activities of $\beta$ - and $\gamma$-secretase, (ii) inhibition of $A \beta$ aggregation, and (iii) $A \beta$ directed active or passive immunotherapy. 


\subsection{References}

1. Tanford C \& Reynolds JA (2001) Nature's Robots: A History of Proteins (Oxford University Press).

2. Wright PE \& Dyson HJ (1999) Intrinsically unstructured proteins: re-assessing the protein structure-function paradigm. $J$ Mol Biol 293(2):321-331.

3. Uversky VN \& Dunker AK (2010) Understanding protein non-folding. Biochim Biophys Acta 1804(6):1231-1264.

4. Dyson HJ \& Wright PE (2005) Intrinsically unstructured proteins and their functions. Nat Rev Mol Cell Biol 6(3):197-208.

5. Tompa P (2010) Biological processess enriched in disorder. Structure and function of intrinsically disordered proteins, (CRC Press (Taylor and Francis Group), Boca Raton, Fl.), pp 143-162.

6. Anfinsen CB, Haber E, Sela M, \& White FH (1961) The kinetics of formation of native ribonuclease during oxidation of the reduced polypeptide chain. Proc Natl Acad Sci U S A 47:1309-1314.

7. Berg JM, Tymoczko JL, \& Stryer L (2002) Biochemistry (5th edition) (W.H. Freeman, New York, USA).

8. Ward JJ, Sodhi JS, McGuffin LJ, Buxton BF, \& Jones DT (2004) Prediction and functional analysis of native disorder in proteins from the three kingdoms of life. $J$ Mol Biol 337(3):635645.

9. Oldfield CJ, et al. (2005) Comparing and combining predictors of mostly disordered proteins. Biochemistry 44(6):1989-2000.

10. Tompa P, Szász C, \& Buday L (2005) Structural disorder throws new light on moonlighting. Trends Biochem Sci 30(9):484-489.

11. Uversky VN, Oldfield CJ, \& Dunker AK (2008) Intrinsically disordered proteins in human diseases: introducing the D2 concept. Annu Rev Biophys 37:215-246.

12. Uversky VN (2014) The triple power of $\mathrm{D}^{3}$ : Protein intrinsic disorder in degenerative diseases. Front Biosci (Landmark Ed) 19:181-258.

13. Dobson CM (2003) Protein folding and misfolding. Nature 426(6968):884-890.

14. Dobson CM (2004) Principles of protein folding, misfolding and aggregation. Semin Cell Dev Biol 15(1):3-16.

15. Tyedmers J, Mogk A, \& Bukau B (2010) Cellular strategies for controlling protein aggregation. Nat Rev Mol Cell Biol 11(11):777-788.

16. Campioni S, Monsellier E, \& Chiti F (2010) Why Proteins Misfold. Protein Misfolding Diseases, (John Wiley \& Sons, Inc.), pp 1-20.

17. Hartl FU \& Hayer-Hartl M (2009) Converging concepts of protein folding in vitro and in vivo. Nat Struct Mol Biol 16(6):574-581.

18. Hartl FU \& Hayer-Hartl M (2002) Molecular chaperones in the cytosol: from nascent chain to folded protein. Science 295(5561):1852-1858.

19. Walter P \& Ron D (2011) The unfolded protein response: from stress pathway to homeostatic regulation. Science 334(6059):1081-1086.

20. Linding R, Schymkowitz J, Rousseau F, Diella F, \& Serrano L (2004) A comparative study of the relationship between protein structure and $\beta$-aggregation in globular and intrinsically disordered proteins. J Mol Biol 342(1):345-353.

21. Lise S \& Jones DT (2005) Sequence patterns associated with disordered regions in proteins. Proteins 58(1):144-150.

22. Dyson HJ \& Wright PE (2002) Coupling of folding and binding for unstructured proteins. Curr Opin Struct Biol 12(1):54-60.

23. Uversky VN (2011) Intrinsically disordered proteins may escape unwanted interactions via functional misfolding. Biochim Biophys Acta 1814(5):693-712.

24. Babu MM, van der Lee R, de Groot NS, \& Gsponer J (2011) Intrinsically disordered proteins: regulation and disease. Curr Opin Struct Biol 21(3):432-440.

25. Koga H, Kaushik S, \& Cuervo AM (2011) Protein homeostasis and aging: The importance of exquisite quality control. Ageing Res Rev 10(2):205-215. 
26. Knowles TP, Vendruscolo M, \& Dobson CM (2014) The amyloid state and its association with protein misfolding diseases. Nat Rev Mol Cell Biol 15(6):384-396.

27. Vendruscolo M, Knowles TP, \& Dobson CM (2011) Protein solubility and protein homeostasis: a generic view of protein misfolding disorders. Cold Spring Harb Perspect Biol 3(12):a010454.

28. Eisenberg D \& Jucker M (2012) The amyloid state of proteins in human diseases. Cell 148(6):1188-1203.

29. Greenwald J \& Riek R (2010) Biology of amyloid: structure, function, and regulation. Structure 18(10):1244-1260.

30. Nilsson MR (2004) Techniques to study amyloid fibril formation in vitro. Methods 34(1):151160.

31. Chiti F \& Dobson CM (2006) Protein misfolding, functional amyloid, and human disease. Annu Rev Biochem 75:333-366.

32. Pepys MB (2001) Pathogenesis, diagnosis and treatment of systemic amyloidosis. Philos Trans R Soc Lond B Biol Sci 356(1406):203-210.

33. Ross CA \& Poirier MA (2004) Protein aggregation and neurodegenerative disease. Nat Med 10 Suppl:S10-17.

34. Fowler DM, Koulov AV, Balch WE, \& Kelly JW (2007) Functional amyloid - from bacteria to humans. Trends Biochem Sci 32(5):217-224.

35. Prince $\mathrm{M}$, et al. (2013) The global prevalence of dementia: a systematic review and metaanalysis. Alzheimers Dement 9(1):63-75.e62.

36. Thies W, Bleiler L, \& Association As (2013) 2013 Alzheimer's disease facts and figures. Alzheimers Dement 9(2):208-245.

37. ADEAR (2008) Alzheimer's disease: unraveling the mystery. (NIH publication no. 08-3782).

38. Azevedo FA, et al. (2009) Equal numbers of neuronal and nonneuronal cells make the human brain an isometrically scaled-up primate brain. J Comp Neurol 513(5):532-541.

39. Herculano-Houzel S (2009) The human brain in numbers: a linearly scaled-up primate brain. Front Hum Neurosci 3:31.

40. Amunts K, et al. (2013) BigBrain: an ultrahigh-resolution 3D human brain model. Science 340(6139):1472-1475.

41. D'Amelio M \& Rossini PM (2012) Brain excitability and connectivity of neuronal assemblies in Alzheimer's disease: from animal models to human findings. Prog Neurobiol 99(1):42-60.

42. Serrano-Pozo A, Frosch MP, Masliah E, \& Hyman BT (2011) Neuropathological alterations in Alzheimer disease. Cold Spring Harb Perspect Med 1(1):a006189.

43. Mandelkow EM \& Mandelkow E (2012) Biochemistry and cell biology of tau protein in neurofibrillary degeneration. Cold Spring Harb Perspect Med 2(7):a006247.

44. Masters CL \& Selkoe DJ (2012) Biochemistry of amyloid $\beta$-protein and amyloid deposits in Alzheimer disease. Cold Spring Harb Perspect Med 2(6):a006262.

45. Buée L, Bussière T, Buée-Scherrer V, Delacourte A, \& Hof PR (2000) Tau protein isoforms, phosphorylation and role in neurodegenerative disorders. Brain Res Brain Res Rev 33(1):95130 .

46. Giuffrida ML, et al. (2010) The monomer state of beta-amyloid: where the Alzheimer's disease protein meets physiology. Rev Neurosci 21(2):83-93.

47. Abramov E, et al. (2009) Amyloid- $\beta$ as a positive endogenous regulator of release probability at hippocampal synapses. Nat Neurosci 12(12):1567-1576.

48. Hardy J \& Allsop D (1991) Amyloid deposition as the central event in the aetiology of Alzheimer's disease. Trends Pharmacol Sci 12(10):383-388.

49. Hardy J \& Selkoe DJ (2002) The amyloid hypothesis of Alzheimer's disease: progress and problems on the road to therapeutics. Science 297(5580):353-356.

50. Tanzi RE \& Bertram L (2005) Twenty years of the Alzheimer's disease amyloid hypothesis: a genetic perspective. Cell 120(4):545-555.

51. Goedert M, Ghetti B, \& Spillantini MG (2012) Frontotemporal dementia: implications for understanding Alzheimer disease. Cold Spring Harb Perspect Med 2(2):a006254.

52. Iqbal K, Liu F, Gong CX, \& Grundke-Iqbal I (2010) Tau in Alzheimer disease and related tauopathies. Curr Alzheimer Res 7(8):656-664. 
53. Medina M \& Avila J (2014) New perspectives on the role of tau in Alzheimer's disease. Implications for therapy. Biochem Pharmacol 88(4):540-547.

54. Sorrentino P, Iuliano A, Polverino A, Jacini F, \& Sorrentino G (2014) The dark sides of amyloid in Alzheimer's disease pathogenesis. FEBS Lett 588(5):641-652.

55. Haass C \& Selkoe DJ (2007) Soluble protein oligomers in neurodegeneration: lessons from the Alzheimer's amyloid $\beta$-peptide. Nat Rev Mol Cell Biol 8(2):101-112.

56. Tarawneh R \& Holtzman DM (2012) The clinical problem of symptomatic Alzheimer disease and mild cognitive impairment. Cold Spring Harb Perspect Med 2(5):a006148.

57. Kern A \& Behl C (2009) The unsolved relationship of brain aging and late-onset Alzheimer disease. Biochim Biophys Acta 1790(10):1124-1132.

58. Tanzi RE (2012) The genetics of Alzheimer disease. Cold Spring Harb Perspect Med 2(10):a006296.

59. Armstrong RA (2013) What causes Alzheimer's disease? Folia Neuropathol 51(3):169-188.

60. Strittmatter WJ, et al. (1993) Apolipoprotein E: high-avidity binding to $\beta$-amyloid and increased frequency of type 4 allele in late-onset familial Alzheimer disease. Proc Natl Acad Sci U S A 90(5):1977-1981.

61. Mahley RW, Weisgraber KH, \& Huang Y (2006) Apolipoprotein E4: a causative factor and therapeutic target in neuropathology, including Alzheimer's disease. Proc Natl Acad Sci U S A 103(15):5644-5651.

62. $\mathrm{Bu} \mathrm{G}$ (2009) Apolipoprotein $\mathrm{E}$ and its receptors in Alzheimer's disease: pathways, pathogenesis and therapy. Nat Rev Neurosci 10(5):333-344.

63. Iurescia S, Fioretti D, Mangialasche F, \& Rinaldi M (2010) The pathological cross talk between apolipoprotein E and amyloid- $\beta$ peptide in Alzheimer's disease: emerging gene-based therapeutic approaches. J Alzheimers Dis 21(1):35-48.

64. Holtzman DM, Herz J, \& Bu G (2012) Apolipoprotein E and apolipoprotein E receptors: normal biology and roles in Alzheimer disease. Cold Spring Harb Perspect Med 2(3):a006312.

65. Kim J, Basak JM, \& Holtzman DM (2009) The role of apolipoprotein E in Alzheimer's disease. Neuron 63(3):287-303.

66. Huang Y (2010) A $\beta$-independent roles of apolipoprotein E4 in the pathogenesis of Alzheimer's disease. Trends Mol Med 16(6):287-294.

67. McKhann GM, et al. (2011) The diagnosis of dementia due to Alzheimer's disease: recommendations from the National Institute on Aging-Alzheimer's Association workgroups on diagnostic guidelines for Alzheimer's disease. Alzheimers Dement 7(3):263-269.

68. Frisoni GB, Fox NC, Jack CR, Scheltens P, \& Thompson PM (2010) The clinical use of structural MRI in Alzheimer disease. Nat Rev Neurol 6(2):67-77.

69. Greicius MD, Srivastava G, Reiss AL, \& Menon V (2004) Default-mode network activity distinguishes Alzheimer's disease from healthy aging: evidence from functional MRI. Proc Natl Acad Sci U S A 101(13):4637-4642.

70. Cohen AD \& Klunk WE (2014) Early detection of Alzheimer's disease using PiB and FDG PET. Neurobiol Dis. Doi: 10.1016/j.nbd.2014.05.001.

71. Ikonomovic MD, et al. (2008) Post-mortem correlates of in vivo PiB-PET amyloid imaging in a typical case of Alzheimer's disease. Brain 131(Pt 6):1630-1645.

72. Johnson KA, Fox NC, Sperling RA, \& Klunk WE (2012) Brain imaging in Alzheimer disease. Cold Spring Harb Perspect Med 2(4):a006213.

73. Blennow K, Zetterberg H, \& Fagan AM (2012) Fluid biomarkers in Alzheimer disease. Cold Spring Harb Perspect Med 2(9):a006221.

74. Blennow K, et al. (2014) Clinical utility of cerebrospinal fluid biomarkers in the diagnosis of early Alzheimer's disease. Alzheimers Dement.Doi: 10.1016/j.alz.2014.02.004.

75. Aisen PS, Cummings J, \& Schneider LS (2012) Symptomatic and nonamyloid/tau based pharmacologic treatment for Alzheimer disease. Cold Spring Harb Perspect Med 2(3):a006395.

76. Parsons CG, Danysz W, Dekundy A, \& Pulte I (2013) Memantine and cholinesterase inhibitors: complementary mechanisms in the treatment of Alzheimer's disease. Neurotox Res 24(3):358-369. 
77. Ford AH (2014) Neuropsychiatric aspects of dementia. Maturitas. Doi: 10.1016/j.maturitas.2014.04.005.

78. Mangialasche F, Solomon A, Winblad B, Mecocci P, \& Kivipelto M (2010) Alzheimer's disease: clinical trials and drug development. Lancet Neurol 9(7):702-716.

79. Huang Y \& Mucke L (2012) Alzheimer mechanisms and therapeutic strategies. Cell 148(6):1204-1222.

80. Hamaguchi T, Ono K, \& Yamada M (2006) Anti-amyloidogenic therapies: strategies for prevention and treatment of Alzheimer's disease. Cell Mol Life Sci 63(13):1538-1552.

81. Takami M, et al. (2009) $\gamma$-Secretase: successive tripeptide and tetrapeptide release from the transmembrane domain of $\beta$-carboxyl terminal fragment. J Neurosci 29(41):13042-13052.

82. Acx H, et al. (2013) Signature A $\beta$ Profiles Are Produced by Different $\gamma$-Secretase Complexes. $J$ Biol Chem 289(7):4346-4455.

83. Finder VH, Vodopivec I, Nitsch RM, \& Glockshuber R (2010) The recombinant amyloid- $\beta$ peptide A $\beta 1-42$ aggregates faster and is more neurotoxic than synthetic A $\beta 1-42 . J$ Mol Biol 396(1):9-18.

84. Yoshiike Y, Chui DH, Akagi T, Tanaka N, \& Takashima A (2003) Specific compositions of amyloid- $\beta$ peptides as the determinant of toxic $\beta$-aggregation. $J$ Biol Chem 278(26):2364823655.

85. Snyder SW, et al. (1994) Amyloid- $\beta$ aggregation: selective inhibition of aggregation in mixtures of amyloid with different chain lengths. Biophys $J$ 67(3):1216-1228.

86. Jan A, Gokce O, Luthi-Carter R, \& Lashuel HA (2008) The ratio of monomeric to aggregated forms of $\mathrm{A} \beta 40$ and $\mathrm{A} \beta 42$ is an important determinant of amyloid- $\beta$ aggregation, fibrillogenesis, and toxicity. $J$ Biol Chem 283(42):28176-28189.

87. Yan $\mathrm{Y} \&$ Wang $\mathrm{C}(2007) \mathrm{A} \beta 40$ protects non-toxic $\mathrm{A} \beta 42$ monomer from aggregation. $J \mathrm{Mol}$ Biol 369(4):909-916.

88. Kuperstein I, et al. (2010) Neurotoxicity of Alzheimer's disease A $\beta$ peptides is induced by small changes in the $\mathrm{A} \beta 42$ to $\mathrm{A} \beta 40$ ratio. The EMBO journal 29(19):3408-3420.

89. Pauwels K, et al. (2012) Structural basis for increased toxicity of pathological A $\beta 42: A \beta 40$ ratios in Alzheimer disease. $J$ Biol Chem 287(8):5650-5660.

90. Vandersteen A, et al. (2012) Molecular plasticity regulates oligomerization and cytotoxicity of the multipeptide-length amyloid- $\beta$ peptide pool. J Biol Chem 287(44):36732-36743.

91. Morris AM, Watzky MA, \& Finke RG (2009) Protein aggregation kinetics, mechanism, and curve-fitting: a review of the literature. Biochim Biophys Acta 1794(3):375-397.

92. Finder VH \& Glockshuber R (2007) Amyloid- $\beta$ aggregation. Neurodegener Dis 4(1):13-27.

93. Karran E, Mercken M, \& De Strooper B (2011) The amyloid cascade hypothesis for Alzheimer's disease: an appraisal for the development of therapeutics. Nat Rev Drug Discov 10(9):698-712.

94. Jan A, et al. (2011) A 342 neurotoxicity is mediated by ongoing nucleated polymerization process rather than by discrete A $\beta 42$ species. J Biol Chem 286(10):8585-8596.

95. Wogulis M, et al. (2005) Nucleation-dependent polymerization is an essential component of amyloid-mediated neuronal cell death. $J$ Neurosci 25(5):1071-1080.

96. Tompa P (2009) Structural disorder in amyloid fibrils: its implication in dynamic interactions of proteins. FEBS J 276(19):5406-5415.

97. Glenner GG \& Wong CW (1984) Alzheimer's disease: initial report of the purification and characterization of a novel cerebrovascular amyloid protein. Biochem Biophys Res Commun 120:885-890.

98. Klyubin I, et al. (2008) A $\beta$ dimer-containing human CSF disrupts synaptic plasticity: prevention by systemic passive immunization. $J$ Neurosci 28(16):4231-4237.

99. Shankar GM, et al. (2008) Amyloid- $\beta$ protein dimers isolated directly from Alzheimer's brains impair synaptic plasticity and memory. Nat Med 14(8):837-842.

100. Jin M, et al. (2011) Soluble amyloid $\beta$-protein dimers isolated from Alzheimer cortex directly induce Tau hyperphosphorylation and neuritic degeneration. Proc Natl Acad Sci U S A 108(14):5819-5824. 
101. Hilbich C, Kisters-Woike B, Reed J, Masters CL, \& Beyreuther K (1991) Aggregation and secondary structure of synthetic amyloid $\beta A 4$ peptides of Alzheimer's disease. J Mol Biol 218(1):149-163.

102. Tseng BP, et al. (1999) Deposition of monomeric, not oligomeric, A $\beta$ mediates growth of Alzheimer's disease amyloid plaques in human brain preparations. Biochemistry 38(32):10424-10431.

103. Jan A, Hartley DM, \& Lashuel HA (2010) Preparation and characterization of toxic A aggregates for structural and functional studies in Alzheimer's disease research. Nat Protoc 5(6):1186-1209.

104. Zhang S, et al. (2000) The Alzheimer's peptide A $\beta$ adopts a collapsed coil structure in water. $J$ Struct Biol 130(2-3):130-141.

105. Riek R, Güntert P, Döbeli H, Wipf B, \& Wüthrich K (2001) NMR studies in aqueous solution fail to identify significant conformational differences between the monomeric forms of two Alzheimer peptides with widely different plaque-competence, $\mathrm{A} \beta(1-40)(\mathrm{ox})$ and $\mathrm{A} \beta(1-$ 42)(ox). Eur J Biochem 268(22):5930-5936.

106. Hou L, et al. (2004) Solution NMR studies of the $A \beta(1-40)$ and $A \beta(1-42)$ peptides establish that the Met35 oxidation state affects the mechanism of amyloid formation. $J$ Am Chem Soc 126(7):1992-2005.

107. Shao H, Jao S, Ma K, \& Zagorski MG (1999) Solution structures of micelle-bound amyloid $\beta$ (1-40) and $\beta-(1-42)$ peptides of Alzheimer's disease. J Mol Biol 285(2):755-773.

108. Tomaselli S, et al. (2006) The $\alpha$-to- $\beta$ conformational transition of Alzheimer's A $\beta-(1-42)$ peptide in aqueous media is reversible: a step by step conformational analysis suggests the location of $\beta$ conformation seeding. Chembiochem 7(2):257-267.

109. Vivekanandan S, Brender JR, Lee SY, \& Ramamoorthy A (2011) A partially folded structure of amyloid-beta(1-40) in an aqueous environment. Biochem Biophys Res Commun 411(2):312-316.

110. Baumketner A, et al. (2006) Structure of the 21-30 fragment of amyloid $\beta$-protein. Protein Sci 15(6):1239-1247.

111. Lazo ND, Grant MA, Condron MC, Rigby AC, \& Teplow DB (2005) On the nucleation of amyloid $\beta$-protein monomer folding. Protein Sci 14(6):1581-1596.

112. Danielsson J, Andersson A, Jarvet J, \& Gräslund A (2006) $15 \mathrm{~N}$ relaxation study of the amyloid $\beta$-peptide: structural propensities and persistence length. Magn Reson Chem $44 \mathrm{Spec}$ No:S114-121.

113. Yan $Y \&$ Wang $C$ (2006) $A \beta 42$ is more rigid than $A \beta 40$ at the $C$ terminus: implications for $A \beta$ aggregation and toxicity. J Mol Biol 364(5):853-862.

114. Sgourakis NG, Yan Y, McCallum SA, Wang C, \& Garcia AE (2007) The Alzheimer's peptides A 440 and 42 adopt distinct conformations in water: a combined MD / NMR study. $J$ Mol Biol 368(5):1448-1457.

115. Sgourakis NG, et al. (2011) Atomic-level characterization of the ensemble of the A $\beta(1-42)$ monomer in water using unbiased molecular dynamics simulations and spectral algorithms. $J$ Mol Biol 405(2):570-583.

116. Yang $\mathrm{M} \&$ Teplow DB (2008) Amyloid $\beta$-protein monomer folding: free-energy surfaces reveal alloform-specific differences. $J$ Mol Biol 384(2):450-464.

117. Rosenman DJ, Connors CR, Chen W, Wang C, \& García AE (2013) A $\beta$ monomers transiently sample oligomer and fibril-like configurations: ensemble characterization using a combined MD/NMR approach. J Mol Biol 425(18):3338-3359.

118. Luhrs T, et al. (2005) 3D structure of Alzheimer's amyloid- $\beta(1-42)$ fibrils. Proc Natl Acad Sci US A 102(48):17342-17347.

119. Qiang W, Yau WM, Luo Y, Mattson MP, \& Tycko R (2012) Antiparallel $\beta$-sheet architecture in Iowa-mutant $\beta$-amyloid fibrils. Proc Natl Acad Sci U S A 109(12):4443-4448.

120. Petkova AT, et al. (2005) Self-propagating, molecular-level polymorphism in Alzheimer's $\beta$ amyloid fibrils. Science 307(5707):262-265.

121. Lu JX, et al. (2013) Molecular Structure of $\beta$-Amyloid Fibrils in Alzheimer's Disease Brain Tissue. Cell 154(6):1257-1268. 
122. Wright PE \& Dyson HJ (2009) Linking folding and binding. Curr Opin Struct Biol 19(1):3138.

123. Török M, et al. (2002) Structural and dynamic features of Alzheimer's A $\beta$ peptide in amyloid fibrils studied by site-directed spin labeling. J Biol Chem 277(43):40810-40815.

124. Kheterpal I, Zhou S, Cook KD, \& Wetzel R (2000) A $\beta$ amyloid fibrils possess a core structure highly resistant to hydrogen exchange. Proc Natl Acad Sci U S A 97(25):13597-13601.

125. Kheterpal I, Williams A, Murphy C, Bledsoe B, \& Wetzel R (2001) Structural features of the A $\beta$ amyloid fibril elucidated by limited proteolysis. Biochemistry 40(39):11757-11767.

126. Wang SS, Tobler SA, Good TA, \& Fernandez EJ (2003) Hydrogen exchange-mass spectrometry analysis of $\beta$-amyloid peptide structure. Biochemistry 42(31):9507-9514.

127. Fändrich M, Meinhardt J, \& Grigorieff N (2009) Structural polymorphism of Alzheimer A $\beta$ and other amyloid fibrils. Prion 3(2):89-93.

128. Ma J, et al. (2013) Intrinsic Structural Heterogeneity and Long-Term Maturation of Amyloid $\beta$ Peptide Fibrils. ACS Chem Neurosci 4(8):1236-1243.

129. Nyström S, et al. (2013) Evidence for Age-Dependent in Vivo Conformational Rearrangement within A $\beta$ Amyloid Deposits. ACS Chem Biol 8(6):1128-1133.

130. Sunde $\mathrm{M}$, et al. (1997) Common core structure of amyloid fibrils by synchrotron X-ray diffraction. J Mol Biol 273(3):729-739.

131. Jahn TR, et al. (2010) The common architecture of cross- $\beta$ amyloid. J Mol Biol 395(4):717727.

132. Petkova AT, et al. (2002) A structural model for Alzheimer's $\beta$-amyloid fibrils based on experimental constraints from solid state NMR. Proc Natl Acad Sci U S A 99(26):1674216747.

133. Bertini I, Gonnelli L, Luchinat C, Mao J, \& Nesi A (2011) A new structural model of A $\beta 40$ fibrils. J Am Chem Soc 133(40):16013-16022.

134. Whittemore NA, et al. (2005) Hydrogen-deuterium (H/D) exchange mapping of A $\beta 1-40$ amyloid fibril secondary structure using nuclear magnetic resonance spectroscopy. Biochemistry 44(11):4434-4441.

135. Olofsson A, Sauer-Eriksson AE, \& Ohman A (2006) The solvent protection of Alzheimer amyloid- $\beta-(1-42)$ fibrils as determined by solution NMR spectroscopy. $J$ Biol Chem 281(1):477-483.

136. Ahmed M, et al. (2010) Structural conversion of neurotoxic amyloid- $\beta(1-42)$ oligomers to fibrils. Nat Struct Mol Biol 17(5):561-567.

137. Morimoto A, et al. (2004) Analysis of the secondary structure of $\beta$-amyloid (A $\beta 42$ ) fibrils by systematic proline replacement. J Biol Chem 279(50):52781-52788.

138. Kheterpal I, Chen M, Cook KD, \& Wetzel R (2006) Structural differences in A $\beta$ amyloid protofibrils and fibrils mapped by hydrogen exchange--mass spectrometry with on-line proteolytic fragmentation. J Mol Biol 361(4):785-795.

139. Sawaya MR, et al. (2007) Atomic structures of amyloid cross- $\beta$ spines reveal varied steric zippers. Nature 447(7143):453-457.

140. Williams AD, et al. (2004) Mapping A $\beta$ amyloid fibril secondary structure using scanning proline mutagenesis. $J$ Mol Biol 335(3):833-842.

141. Scheidt HA, Morgado I, Rothemund S, Huster D, \& Fändrich M (2011) Solid-state NMR spectroscopic investigation of $A \beta$ protofibrils: implication of a $\beta$-sheet remodeling upon maturation into terminal amyloid fibrils. Angew Chem Int Ed Engl 50(12):2837-2840.

142. Scheidt HA, Morgado I, Rothemund S, \& Huster D (2012) Dynamics of amyloid $\beta$ fibrils revealed by solid-state NMR. $J$ Biol Chem 287(3):2017-2021.

143. Morel B, Varela L, \& Conejero-Lara F (2010) The thermodynamic stability of amyloid fibrils studied by differential scanning calorimetry. J Phys Chem B 114(11):4010-4019.

144. Kheterpal I \& Wetzel R (2006) Hydrogen/deuterium exchange mass spectrometry - a window into amyloid structure. Acc Chem Res 39(9):584-593.

145. Tycko R \& Wickner RB (2013) Molecular Structures of Amyloid and Prion Fibrils: Consensus versus Controversy. Acc Chem Res 46(7):1487-1496.

146. Crowther RA \& Goedert M (2000) Abnormal tau-containing filaments in neurodegenerative diseases. J Struct Biol 130(2-3):271-279. 
147. Jiménez JL, Tennent G, Pepys M, \& Saibil HR (2001) Structural diversity of ex vivo amyloid fibrils studied by cryo-electron microscopy. J Mol Biol 311(2):241-247.

148. Bousset L, et al. (2013) Structural and functional characterization of two alpha-synuclein strains. Nat Commun 4:2575.

149. Kodali R, Williams AD, Chemuru S, \& Wetzel R (2010) A $\beta(1-40)$ forms five distinct amyloid structures whose $\beta$-sheet contents and fibril stabilities are correlated. J Mol Biol 401(3):503517.

150. Klement K, et al. (2007) Effect of different salt ions on the propensity of aggregation and on the structure of Alzheimer's A $\beta(1-40)$ amyloid fibrils. J Mol Biol 373(5):1321-1333.

151. Pedersen JS \& Otzen DE (2008) Amyloid - a state in many guises: survival of the fittest fibril fold. Protein Sci 17(1):2-10.

152. Meinhardt J, Sachse C, Hortschansky P, Grigorieff N, \& Fändrich M (2009) A $\beta(1-40)$ fibril polymorphism implies diverse interaction patterns in amyloid fibrils. $J$ Mol Biol 386(3):869877.

153. Qiang W, Kelley K, \& Tycko R (2013) Polymorph-specific kinetics and thermodynamics of $\beta$-amyloid fibril growth. J Am Chem Soc 135(18):6860-6871.

154. Sachse C, et al. (2006) Quaternary structure of a mature amyloid fibril from Alzheimer's A $\beta(1-40)$ peptide. $J$ Mol Biol 362(2):347-354.

155. Sachse C, Fändrich M, \& Grigorieff N (2008) Paired $\beta$-sheet structure of an A $\beta(1-40)$ amyloid fibril revealed by electron microscopy. Proc Natl Acad Sci U S A 105(21):7462-7466.

156. Schmidt $M$, et al. (2009) Comparison of Alzheimer $A \beta(1-40)$ and $A \beta(1-42)$ amyloid fibrils reveals similar protofilament structures. Proc Natl Acad Sci U S A 106(47):19813-19818.

157. Zhang R, et al. (2009) Interprotofilament interactions between Alzheimer's A $\beta 1-42$ peptides in amyloid fibrils revealed by cryoEM. Proc Natl Acad Sci U S A 106(12):4653-4658.

158. Goldsbury CS, et al. (2000) Studies on the in vitro assembly of A $\beta 1-40$ : implications for the search for a $\beta$ fibril formation inhibitors. J Struct Biol 130(2-3):217-231.

159. Goldsbury CS, Frey P, Olivieri V, Aebi U, \& Müller SA (2005) Multiple assembly pathways underlie amyloid- $\beta$ fibril polymorphisms. J Mol Biol 352(2):282-298.

160. Petkova AT, Yau WM, \& Tycko R (2006) Experimental constraints on quaternary structure in Alzheimer's $\beta$-amyloid fibrils. Biochemistry 45(2):498-512.

161. Paravastu AK, Leapman RD, Yau WM, \& Tycko R (2008) Molecular structural basis for polymorphism in Alzheimer's $\beta$-amyloid fibrils. Proc Natl Acad Sci U S A 105(47):1834918354.

162. Cameron B \& Landreth GE (2010) Inflammation, microglia, and Alzheimer's disease. Neurobiol Dis 37(3):503-509.

163. Ill-Raga G, et al. (2010) Amyloid- $\beta$ peptide fibrils induce nitro-oxidative stress in neuronal cells. J Alzheimers Dis 22(2):641-652.

164. McKee AC, Kosik KS, \& Kowall NW (1991) Neuritic pathology and dementia in Alzheimer's disease. Ann Neurol 30(2):156-165.

165. Berg L, et al. (1998) Clinicopathologic studies in cognitively healthy aging and Alzheimer's disease: relation of histologic markers to dementia severity, age, sex, and apolipoprotein $\mathrm{E}$ genotype. Arch Neurol 55(3):326-335.

166. Seilheimer B, et al. (1997) The toxicity of the Alzheimer's $\beta$-amyloid peptide correlates with a distinct fiber morphology. J Struct Biol 119(1):59-71.

167. Kayed R \& Lasagna-Reeves CA (2013) Molecular mechanisms of amyloid oligomers toxicity. $J$ Alzheimers Dis 33 Suppl 1:S67-78.

168. Ihse E, et al. (2008) Amyloid fibril composition is related to the phenotype of hereditary transthyretin V30M amyloidosis. J Pathol 216(2):253-261.

169. Benilova I, Karran E, \& De Strooper B (2012) The toxic A $\beta$ oligomer and Alzheimer's disease: an emperor in need of clothes. Nat Neurosci 15(3):349-357.

170. Broersen K, Rousseau F, \& Schymkowitz J (2010) The culprit behind amyloid beta peptide related neurotoxicity in Alzheimer's disease: oligomer size or conformation? Alzheimers Res Ther 2(4):12.

171. Ono K, Condron MM, \& Teplow DB (2009) Structure-neurotoxicity relationships of amyloid $\beta$-protein oligomers. Proc Natl Acad Sci U S A 106(35):14745-14750. 
172. Cizas P, et al. (2010) Size-dependent neurotoxicity of $\beta$-amyloid oligomers. Arch Biochem Biophys 496(2):84-92.

173. Campioni S, et al. (2010) A causative link between the structure of aberrant protein oligomers and their toxicity. Nat Chem Biol 6(2):140-147.

174. Nekooki-Machida Y, et al. (2009) Distinct conformations of in vitro and in vivo amyloids of huntingtin-exon1 show different cytotoxicity. Proc Natl Acad Sci U S A 106(24):9679-9684.

175. Ladiwala AR, et al. (2012) Conformational differences between two amyloid $\beta$ oligomers of similar size and dissimilar toxicity. J Biol Chem 287(29):24765-24773.

176. Deshpande A, Mina E, Glabe C, \& Busciglio J (2006) Different conformations of amyloid $\beta$ induce neurotoxicity by distinct mechanisms in human cortical neurons. $J$ Neurosci 26(22):6011-6018.

177. Kayed R, et al. (2003) Common structure of soluble amyloid oligomers implies common mechanism of pathogenesis. Science 300(5618):486-489.

178. Glabe CG (2008) Structural classification of toxic amyloid oligomers. J Biol Chem 283(44):29639-29643.

179. Kayed R, et al. (2009) Annular protofibrils are a structurally and functionally distinct type of amyloid oligomer. $J$ Biol Chem 284(7):4230-4237.

180. Kayed R, et al. (2010) Conformation dependent monoclonal antibodies distinguish different replicating strains or conformers of prefibrillar A $\beta$ oligomers. Mol Neurodegener 5:57.

181. Cerf E, et al. (2009) Antiparallel $\beta$-sheet: a signature structure of the oligomeric amyloid $\beta$ peptide. Biochem J 421(3):415-423.

182. Sarroukh R, et al. (2011) Transformation of amyloid $\beta(1-40)$ oligomers into fibrils is characterized by a major change in secondary structure. Cell Mol Life Sci 68(8):1429-1438.

183. Celej MS, et al. (2012) Toxic prefibrillar $\alpha$-synuclein amyloid oligomers adopt a distinctive antiparallel $\beta$-sheet structure. Biochem J 443(3):719-726.

184. Vandersteen A, et al. (2012) A comparative analysis of the aggregation behavior of amyloid- $\beta$ peptide variants. FEBS Lett 586(23):4088-4093.

185. Laganowsky A, et al. (2012) Atomic view of a toxic amyloid small oligomer. Science 335(6073):1228-1231.

186. Gu L, Liu C, \& Guo Z (2013) Structural insights into A 342 oligomers using site-directed spin labeling. J Biol Chem 288(26):18673-18683.

187. Zhang Y, et al. (2013) Pulsed hydrogen-deuterium exchange mass spectrometry probes conformational changes in amyloid beta (A $\beta$ ) peptide aggregation. Proc Natl Acad Sci U S A 110(36):14604-14609.

188. Bolognesi B, et al. (2010) ANS binding reveals common features of cytotoxic amyloid species. ACS Chem Biol 5(8):735-740.

189. Williams TL, et al. (2011) A $\beta 42$ oligomers, but not fibrils, simultaneously bind to and cause damage to ganglioside-containing lipid membranes. Biochem J 439(1):67-77.

190. Teplow DB (2013) On the subject of rigor in the study of amyloid $\beta$-protein assembly. Alzheimers Res Ther 5(4):39.

191. Lesné S, et al. (2006) A specific amyloid- $\beta$ protein assembly in the brain impairs memory. Nature 440(7082):352-357.

192. Qi-Takahara Y, et al. (2005) Longer forms of amyloid $\beta$ protein: implications for the mechanism of intramembrane cleavage by $\gamma$-secretase. $J$ Neurosci 25(2):436-445.

193. Wiltfang J, et al. (2002) Highly conserved and disease-specific patterns of carboxyterminally truncated $\mathrm{A} \beta$ peptides 1-37/38/39 in addition to 1-40/42 in Alzheimer's disease and in patients with chronic neuroinflammation. Journal of Neurochemistry 81(3):481-496.

194. Vigo-Pelfrey C, Lee D, Keim P, Lieberburg I, \& Schenk DB (1993) Characterization of betaamyloid peptide from human cerebrospinal fluid. Journal of Neurochemistry 61(5):19651968.

195. Moro ML, Collins MJ, \& Cappellini E (2010) Alzheimer's disease and amyloid $\beta$-peptide deposition in the brain: a matter of 'aging'? Biochem Soc Trans 38(2):539-544.

196. Mori H, et al. (1994) Racemization: its biological significance on neuropathogenesis of Alzheimer's disease. Tohoku J Exp Med 174(3):251-262. 
197. Kubo T, Kumagae Y, Miller CA, \& Kaneko I (2003) Beta-amyloid racemized at the Ser26 residue in the brains of patients with Alzheimer disease: implications in the pathogenesis of Alzheimer disease. J Neuropathol Exp Neurol 62(3):248-259.

198. Kuo YM, Webster S, Emmerling MR, De Lima N, \& Roher AE (1998) Irreversible dimerization/tetramerization and post-translational modifications inhibit proteolytic degradation of A beta peptides of Alzheimer's disease. Biochim Biophys Acta 1406(3):291298.

199. Milton NG (2001) Phosphorylation of amyloid- $\beta$ at the serine 26 residue by human cdc2 kinase. Neuroreport 12(17):3839-3844.

200. Kumar S, et al. (2011) Extracellular phosphorylation of the amyloid $\beta$-peptide promotes formation of toxic aggregates during the pathogenesis of Alzheimer's disease. EMBO J 30(11):2255-2265.

201. Dong J, et al. (2003) Metal binding and oxidation of amyloid- $\beta$ within isolated senile plaque cores: Raman microscopic evidence. Biochemistry 42(10):2768-2773.

202. Hou L, et al. (2013) Modification of amyloid- $\beta 1-42$ fibril structure by methionine-35 oxidation. J Alzheimers Dis 37(1):9-18.

203. Vitek MP, et al. (1994) Advanced glycation end products contribute to amyloidosis in Alzheimer disease. Proc Natl Acad Sci U S A 91(11):4766-4770.

204. Jawhar S, Wirths $O$, \& Bayer TA (2011) Pyroglutamate amyloid- $\beta$ (A $\beta$ ): a hatchet man in Alzheimer disease. J Biol Chem 286(45):38825-38832.

205. Brown AM, Lemkul JA, Schaum N, \& Bevan DR (2014) Simulations of monomeric amyloid $\beta$-peptide (1-40) with varying solution conditions and oxidation state of Met35: Implications for aggregation. Arch Biochem Biophys 545:44-52.

206. Srikanth V, et al. (2011) Advanced glycation endproducts and their receptor RAGE in Alzheimer's disease. Neurobiol Aging 32(5):763-777.

207. Fawzi NL, Ying J, Torchia DA, \& Clore GM (2010) Kinetics of amyloid $\beta$ monomer-tooligomer exchange by NMR relaxation. J Am Chem Soc 132(29):9948-9951.

208. Krishnamoorthy J, Brender JR, Vivekanandan S, Jahr N, \& Ramamoorthy A (2012) Sidechain dynamics reveals transient association of A $\beta(1-40)$ monomers with amyloid fibers. $J$ Phys Chem B 116(46):13618-13623.

209. Fawzi NL, Ying J, Ghirlando R, Torchia DA, \& Clore GM (2011) Atomic-resolution dynamics on the surface of amyloid- $\beta$ protofibrils probed by solution NMR. Nature 480(7376):268-272.

210. Carulla N, Zhou M, Giralt E, Robinson CV, \& Dobson CM (2010) Structure and intermolecular dynamics of aggregates populated during amyloid fibril formation studied by hydrogen/deuterium exchange. Acc Chem Res 43(8):1072-1079.

211. Cruz L, et al. (1997) Aggregation and disaggregation of senile plaques in Alzheimer disease. Proc Natl Acad Sci U S A 94(14):7612-7616.

212. Koffie RM, et al. (2009) Oligomeric amyloid $\beta$ associates with postsynaptic densities and correlates with excitatory synapse loss near senile plaques. Proc Natl Acad Sci U S A 106(10):4012-4017.

213. Cohen SI, et al. (2013) Proliferation of amyloid- $\beta 42$ aggregates occurs through a secondary nucleation mechanism. Proc Natl Acad Sci U S A 110(24):9758-9763.

214. Spires-Jones TL, et al. (2009) Passive immunotherapy rapidly increases structural plasticity in a mouse model of Alzheimer disease. Neurobiol Dis 33(2):213-220.

215. Martins IC, et al. (2008) Lipids revert inert A $\beta$ amyloid fibrils to neurotoxic protofibrils that affect learning in mice. EMBO J 27(1):224-233.

216. Xue WF, Hellewell AL, Hewitt EW, \& Radford SE (2010) Fibril fragmentation in amyloid assembly and cytotoxicity: when size matters. Prion 4(1):20-25.

217. Cremades N, et al. (2012) Direct observation of the interconversion of normal and toxic forms of $\alpha$-synuclein. Cell 149(5):1048-1059.

218. Tanzi RE, Moir RD, \& Wagner SL (2004) Clearance of Alzheimer's A $\beta$ peptide: the many roads to perdition. Neuron 43(5):605-608.

219. Zlokovic BV (2004) Clearing amyloid through the blood-brain barrier. $J$ Neurochem 89(4):807-811. 
220. Shibata M, et al. (2000) Clearance of Alzheimer's amyloid- $\beta(1-40)$ peptide from brain by LDL receptor-related protein-1 at the blood-brain barrier. J Clin Invest 106(12):1489-1499.

221. Deane R, et al. (2003) RAGE mediates amyloid- $\beta$ peptide transport across the blood-brain barrier and accumulation in brain. Nat Med 9(7):907-913.

222. Schmidt AM, et al. (2009) The role of RAGE in amyloid- $\beta$ peptide-mediated pathology in Alzheimer's disease. Curr Opin Investig Drugs 10(7):672-680.

223. Miners JS, et al. (2008) A $\beta$-degrading enzymes in Alzheimer's disease. Brain Pathol 18(2):240-252.

224. De Strooper B (2010) Proteases and proteolysis in Alzheimer disease: a multifactorial view on the disease process. Physiol Rev 90(2):465-494.

225. Saido T \& Leissring MA (2012) Proteolytic degradation of amyloid $\beta$-protein. Cold Spring Harb Perspect Med 2(6):a006379.

226. Hersh LB \& Rodgers DW (2008) Neprilysin and amyloid $\beta$ peptide degradation. Curr Alzheimer Res 5(2):225-231.

227. Qiu WQ \& Folstein MF (2006) Insulin, insulin-degrading enzyme and amyloid- $\beta$ peptide in Alzheimer's disease: review and hypothesis. Neurobiol Aging 27(2):190-198.

228. Malito E, Hulse RE, \& Tang WJ (2008) Amyloid $\beta$-degrading cryptidases: insulin degrading enzyme, presequence peptidase, and neprilysin. Cell Mol Life Sci 65(16):2574-2585.

229. Mandrekar S, et al. (2009) Microglia mediate the clearance of soluble A $\beta$ through fluid phase macropinocytosis. J Neurosci 29(13):4252-4262.

230. Basak JM, Verghese PB, Yoon H, Kim J, \& Holtzman DM (2012) Low-density lipoprotein receptor represents an apolipoprotein E-independent pathway of $\mathrm{A} \beta$ uptake and degradation by astrocytes. $J$ Biol Chem 287(17):13959-13971.

231. Tiiman A, Palumaa P, \& Tõugu V (2013) The missing link in the amyloid cascade of Alzheimer's disease - metal ions. Neurochem Int 62(4):367-378.

232. Pithadia AS \& Lim MH (2012) Metal-associated amyloid- $\beta$ species in Alzheimer's disease. Curr Opin Chem Biol 16(1-2):67-73.

233. Exley C (2005) The aluminium-amyloid cascade hypothesis and Alzheimer's disease. Subcell Biochem 38:225-234.

234. Rezaei-Ghaleh N, Giller K, Becker S, \& Zweckstetter M (2011) Effect of zinc binding on $\beta$ amyloid structure and dynamics: implications for A $\beta$ aggregation. Biophys $J$ 101(5):12021211.

235. Syme CD, Nadal RC, Rigby SE, \& Viles JH (2004) Copper binding to the amyloid- $\beta$ (A $\beta$ ) peptide associated with Alzheimer's disease: folding, coordination geometry, $\mathrm{pH}$ dependence, stoichiometry, and affinity of $\mathrm{A} \beta-(1-28)$ : insights from a range of complementary spectroscopic techniques. J Biol Chem 279(18):18169-18177.

236. Peters I, et al. (2009) The interaction of beta-amyloid protein with cellular membranes stimulates its own production. Biochim Biophys Acta 1788(5):964-972.

237. Williams TL \& Serpell LC (2011) Membrane and surface interactions of Alzheimer's A $\beta$ peptide - insights into the mechanism of cytotoxicity. FEBS J 278(20):3905-3917.

238. Sciacca MF, et al. (2012) Two-step mechanism of membrane disruption by $\mathrm{A} \beta$ through membrane fragmentation and pore formation. Biophys $J$ 103(4):702-710.

239. Kotler SA, Walsh P, Brender JR, \& Ramamoorthy A (2014) Differences between amyloid- $\beta$ aggregation in solution and on the membrane: insights into elucidation of the mechanistic details of Alzheimer's disease. Chem Soc Rev. Doi: 10.1039/C3CS6043.

240. Burke KA, Yates EA, \& Legleiter J (2013) Biophysical insights into how surfaces, including lipid membranes, modulate protein aggregation related to neurodegeneration. Front Neurol 4:17.

241. Silva T, Teixeira J, Remião F, \& Borges F (2013) Alzheimer's disease, cholesterol, and statins: the junctions of important metabolic pathways. Angew Chem Int Ed Engl 52(4):11101121.

242. Ariga T, Miyatake T, \& Yu RK (2010) Role of proteoglycans and glycosaminoglycans in the pathogenesis of Alzheimer's disease and related disorders: amyloidogenesis and therapeutic strategies - a review. J Neurosci Res 88(11):2303-2315. 
243. Magrané J, Smith RC, Walsh K, \& Querfurth HW (2004) Heat shock protein 70 participates in the neuroprotective response to intracellularly expressed $\beta$-amyloid in neurons. $J$ Neurosci 24(7):1700-1706.

244. Koren J, et al. (2009) Chaperone signalling complexes in Alzheimer's disease. J Cell Mol Med 13(4):619-630.

245. Fonte V, et al. (2002) Interaction of intracellular $\beta$ amyloid peptide with chaperone proteins. Proc Natl Acad Sci U S A 99(14):9439-9444.

246. Evans CG, Wisén S, \& Gestwicki JE (2006) Heat shock proteins 70 and 90 inhibit early stages of amyloid $\beta$-(1-42) aggregation in vitro. J Biol Chem 281(44):33182-33191.

247. Ju YE, Lucey BP, \& Holtzman DM (2013) Sleep and Alzheimer disease pathology-a bidirectional relationship. Nat Rev Neurol.

248. Roh JH, et al. (2012) Disruption of the sleep-wake cycle and diurnal fluctuation of $\beta$-amyloid in mice with Alzheimer's disease pathology. Sci Transl Med 4(150):150ra122.

249. Kang JE, et al. (2009) Amyloid- $\beta$ dynamics are regulated by orexin and the sleep-wake cycle. Science 326(5955):1005-1007.

250. Costandi M (2013) Neurodegeneration: amyloid awakenings. Nature 497(7450):S19-20.

251. Ramesh BN, Rao TS, Prakasam A, Sambamurti K, \& Rao KS (2010) Neuronutrition and Alzheimer's disease. J Alzheimers Dis 19(4):1123-1139.

252. Smid SD, Maag JL, \& Musgrave IF (2012) Dietary polyphenol-derived protection against neurotoxic $\beta$-amyloid protein: from molecular to clinical. Food Funct 3(12):1242-1250.

253. Radak Z, et al. (2010) Exercise plays a preventive role against Alzheimer's disease. $J$ Alzheimers Dis 20(3):777-783.

254. Farina N, Rusted J, \& Tabet N (2013) The effect of exercise interventions on cognitive outcome in Alzheimer's disease: a systematic review. Int Psychogeriatr 26(1):9-18.

255. Hoffmann K, et al. (2013) Preserving Cognition, Quality of Life, Physical Health and Functional Ability in Alzheimer's Disease: The Effect of Physical Exercise (ADEX Trial): Rationale and Design. Neuroepidemiology 41(3-4):198-207.

256. Li S, et al. (2013) Environmental novelty activates $\beta 2$-adrenergic signaling to prevent the impairment of hippocampal LTP by A $\beta$ oligomers. Neuron 77(5):929-941.

257. Extance A (2010) Alzheimer's failure raises questions about disease-modifying strategies. Nat Rev Drug Discov 9(10):749-751.

258. Schor NF (2011) What the halted phase III $\gamma$-secretase inhibitor trial may (or may not) be telling us. Ann Neurol 69(2):237-239.

259. Albright CF, et al. (2013) Pharmacodynamics of selective inhibition of $\gamma$-secretase by avagacestat. J Pharmacol Exp Ther 344(3):686-695.

260. Golde TE, Koo EH, Felsenstein KM, Osborne BA, \& Miele L (2013) $\gamma$-Secretase inhibitors and modulators. Biochim Biophys Acta 1828(12):2898-2907.

261. Lannfelt L, Relkin NR, \& Siemers ER (2014) Amyloid- $\beta$-directed immunotherapy for Alzheimer's disease. J Intern Med 275(3):284-295.

262. Härd T \& Lendel C (2012) Inhibition of amyloid formation. J Mol Biol 421(4-5):441-465.

263. Hamley IW (2012) The amyloid beta peptide: a chemist's perspective. Role in Alzheimer's and fibrillization. Chem Rev 112(10):5147-5192.

264. Arosio P, Vendruscolo M, Dobson CM, \& Knowles TP (2014) Chemical kinetics for drug discovery to combat protein aggregation diseases. Trends Pharmacol Sci 35(3):127-135.

265. Hoozemans JJ, Veerhuis R, Rozemuller JM, \& Eikelenboom P (2011) Soothing the inflamed brain: effect of non-steroidal anti-inflammatory drugs on Alzheimer's disease pathology. CNS Neurol Disord Drug Targets 10(1):57-67.

266. Morales I, Guzmán-Martínez L, Cerda-Troncoso C, Farías GA, \& Maccioni RB (2014) Neuroinflammation in the pathogenesis of Alzheimer's disease. A rational framework for the search of novel therapeutic approaches. Front Cell Neurosci 8:112.

267. Teixeira J, Silva T, Andrade PB, \& Borges F (2013) Alzheimer's disease and antioxidant therapy: how long how far? Curr Med Chem 20(24):2939-2952.

268. Citron M (2004) Strategies for disease modification in Alzheimer's disease. Nat Rev Neurosci 5(9):677-685.

269. Morphy R \& Harris C (2012) Designing multi-target drugs (RSC Publishing). 
270. Lee S, et al. (2014) Rational design of a structural framework with potential use to develop chemical reagents that target and modulate multiple facets of Alzheimer's disease. J Am Chem Soc 136(1):299-310.

271. Zheng H, Fridkin M, \& Youdim M (2014) From Single Target to Multitarget/Network Therapeutics in Alzheimer's Therapy. Pharmaceuticals 7(2):113-135.

272. Carreiras MC, Mendes E, Perry MJ, Francisco AP, \& Marco-Contelles J (2013) The multifactorial nature of Alzheimer's disease for developing potential therapeutics. Curr Top Med Chem 13(15):1745-1770.

273. Calzà L, et al. (2013) From the multifactorial nature of Alzheimer's disease to multitarget therapy: the contribution of the translational approach. Curr Top Med Chem 13(15):18431852.

274. Barabási AL, Gulbahce N, \& Loscalzo J (2011) Network medicine: a network-based approach to human disease. Nat Rev Genet 12(1):56-68.

275. Jacunski A \& Tatonetti NP (2013) Connecting the dots: applications of network medicine in pharmacology and disease. Clin Pharmacol Ther 94(6):659-669. 


\section{Chapter 2}

\section{A comparative analysis of the aggregation behaviour of $A \beta$ peptide variants}

This chapter has been published as:

Vandersteen A*, Hubin E*, Sarroukh R, De Baets G, Schymkowitz J, Rousseau F, Subramaniam V, Raussens V, Wenschuh H, Wildemann D, and Broersen K (2012). A comparative analysis of the aggregation behavior of amyloid- $\beta$ peptide variants.

FEBS Letters 586(23), 4088-4093.

* Joint first authors, contributed equally to the manuscript.

Aggregated forms of $\mathrm{A} \beta$ are hypothesized to act as the primary toxic agents in AD. The in vivo $\mathrm{A} \beta$ peptide pool consists of both $\mathrm{C}$ - and $\mathrm{N}$-terminally truncated or mutated peptides, and the composition thereof significantly determines AD risk. Other variations, such as biotinylation, are introduced in vitro as molecular tools to aid the understanding of disease mechanisms. Since these modifications have the potential to alter key aggregation properties of $\mathrm{A} \beta$, we present a comparative study of the aggregation of a substantial set of the most common in vivo identified and in vitro produced $\mathrm{A} \beta$ peptides. 


\section{$\underline{\text { 2.1. Introduction }}$}

Early aggregated forms of $A \beta$, a peptide which is generated from the transmembrane precursor APP, have been considered the basis for the development of AD $(1,2)$. Despite extensive research, the exact link between $\mathrm{A} \beta$ and $\mathrm{AD}$ remains elusive. One of the underlying reasons is the heterogeneity of the A $\beta$ peptide pool in the brain, as APP processing does not generate a single, well-defined $A \beta$ species. The main cause for peptide heterogeneity stems from the identification of two main APP processing pathways, termed non-amyloidogenic and amyloidogenic (Fig. 2.1). The non-amyloidogenic pathway involves APP cleavage by $\alpha$ - and $\gamma$-secretase and generates the p3 peptide, an $\mathrm{N}$-terminally truncated form of $\mathrm{A} \beta$, while the amyloidogenic pathway releases $A \beta$ by action of $\beta$ - and $\gamma$-secretase (3). Besides the dual processing of APP generating either $\mathrm{p} 3$ or $\mathrm{A} \beta$, the $\gamma$-secretase cleavage site is ill-defined resulting in variation at the $\mathrm{C}$-terminus of these peptides $(4,5)$. As a result thereof, released $\mathrm{A} \beta$ alloforms vary in length from 37 to 49 amino acids $(6,7)$. Additional variation is attained by mutations within the $\mathrm{A} \beta$-coding region of the $A P P$ gene. Mutations related to familial $\mathrm{AD}$ (FAD) include the Flemish (Ala 21 -to-Gly), Dutch (Glu 22 -to-Gln), Italian (Glu 22 -to-Lys), Arctic (Glu G2 $_{2}$-to-Gly), Iowa (Asp 23 -to-Asn), and Tottori (Asp 7 -to-Asn) mutations $(8,9)$. Furthermore, an additional source of peptide variation results from the introduction of biotinylation as a research tool for interaction studies (10-13). All modifications described above could affect peptide behaviour due to altered aggregation properties. In this study, we therefore systematically compared the aggregation behaviour of $\mathrm{p} 3$ and $\mathrm{A} \beta$ peptides resulting from heterogeneous APP processing, as well as a selection of FAD-associated A $\beta$ mutants and biotinylated variants.

\section{$\underline{\text { 2.2. Experimental procedures }}$}

\subsubsection{A $\beta$ and $p 3$ peptide synthesis and purity assessment}

$\mathrm{A} \beta$ and p3 peptides were chemically synthesized by JPT (JPT Peptide Technologies, Germany) on preloaded TentaGel ${ }^{\circledR}$ S TRT resins (Rapp Polymer) using an ABI 433A Peptide Synthesizer (Applied Biosystems). Synthesis was performed using 2-(1H-7-azabenzotriazol1-yl)-1,1,3,3-tetramethyl uronium hexafluorophosphate as an activation reagent and standard procedures of Fmoc-based solid phase peptide synthesis were applied. Peptides were cleaved from the resin with trifluoroacetic acid, containing $3 \% \mathrm{H}_{2} \mathrm{O}, 3 \%$ 1,2-ethanedithiol, and $4 \%$ triisopropylsilane, and purified by preparative high performance liquid chromatography (LC). The purity and identity of the peptides was assessed by JPT using matrix-assisted laser desorption/ionization-time of flight mass spectrometry (MALDI-TOF MS, Voyager-DE ${ }^{\mathrm{TM}}$, Perseptive Biosystems) and LC (Agilent Technologies, LC/MSD Trap series 1100). The LC system was used in combination with a $\mathrm{C} 18$ Gemini-NX column (Phenomenex) at a flow rate of $1 \mathrm{ml} / \mathrm{min}$, and a gradient of 5-95\% acetonitrile was run during a time frame of $6 \mathrm{~min}$.

\subsubsection{Peptide solubilization}

Peptides were dissolved according to the standard procedure developed and validated in our laboratory, demonstrated to yield virtually aggregate-free peptide solutions (14). In short, A $\beta$ peptides were dissolved at a concentration of $1 \mathrm{mg} / \mathrm{ml}$ in 1,1,1,3,3,3-hexafluoro-2-propanol (HFIP). 

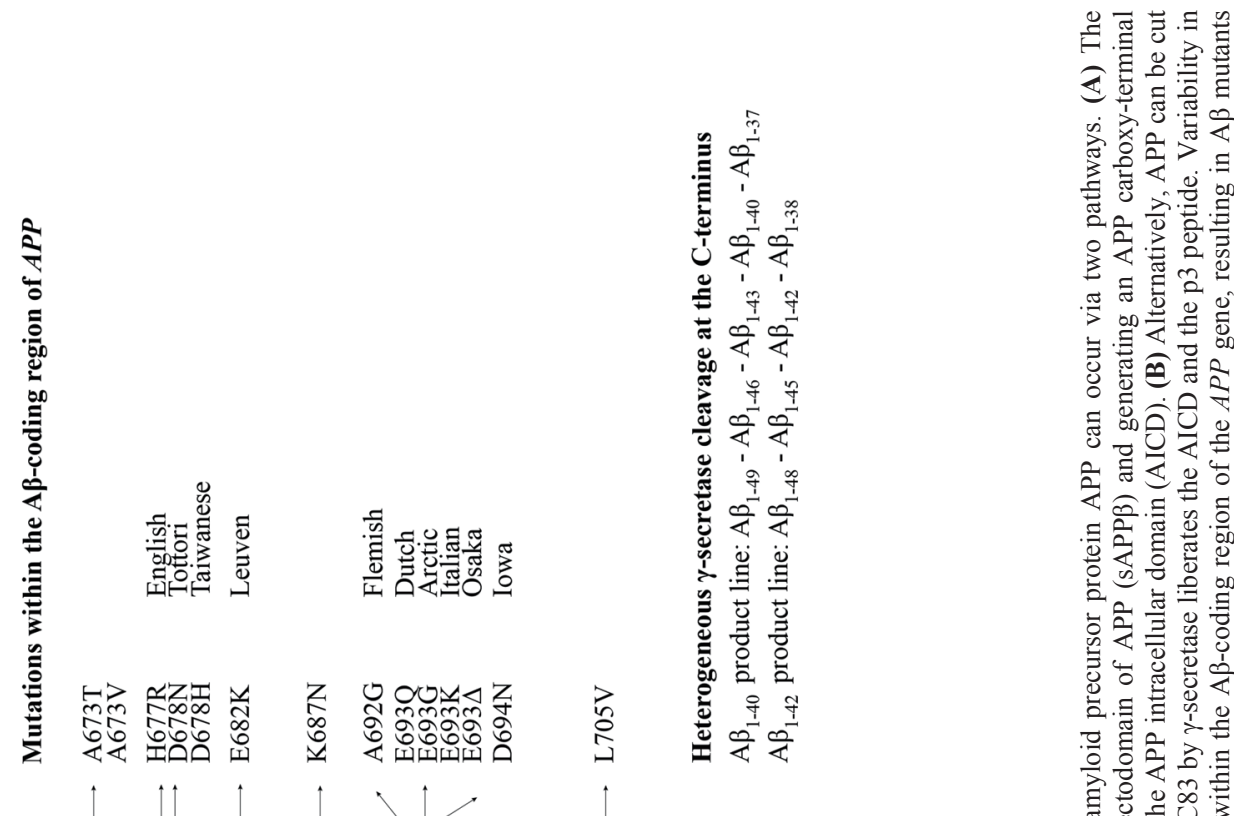

뭉

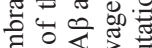

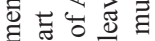
क्ष 牙品

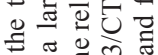
更加 . 的需 ơ 它芯

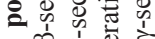

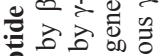
월 :

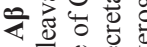

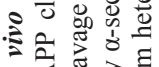

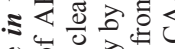

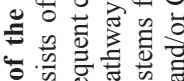
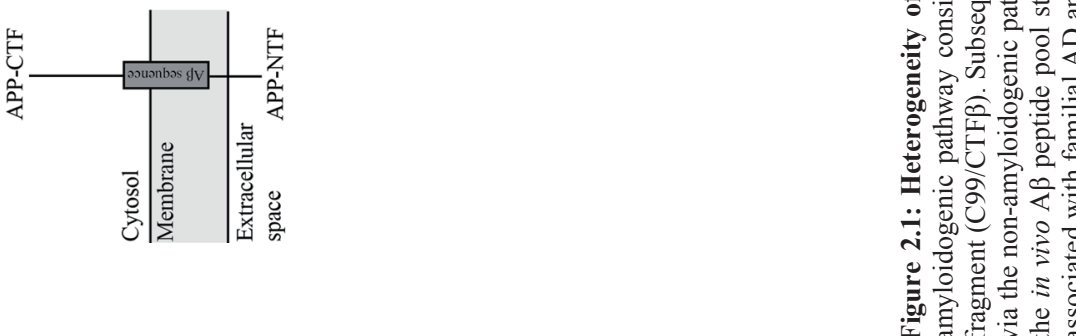
HFIP was evaporated using nitrogen gas and the peptide film was redissolved at a peptide concentration of $1 \mathrm{mg} / \mathrm{ml}$ using dimethyl sulfoxide (DMSO). The peptide was separated from DMSO by elution from a precalibrated HiTrap ${ }^{\mathrm{TM}}$ desalting column (GE Healthcare) into a 50 $\mathrm{mM}$ Tris $\mathrm{pH} 7.5$ buffer containing $1 \mathrm{mM}$ disodium ethylenediaminetetraacetate (EDTA). The resulting samples were kept on ice until experiments started with a maximum lag time of 30 min. Peptide concentration was determined using the Coomassie (Bradford) Protein Assay kit and diluted to $25 \mu \mathrm{M}$ in $50 \mathrm{mM}$ Tris $\mathrm{pH} 7.5$ buffer containing $1 \mathrm{mM}$ EDTA. Incubation of A $\beta$ peptides occurred for the given time periods at $25^{\circ} \mathrm{C}$ under quiescent conditions.

\subsubsection{Determination of peptide fibrillization kinetics using ThT fluorescence}

Peptide concentrations were adjusted to $1 \mu \mathrm{M}$ using $50 \mathrm{mM}$ Tris $\mathrm{pH} 7.5$ buffer containing 1 $\mathrm{mM}$ EDTA and a final concentration of $12 \mu \mathrm{M}$ ThT. The fibrillization kinetics of the various $\mathrm{A} \beta$ preparations were monitored in situ in a Greiner 96-well plate using a FLUOstar OPTIMA fluorescence plate reader (BMG LABTECH GmbH, Germany) at an excitation wavelength of $440 \mathrm{~nm}$ (9 $\mathrm{nm}$ bandwidth) and an emission wavelength of $480 \mathrm{~nm}$ (20 nm bandwidth). Fluorescence readings were recorded every $5 \mathrm{~min}$ for a period of $20 \mathrm{~h}$. Measurements were performed as independent triplicates. Recorded values were averaged and background measurements (buffer containing $12 \mu \mathrm{M}$ ThT) were subtracted.

\subsubsection{TEM imaging of fibril morphology}

After 2 weeks of incubation, peptide aliquots ( $5 \mu \mathrm{l}$ of a $25 \mu \mathrm{M}$ solution) were adsorbed to carbon-coated Formvar 400-mesh copper grids (Agar Scientific) for $1 \mathrm{~min}$. The grids were blotted, washed, and stained with $1 \%(\mathrm{w} / \mathrm{v})$ uranyl acetate. Samples were studied with a JEM-1400 microscope (JEOL Ltd., Tokyo, Japan) at $80 \mathrm{kV}$. TEM images are representative of three independently prepared peptide solutions.

\subsubsection{Dot blotting with $A \beta$ oligomer-specific A11 antibody}

After $0.5 \mathrm{~h}$ of incubation, a volume of $5 \mu \mathrm{l}$ peptide sample was spotted onto a nitrocellulose membrane. Membranes were blocked in phosphate-buffered saline containing $0.2 \%$ Tween$20\left(1 \mathrm{~h}, 25^{\circ} \mathrm{C}\right)$, and incubated $\left(1 \mathrm{~h}, 25^{\circ} \mathrm{C}\right)$ with primary A11 antibody (Invitrogen), diluted 1:4000 in $100 \mathrm{mM}$ Hepes, $\mathrm{pH} 7.0$ (15). After incubation $\left(0.5 \mathrm{~h}, 25^{\circ} \mathrm{C}\right)$ with a secondary antirabbit-horseradish peroxidase (HRP)-tagged antibody (Promega), diluted 1:5000 in phosphate-buffered saline containing $0.05 \%$ Tween-20, membranes were visualized using the Immobilon $^{\mathrm{TM}}$ Western chemiluminescent HRP substrate system. Spots were manually selected and intensities of the spots were analysed as mean grey values using ImageJ software (16). Images were background subtracted.

\subsubsection{Secondary structure estimation using ATR-FTIR}

The peptide solubilization procedure and buffer composition were slightly adapted to obtain attenuated total reflectance (ATR)-FTIR spectra with sufficient intensity and without interference due to the presence of EDTA or salts. In short, peptide samples were dissolved in HFIP at a peptide concentration of $1 \mathrm{mg} / \mathrm{ml}$. HFIP was evaporated using nitrogen gas and the resulting peptide film was redissolved in $10 \mathrm{mM}$ Tris $\mathrm{pH} 7.5$ at a concentration of $1 \mathrm{mg} / \mathrm{ml}$. Samples were incubated for $1.5 \mathrm{~h}$ at $25^{\circ} \mathrm{C}$ under quiescent conditions. ATR-FTIR spectra were then recorded on an Equinox 55 IR spectrophotometer (Bruker Optics, Ettlingen, 
Germany). Briefly, $2 \mu \mathrm{g}$ of peptide was spread on the diamond surface $\left(2 \times 2 \mathrm{~mm}^{2}\right)$ of an internal reflection element and was washed with excess water to eliminate salts. Water was evaporated under nitrogen flow. Data were processed by subtracting the water vapour contribution and spectra were baseline corrected. Each IR spectrum represents the mean of 128 repetitions and was recorded at a resolution of $2 \mathrm{~cm}^{-1}$. Spectral intensities were normalized to the intensity of the major $\beta$-structure peak around $1630 \mathrm{~cm}^{-1}$, and were smoothed at a final resolution of $4 \mathrm{~cm}^{-1}$ by apodization of their Fourier transform by a Gaussian line. All depicted spectra were deconvolved using a Lorentzian deconvolution factor with a full width at half height (FWHH) of $20 \mathrm{~cm}^{-1}$ and a Gaussian apodization factor with a FWHH of $13.33 \mathrm{~cm}^{-1}$, to obtain a resolution enhancement factor of 1.5. Deconvolution increases the resolution of the spectra in the amide I region which is most sensitive to the secondary structure of proteins.

Curve fitting was then performed on the non-deconvolved ATR-FTIR spectra to determine the secondary structure contributions. The proportion of a particular structure is computed to be the sum of the area of all the fitted bands (having their maximum in the frequency region where that structure occurs) divided by the area of all the Lorentzian bands (having their maximum between 1700 and $1600 \mathrm{~cm}^{-1}$ ). These regions were chosen by the program software Kinetics, that was developed in the laboratory of Goormaghtigh and co-workers, and were based on the shape of the most deconvolved spectrum ( $\alpha$-helices and random coil: 1637-1662 $\mathrm{cm}^{-1}$, turn: $1662-1682 \mathrm{~cm}^{-1}, \beta$-sheet: $1613-1637 \mathrm{~cm}^{-1}$ and $\left.1682-1689 \mathrm{~cm}^{-1}\right)$.

\subsubsection{Statistical analysis}

The intensities of A11-positive spots were determined using ImageJ software and were further analysed using the two-tailed unpaired t-test for significance. Significant differences are denoted $* \mathrm{P}<0.05$.

\subsection{Results}

We present a comparison of the aggregation profiles of an extensive set of $A \beta$ peptides with $\mathrm{N}$ - or C-terminal variation, FAD-related mutations, and biotinylated forms of A $\beta$. Peptides were prepared by solid phase peptide synthesis, and their identity and purity were confirmed by JPT using MALDI-TOF MS and LC (Fig. 2.2).

\subsubsection{C-terminal elongation of $A \beta$ increases aggregation propensity and affects fibril packing}

Aggregation kinetics of various $\mathrm{A} \beta$ alloforms were recorded by ThT fluorescence and two different aggregation profiles could be distinguished. First, "slow" aggregation taking at least approximately 17 hours to reach plateau values, accompanied by "long" nucleation times (5$10 \mathrm{~h}$ ) and high final fluorescence intensity were detected for $A \beta_{1-37}, A \beta_{1-38}$, and $A \beta_{1-40}$. In contrast, $A \beta_{1-42}$ and $A \beta_{1-43}$ aggregated rapidly with almost immediate onset, resulting in low final ThT fluorescence intensity after approximately 7 hours (Fig. 2.3A and B). Differences in fibril morphology have been related to different affinities and/or accessibilities of the ThT dye, affecting the extent of ThT fluorescence intensity $(17,18)$. Accordingly, visualization of fibrils by TEM indeed revealed morphologically distinct aggregates showing extended negatively stained fibrils for $A \beta_{1-37}, A \beta_{1-38}$ and $A \beta_{1-40}$, and heavily intertwined and dense fibril networks for $A \beta_{1-42}$ and $A \beta_{1-43}$ (Fig. 2.3C). 

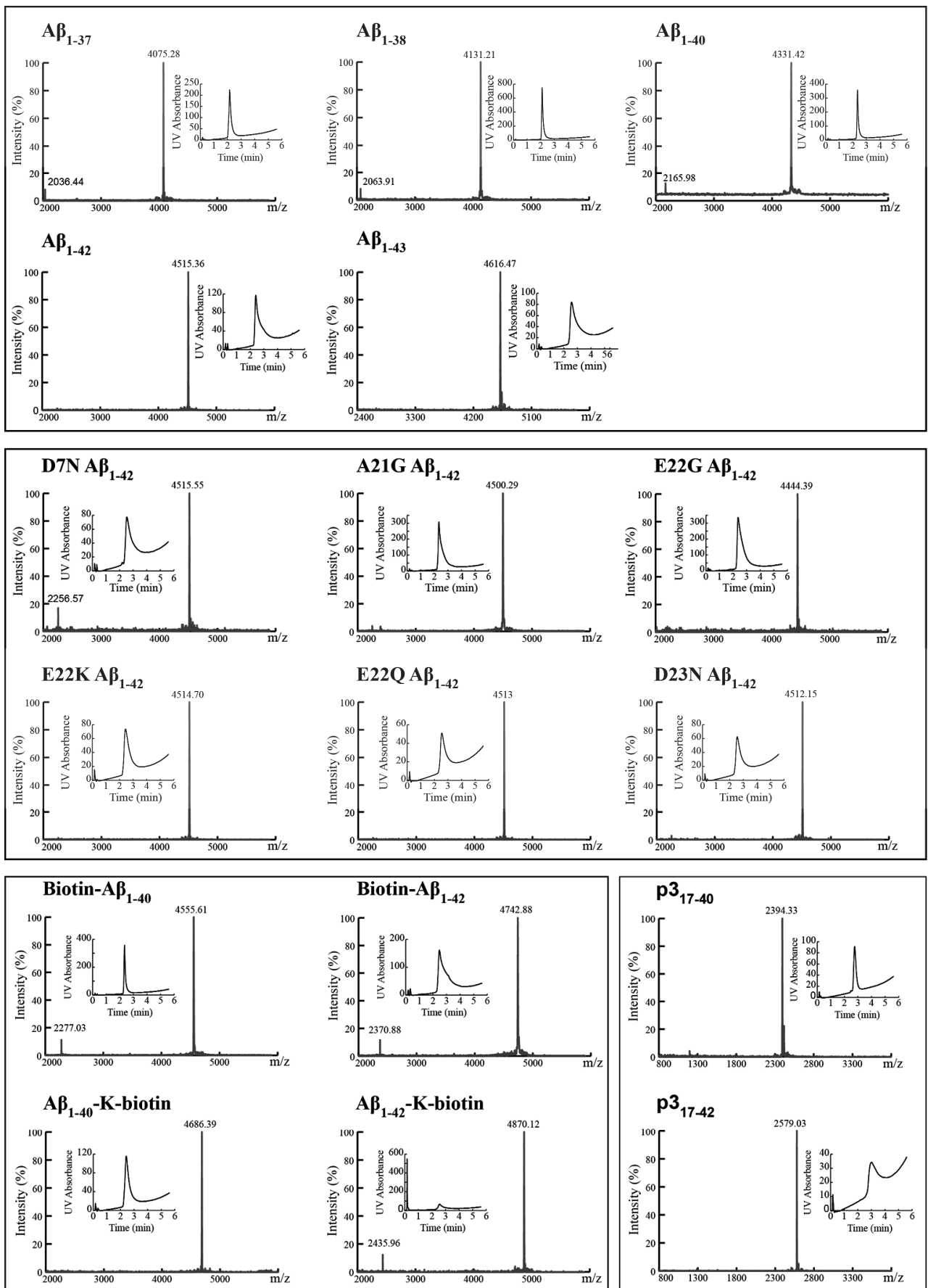

Figure 2.2: Identity and purity assessment of the chemically synthesized peptides by MALDI-TOF MS and LC (insets). The mass spectra display one or two major peaks corresponding to the single or double charged ion species arising from the full-length monomeric peptide. Insets show the elution of each peptide from a C18 Gemini-NX column in a single peak corresponding to monomeric peptide. 
A.

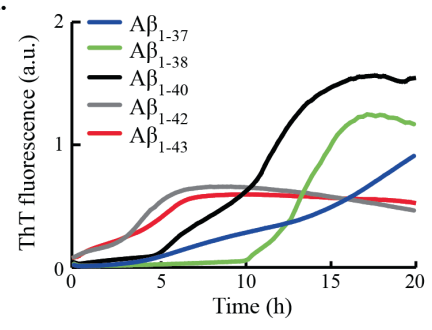

C.

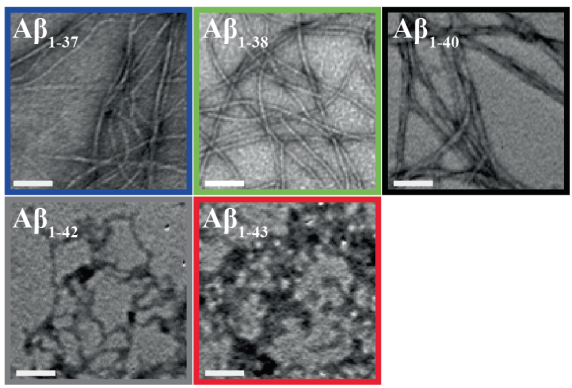

B.
E.

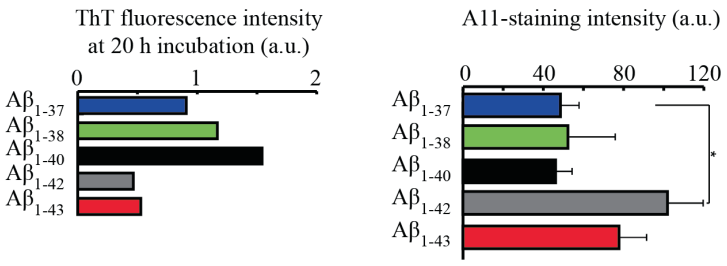

D.

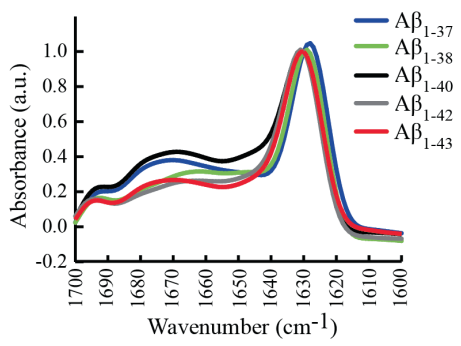

Figure 2.3: Increased aggregation rate of $\mathrm{A} \beta$ alloforms with increasing peptide length. Incubation of $\mathrm{A} \beta$ alloforms occurred for the given time periods at $25{ }^{\circ} \mathrm{C}$ under quiescent conditions. (A) Aggregation of Cterminal varying $\mathrm{A} \beta$ peptides monitored by ThT fluorescence. (B) ThT fluorescence intensities after $20 \mathrm{~h}$ of incubation. (C) TEM images of $\mathrm{A} \beta$ alloforms incubated for 2 weeks. Scale bars represent $100 \mathrm{~nm}$. (D) Deconvolved ATR-FTIR spectra of A $\beta$ alloforms recorded after $1.5 \mathrm{~h}$ of incubation. (E) A11-reactivity of $0.5 \mathrm{~h}$ pre-incubated $A \beta$ alloforms in a dot blot assay. Statistical significance levels are denoted $* \mathrm{P}<0.05$.

Early $A \beta$ aggregation time points, i.e. after $0.5-1.5 \mathrm{~h}$ of incubation, have previously been demonstrated to be enriched for toxic oligomeric species (14). Secondary structure analysis of these early aggregation species was performed by ATR-FTIR using the amide I absorption band $\left(1600-1700 \mathrm{~cm}^{-1}\right)$, as this band results from $\mathrm{C}=\mathrm{O}$ stretch vibrations of peptide linkages and is most sensitive to changes in H-bonding in proteins $(19,20)$. IR analysis of early aggregation species revealed a strong absorption peak around $1630 \mathrm{~cm}^{-1}$, which is indicative of a $\beta$-sheet conformation (Fig. 2.3D). However, $A \beta_{1-42}$ and $A \beta_{1-43}$ displayed higher $\beta$-sheet content than the shorter $A \beta$ peptides, which appeared more as a mixture of $\beta$-sheet, random coil, and $\alpha$-helical secondary structure elements (Table 2.1). Moreover, increasing peptide length lead to a more pronounced reactivity with the oligomer-specific A11 antibody, as detected through dot blotting: $A \beta_{1-37}, A \beta_{1-38}$, and $A \beta_{1-40}$ showed less oligomer accumulation after $0.5 \mathrm{~h}$ of incubation than $\mathrm{A} \beta_{1-42}$ and $\mathrm{A} \beta_{1-43}$ (Fig. 2.3E).

\subsubsection{FAD mutations affect the rate of $A \beta$ fibril elongation to various extents}

Familial mutations of $A \beta_{1-42}$ displayed a short nucleation phase similar to that observed for wild type (WT) $A \beta_{1-42}$, but affected the rate of fibril elongation and the final ThT fluorescence intensity (Fig. 2.4A and B). The slow elongation rate of the D23N mutant coincided with a relatively low final ThT fluorescence, while the $A 21 \mathrm{G} A \beta_{1-42}$ mutant aggregated at a higher rate with an increased final ThT fluorescence intensity compared to WT A $\beta_{1-42}$. All mutants of $\mathrm{A} \beta_{1-42}$ predominantly displayed $\beta$-sheet structure (Fig. 2.4D, Table 2.1) and formed dense fibrillar networks, similar to WT peptide (Fig. 2.4C). Oligomerization of the mutated A $\beta_{1-42}$ peptides showed little variability compared to WT $A \beta_{1-42}$ after incubation of $0.5 \mathrm{~h}$ as seen by A11-reactivity (Fig. 2.4E), with exception of D23N and A21G A $\beta_{1-42}$. 
A.

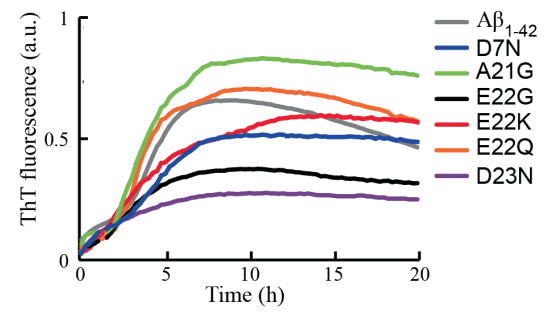

C.

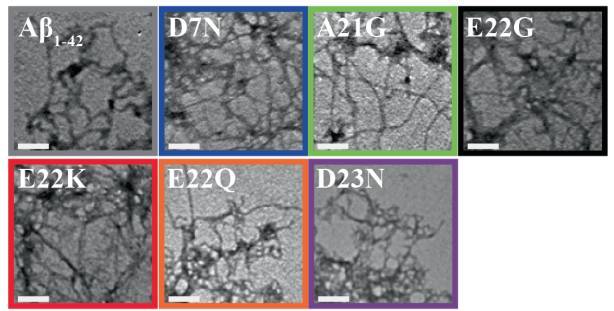

B.

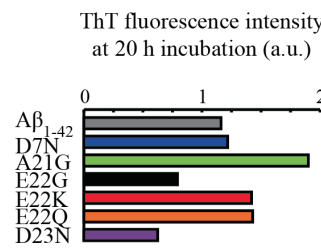

D.

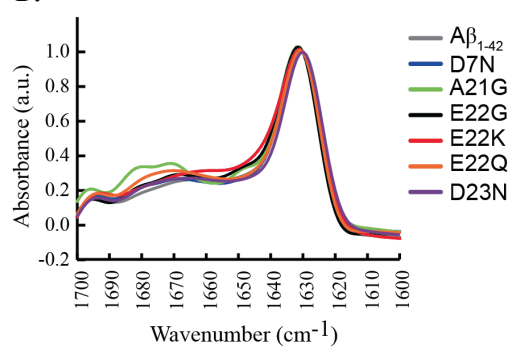

Figure 2.4: Several FAD mutations affect aggregation and oligomerization of $\mathbf{A} \boldsymbol{\beta}_{1-42}$. Incubation of FADassociated $\mathrm{A} \beta$ mutants occurred for the given time periods at $25{ }^{\circ} \mathrm{C}$ under quiescent conditions. (A) Aggregation of FAD $A \beta_{1-42}$ mutants monitored by ThT fluorescence. (B) ThT fluorescence intensities after $20 \mathrm{~h}$ of incubation. (C) TEM images of FAD A $\beta_{1-42}$ mutants incubated for 2 weeks. Scale bars represent $100 \mathrm{~nm}$. (D) Deconvolved ATR-FTIR spectra of $\mathrm{A} \beta_{1-42}$ mutants recorded after $1.5 \mathrm{~h}$ of incubation. (E) A11-reactivity of $0.5 \mathrm{~h}$ pre-incubated mutant $A \beta_{1-42}$ peptides in a dot blot assay.

\subsubsection{Effect of biotinylation on aggregation of $A \beta_{1-40}$ and $A \beta_{1-42}$ depends on the biotinylation site}

$\mathrm{N}$ - and $\mathrm{C}$-terminal biotinylation of $\mathrm{A} \beta_{1-40}$ increased the lag time of aggregation (Fig. 2.5A) while decreasing final ThT fluorescence (Fig. 2.5B), without affecting fibril morphology (Fig. $2.5 \mathrm{C})$. Oligomerization of biotinylated $\mathrm{A} \beta_{1-40}$, as probed by $\mathrm{A} 11$-reactivity, was unaffected compared to WT A $\beta_{1-40}$ (Fig. 2.5E). Structural analysis of the biotinylated peptides by ATRFTIR however revealed absorption differences in the $1680-1640 \mathrm{~cm}^{-1}$ region, which are indicative of distinct contributions of secondary structure elements (Fig. 2.5D, Table 2.1).

In contrast, biotinylation of $A \beta_{1-42}$ reduced the aggregation rate of the peptide compared to WT A $\beta_{1-42}$ (Fig. 2.5A) without affecting final ThT fluorescence (Fig. 2.5B), fibril morphology (Fig. 2.5C), and secondary structure content (Fig. 2.5D, Table 2.1). For $\mathrm{A} \beta_{1-42}$, the impact of biotinylation on oligomerization depended on the location of the modification. C-terminal biotinylation did not affect A11-reactivity, whereas N-terminal modification strongly impaired A11-reactivity (Fig. 2.5E). 
A.

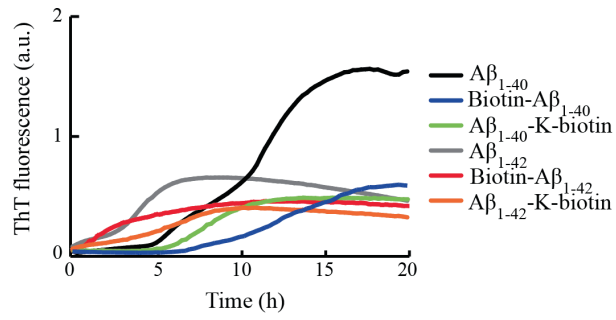

C.

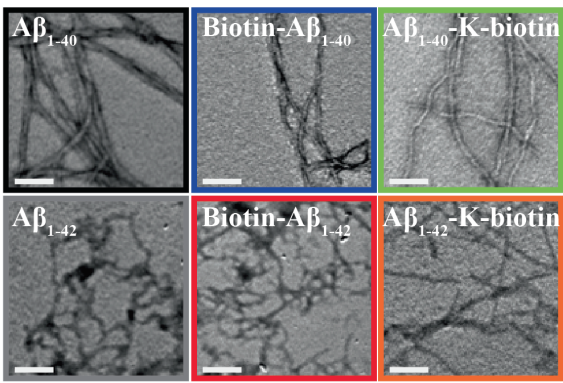

B.

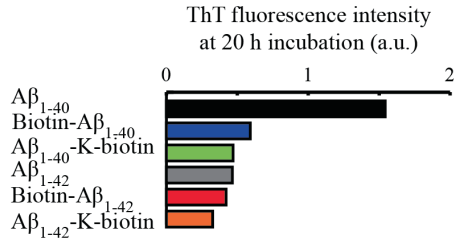

D.

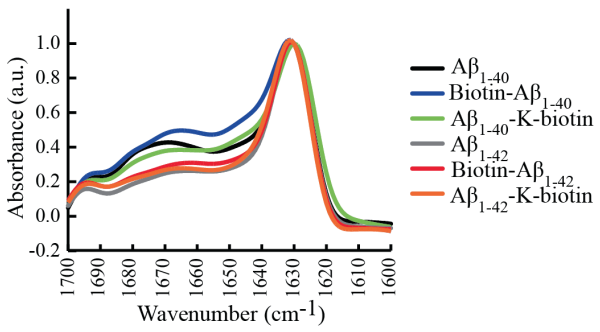

E. A11-staining intensity (a.u.)

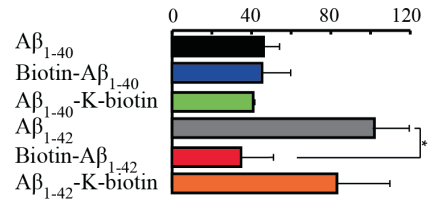

Figure 2.5: $\mathrm{N}$ - and $\mathrm{C}$-terminal biotinylation of $A \beta_{1-40}$ and $A \beta_{1-42}$ differentially affect aggregation. Incubation of biotinylated $\mathrm{A} \beta$ mutants occurred for the given time periods at $25{ }^{\circ} \mathrm{C}$ under quiescent conditions. (A) Aggregation of $\mathrm{N}$ - and $\mathrm{C}$-terminally biotinylated forms of $\mathrm{A} \beta_{1-40}$ and $\mathrm{A} \beta_{1-42}$ monitored by ThT fluorescence. (B) ThT fluorescence intensities after $20 \mathrm{~h}$ of incubation. (C) TEM images of biotinylated A $\beta$ peptides incubated for 2 weeks. Scale bars represent $100 \mathrm{~nm}$. (D) Deconvolved ATR-FTIR spectra of biotinylated A $\beta$ peptides recorded after $1.5 \mathrm{~h}$ of incubation. (E) A11-reactivity of $0.5 \mathrm{~h}$ pre-incubated biotinylated A $\beta$ peptides in a dot blot assay. Statistical significance levels are denoted $* \mathrm{P}<0.05$.

\subsection{4. $\mathrm{N}$-terminal truncation of $\mathrm{A} \beta$ induces rapid onset of aggregation}

N-terminally truncated forms of $A \beta_{1-40}$ and $A \beta_{1-42}, p 3_{17-40}$ and $\mathrm{p} 3_{17-42}$ respectively, were characterized by rapid onset of aggregation compared to their corresponding full-length forms, with decreased final ThT fluorescence intensities after $20 \mathrm{~h}$ of incubation in the case of p3 $3_{17-40}$ (Fig. 2.6A and B). TEM visualization revealed short fibrillar fragments for p3 ${ }_{17-40}$, dissimilar from the long extended networks observed for full-length $A \beta_{1-40}$ (Fig. 2.6C). Truncation of $A \beta_{1-42}$ to $p 3_{17-42}$ only slightly affected fibril morphology, resulting in less curly fibrils (Fig. 2.6C). Structural analysis by ATR-FTIR indicated that $\mathrm{p} 3_{17-40}$ displayed less $\beta$ sheet content and more random coil and $\alpha$-helical content than full-length $A \beta_{1-40}$. A similar observation was made for $\mathrm{p} 3_{17-42}$ compared to $A \beta_{1-42}$ (Fig. 2.6D, Table 2.1). Oligomerization of the p3 peptides, as analysed by A11-reactivity, was not significantly affected compared to their full-length counterparts (Fig. 2.6E). 


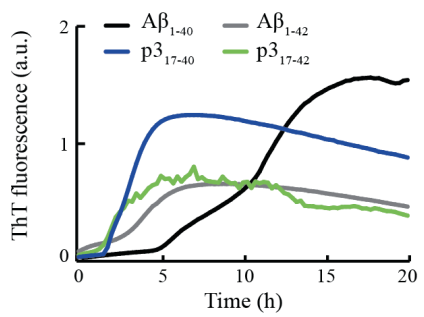

C.

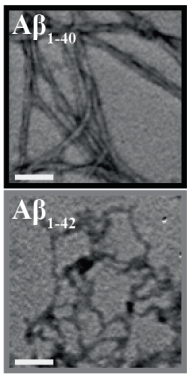

B.

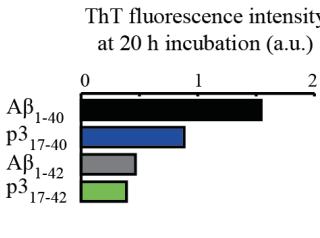

E.

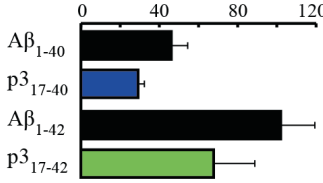

D.

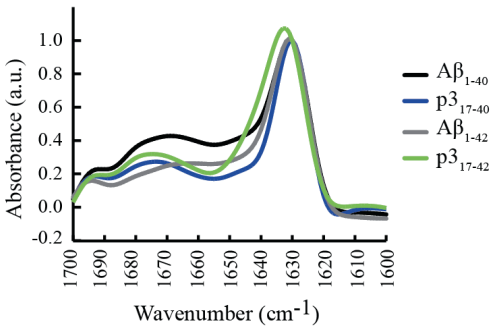

Figure 2.6: $\mathrm{p} 3$ peptides show pronounced aggregation. Incubation of p3 peptides occurred for the given time periods at $25{ }^{\circ} \mathrm{C}$ under quiescent conditions. (A) Aggregation of p3 $3_{17-40}$ and p3 $3_{17-42}$, and their full-length counterparts, monitored by ThT fluorescence. (B) ThT fluorescence intensities after $20 \mathrm{~h}$ of incubation. (C) TEM images of p3 peptides incubated for 2 weeks. Scale bars represent $100 \mathrm{~nm}$. (D) Deconvolved ATR-FTIR spectra of $\mathrm{p} 3$ peptides recorded after $1.5 \mathrm{~h}$ of incubation. (E) A11-reactivity of $0.5 \mathrm{~h}$ pre-incubated p3 peptides in a dot blot assay.

Table 2.1: Estimation of the peptide secondary structure content after $1.5 \mathrm{~h}$ of incubation, based on ATRFTIR analysis.

\begin{tabular}{|c|c|c|c|}
\hline \multirow[t]{2}{*}{ Peptide } & \multicolumn{3}{|c|}{ Secondary structure element (\%) } \\
\hline & $\beta$-sheet & Random coil $+\alpha$-helix & Turn \\
\hline \multicolumn{4}{|l|}{$A \beta$ length variants } \\
\hline $\mathrm{A} \beta_{1-37}$ & 36 & 44 & 20 \\
\hline $\mathrm{A} \beta_{1-38}$ & 37 & 43 & 20 \\
\hline $\mathrm{A} \beta_{1-40}$ & 47 & 33 & 20 \\
\hline$A \beta_{1-42}$ & 55 & 32 & 13 \\
\hline $\mathrm{A} \beta_{1-43}$ & 56 & 28 & 16 \\
\hline \multicolumn{4}{|l|}{ FAD A $\beta$ mutants } \\
\hline D7N A $\beta_{1-42}$ & 55 & 30 & 15 \\
\hline $\mathrm{A} 21 \mathrm{G} \mathrm{A} \beta_{1-42}$ & 51 & 33 & 16 \\
\hline $\mathrm{E} 22 \mathrm{G} \mathrm{A} \beta_{1-42}$ & 41 & 37 & 22 \\
\hline $\mathrm{E} 22 \mathrm{~K} \mathrm{~A} \beta_{1-42}$ & 45 & 39 & 16 \\
\hline E22Q A $\beta_{1-42}$ & 50 & 32 & 19 \\
\hline D23N A $\beta_{1-42}$ & 46 & 32 & 23 \\
\hline \multicolumn{4}{|l|}{ Biotinylated A $\boldsymbol{\beta}$} \\
\hline Biotin- $\mathrm{A} \beta_{1-40}$ & 34 & 44 & 22 \\
\hline $\mathrm{A} \beta_{1-40}-\mathrm{K}$-biotin & 42 & 39 & 19 \\
\hline Biotin- $A \beta_{1-42}$ & 54 & 34 & 12 \\
\hline $\mathrm{A} \beta_{1-42}$-K-biotin & 44 & 38 & 17 \\
\hline \multicolumn{4}{|l|}{ p3 peptides } \\
\hline $\mathrm{p} 3_{17-40}$ & 39 & 40 & 20 \\
\hline $\mathrm{p} 3_{17-42}$ & 49 & 34 & 17 \\
\hline
\end{tabular}




\section{$\underline{\text { 2.4. Discussion }}$}

The $\mathrm{A} \beta$ peptide pool in the brain contains a high degree of variability, consisting of peptides with C-terminal variations and N-terminal truncations, and FAD-associated mutations (21). To elucidate the mechanisms leading to $\mathrm{AD}$, some peptides are additionally modified, e.g. biotinylated, to enable their investigation in experimental research. We chemically synthesized $A \beta$ peptide variants to compare their aggregation and oligomerization behaviour using biophysical techniques. Our observations show that variations in the $A \beta$ sequence have profound consequences for the propensity of the $A \beta$ peptide to aggregate and oligomerize.

Even though approximately $90 \%$ of the $A \beta$ peptide pool is composed of $A \beta_{1-40}$ and $A \beta_{1-42}$, it has been recognized that $A \beta_{1-37}, A \beta_{1-38}$, and $A \beta_{1-43}$ are also present in minor amounts in the brain and may modulate disease progress (22). It is known that the $A \beta_{1-42}$ peptide aggregates at a higher rate than $A \beta_{1-40}(23,24)$, but we show that $C$-terminal extension in general results in faster aggregation (Fig. 2.3). Furthermore, longer $\mathrm{A} \beta$ peptides gradually transform into mature and densely packed $\beta$-sheet rich fibril networks, whereas shorter peptides form more extended fibrils. We further report that $A \beta_{1-37}$ and $A \beta_{1-38}$ generally behave similar to $A \beta_{1-40}$, while the behaviour of $A \beta_{1-43}$ strongly resembles that of $A \beta_{1-42}$. The dense fibril networks formed by $A \beta_{1-42}$ and $A \beta_{1-43}$ possibly provide less access to, or have a decreased affinity for the ThT dye, compared to the more extended fibrils of shorter peptides, resulting in a lower final ThT fluorescence intensity. Alternatively, the denser peptide networks can be more prone to precipitation in the test tube which would lead to a similar observation.

Most FAD-associated mutations are located in or near the central hydrophobic cluster of the A $\beta$ peptide, which has been predicted and demonstrated to play an important role in aggregation. The effect of FAD mutations on $A \beta_{1-42}$ aggregation has therefore been investigated in the past $(9,25-28)$, but no comprehensive study has been reported that directly compares the majority of the currently known mutants under the same experimental conditions. Different $A \beta$ preparation methods and experimental conditions have led to considerable variation in the reported effects of these mutations, as described in the literature. In our experimental setup, we show that FAD mutations can either slow down or facilitate $\mathrm{A} \beta$ aggregation, yet without affecting overall fibril morphology (Fig. 2.4). The effect on aggregation rate has been suggested to be dependent on the suitability of the replacing amino acid to accommodate an amyloidogenic or aggregated structure $(25,29-33)$. Factors that have been suggested to modulate aggregation of FAD A $\beta$ mutants are the loss of the electrostatic repulsion between monomers and the destabilization of the turn region of the peptide $(27,34)$. The central hydrophobic region is however not the absolute key in determining aggregation tendency, as a subset of the FAD mutations in this region has no effect on the aggregation rate and most likely exert their pathological function through aberrant APP processing or reduced proteolytic $A \beta$ degradation (35-37).

Upregulation of the $\alpha$-secretase cleavage pathway initiating the non-amyloidogenic processing of APP has served as the guiding principle for the generation of various potential AD-modulating drugs (38). However, we show that complete destruction of the central aggregation zone by deletion of the first $17 \mathrm{~N}$-terminal amino acids, as naturally occurs by APP processing via the non-amyloidogenic pathway, does not abolish the aggregating character of the peptides (Fig. 2.6). This observation is consistent with previous findings (39). Moreover, p3 peptides have been demonstrated to induce toxicity via an ion channel mechanism (40). These findings raise doubts about the validity of upregulating the non- 
amyloidogenic pathway, call into question the terminology "non-amyloidogenic", and necessitate more research on $\mathrm{p} 3$ peptide behaviour.

Biotinylation of $\mathrm{A} \beta$ has been applied in several studies (10-13). Our data show that this modification can affect the onset of aggregation substantially depending on the location of biotinylation, either $\mathrm{N}$ - or C-terminally, but without affecting fibril morphology or oligomer formation (Fig. 2.5). These observations underline the importance of selecting and validating the type of labelling required for experiments, without inducing changes in the behaviour of the peptides that are subject to study.

In this work, we systematically compared the aggregation properties of a wide range of $A \beta$ peptides. The overall aggregation profile was determined by ThT fluorescence at a physiologically relevant $\mathrm{A} \beta$ concentration of $1 \mu \mathrm{M}$ (41). Moreover, we attempted to gain insights into early aggregation events by probing oligomerization of the peptides. We therefore used A11-reactivity as well as IR-based analysis of secondary structure content of early aggregation species, which were however not always completely in agreement. This could be attributed to the polyclonal nature of the A11 antibody (15), that might recognize more than one conformation. It is however also possible that both methods detect different oligomeric species, due to the difference in aggregation time points of the measured fractions, i.e. $0.5 \mathrm{~h}$ for dot blotting and $1.5 \mathrm{~h}$ for ATR-FTIR measurements.

In conclusion, our results highlight that minor sequential variations profoundly affect the aggregation of $A \beta$. Both the central and the $C$-terminal $A \beta$ region can play a regulating role in the aggregation process and affect several $A \beta$ properties, including aggregation rate, secondary structure, and fibril morphology. Further research is required to understand how these variations influence $A \beta$ toxicity and how they are associated with AD pathology. 


\subsection{References}

1. Glenner GG \& Wong CW (1984) Alzheimer's disease: initial report of the purification and characterization of a novel cerebrovascular amyloid protein. Biochem Biophys Res Commun 120:885-890.

2. Pike CJ, Walencewicz AJ, \& Glabe CG (1991) In vitro aging of beta-amyloid protein causes peptide aggregation and neurotoxicity. Brain Res 563:311-314.

3. Nunan J \& Small DH (2000) Regulation of APP cleavage by $\alpha$-, $\beta$-and $\gamma$-secretases. FEBS Lett 483:6-10.

4. Weidemann A, et al. (2002) A novel $\varepsilon$-cleavage within the transmembrane domain of the Alzheimer amyloid precursor protein demonstrates homology with Notch processing. Biochemistry 41(8):2825-2835.

5. Zhao G, et al. (2004) Identification of a new presenilin-dependent $\zeta$-cleavage site within the transmembrane domain of amyloid precursor protein. J Biol Chem 279(49):50647-50650.

6. Vigo-Pelfrey C, Lee D, Keim P, Lieberburg I, \& Schenk DB (1993) Characterization of betaamyloid peptide from human cerebrospinal fluid. J Neurochem 61(5):1965-1968.

7. Takami M, et al. (2009) $\gamma$-Secretase: successive tripeptide and tetrapeptide release from the transmembrane domain of $\beta$-carboxyl terminal fragment. J Neurosci 29(41):13042-13052.

8. Van Dam D \& De Deyn PP (2006) Drug discovery in dementia: the role of rodent models. Nat Rev Drug Discov 5(11):956-970.

9. Attar A, Meral D, Urbanc B, \& Bitan G (2014) Assembly of amyloid- $\beta$ protein variants containing familial Alzheimer's disease-linked amino acid substitutions. Bio-nanoimaging, eds Uversky VN \& Lyubchecnko YL (Academic Press, Boston), pp 429-442.

10. Bohrmann B, et al. (1999) Endogenous proteins controlling amyloid $\beta$-peptide polymerization. Possible implications for $\beta$-amyloid formation in the central nervous system and in peripheral tissues. $J$ Biol Chem 274(23):15990-15995.

11. Leissring MA, et al. (2003) Kinetics of amyloid $\beta$-protein degradation determined by novel fluorescence- and fluorescence polarization-based assays. J Biol Chem 278(39):37314-37320.

12. Liu R, Barkhordarian H, Emadi S, Park C, \& Sierks M (2005) Trehalose differentially inhibits aggregation and neurotoxicity of beta-amyloid 40 and 42. Neurobiol Dis 20(1):74-81.

13. Nelson TJ \& Alkon DL (2007) Protection against $\beta$-amyloid-induced apoptosis by peptides interacting with $\beta$-amyloid. J Biol Chem 282(43):31238-31249.

14. Broersen K, et al. (2011) A standardized and biocompatible preparation of aggregate-free amyloid beta peptide for biophysical and biological studies of Alzheimer's disease. Protein Eng Des Sel 24(9):743-750.

15. Kayed R, et al. (2003) Common Structure of Soluble Amyloid Oligomers Implies Common Mechanism of Pathogenesis. Science 300(5618):486-489.

16. Abramoff MD, Magalhaes PJ, \& Ram SJ (2004) Image Processing with ImageJ Biophotonics International 11(7):36-42.

17. Groenning M (2009) Binding mode of Thioflavin T and other molecular probes in the context of amyloid fibrils-current status. $J$ Chem Biol 3(1):1-18.

18. Biancalana M \& Koide S (2010) Molecular mechanism of Thioflavin-T binding to amyloid fibrils. Biochim Biophys Acta 1804(7):1405-1412.

19. Oberg KA, Ruysschaert JM, \& Goormaghtigh E (2004) The optimization of protein secondary structure determination with infrared and circular dichroism spectra. Eur $J$ Biochem 271(14):2937-2948.

20. Goormaghtigh E, Raussens V, \& Ruysschaert JM (1999) Attenuated total reflection infrared spectroscopy of proteins and lipids in biological membranes. Biochim Biophys Acta 1422(2):105-185.

21. Hubin E, van Nuland NA, Broersen K, \& Pauwels K (2014) Transient dynamics of A $\beta$ contribute to toxicity in Alzheimer's disease. Cell Mol Life Sci. Doi: 10.1007/s00018-0141634-z.

22. Portelius E, et al. (2010) Mass spectrometric characterization of brain amyloid beta isoform signatures in familial and sporadic Alzheimer's disease. Acta Neuropathol 120(2):185-193. 
23. Jarrett JT, Berger EP, \& Lansbury PT (1993) The carboxy terminus of the $\beta$ amyloid protein is critical for the seeding of amyloid formation: implications for the pathogenesis of Alzheimer's disease. Biochemistry 32(18):4693-4697.

24. Snyder SW, et al. (1994) Amyloid- $\beta$ aggregation: selective inhibition of aggregation in mixtures of amyloid with different chain lengths. Biophys $J$ 67(3):1216-1228.

25. Murakami K, et al. (2003) Neurotoxicity and physicochemical properties of A $\beta$ mutant peptides from cerebral amyloid angiopathy: implication for the pathogenesis of cerebral amyloid angiopathy and Alzheimer's disease. J Biol Chem 278(46):46179-46187.

26. Baumketner A, Krone MG, \& Shea JE (2008) Role of the familial Dutch mutation E22Q in the folding and aggregation of the 15-28 fragment of the Alzheimer amyloid- $\beta$ protein. Proc Natl Acad Sci U S A 105(16):6027.

27. Krone MG, et al. (2008) Effects of familial Alzheimer's disease mutations on the folding nucleation of the amyloid $\beta$-protein. $J$ Mol Biol 381(1):221-228.

28. Ono K, Condron MM, \& Teplow DB (2010) Effects of the English (H6R) and Tottori (D7N) familial Alzheimer disease mutations on amyloid $\beta$-protein assembly and toxicity. $J$ Biol Chem 285(30):23186-23197.

29. Fernandez-Escamilla A-M, Rousseau F, Schymkowitz J, \& Serrano L (2004) Prediction of sequence-dependent and mutational effects on the aggregation of peptides and proteins. Nat Biotechnol 22(10):1302-1306.

30. Liu R, McAllister C, Lyubchenko Y, \& Sierks MR (2004) Residues 17-20 and 30-35 of betaamyloid play critical roles in aggregation. $J$ Neurosci Res 75(2):162-171.

31. Lopez-De la Paz ML, et al. (2002) De novo designed peptide-based amyloid fibrils. Proc Natl Acad Sci U S A 99(25):16052-16057.

32. Sánchez de Groot N, Pallarés I, Avilés FX, Vendrell J, \& Ventura S (2005) Prediction of "hot spots" of aggregation in disease-linked polypeptides. BMC Struct Biol 5:18.

33. Chiti F, Stefani M, Taddei N, Ramponi G, \& Dobson CM (2003) Rationalization of the effects of mutations on peptide and protein aggregation rates. Nature 424(6950):805-808.

34. Lin YS \& Pande VS (2012) Effects of familial mutations on the monomer structure of $A \beta_{42}$. Biophys $J$ 103(12):L47-49.

35. Tian Y, Bassit B, Chau D, \& Li YM (2010) An APP inhibitory domain containing the Flemish mutation residue modulates $\gamma$-secretase activity for $\mathrm{A} \beta$ production. Nat Struct Mol Biol 17(2):151-158.

36. Betts V, et al. (2008) Aggregation and catabolism of disease-associated intra-A $\beta$ mutations: reduced proteolysis of A $\beta$ A21G by neprilysin. Neurobiol Dis 31(3):442-450.

37. Morelli L, et al. (2003) Differential degradation of amyloid $\beta$ genetic variants associated with hereditary dementia or stroke by insulin-degrading enzyme. J Biol Chem 278(26):2322123226.

38. Fahrenholz F (2007) Alpha-secretase as a therapeutic target. Curr Alzheimer Res 4(4):412417.

39. Pike CJ, Overman MJ, \& Cotman CW (1995) Amino-terminal deletions enhance aggregation of $\beta$-amyloid peptides in vitro. $J$ Biol Chem 270(41):23895-23898.

40. Jang H, et al. (2010) Truncated $\beta$-amyloid peptide channels provide an alternative mechanism for Alzheimer's Disease and Down syndrome. Proc Natl Acad Sci U S A 107(14):6538-6543.

41. Seubert $P$, et al. (1992) Isolation and quantification of soluble Alzheimer's $\beta$-peptide from biological fluids. Nature 359(6393):325-327. 


\title{
Chapter 3
}

\section{Distinct $\beta$-sheet structures in wild type and Italian-mutant $\mathbf{A} \beta$ fibrils: a possible link to different clinical phenotypes}

\author{
Parts of this chapter have been submitted to \\ Proceedings of the National Academy of Sciences of the United States of America. \\ Hubin E, Deroo S, Kaminski Schierle G, Kaminksi C, Serpell L, \\ Subramaniam V, van Nuland N, Raussens V, Broersen K, and Sarroukh R.
}

\begin{abstract}
Most $\mathrm{AD}$ cases are late-onset and characterized by the aggregation and deposition of the $\mathrm{A} \beta$ peptide in extracellular plaques in the brain. However, a few rare and hereditary $A \beta$ mutations, such as the Italian $\mathrm{Glu}_{22}$-to-Lys (E22K) mutation, guarantee development of earlyonset familial $\mathrm{AD}$ associated with $\mathrm{A} \beta$ deposition in cerebral blood vessel walls, giving rise to CAA. It remains largely unknown how the Italian mutation results in a different disease pathology and age of disease onset. Therefore, we investigated the aggregation of wild type and E22K A $\beta_{1-42}$ in vitro and structurally characterized the resulting fibrils using a biophysical approach. This paper reports that E22K A $\beta_{1-42}$ oligomers and fibrils both display an antiparallel $\beta$-sheet structure, in comparison with the parallel $\beta$-sheet structure of wild type fibrils, characteristic of most amyloid fibrils described in the literature. Moreover, this is the first study that experimentally demonstrates structural plasticity for Italian-mutant A $\beta$ fibrils in a $\mathrm{pH}$-dependent manner, in terms of their underlying $\beta$-sheet arrangement. These findings are of interest in the ongoing debate that (i) antiparallel $\beta$-sheet structure might represent a signature for toxicity, which could explain the high toxicity reported for the Italian-mutant, and that (ii) fibril polymorphism might underlie differences in disease pathology and location of amyloid deposition (i.e. tropism). We suggest that the in vitro structural differences of wild type and $\mathrm{E} 22 \mathrm{~K} A \beta_{1-42}$ might relate to their in vivo differences, and suggest that the antiparallel $\beta$-sheet structure predisposes the Italian-mutant $A \beta$ peptide to deposit mainly in blood vessel walls, rather than accumulating in plaques in the brain parenchyma.
\end{abstract}




\subsection{Introduction}

The conversion of a native and functional polypeptide into higher ordered, toxic aggregates, and eventually into amyloid fibrils, is characteristic of many human proteinopathies (1). Amyloid fibrils deposit extra- or intracellularly and are implicated in neurodegenerative disorders and non-neuropathic amyloidoses (2). The defining molecular unit of these amyloid fibrils is the cross- $\beta$ spine that originates from extending $\beta$-sheets composed of $\beta$-strands that are arranged perpendicular to the fibre axis $(3,4)$.

However, although the cross- $\beta$ spine is a common structural feature, amyloid fibrils show a great variety of structural complexity and can differ in their underlying structure, symmetry, width, twist period, and curvature (5-7). This structural polymorphism can have several molecular origins. First, fibril polymorphs can differ in the number of protofilaments (the minimal fibrillar entities) (7). Second, distinct orientations and modes of lateral association of protofilaments and patterns of inter-residue interactions determine how protofilaments are oriented (8-12). Third, variations in the underlying protofilament substructure can contribute to fibril polymorphism $(13,14)$. Despite the highly conserved arrangement of fibrils in a cross- $\beta$ manner along the elongation axis, fibrils can thus display considerable heterogeneity and structural polymorphism.

The biological relevance of fibril polymorphism is not yet fully understood, but it is notable that fibril polymorphism has been reported for several disease-related proteins. Substantial evidence indicates that different fibril morphologies exert different toxicities in vitro and could be related to differences in disease pathology and progression in vivo, or could underlie the preference of amyloid to deposit in specific cellular locations (i.e. tropism) (14-24). However, the link between fibril polymorphism and clinical subtypes of amyloidoses is still lacking.

One of the disease-related proteins for which fibril polymorphism has been reported is the $A \beta$ peptide (25). The $\mathrm{A} \beta$ peptide is one of the underlying causes of $\operatorname{AD}(26,27)$, inclusion body myositis (28), dementia with Lewy bodies (29), and CAA (30-32). CAA is pathophysiologically related to AD and found with high prevalence in $\mathrm{AD}$ patients $(80-90 \%)$ (33).

CAA is a common clinical symptom of early-onset FAD, in which disease symptoms occur earlier in life compared to the more prevalent sporadic, late-onset AD (34). Several mutations within the $\mathrm{A} \beta$ sequence have been identified that are causative of FAD associated with CAA, including the Italian E22K, Iowa D23N, Dutch E22Q, Arctic E22G, Flemish A21G, and Piedmont L34V mutations (35). Whereas $\mathrm{A} \beta$ in $\mathrm{AD}$ is primarily deposited in the brain parenchyma, CAA is related to cerebrovascular amyloid deposition (36). A $\beta$ deposition in vessel walls makes them prone to rupture and narrows their lumina to the point of occlusion, resulting in secondary lesions associated with CAA, such as intracerebral and subarachnoid bleeding, multiple infarcts, and periventricular oedema (37).

In this study, we monitored the aggregation of WT and Italian-mutant $E 22 \mathrm{~K} \mathrm{~A} \beta_{1-42}$ under different experimental conditions, and structurally characterized the resulting fibrils. We provide evidence that, under near-physiological conditions, E22K A $\beta_{1-42}$ spontaneously forms fibrils comprising stable antiparallel $\beta$-sheets, in contrast to WT fibrils that are composed of parallel $\beta$-sheets, similar to most amyloid fibrils described in the literature (38). Moreover, to the best of our knowledge, this is the first experimental demonstration that the underlying $\beta$ sheet arrangement of Italian-mutant $\mathrm{A} \beta$ fibrils is altered upon a change in $\mathrm{pH}$, and that interconversion of the corresponding fibril polymorphs occurs. 
These results are interesting in light of the emerging view that (i) antiparallel $\beta$-sheet structure may be of importance in the pathology of $\mathrm{AD}$ (6) and that (ii) fibril polymorphism may be implicated in in vivo differences in terms of disease pathology and age of disease onset. In addition to the Italian E22K A $\beta$ mutant presented in this work, another CAA-related A $\beta$ mutant (Iowa D23N) has recently been shown to form antiparallel $\beta$-sheet fibrils (39). Therefore, we suggest that the antiparallel $\beta$-sheet signature of $A \beta$ peptides associated with CAA, containing a mutation in the central turn region, predisposes them to deposit mainly in blood vessel walls.

\section{$\underline{\text { 3.2. Experimental procedures }}$}

\subsubsection{Reagents and chemicals}

WT $A \beta_{1-42}$ was purchased from American Peptide Co. (Sunnyvale, CA, USA), E22K and D23N A $\beta_{1-42}$ were purchased from JPT (JPT Peptide Technologies, Germany). Primary sequences of WT and E22K A $\beta_{1-42}$ peptides are depicted in fig. 3.1A. DMSO, HFIP, pepsin and ThT were obtained from Sigma-Aldrich (St. Louis, MO, USA). Antibodies (6E10, 4G8, 12F4) were purchased from Covance (Emeryville, CA, USA). HRP-conjugated anti-mouse and anti-rabbit antibodies were purchased from Millipore (Billerica, MA, USA) and Cell Signalling Technology (Danvers, MA, USA), respectively. The Supersignal West Pico Chemiluminescent Substrate and the Enhanced Chemiluminescence (ECL) ${ }^{\circledR}$ Plus Western Blot detection kit were obtained from Pierce (Biotechnology, Rockford, IL, USA) and GE Healthcare (Piscataway, NJ, USA), respectively.

\subsubsection{A $\beta$ peptide solubilization}

$\mathrm{A} \beta$ peptides were dissolved in cold HFIP at a concentration of $2 \mathrm{mg} / \mathrm{ml}$ and incubated at room temperature $\left(25^{\circ} \mathrm{C}\right)$ for $1 \mathrm{~h}$. HFIP was evaporated under nitrogen flow and residual HFIP was removed under vacuum using a Speed Vac (Thermo Savant). Prior to incubation, peptides were dissolved in DMSO at a final concentration of $2 \mathrm{mM}$ and then immediately diluted to a final concentration of $100 \mu \mathrm{M}$ in TBS (Tris-buffered saline: $20 \mathrm{mM}$ Tris/ $\mathrm{HCl} \mathrm{pH} 7.4$ containing $100 \mathrm{mM} \mathrm{NaCl}$ ) or in $10 \mathrm{mM} \mathrm{HCl} \mathrm{pH} \mathrm{2.0.} \mathrm{Peptides} \mathrm{were} \mathrm{incubated} \mathrm{at} 37^{\circ} \mathrm{C}$ under quiescent conditions. Fibrillar samples were collected by centrifugation for $30 \mathrm{~min}$ at 13200 rpm prior to analysis by ATR-FTIR and HDX-MS.

\subsubsection{TEM}

$\mathrm{A} \beta$ samples (5 $\mu \mathrm{l}$ of a $100 \mu \mathrm{M}$ concentration) were adsorbed to carbon-coated Formvar 400 mesh copper grids (Agar Scientific) for $1 \mathrm{~min}$. The grids were washed, blotted, and stained with $1 \%(\mathrm{w} / \mathrm{v})$ uranyl acetate. Samples were studied with a JEM-1400 microscope (JEOL Ltd., Tokyo, Japan) at $80 \mathrm{kV}$. Images are representative of three independently prepared $\mathrm{A} \beta$ solutions.

\subsubsection{AFM}

AFM images were acquired using a VEECO Dimension 3100 atomic force microscope (Bruker), operated in tapping mode in air by using silicon cantilevers with a resonance frequency of $325 \mathrm{kHz}$, a spring constant of $46 \mathrm{Nm}^{-1}$, and a tip radius of $10 \mathrm{~nm}(\mu \mathrm{MASCH}$, NSC15/no Al). Images were collected at a scan rate of $1 \mathrm{~Hz}$. Each fibrillar sample $(5 \mu 1$ of a $100 \mu \mathrm{M}$ concentration) was deposited for $15 \mathrm{~min}$ onto freshly cleaved mica surfaces to enable 
adsorption. The samples were rinsed with ultrapure water $(5 \times 200 \mu \mathrm{L})$ and left to dry in air before imaging.

\subsubsection{Dot blot analysis with $A \beta$-region specific antibodies}

$\mathrm{A} \beta$ aggregation was monitored by spotting $1 \mu \mathrm{g}$ of $\mathrm{A} \beta$ onto a nitrocellulose membrane at different $A \beta$ incubation times. Membranes were blocked for $1 \mathrm{~h}$ at $4{ }^{\circ} \mathrm{C}$ in $5 \%$ non-fat dry milk in TBS containing Tween-20 and then incubated $\left(24 \mathrm{~h}, 4{ }^{\circ} \mathrm{C}\right)$ with mouse monoclonal $\mathrm{A} \beta$-region specific antibodies $6 \mathrm{E} 10,4 \mathrm{G} 8$, or $12 \mathrm{~F} 4$ (all diluted $1: 3000$ in $0.5 \%$ non-fat dry milk in TBS containing Tween-20). HRP-conjugated anti-mouse antibody (1:2000 in $0.5 \%$ non-fat dry milk in TBS containing Tween-20, $4{ }^{\circ} \mathrm{C}, 1 \mathrm{~h}$ ) was used as secondary antibody. Detection was carried out using the Supersignal West Pico Chemiluminescent Substrate and the $\mathrm{ECL}^{\circledR}$ Western blot kit. Images were recorded and analysed using the ImageQuant 400 gel imager and ImageQuant TL software (GE Healthcare).

\subsubsection{Secondary structure and HDX measurements using ATR-FTIR spectroscopy}

ATR-FTIR spectra were recorded on an Equinox 55 IR spectrophotometer (Bruker Optics, Ettlingen, Germany). A quantity of $2 \mu \mathrm{g}$ of $\mathrm{A} \beta$ peptide was spread on the diamond surface $\left(2 \times 2 \mathrm{~mm}^{2}\right)$ of an internal reflection element and was washed with excess water to eliminate salts. Residual water was evaporated under nitrogen flow. Each spectrum represents the mean of 128 repetitions and was recorded at a resolution of $2 \mathrm{~cm}^{-1}$. The ATR-FTIR data were analysed using Kinetics software (SFMB, Brussels, Belgium) and processed for baseline correction and subtraction of the water vapour contribution. Spectra were smoothed at a final resolution of $4 \mathrm{~cm}^{-1}$ by apodization of their Fourier transform by a Gaussian line and intensities were normalized to the intensity of the major $\beta$-structure peak around $1630 \mathrm{~cm}^{-1}$. All depicted spectra were deconvolved using a Lorentzian deconvolution factor with a FWHH of $20 \mathrm{~cm}^{-1}$ and a Gaussian apodization factor with a FWHH of $16.67 \mathrm{~cm}^{-1}$, to obtain a resolution enhancement factor of 1.2. Deconvolution increases the resolution of the spectra in the amide I region which is most sensitive to the secondary structure of proteins. Next, curve fitting was performed on the non-deconvolved ATR-FTIR spectra as described in chapter 2, to determine the secondary structure of both peptides. Finally, HDX experiments using IR were performed on $\mathrm{A} \beta$ fibrils ( 7 days old) and the decay of the $\mathrm{NH}$-associated amide II band (1500-1600 $\mathrm{cm}^{-1}$, arising mainly from the N-H bending mode of vibration of the peptide bond) was used to monitor the exchange of the amide group during a time lapse of $1 \mathrm{~h}$. Results were analysed as described previously (38).

\subsubsection{ThT fluorescence}

$\mathrm{A} \beta$ fibril formation was probed using ThT fluorescence as described previously (40). Briefly, $5 \mu \mathrm{M}$ of ThT was freshly dissolved in $50 \mathrm{mM}$ glycine/ $\mathrm{NaOH} \mathrm{pH} 8.5$ and $4.5 \mu \mathrm{g}$ of $\mathrm{A} \beta$ was added to $1 \mathrm{ml}$ of ThT solution. The excitation wavelength was set at $450 \mathrm{~nm}$ and the ThT fluorescence emission was recorded at $485 \mathrm{~nm}$ or between 460 and $560 \mathrm{~nm}$. All measurements were recorded on a LS55 fluorimeter (PerkinElmer Instruments) at $25{ }^{\circ} \mathrm{C}$ with bandwidths of $5 \mathrm{~nm}$.

\subsubsection{X-ray fibre diffraction}

A $\beta$ fibrils $(8 \mathrm{mg} / \mathrm{ml})$ were aligned between wax-tipped capillaries and allowed to dry in air (41). The partially aligned fibre was placed on a goniometer head and data were collected 
using a Rigaku rotating anode source $(\mathrm{CuK} \alpha)$ and a Saturn $944+\mathrm{CCD}$ detector. The diffraction patterns were examined and measured using CLEARER software (42).

\subsubsection{FLIM}

Fluorescence lifetime imaging microscopy (FLIM) was performed on a home-built confocal microscopy platform based on a confocal microscope scanning unit (Olympus FluoView 300) coupled with an Olympus IX70 inverted microscope frame. A $405 \mathrm{~nm}$ diode laser was used as the excitation source and the detection wavelength range was set at $470 \mathrm{~nm}$. Acquisition of FLIM images was controlled using the software SPMC (Becker \& Hickl GmbH, Berlin, Germany). Results were analysed as described previously (43).

\subsubsection{HDX-MS measurements and data analysis}

A volume of $25 \mu \mathrm{l}$ of amyloid fibrils of WT and E22K A $\beta_{1-42}$, grown for 21 days in TBS (100 $\mu \mathrm{M}$ monomeric concentration), were collected by centrifugation at $13200 \mathrm{rpm}$ for $30 \mathrm{~min}$ at 4 ${ }^{\circ} \mathrm{C}$. A volume of $24 \mu \mathrm{l}$ of supernatant was removed and the pellet was resuspended with $24 \mu \mathrm{l}$ $\mathrm{D}_{2} \mathrm{O}$. Labelling was carried out for $15 \mathrm{~min}$ at room temperature. Fibril samples were recovered by centrifugation at $13200 \mathrm{rpm}$ for $30 \mathrm{~min}$ at $4{ }^{\circ} \mathrm{C}$. From then, samples and solutions were held on ice. A volume of $24 \mu \mathrm{l}$ of $\mathrm{D}_{2} \mathrm{O}$ supernatant was removed and fibrils were dissolved in $20.4 \mu \mathrm{l}$ of $100 / 0.5 \quad(\mathrm{v}: \mathrm{v}) \mathrm{H}_{2} \mathrm{O} / \mathrm{HCOOH}$ containing pepsin $(1: 5$, enzyme:substrate, w:w). After $20 \mathrm{~s}, 3.6 \mu \mathrm{l}$ of 100/0.5 (v:v) $\mathrm{MeCN} / \mathrm{HCOOH}$ was added (85/15/0.5 (v:v:v) $\mathrm{H}_{2} \mathrm{O} / \mathrm{MeCN} / \mathrm{HCOOH}$ final concentration) allowing fibril dissolution (58).

For HDX on WT and E22K A $\beta_{1-42}$ monomers, peptides were first dissolved in DMSO at a concentration of $2 \mathrm{mM}$, subsequently resuspended in $\mathrm{D}_{2} \mathrm{O}$ (final concentration: $80 \mu \mathrm{M}$ ), and exchange was allowed for $45 \mathrm{~min}$. One $\mu \mathrm{l}$ of the exchanged monomeric peptide was added to $20.4 \mu \mathrm{l}$ of $100 / 0.5$ (v:v) $\mathrm{H}_{2} \mathrm{O} / \mathrm{HCOOH}$ containing pepsin (1:5, enzyme:substrate, w:w). After $20 \mathrm{~s}, \quad 3.6 \mu \mathrm{l}$ of $100 / 0.5 \quad(\mathrm{v}: \mathrm{v}) \quad \mathrm{MeCN} / \mathrm{HCOOH}$ was added (85/15/0.5 (v:v:v) $\mathrm{H}_{2} \mathrm{O} / \mathrm{MeCN} / \mathrm{HCOOH}$ final concentration).

HDX was then evaluated by electrospray ionization-MS (ESI-MS). The deuterium content of the samples was analysed by ESI-MS on a Q-TOF Ultima API spectrometer (Waters/Micromass). Samples were electrosprayed from gold-coated glass capillaries (ThermoFisher). Capillary and cone voltages applied were $1.8 \mathrm{kV}$ and $50 \mathrm{~V}$ respectively. The same dead time $(1 \mathrm{~min})$ after mixing in protic solvent was used for all experiments. All measurements were done in triplicates and mass spectra presented are averages of $20 \mathrm{~s}$ acquisition.

\section{Data analysis of HDX-MS experiments}

The fraction of $\mathrm{D}_{2} \mathrm{O}$ in the pepsin solution, used for monomeric and fibrillar samples, was $4 \%$ (1 $\mu \mathrm{L}_{2} \mathrm{O}$ for $24 \mu \mathrm{l} \mathrm{H}_{2} \mathrm{O}$ ). As the labile terminal and side chain hydrogens exchange very rapidly, even at $\mathrm{pH}$ 2.0-3.0, the final measured deuterium content should include an equilibrium distribution of deuterium into these sites. Because there are 27 and 28 of these hydrogens in WT and $\mathrm{E} 22 \mathrm{~K} \mathrm{~A} \beta_{1-42}$ respectively, a total of only 1 deuterium (4\% of 27.5) should be incorporated at these sites for full-length monomeric $A \beta$, and this is thus not considered here. The deuterium content of the peptides was determined from the centroid of the molecular ion isotope peaks as described earlier (44). The measured deuterium content in each peptide was corrected for back exchange. Back exchange occurs during the pepsin 
processing of samples in solvent that contains exchangeable hydrogens, and during ionization itself, as previously described (45) and described in equation 3.1.

$$
\begin{gathered}
\mathrm{D}_{\text {corr }}=\mathrm{m}-\mathrm{MW}+\text { Back Exchange } \\
\text { Back Exchange }=\mathrm{MW}+\mathrm{N}-\mathrm{m}_{100 \%}(\text { Eq. 3.1) }
\end{gathered}
$$

$D_{\text {corr }}$ is the corrected average number of amide deuterons after incubation in $\mathrm{D}_{2} \mathrm{O}, \mathrm{m}$ is the measured centroid mass after $45 \mathrm{~min}$ of labelling, MW is the measured average molecular weight in $\mathrm{H}_{2} \mathrm{O}, \mathrm{N}$ is the total number of amide hydrogens in each peptide (exchangeable sites) and $\mathrm{m}_{100 \%}$ is the measured centroid peptide mass from $100 \%$ deuterated controls. Monomeric $\mathrm{A} \beta$ is expected to be fully deuterated after only $30 \mathrm{~min}$ and was used as the control to estimate the back exchange during the analysis. The back exchange ranged from 12.5 to $37.8 \%$ and was similar to values reported in other studies $(46,47)$.

\subsubsection{Immune response of THP-1 monocytes to A $\beta$ fibrils}

The human monocytic leukemia cell line THP-1 (American Type Culture Collection, Rockville, Md.) was grown in RPMI 1640 medium supplemented with $10 \%$ fetal bovine serum and $1 \%$ penicillin/streptomycin. Cells were incubated at $37{ }^{\circ} \mathrm{C}$ and $5 \% \mathrm{CO}_{2}$, and diluted to a cell density of $10^{6}$ cells per $\mathrm{ml}$ in 24 -well plates prior to experiments $(1 \mathrm{ml} / \mathrm{well})$. Cells were exposed to a concentration range of WT and E22K A $\beta_{1-42}$ fibrils (4 days old; 0.1 $\mu \mathrm{M}, 1 \mu \mathrm{M}$, and $10 \mu \mathrm{M}$ ) for $3 \mathrm{~h}$. Control samples included the bacterial lipopolysaccharide (LPS, E. coli 0111:B4) as positive control, and medium alone as negative control. Samples were added to cells in triplicates. Prior to addition of fibrils to cells, peptide samples were assured to be endotoxin-free using the EndoZyme ${ }^{\circledR}$ recombinant Factor $\mathrm{C}$ assay (Hyglos $\mathrm{GmbH}$, Germany) (section 3.5).

After $3 \mathrm{~h}$ of incubation with the samples, cells were harvested for total RNA isolation and complementary DNA (cDNA) synthesis, and subsequent assessment of gene expression by real-time quantitative polymerase chain reaction (RT-qPCR). Briefly, cells were centrifuged for $5 \mathrm{~min}$ at $500 \mathrm{~g}$ and cell pellets were lyzed with Trizol. Chloroform was added to the lyzed cells and $15 \mathrm{~min}$ of centrifugation $(12000 \mathrm{~g})$ at $4{ }^{\circ} \mathrm{C}$ resulted in a phase separation. The upper aqueous phase (containing RNA) was carefully collected without transferring the interphase (containing DNA) or the lower phase (comprising proteins and lipids). After addition of ethanol (70 \%) to the upper phase, the RNeasy Mini kit (Qiagen) and the RNase free DNase set (Qiagen) were combined to extract total RNA from every sample and remove DNA contamination. RNA concentration was determined by measuring absorbance at $260 \mathrm{~nm}$ using a Nanodrop (Thermo Scientific), and purity was assessed on a $1 \%$ agarose gel $(20 \mathrm{~min}$, constant $100 \mathrm{~V}$ ). RNA was then reverse transcribed to cDNA with the iScript cDNA synthesis kit (BioRad, USA). Therefore, $200 \mathrm{ng}$ of isolated RNA template (in a total volume of $15 \mu \mathrm{l}$ ) was mixed with $1 \mu 1$ reverse transcriptase (RT), $4 \mu 1$ of iScript reaction mix (containing oligo(dT) and random hexamer primers), and subjected to PCR (annealing: 5 min at $25^{\circ} \mathrm{C}$, reverse transcription: $30 \mathrm{~min}$ at $42{ }^{\circ} \mathrm{C}$, inactivation of RT: $5 \mathrm{~min}$ at $85{ }^{\circ} \mathrm{C}$, hold at $8{ }^{\circ} \mathrm{C}$ ). Transcription profiles of genes related to pro-inflammatory cytokines, related enzymes, and transcription factors, were then determined using qPCR. Reaction samples contained $5 \mu 1$ cDNA template, $10 \mu \mathrm{l}$ SYBR-Green master mix, and primers corresponding to a subset of ten target genes (Table 3.1). The qPCR was carried out as followed: denaturation for $1.5 \mathrm{~min}$ at $95^{\circ} \mathrm{C}$, and then 40 amplification cycles (denaturation: $10 \mathrm{~s}$ at $95^{\circ} \mathrm{C}$, annealing: $10 \mathrm{~s}$ at $58{ }^{\circ} \mathrm{C}$, elongation: $15 \mathrm{~s}$ at $72{ }^{\circ} \mathrm{C}$ ). The PCRs of all products were then subjected to a melting curve analysis to verify the single amplification products. The temperature of the thermal 
cycler was set at $55{ }^{\circ} \mathrm{C}$, and was subsequently increased by incremental steps of $1{ }^{\circ} \mathrm{C} / 5 \mathrm{~s}$. The comparative $\mathrm{C}_{\mathrm{T}}$ method was used for analysis of RT-qPCR results and presentation of the relative mRNA expression values (48). $\mathrm{C}_{\mathrm{T}}$ values were corrected for the expression of housekeeping genes glyceraldehyde-3-phosphate dehydrogenase (GADPH) and actin- $\beta$ chain, and the negative control containing only medium. Housekeeping genes were chosen for normalization because they have been shown to be stably expressed. The relative gene expression is thus defined as a "fold change in expression" relative to housekeeping genes and the negative control (Equation 3.2).

$$
\begin{aligned}
& \Delta \mathrm{C}_{\mathrm{T}}=\mathrm{C}_{\mathrm{T} \text { averaged housekeeping genes }}-\mathrm{C}_{\mathrm{T} \text { sample }} \\
& \Delta \Delta \mathrm{C}_{\mathrm{T}}=\Delta \mathrm{C}_{\mathrm{T} \text { gene of interest }-} \Delta \mathrm{C}_{\mathrm{T} \text { medium }} \\
& \text { Relative gene expression }=2^{\Delta \Delta \mathrm{C}_{\mathrm{T}}} \text { (Eq. 3.2) }
\end{aligned}
$$

\begin{tabular}{|c|c|c|}
\hline Gene & $\begin{array}{l}\text { Final concentration of } \\
\text { primer in qPCR mix }(\mu \mathrm{M})\end{array}$ & $\begin{array}{l}\text { Sequences of forward (FWD) and reverse (REV) } \\
\text { primers }\end{array}$ \\
\hline GADPH & 0.1 & $\begin{array}{l}\text { FWD: TGCACCACCAACTGCTTAGC } \\
\text { REV: GGCATGGACTGTGGTCATGAG }\end{array}$ \\
\hline Actin $-\beta$ chain & 0.1 & $\begin{array}{l}\text { FWD: CTGGAACGGTGAAGGTGACA } \\
\text { REV: AAGGGACTTCCTGTAACAATGCA }\end{array}$ \\
\hline Interleukin (IL)-1 $\beta$ & 0.1 & $\begin{array}{l}\text { FWD: GTGGCAATGAGGATGACTTGTTC } \\
\text { REV: TAGTGGTGGTCGGAGATTCGTA }\end{array}$ \\
\hline $\begin{array}{l}\text { Tumour necrosis } \\
\text { factor-alpha (TNF } \alpha)\end{array}$ & 0.1 & $\begin{array}{l}\text { FWD: CTGCTGCACTTTGGAGTGAT } \\
\text { REV: AGATGATCTGACTGCCTGGG }\end{array}$ \\
\hline IL-6 & 0.1 & $\begin{array}{l}\text { FWD: AGCCACTCACCTCTTCAGAAC } \\
\text { REV: GCCTCTTTGCTGCTTTCACAC }\end{array}$ \\
\hline IL-8 & 0.1 & $\begin{array}{l}\text { FWD: CTGATTTCTGCAGCTCTGTG } \\
\text { REV: GGGTGGAAAGGTTTGGAGTATG }\end{array}$ \\
\hline IL-10 & 0.4 & $\begin{array}{l}\text { FWD: GTGATGCCCCAAGCTGAGA } \\
\text { REV: CACGGCCTTGCTCTTGTTTT }\end{array}$ \\
\hline IL-12p40 & 0.1 & $\begin{array}{l}\text { FWD: CTCTGGCAAAACCCTGACC } \\
\text { REV: GCTTAGAACCTCGCCTCCTT }\end{array}$ \\
\hline IL-18 & 0.4 & $\begin{array}{l}\text { FWD: CTGATTCTGACTGTAGAGATAATG } \\
\text { REV: TTCTCACACTTCACAGAGATAG }\end{array}$ \\
\hline $\begin{array}{l}\text { Cyclo-oxygenase- } 2 \\
(\mathrm{COX}-2)\end{array}$ & 0.1 & $\begin{array}{l}\text { FWD: CAGCACTTCACGCATCAGTT } \\
\text { REV: CGCAGTTTACGCTGTCTAGC }\end{array}$ \\
\hline
\end{tabular}

Table 3.1: Set of primers used in RT-qPCR for quantification of mRNA expression of genes related to pro-inflammatory cytokines, transcription factors, and related enzymes.

\subsection{Results}

\subsubsection{E22K $A \beta_{1-42}$ forms fibrils with an antiparallel $\beta$-sheet conformation}

WT and E22K A $\beta_{1-42}$ were dissolved in $100 \%$ HFIP to ensure removal of pre-formed aggregates. After evaporation of HFIP, the aggregation of $\mathrm{A} \beta$ was induced by dissolving the peptide film in TBS buffer $\mathrm{pH} 7.4$ containing $2 \%(\mathrm{v} / \mathrm{v})$ DMSO. TEM confirmed the emergence of heterogeneous oligomeric and prefibrillar species, and subsequently fibril formation was imaged by TEM and AFM for both WT and E22K A $\beta_{1-42}$ (Fig. S1 in section 
3.5). Moreover, the accessibility of the C-terminus of both peptides was lost upon aggregation as assessed by dot blotting with region specific anti-A $\beta$ antibodies (Fig. S2). This is in full agreement with previous NMR studies showing folding of the C-terminus of the A $\beta$ peptide into the fibril core $(18,49)$.

To gain insight into the structural rearrangements occurring during aggregation of the E22K $\mathrm{A} \beta_{1-42}$ peptide and into the differences with WT $A \beta_{1-42}$, we monitored the $A \beta$ aggregation process using ATR-FTIR spectroscopy (Fig. 3.1B and C). The amide I absorption band (1600-1700 $\mathrm{cm}^{-1}$ ) was used for IR spectra analysis because this band results from $\mathrm{C}=\mathrm{O}$ stretch vibrations of peptide linkages and is most sensitive to changes in $\mathrm{H}$-bonding in proteins (50, 51). Upon aggregation, WT and $E 22 \mathrm{~K} \mathrm{~A} \beta_{1-42}$ both displayed $\beta$-sheet structure, indicated by a major peak around $1630 \mathrm{~cm}^{-1}$ (Fig. 3.1B and C). The position and width of this peak have been related to the number of $\beta$-strands and the formation of $\mathrm{H}$-bonds (52-54). Both peptides also showed an additional minor peak around $1695 \mathrm{~cm}^{-1}$ at early aggregation time points $(0 \mathrm{~h}$, $24 \mathrm{~h}$ ). This peak, in conjunction with the major peak, is the signature of an antiparallel arrangement of $\beta$-strands (55-57) and can be attributed to the presence of oligomers (58-62).

Mature fibril formation was marked by a high $\beta$-sheet content for both WT and E22K A $\beta_{1-42}$, as demonstrated by curve fitting of the amide I region (Table 3.2). However, the structural rearrangements occurring during the oligomer-to-fibril transformation were different for WT and $\mathrm{E} 22 \mathrm{~K} A \beta_{1-42}$. As demonstrated previously, the oligomer-to-fibril transformation of WT $A \beta_{1-42}$ was accompanied by a major change in secondary structure. The antiparallel contribution associated with the minor peak around $1695 \mathrm{~cm}^{-1}$ disappeared when fibrils were formed (Fig. 3.1B), indicating reorganization of $\beta$-strands from an antiparallel to a parallel orientation (60). In contrast, in the case of E22K A $\beta_{1-42}$, the $1695 \mathrm{~cm}^{-1}$ peak persisted in time, suggesting that Italian-mutant fibrils are composed of antiparallel $\beta$-sheets (Fig. 3.1C). A similar IR spectrum was obtained for Iowa D23N A $\beta$ fibrils, shown previously to contain antiparallel $\beta$-sheets (Fig. S3) (39). The structural differences occurring during aggregation were quantified by the $\beta$-index ratio (defined as the $1695 / 1630 \mathrm{~cm}^{-1}$ intensity ratio), which has been shown to be proportional to the percentage of antiparallel arrangement of $\beta$-strands in a $\beta$-sheet $(55,58,60,61)$. The $\beta$-index ratio of $\mathrm{WT} A \beta_{1-42}$ dropped significantly in time during the oligomer-to-fibril transformation $(0.20 \pm 0.01$ to $0.03 \pm 0.02$ after 7 days of incubation), whereas the E22K $\beta$-index ratio retained a high value throughout aggregation $(0.21 \pm 0.05$ to $0.15 \pm 0.03$ after 7 days) (Fig. 3.1D). High $\beta$-index ratios have been reported to be characteristic for antiparallel $\beta$-structured proteins such as avidin, concanavalin $\mathrm{A}$, and bacterial outer membrane porin $F(58,59)$. These results suggest that, contrary to most structures reported previously for amyloid fibrils $(8,9,18)$, Italian-mutant $A \beta_{1-42}$ fibrils display an antiparallel $\beta$-sheet architecture.

To structurally characterize $\mathrm{E} 22 \mathrm{~K}$ and $\mathrm{WT} \mathrm{A} \beta_{1-42}$ fibrils in more depth and to ensure samples were oligomer-free, fibrillar samples (7 days old) were centrifuged at $13200 \mathrm{rpm}$ for $30 \mathrm{~min}$ and the fibril pellet was resuspended in water prior to IR data collection. Dense amyloid networks with protruding, negatively stained fibrils were visualized for both preparations using TEM (Fig. 3.2A). The IR spectrum of the E22K A $\beta_{1-42}$ fibril pellet still displayed the minor peak at $1695 \mathrm{~cm}^{-1}$ and a shift in the amide II band region $\left(1500-1600 \mathrm{~cm}^{-1}\right)$ to lower wavenumbers (Fig. 3.2B), features both corresponding to antiparallel $\beta$-sheet structure (60). As oligomers were removed by the centrifugation procedure, this observation provides evidence that the antiparallel structural signature detected in the total aggregated E22K A $\beta_{1-42}$ sample after 7 days of incubation (Fig. 3.1C) can be attributed to E22K A $\beta_{1-42}$ fibrils, as these are the main aggregation species at this time point. 
A.

$\begin{array}{llllll} & 1 & 11 & 21 & 31 & 41 \\ \text { WT A } \beta_{1-42} & \text { DAEFRHDSGY } & \text { EVHHQKLVFF } & \text { AEDVGSNKGA } & \text { IIGLMVGGVV } & \text { IA } \\ \text { E22K A } \beta_{1-42} & \text { DAEFRHDSGY } & \text { EVHHQKLVFF } & \text { AKDVGSNKGA } & \text { IIGLMVGGVV } & \text { IA }\end{array}$

B.

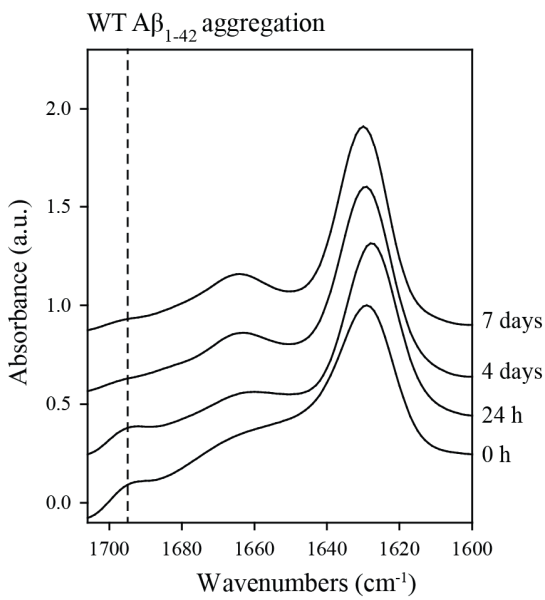

D.

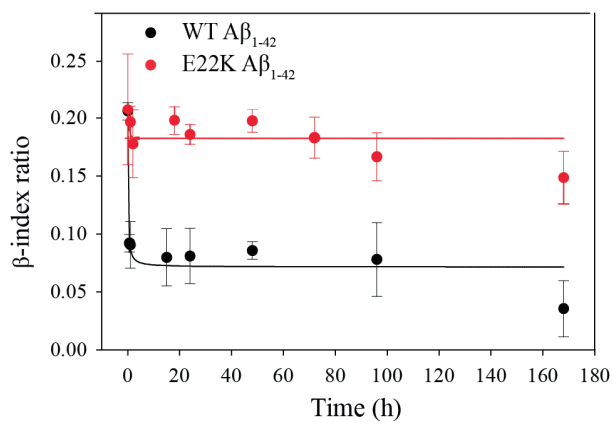

C.

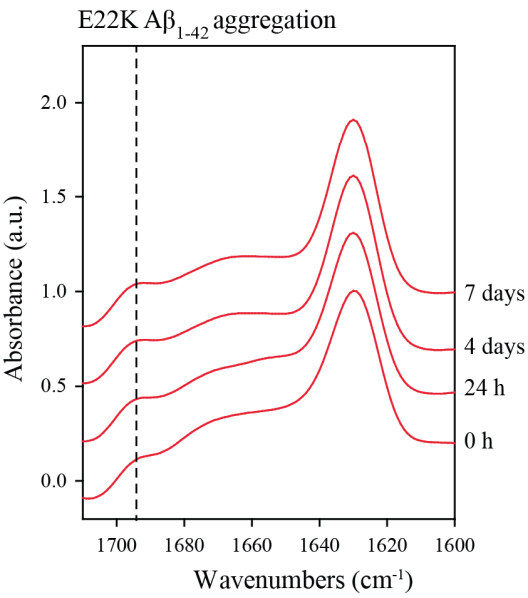

E.

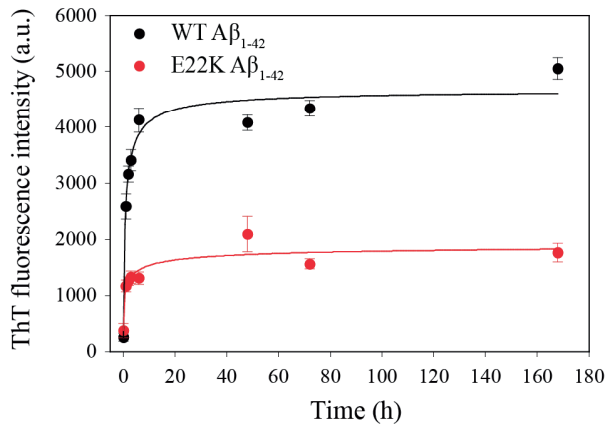

Figure 3.1: The Italian E22K A $\beta$ mutation induces formation of antiparallel $\beta$-sheet fibrils. (A) The Italian mutation comprises a Glu-to-Lys switch at residue 22 (E22K) of the A $\beta$ sequence. (B-E) Aggregation of WT and E22K A $\beta_{1-42}$ peptide in TBS pH 7.4 at $37{ }^{\circ} \mathrm{C}$ was monitored using ATR-FTIR (B-D) and ThT fluorescence (E) for $7 \mathrm{~d}$. The amide I region (1700-1600 $\left.\mathrm{cm}^{-1}\right)$ of the ATR-FTIR spectra of (B) WT and (C) E22K A $\beta_{1-42}$ is depicted and vertical broken lines are shown at $1695 \mathrm{~cm}^{-1}$. Spectral intensities were normalized to the intensity of the major contribution of $\beta$-structure around $1630 \mathrm{~cm}^{-1}$. Spectra were vertically offset for better visualization. Spectra depicted here were deconvolved using a Lorentzian deconvolution factor with a FWHH of $20 \mathrm{~cm}^{-1}$ and a Gaussian apodization factor with a FWHH of $16.67 \mathrm{~cm}^{-1}$, to obtain a resolution enhancement factor $\mathrm{K}=1.2$. Spectra are representative of at least three independent experiments. (D) The $\beta$-index ratio $\left(1695 / 1630 \mathrm{~cm}^{-1}\right.$ intensity ratio) was calculated on the basis of non-deconvolved ATR-FTIR spectra. Means and error bars have been calculated on the basis of three independent experiments. (E) ThT fluorescence emission was measured during aggregation at $485 \mathrm{~nm}\left(\lambda_{\mathrm{ex}}=450 \mathrm{~nm}\right)$. Intensities were corrected for the ThT fluorescence background. Means and error bars have been calculated on the basis of three independent experiments.

The distinct underlying conformations of WT and $\mathrm{E} 22 \mathrm{~K} \mathrm{~A} \beta_{1-42}$ fibrils were further marked by different reactivities with ThT, a dye whose fluorescence emission is largely enhanced upon binding to amyloid fibrils $(40,63)$. Whereas WT $\mathrm{A} \beta_{1-42}$ fibrils displayed a high ThT fluorescence intensity, the reactivity of $\mathrm{E} 22 \mathrm{~K} \mathrm{~A} \beta_{1-42}$ fibrils with ThT was significantly lower (Fig. 3.1E and 3.2C). Lower levels of ThT fluorescence could be indicative of a lower affinity 
of Italian-mutant fibrils for ThT, as shown previously for the Japanese $\mathrm{E} 22 \Delta \mathrm{A} \beta_{1-39}$ mutant, and/or less accessibility of the dye to potential binding sites (64). The distinct structures of both fibril types also resulted in different intrinsic fluorescence lifetimes, measured using FLIM (Fig. 3.2D). Intrinsic fluorescence has been proposed to be a generic property of amyloid structures related to electron delocalization in the H-bonded underlying $\beta$-sheet structure $(43,65)$. Different orientations of the H-bonding network, i.e. parallel and antiparallel $\beta$-sheet organizations, could possibly underlie differences in electron delocalization and therefore translate into different intrinsic fluorescence lifetimes.

A.

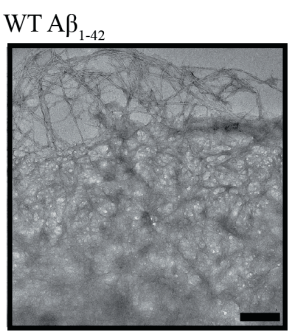

$\mathrm{E} 22 \mathrm{~K} \mathrm{~A} \beta_{1-42}$

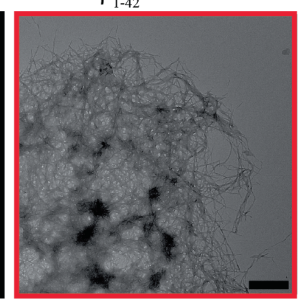

C.

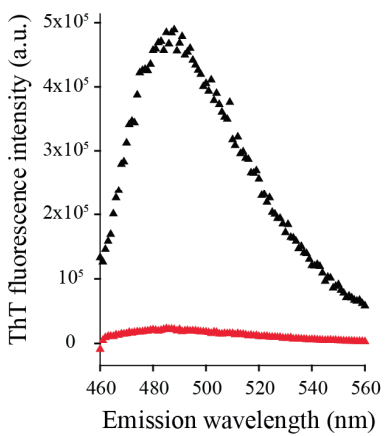

D.

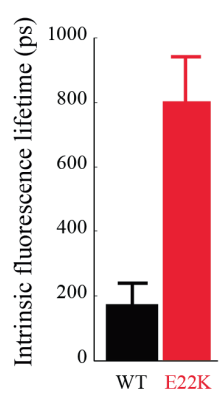

B.

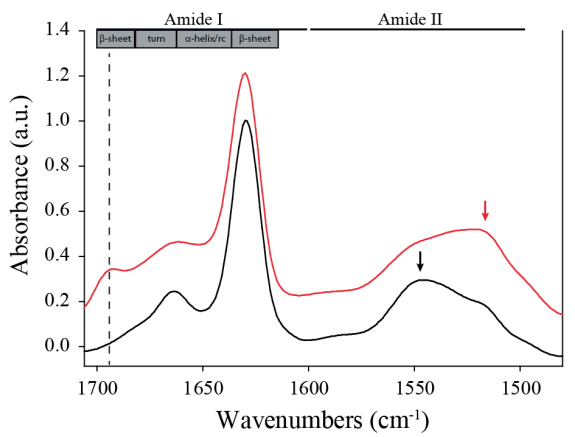

E.

WT A $\beta_{1-12}$

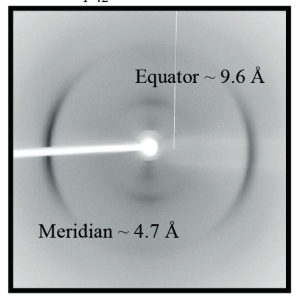

$\mathrm{E} 22 \mathrm{~K} \mathrm{~A} \beta_{1-42}$

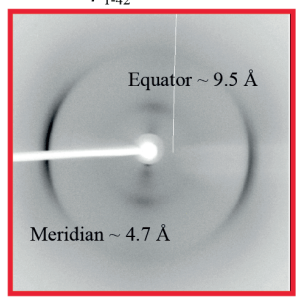

Figure 3.2: WT and E22K A $\beta_{1-42}$ fibrils comprise distinct underlying structures. WT and E22K A $\beta_{1-42}$ fibrils (depicted in black and red, respectively) were structurally characterized after $7 \mathrm{~d}$ of incubation in TBS pH 7.4 at $37^{\circ} \mathrm{C}$. (A) TEM revealed dense networks of negatively stained fibrils for both fibril types. Scale bars represent $500 \mathrm{~nm}$. (B) ATR-FTIR spectra of E22K and WT A $\beta_{1-42}$ fibrils, harvested after 30 min of centrifugation at 13200 rpm. E22K fibrils displayed an additional peak around $1695 \mathrm{~cm}^{-1}$ (vertical broken line) and a shift in the amide II band to lower wavenumbers (as depicted by arrows), indicative of an underlying antiparallel $\beta$-sheet architecture, compared to the parallel $\beta$-sheet orientation of WT fibrils. Spectral intensities were normalized to the intensity of the major contribution of $\beta$-structure around $1630 \mathrm{~cm}^{-1}$. Spectra were vertically offset for better visualization. Spectra depicted here were deconvolved using a Lorentzian deconvolution factor with a FWHH of $20 \mathrm{~cm}^{-1}$ and a Gaussian apodization factor with a FWHH of $16.67 \mathrm{~cm}^{-1}$, to obtain a resolution enhancement factor $\mathrm{K}=1.2$. (C) ThT fluorescence emission spectra $\left(\lambda_{\text {ex }}=450 \mathrm{~nm}\right)$ corresponding to fibrils in (A). E22K A $\beta_{1-42}$ fibrils showed low ThT reactivity, whereas WT fibrils induced a high ThT fluorescence signal. Spectra were corrected for the ThT fluorescence background. (D) E22K A $\beta_{1-42}$ fibrils displayed a higher intrinsic fluorescence lifetime than WT fibrils $\left(\lambda_{\mathrm{ex}}=405 \mathrm{~nm}\right)$. Fluorescence lifetimes were corrected for background and are representative of three independent experiments. (E) X-ray fibre diffraction resulted in the cross- $\beta$ spine reflections, characteristic of amyloid fibrils (41), for both fibril types. 
Furthermore, X-ray fibre diffraction revealed that both fibril types displayed meridional (4.7 $\AA$ ) and equatorial (9.5-9.6 $\AA$ ) reflections, corresponding to the distance between $\beta$-strands within one $\beta$-sheet, and to the distance between $\beta$-sheets, respectively (Fig. 3.2E). These reflections are consistent with the cross- $\beta$ diffraction pattern that is characteristic for amyloid fibrils (66). The orientation obtained was however not sufficient to distinguish between parallel and antiparallel $\beta$-sheet structure, but it is difficult to establish antiparallel $\beta$-sheet signatures from X-ray fibre diffraction due to a systematic absence arising from the $2_{1}$ helix (67).

Both ATR-FTIR and fluorescence spectroscopy data indicated that WT and E22K A $\beta_{1-42}$ fibrils contain different $\beta$-sheet organizations. Further analysis was therefore performed to gain more detailed understanding of their structural differences.

\subsubsection{The central region is more exposed in $\mathbf{E} 22 \mathrm{~K} A \beta_{1-42}$ fibrils than in WT fibrils}

HDX patterns of fibrils were measured using ATR-FTIR spectroscopy to gain insight into the $\mathrm{H}$-bonded $\beta$-sheet network. Hydrogen atoms exchange most easily when not involved in $\mathrm{H}$ bonds and/or when they are not buried in the fibril core. Estimates of the secondary structure contributions, based on analysis of IR spectra (Fig. 3.2B), indicated that E22K A $\beta_{1-42}$ fibrils contain slightly less $\beta$-sheet and more intrinsic disorder and turn contributions compared to WT fibrils (Table 3.2). Accordingly, E22K A $\beta_{1-42}$ fibrils demonstrated a higher HDX ratio than WT fibrils: $(50 \pm 5) \%$ of amide hydrogens were exchanged by deuterium compared to $(30 \pm 5) \%$ for WT fibrils, during a time lapse of $1 \mathrm{~h}$ (Table 3.2). The difference in total HDX between WT and mutant fibrils corresponds to the backbone of eight amino acids, but the specific region responsible for this difference cannot be derived from this dataset.

Table 3.2: Distinct HDX and secondary structure contributions for WT and E22K A $\beta_{1-42}$ fibrils*.

\begin{tabular}{|c|c|c|c|c|c|c|c|c|}
\hline & \multicolumn{4}{|l|}{ ATR-FTIR } & \multicolumn{4}{|c|}{ HDX-MS coupled to pepsin proteolysis } \\
\hline & $\begin{array}{l}\text { Secondar } \\
\text { structure }\end{array}$ & & $\begin{array}{l}\text { Exchanged } \\
\text { amide } \\
\text { protons (\%) }\end{array}$ & $\begin{array}{c}\beta \text {-index } \\
\text { ratio }\end{array}$ & $\begin{array}{c}\text { Pepsin- } \\
\text { induced A } \\
\text { fragments }\end{array}$ & $\begin{array}{c}\text { Exchanged } \\
\text { amide } \\
\text { protons }\end{array}$ & $\begin{array}{c}\text { Protected } \\
\text { NH/total }\end{array}$ & $\begin{array}{c}\text { Protected } \\
\text { NH/total } \\
(\%)\end{array}$ \\
\hline $\begin{array}{l}\text { WT } \\
\text { A } \beta_{1-42} \\
\text { fibrils }\end{array}$ & $\begin{array}{l}\beta \text {-sheet } \\
\alpha \text {-helix } \\
\text { Random coil } \\
\text { Turn }\end{array}$ & $\begin{array}{l}63 \\
11 \\
7 \\
79\end{array}$ & $30 \pm 5$ & 0.07 & $\begin{array}{l}{[1-19]} \\
{[20-42]} \\
{[35-42]}\end{array}$ & $\begin{array}{l}14.0 \pm 0.5 \\
7.3 \pm 0.7 \\
3.1 \pm 0.5\end{array}$ & $\begin{array}{c}4 / 18 \\
14.7 / 22 \\
3.9 / 7\end{array}$ & $\begin{array}{l}22 \\
67 \\
56\end{array}$ \\
\hline $\begin{array}{l}\text { E22K } \\
\text { A } \beta_{1-42} \\
\text { fibrils }\end{array}$ & $\begin{array}{l}\beta \text {-sheet } \\
\alpha \text {-helix } \\
\text { Random coil } \\
\text { Turn }\end{array}$ & $\begin{array}{r}58 \\
5 \\
5 \\
11 \\
26\end{array}$ & $50 \pm 5$ & 0.19 & $\begin{array}{l}{[1-19]} \\
{[20-42]} \\
{[35-42]}\end{array}$ & $\begin{array}{l}14.3 \pm 0.4 \\
9.6 \pm 0.8 \\
3.4 \pm 0.3\end{array}$ & $\begin{array}{c}3.7 / 18 \\
12.4 / 22 \\
3.6 / 7\end{array}$ & $\begin{array}{l}20 \\
56 \\
51\end{array}$ \\
\hline
\end{tabular}

* HDX was determined using ATR-FTIR (during a time lapse of $1 \mathrm{~h}$ ) and ESI-MS (during a time lapse of 45 min) coupled to pepsin proteolysis. Secondary structure contributions were estimated using ATR-FTIR. 
Additional segmental exchange information of fibrils was therefore revealed using HDX-MS coupled with pepsin proteolysis. We identified three proteolytic $A \beta$ fragments comprising residues [1-19], [20-42], and [35-42], covering the whole sequence of the peptide. The mass spectra of the N-terminal fragment [1-19] and C-terminal fragment [35-42] were similar for both WT and E22K fibrils after HDX, indicating no difference in deuterium incorporation in these regions within the time frame of the exchange. In contrast, the mass spectra for the fragment [20-42] showed that E22K A $\beta_{1-42}$ fibrils were more exchanged than WT fibrils in this region as the shift in the spectrum (to higher $\mathrm{m} / \mathrm{z}$ values), and thus the increase in mass after deuteration, was more pronounced (Fig. 3.3).

The number of deuterium molecules incorporated in each $\mathrm{A} \beta$ fragment was measured and data were corrected for back exchange. The corrected numbers of backbone amide protons exchanged after 45 min of incubation in $\mathrm{D}_{2} \mathrm{O}$ are summarized in table 3.2. For both WT and E22K A $\beta_{1-42}$, the N-terminal region [1-19] showed little protection (22\% and $20 \%$, respectively) in comparison to the $\mathrm{C}$-terminal region (67\% and $56 \%$, respectively) which is in agreement with the dot blotting results (Fig. S2) and data obtained by others using NMR $(18,49)$. The deuterium incorporation in regions [1-19] and [35-42] showed no significant difference between WT and E22K fibrils, as qualitatively observed on the mass spectra (Fig. 3.3). For peptide fragment [20-42], the solvent accessibility data resulted in (9.6 \pm 0.8$)$ total exchanged amide protons for E22K, which is significantly higher than the value obtained for the WT peptide: $(7.3 \pm 0.7)$. Assuming that there is no difference in labelling in peptide [3542], the difference in deuterium incorporation between WT and E22K A $\beta_{1-42}$ fibrils can thus be localized to the central region [20-34] of the peptide.
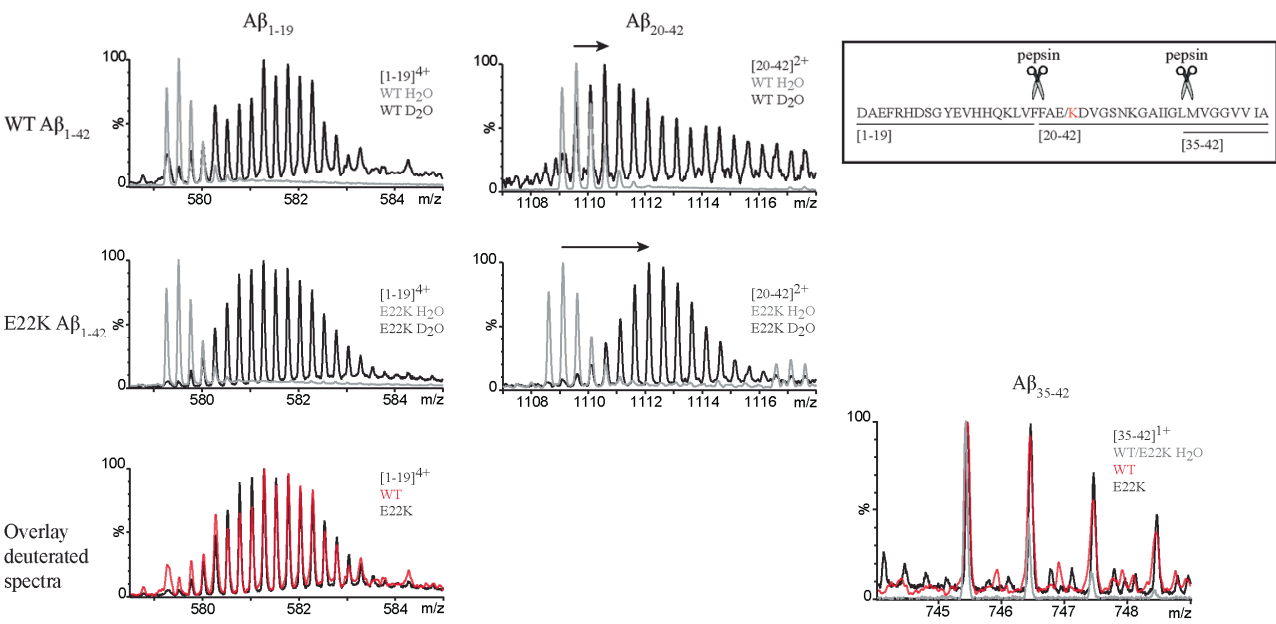

Figure 3.3: The central $A \beta$ region is more exposed in $E 22 K A \beta_{1-42}$ fibrils than in WT fibrils. Segmental HDX information of E22K and WT $A \beta_{1-42}$ fibrils was revealed by ESI-MS coupled with pepsin proteolysis. Mass spectra corresponding to E22K and WT $\mathrm{A} \beta_{1-42}$ fibrils are displayed before (grey) and after (black) deuteration for $45 \mathrm{~min}$. The charge state of each fragment is indicated in each panel. The mass spectra of the Nterminal fragment [1-19] and C-terminal fragment [35-42] were very similar after deuteration for both WT and E22K indicating no difference in deuterium incorporation in these regions. In contrast, the mass spectra for the fragment [20-42] showed more exchange for E22K compared to WT $\mathrm{A} \beta_{1-42}$, as seen by the more pronounced increase in mass after deuteration (indicated by arrows). 


\subsubsection{A change in $p H$ reveals different $\beta$-sheet conformations for $E 22 K A \beta_{1-42}$ fibrils}

The antiparallel $\beta$-sheet fibrils that have been recently reported for the Iowa $\mathrm{D} 23 \mathrm{~N}$ A $\beta_{1-40}$ peptide were suggested to be thermodynamically metastable (39). In contrast, Italian-mutant fibrils displayed a high $\beta$-index ratio up to at least one year of incubation under nearphysiological conditions (TBS pH 7.4) (Fig. S4).

To gain more insight into the interactions that play a role in antiparallel $\beta$-sheet formation, we studied the behaviour of E22K A $\beta_{1-42}$ under different experimental conditions. Aggregation of E22K A $\beta_{1-42}$ was therefore monitored at low $\mathrm{pH}\left(10 \mathrm{mM} \mathrm{HCl} \mathrm{pH} \mathrm{2.0)}\right.$ at $37^{\circ} \mathrm{C}$. It has been suggested that WT A $\beta$ fibrils are stabilized by a salt bridge between D23 and K28 $(14,18)$, whereas a salt bridge between K22 and D23 would be present in E22K A $\beta$ fibrils (68). These salt bridges would however not occur at low $\mathrm{pH}$ due to neutralization of the negative charge of the D23 side chain ( $\mathrm{pH}<\mathrm{pKa}$ of Glu/Asp), and this might elicit structural changes during the beginning of the aggregation process. Accordingly, ATR-FTIR analysis revealed a WTlike behaviour for the aggregation of the Italian mutant at $\mathrm{pH} 2.0$ with (i) the $\beta$-index ratio dropping significantly from $0.12 \pm 0.01$ to $0.06 \pm 0.02$, indicating a conversion from antiparallel oligomers to parallel fibrils (Fig. 3.4), (ii) a high reactivity of fibrils with ThT, and (iii) dense fibril networks as visualized by TEM (Fig. S5). Hence, the E22K A $\beta$ peptide evolves into the parallel $\beta$-sheet fibrillar state at low $\mathrm{pH}$, possibly due to alterations of electrostatic interactions.

Next, E22K antiparallel fibrils were grown at neutral pH (TBS pH 7.4) and $37^{\circ} \mathrm{C}$, and the fibril pellet (obtained after centrifugation for $30 \mathrm{~min}$ at $13200 \mathrm{rpm}$ ) was redissolved in $10 \mathrm{mM}$ $\mathrm{HCl} \mathrm{pH}$ 2.0. This $\mathrm{pH}$ jump lead to a significant and immediate drop in the $\beta$-index ratio from $0.21 \pm 0.01$ to $0.08 \pm 0.01$ reaching values corresponding to parallel $\beta$-structured fibrils, indicating that an antiparallel-to-parallel conversion occurred and demonstrating that the interconversion of fibrils polymorphs is energetically possible (Fig. 3.4).
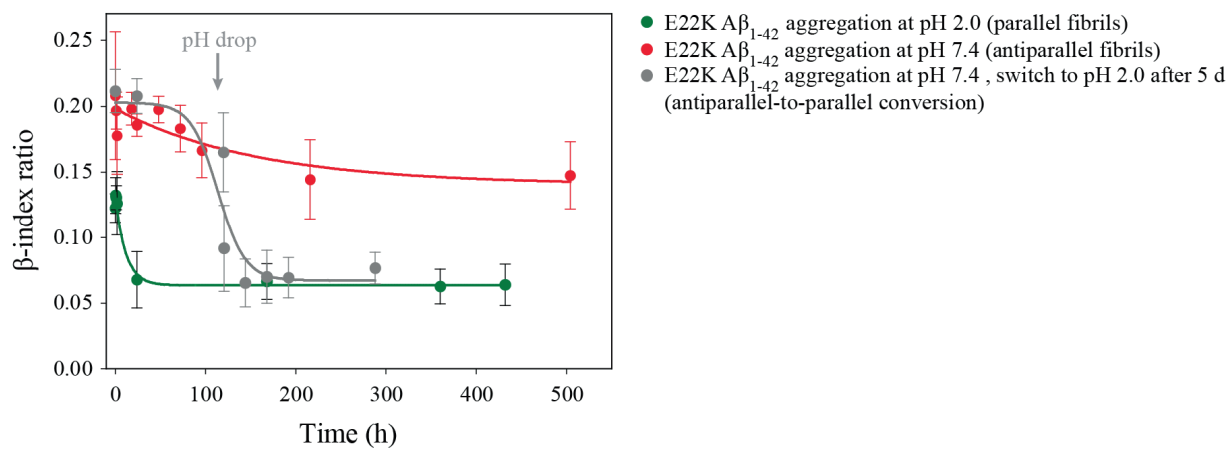

Figure 3.4: The underlying $\boldsymbol{\beta}$-sheet structure of Italian-mutant $\mathbf{A} \boldsymbol{\beta}_{1-42}$ fibrils is $\mathbf{p H}$ sensitive. $\beta$-index ratios of E22K A $\beta_{1-42}$ obtained during aggregation in TBS pH 7.4 (red curve) and in $10 \mathrm{mM} \mathrm{HCl} \mathrm{pH} 2.0$ (green curve) at $37{ }^{\circ} \mathrm{C}$ show that antiparallel $\beta$-sheet fibrils are formed at neutral $\mathrm{pH}$, while parallel fibrils are formed under acidic conditions. Moreover, fibrils grown at neutral $\mathrm{pH}$ undergo a structural change upon a shift to acidic $\mathrm{pH}$ (antiparallel-to-parallel transition) as seen by the significant drop in $\beta$-index ratio (grey curve). $\beta$-index ratios are representative of at least three independent experiments. 


\subsubsection{WT and E22K $A \beta_{1-42}$ fibrils elicit different inflammatory responses in $T H P-1$ monocytes}

As the antiparallel $\beta$-sheet orientation has been suggested to represent a toxic signature responsible for the impairment of cellular processes, we tested the toxicity of WT and E22K $\mathrm{A} \beta_{1-42}$ fibrils in vitro in different cell lines using a range of cell toxicity readouts. We expected the antiparallel Italian-mutant fibrils formed in vitro to be more toxic to cells compared to parallel WT fibrils. Unfortunately, the outcome of these assays was not conclusive as reproducibility problems occurred and internal controls raised doubts on the significance of the results (data not shown). This may be related to batch-to-batch purity differences of the peptide manufacturer or cell-related issues (e.g. increase in resistance of cells to $A \beta$ toxicity with higher cell passage numbers, problem of $A \beta$ peptide uptake).

The biological significance of both fibril types was therefore approached from a different angle. Amyloid plaques have been associated with inflammatory responses in the brain, and inflammation is considered an important pathological hallmark of AD. Fibrils have been shown to initiate inflammation in brain tissues and in cell culture, and induce secretion of proinflammatory cytokines (69). Therefore, the immune response to both fibril types was measured in THP-1 cells, a human leukemia monocytic cell line resembling primary monocytes in morphological and differentiation properties and widely used as a model to study innate immunity (70). Gene expression of inflammation-related cytokines, enzymes, and transcription factors, was investigated using RT-qPCR.

Exposure of THP-1 monocytes to a concentration range of WT and E22K A $\beta_{1-42}$ fibrils $(0.1$ to $10 \mu \mathrm{M}$ final $\mathrm{A} \beta$ concentration) for $3 \mathrm{~h}$ at $37^{\circ} \mathrm{C}$ resulted in a dose-dependent immune response to both fibril types with a stronger response in general to WT fibrils for several immune markers (Fig. 3.5). An $\mathrm{A} \beta$ concentration of $10 \mu \mathrm{M}$ markedly induced mRNA expression of IL-1 $\beta$ and IL-8. Other expressed markers included TNF $\alpha$, IL-6, IL-12p40, and very minor expression of IL-10 and COX-2. In contrast, an A $\beta$ concentration of $0.1 \mu \mathrm{M}$ was too low to induce mRNA expression of the studied target genes.

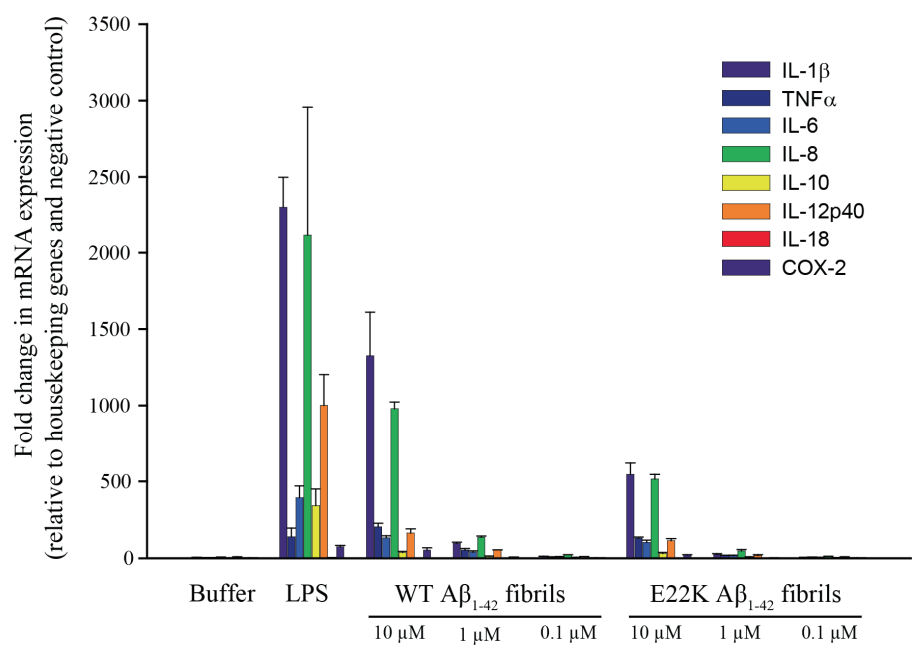

Figure 3.5: Immune response of THP-1 monocytes upon exposure to WT and E22K A $\beta_{1-42}$ fibrils. Dosedependent increase of mRNA expression of several pro-inflammatory molecules (relative to housekeeping genes and negative control) after $3 \mathrm{~h}$ of incubation of THP-1 monocytes with A $\beta$ fibril samples. 


\section{$\underline{\text { 3.4. Discussion }}$}

\section{Antiparallel $\beta$-sheet structure: a key organization in amyloid aggregates?}

The impact of antiparallel $\beta$-sheet structure in the amyloid field is still under debate, but evidence emerges that this structural signature can be attributed to several toxic intermediates or off-pathway aggregates of the amyloid formation pathway. Streltsov and co-workers reported the first crystal structure of oligomers of the $\mathrm{p} 3$ fragment, the N-terminally truncated $A \beta$ variant, and provided evidence for their antiparallel arrangement (71). Later, the research team of Eisenberg revealed the structure of an off-pathway, cylindrical oligomer of a segment of the amyloid-forming protein $\alpha \mathrm{B}$ crystallin, that resembled a $\beta$-barrel composed of six antiparallel $\beta$-strands (72). We and other groups demonstrated that amyloidogenic proteins, such as $A \beta$, pass through an antiparallel $\beta$-sheet structured state, corresponding to oligomers, before undergoing a transition in structure to parallel $\beta$-sheet fibrils $(58-60,73-75)$. Recently, the group of Tycko demonstrated that $A \beta_{1-40}$, containing the FAD-linked Iowa D23N mutation and causing CAA, assembled into antiparallel $\beta$-sheet structured fibrils that were thermodynamically metastable and had a ribbon-like appearance (39). As these aggregates were all described to be transient and toxic, the antiparallel $\beta$-sheet arrangement has been suggested to represent a unique toxic signature (61).

In this study, we report that an antiparallel $\beta$-sheet signature is shared by oligomers and fibrils comprising the Italian E22K A $\beta_{1-42}$ peptide (Fig. 3.1 and 3.2). The antiparallel $\beta$-sheet fibrils are formed spontaneously under near-physiological conditions and still display a high $\beta$-index ratio after one year of incubation (Fig. S4). The Italian-mutant $A \beta$ peptide can thus potentially provide a major source of neurotoxicity, either in the form of soluble and diffusible oligomers that are considered the main toxic agents in $\mathrm{AD}$ (76-79), or in its fibrillar form as a trigger of neuroinflammation (69). One may speculate that its unique structural signature may be linked to the early-onset and aggressive progression of the associated FAD. Accordingly, the Italian A $\beta$ mutant shows increased pathogenicity compared to the WT A $\beta$ peptide and is up to tenfold more toxic to cerebrovascular smooth muscle cells and PC12 cells in vitro (80-82), supporting its role in CAA.

\section{The Italian A $\beta$ mutant can form antiparallel and parallel $\beta$-sheet fibrils}

Amyloid fibrils share the cross- $\beta$ spine motif, but their quaternary arrangement can differ due to distinct nonpolar interactions, i.e. Van der Waals forces and aromatic packing, and polar interactions, i.e. electrostatic and H-bonding interactions. It is conceivable that substitution of a glutamic acid to a lysine at position 22 within the $A \beta$ sequence may profoundly affect the pattern of interactions that determines its fibrillar structure. The residue at position 22 is part of the central $A \beta$ region that poses the critical limiting step leading to the formation of the $\beta$ hairpin, the ordered $\beta$-turn- $\beta$-structural organization characteristic of $A \beta$ monomers within the fibril $(81,83,84)$. Based on solid state NMR data, Masuda and co-workers suggested previously that intermolecular $\beta$-sheet contacts in E22K A $\beta_{1-42}$ fibrils are key events driven by this turn region $(68,85)$.

The resulted obtained at $\mathrm{pH} 7.4$ in this study give more insight into the possible effects of a charge alteration in this central $A \beta$ region on fibril structure. First, we demonstrate that the E22K mutation results in differences in IR spectra and intrinsic fluorescence lifetimes (Fig. 3.1 and 3.2), that reflect distinct $\mathrm{H}$-bonding organizations of $\mathrm{WT}$ and $\mathrm{E} 22 \mathrm{~K} \mathrm{~A} \beta_{1-42}$ fibrils, i.e. parallel and antiparallel $\beta$-sheet arrangements, respectively. Second, the E22K mutation most likely induces changes in the pattern of stabilizing electrostatic interactions, as it can interfere 
with salt bridges that have been suggested to occur within the monomeric unit of the fibrillar structure, e.g. between D23 and K28 $(14,18)$, but potentially also between K16 and E22 (14), and E22 and K28 (86). Differences in electrostatic interactions could underlie the structural alterations demonstrated for E22K fibrils at different $\mathrm{pH}$ values (Fig. 3.4). Third, the E22K mutation may potentially influence conserved hydrophobic contacts within the monomer unit composing the fibril, e.g. between F19 and G38 (87), or affect the interdigitation of $\beta$-sheets that is responsible for the steric zipper interface underlying the cross- $\beta$ spine structure (1). The steric hindrance induced by the large side chain of K22 may result in changes in the exposure of side chains to the outer fibril surface and contribute to packing polymorphism. Accordingly, the E22K mutation induced changes in solvent accessibility around the central region, as assessed by HDX measurements (Table 3.2, Fig. 3.3).

Furthermore, we provide evidence that structural alterations occur for E22K A $\beta$ fibrils under different environmental growing conditions. At neutral $\mathrm{pH}$, the antiparallel $\beta$-sheet fibrillar structure is favoured. In contrast, the $\mathrm{E} 22 \mathrm{~K} \mathrm{~A} \beta_{1-42}$ peptide forms fibrils with a parallel $\beta$-sheet arrangement at low pH (Fig. 3.4 and S5). To the best of our knowledge, this is the first experimental demonstration that a mutated form of the full-length $\mathrm{A} \beta$ peptide can form amyloid fibrils with two different $\beta$-sheet structures in a $\mathrm{pH}$-dependent manner. This structural diversity might be due to neutralization of charges of amino acid side chains involved in key fibril contacts, as mentioned in the previous paragraph. Moreover, our results show interconversion of antiparallel-to-parallel $\beta$-sheet Italian-mutant fibrils when changing from neutral to acidic $\mathrm{pH}$ conditions. Recently, Tycko and co-workers demonstrated the evolution of a mixture of two fibril polymorphs of WT A $\beta_{1-40}$ to the thermodynamically most stable polymorph (88). It remains to be discovered whether the interconversion of Italianmutant fibril polymorphs demonstrated in this work is due to internal structural rearrangement, or whether the antiparallel $\beta$-sheet fibrils are destabilized upon a decrease in $\mathrm{pH}$ and are rebuilt in a parallel $\beta$-sheet arrangement.

A detailed molecular understanding of the intermolecular interactions that dictate the quaternary structure of Italian-mutant $\mathrm{A} \beta$ is still lacking, but the results presented here suggest that differences in the $\mathrm{H}$-bonding pattern, electrostatic interactions, and balance of multiple side chain contacts may underlie fibril polymorphism for this $\mathrm{A} \beta$ mutant.

\section{Pathophysiological relevance of different $\beta$-sheet architectures}

Recently, it has been suggested that $\mathrm{A} \beta$ fibril polymorphism may have biological significance. Fibril polymorphism could underlie in vitro differences in neurotoxicity or in vivo differences in disease pathology and progression in different individuals/cell types and/or types of amyloidosis (i.e. tropism) (14-24). Recently, the first detailed look at the architecture of amyloid fibrils from patient brains demonstrated that two AD patients with distinct clinical histories possessed $A \beta$ fibrils with a different underlying structure (17). Moreover, Prusiner and co-workers showed that mice inoculated with brain homogenates from an Arctic AD case exhibited a pathology that could be distinguished from mice inoculated with Swedish or sporadic $\mathrm{AD}$ samples, as seen by differential accumulation of $\mathrm{A} \beta$ isoforms and distinct morphology of cerebrovascular $A \beta$ deposition (89). It now becomes clear that mutations in the central $A \beta$ region that are linked to CAA, including the Iowa D23N (39) and the Italian E22K mutation, result in the formation of fibrils with an antiparallel $\beta$-sheet structure. We suggest that this unique structural signature might predispose these $A \beta$ mutants to deposit in cerebral blood vessels, rather than mainly accumulating in plaques, as seen for the WT A $\beta$ peptide. 
It remains to be solved how these in vitro observations of structural differences can translate into differences in vivo, but one possibility is through distinct interactions with receptors responsible for $\mathrm{A} \beta$ clearance across the BBB (Fig. 3.6). Two receptors have been demonstrated to regulate the transport of the $A \beta$ peptide across the BBB. The RAGE receptor is thought to be a major transporter of $A \beta$ from the blood circulation into the brain, whereas LRP-1 mediates $A \beta$ efflux $(90,91)$. Both receptors are responsible for binding and internalization of a broad spectrum of structurally unrelated ligands $(92,93)$. They are important for the regulation of $A \beta$ levels in the brain and in the circulating $A \beta$ pool, and are genetically related to FAD and late-onset AD (91, 94-97). Differences between E22K and WT $A \beta_{1-42}$ in $\beta$-organization of the subunits in fibrils may result in differences in receptor interactions and associated BBB passage, with $\mathrm{E} 22 \mathrm{~K} \mathrm{~A} \beta$ being more efficiently transported to the blood periphery. This would explain the relation of the Italian $A \beta$ mutant to CAA, although these suggestions require experimental investigation.
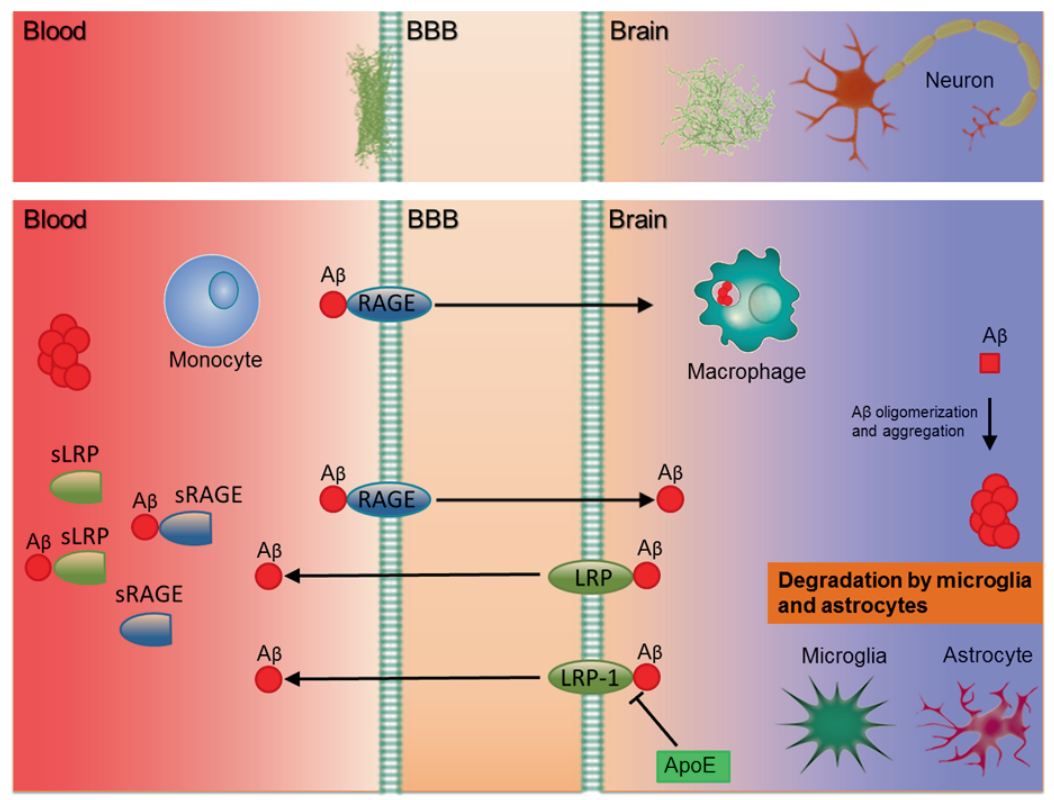

Figure 3.6: Pathophysiological relevance of different $\boldsymbol{\beta}$-sheet architectures. RAGE receptor and LRP, two membrane proteins, have been demonstrated to regulate the transport of $\mathrm{A} \beta$ through the $\mathrm{BBB}$. They are important in the regulation of $A \beta$ levels in the brain and in the circulating $A \beta$ pool, and are therefore relevant in the context of FAD and AD. First, the RAGE receptor is thought to be a major transporter of A $\beta$ influx from the blood circulation into the brain and has been related to processes such as inflammation, monocyte migration through the BBB, proliferation, apoptosis, and autophagy. Second, LRP mediates the efflux of soluble A $\beta$, or A $\beta$ complexed with ApoE. The systemic clearance of $A \beta$ in the blood circulation is directed by soluble LRP (sLRP) and soluble RAGE (sRAGE). Distinct interactions of parallel and antiparallel $\beta$-sheet arrangements with receptors at the $\mathrm{BBB}$ may be associated with the difference in pathophysiology between late-onset $\mathrm{AD}$ and CAA-associated FAD.

Moreover, RAGE receptor and LRP-1 are implicated in the innate immune system, and promote the secretion of pro-inflammatory cytokines (90). The extent to which the immune system is involved in the pathogenesis of neurodegenerative diseases such as AD is not yet clear, but aggregate deposits induce chronic inflammatory reactions (69, 98-102). 
Inflammatory cascades in AD and FAD are known to trigger different cell dysfunctions and pathogenic processes $(99,100,103)$. Accordingly, we revealed differences in the inflammatory response of THP-1 monocytes to WT and E22K A $\beta_{1-42}$ fibrils (Fig. 3.5). Distinct interactions of $\beta$-sheet arrangements with these receptors may thus also be associated with the difference in pathophysiology between late-onset $\mathrm{AD}$ and CAA-associated FAD. However, the results in fig. 3.5 are preliminary, and future experiments are required to establish a full inflammatory profile for both fibril types and understand which signalling pathways and cascades are affected. Furthermore, these experiments should be extended to include other cell types, such as microglia and astrocytes, as they are abundant in the brain and play important roles in neuroinflammation (104-106).

In conclusion, the Italian-mutant $A \beta$ peptide forms oligomers and fibrils in vitro that share the antiparallel $\beta$-sheet organization. Our results are particularly interesting in light of the ongoing debate that suggests that the antiparallel $\beta$-sheet structure might provide the potential detrimental toxic effect of $\mathrm{A} \beta$. Moreover, this is the first study that experimentally demonstrates structural plasticity for $\mathrm{E} 22 \mathrm{~K} \mathrm{~A} \beta$ fibrils. The structural differences and different inflammation profiles of WT and E22K A $\beta$ fibrils occurring in vitro might be implicated in their in vivo differences: WT and E22K A $\beta$ deposition in extracellular plaques and cerebral blood vessel walls, respectively, and associated with late- and early-onset $\mathrm{AD}$, respectively. 


\subsection{Supplementary information}

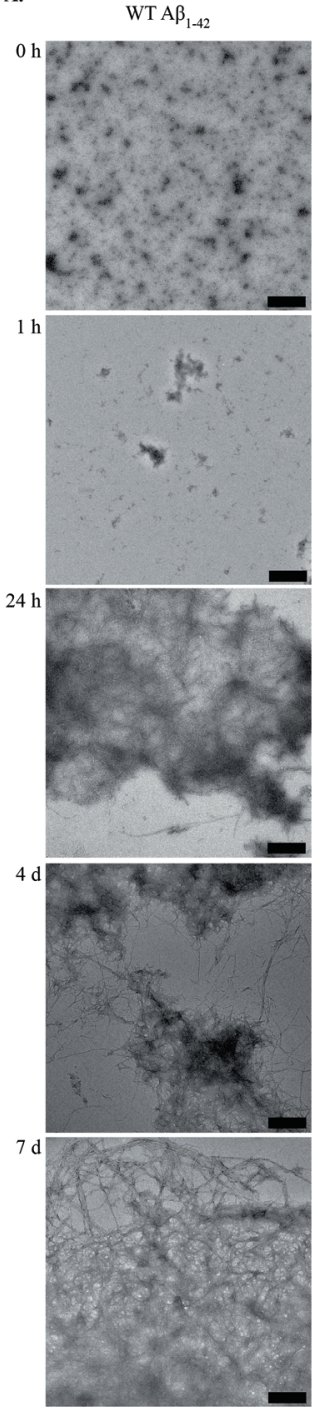

$\mathrm{E} 22 \mathrm{~K} \mathrm{~A} \beta_{1-42}$
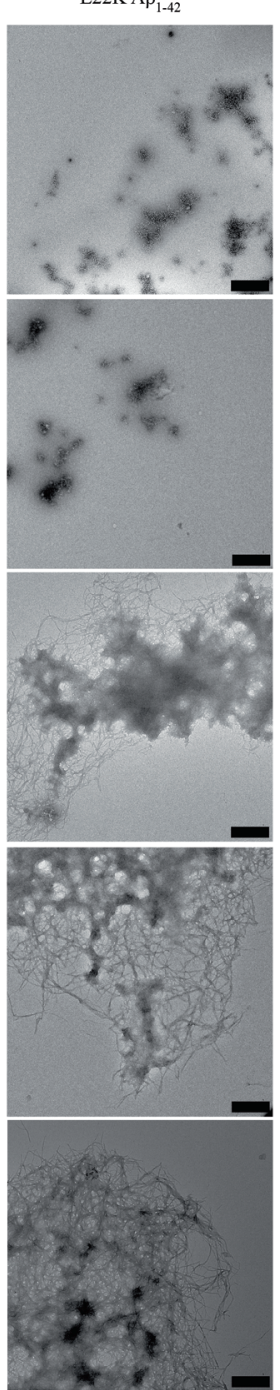

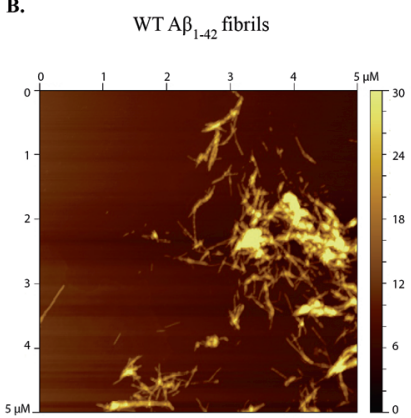

$\mathrm{E} 22 \mathrm{~K} \mathrm{~A} \beta_{1-42}$ fibrils

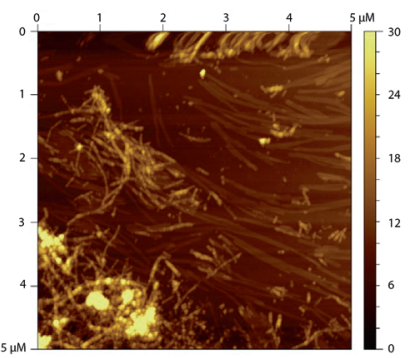

Figure S1: WT and E22K A $\boldsymbol{\beta}_{1-42}$ fibrils display similar morphologies. (A) The aggregation of WT and E22K $\mathrm{A} \beta_{1-42}$ at $37{ }^{\circ} \mathrm{C}$ was monitored using TEM. At early $\mathrm{A} \beta$ aggregation time points only spherical oligomeric and small thread-like prefibrillar species were detected for both peptides. WT and E22K A $\beta_{1-42}$ then evolved into dense fibril networks. Scale bars represent $500 \mathrm{~nm}$. (B) AFM characterization of both fibril types after $7 \mathrm{~d}$ of incubation at $37{ }^{\circ} \mathrm{C}$. Overall, WT $\mathrm{A} \beta_{1-42}$ fibrils appear to be slightly more twisted compared to $\mathrm{E} 22 \mathrm{~K} \mathrm{~A} \beta_{1-42}$ fibrils. 


$\frac{1}{\mathrm{D}-\mathrm{A}-\mathrm{E}-\mathrm{F}-\mathrm{R}-\mathrm{H}-\mathrm{D}-\mathrm{S}-\mathrm{G}-\mathrm{Y}-\mathrm{E}-\mathrm{V}-\mathrm{H}-\mathrm{H}-\mathrm{Q}-\mathrm{K}-\mathrm{L}-\mathrm{V}-\mathrm{F}-\mathrm{F}-\mathrm{A}-\mathrm{E} / \mathrm{K}-\mathrm{D}-\mathrm{V}-\mathrm{G}-\mathrm{S}-\mathrm{N}-\mathrm{K}-\mathrm{G}-\mathrm{A}-\mathrm{I}-\mathrm{I}-\mathrm{G}-\mathrm{L}-\mathrm{M}-\mathrm{V}-\mathrm{G}-\mathrm{G}-\mathrm{V}-\mathrm{V}-\mathrm{I}-\mathrm{A}} \frac{42}{4 \mathrm{G} 8}$
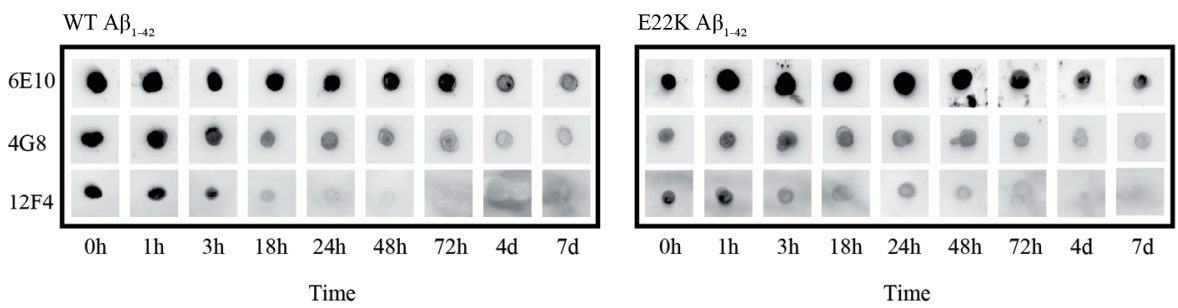

Figure S2: The A $\beta$ peptide $C$-terminus becomes inaccessible for antibody detection upon fibril formation. Aggregation of WT and E22K A $\beta_{1-42}$ at $37{ }^{\circ} \mathrm{C}$ was monitored using dot blotting with three $\mathrm{A} \beta$ region-specific monoclonal antibodies $(6 \mathrm{E} 10,4 \mathrm{G} 8,12 \mathrm{~F} 4)$. Detection with region-specific antibodies was comparable for both peptides, with the $\mathrm{C}$-terminus of the $\mathrm{A} \beta$ peptide becoming inaccessible upon fibril formation.

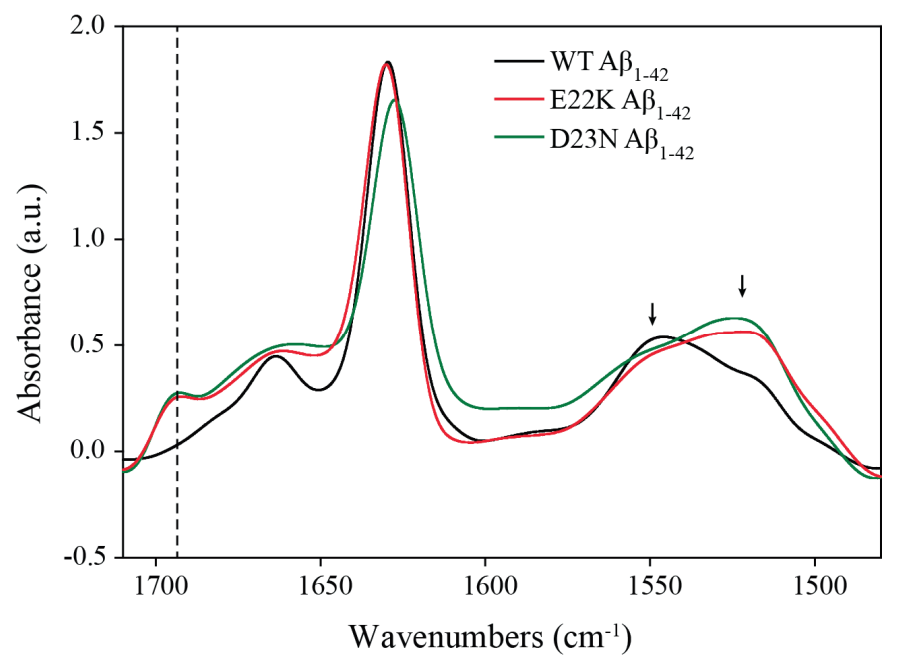

Figure S3: ATR-FTIR analysis confirms that the Iowa D23N A $\beta_{1-42}$ mutant forms antiparallel $\beta$-sheet fibrils. WT, E22K, and D23N A $\beta_{1-42}$ fibrils (depicted in black, red, and green, respectively) were structurally characterized after $7 \mathrm{~d}$ of incubation in TBS pH 7.4 at $37{ }^{\circ} \mathrm{C}$. Fibrils were harvested by centrifugation $(30 \mathrm{~min}$ at $13200 \mathrm{rpm}$ ) prior to IR measurements. E22K and D23N fibrils displayed an additional peak around $1695 \mathrm{~cm}^{-1}$ (vertical dashed line) and a shift in the amide II band to lower wavenumbers (as depicted by arrows), indicative of an underlying antiparallel $\beta$-sheet architecture. In contrast, WT fibrils were marked by a parallel orientation of $\beta$-sheets. Spectral intensities were normalized to the intensity of the major contribution of $\beta$-structure around $1630 \mathrm{~cm}^{-1}$. Spectra depicted here were deconvolved using a Lorentzian deconvolution factor with a FWHH of 20 $\mathrm{cm}^{-1}$ and a Gaussian apodization factor with a FWHH of $16.67 \mathrm{~cm}^{-1}$, to obtain a resolution enhancement factor $\mathrm{K}=1.2$. 
A. WT $\mathrm{A} \beta_{1-42}$
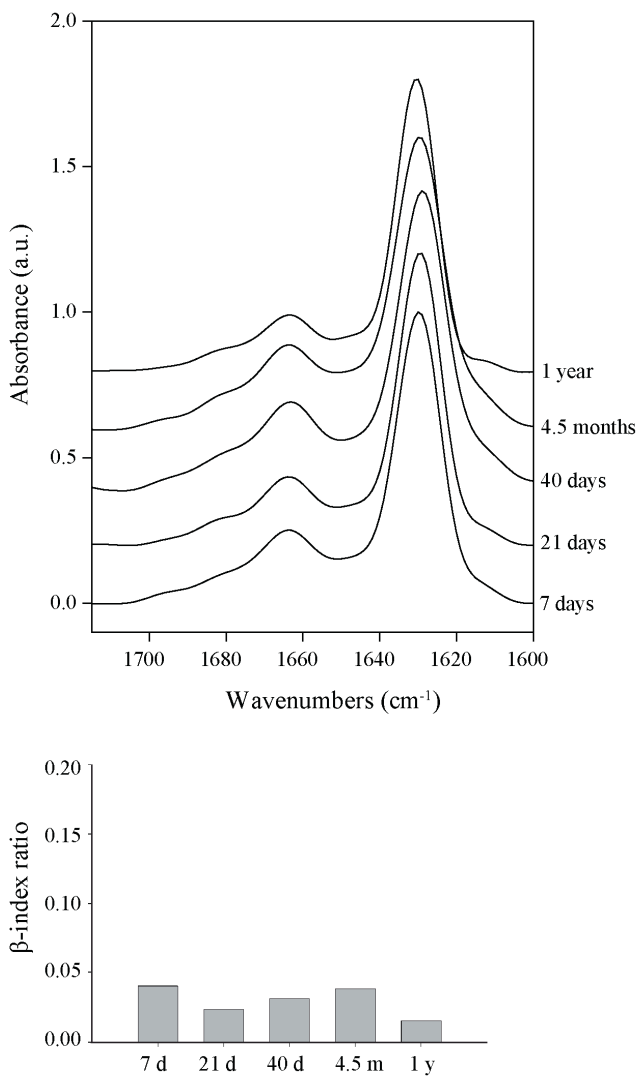

B. $\mathrm{E} 22 \mathrm{~K} \mathrm{~A} \beta_{1-42}$
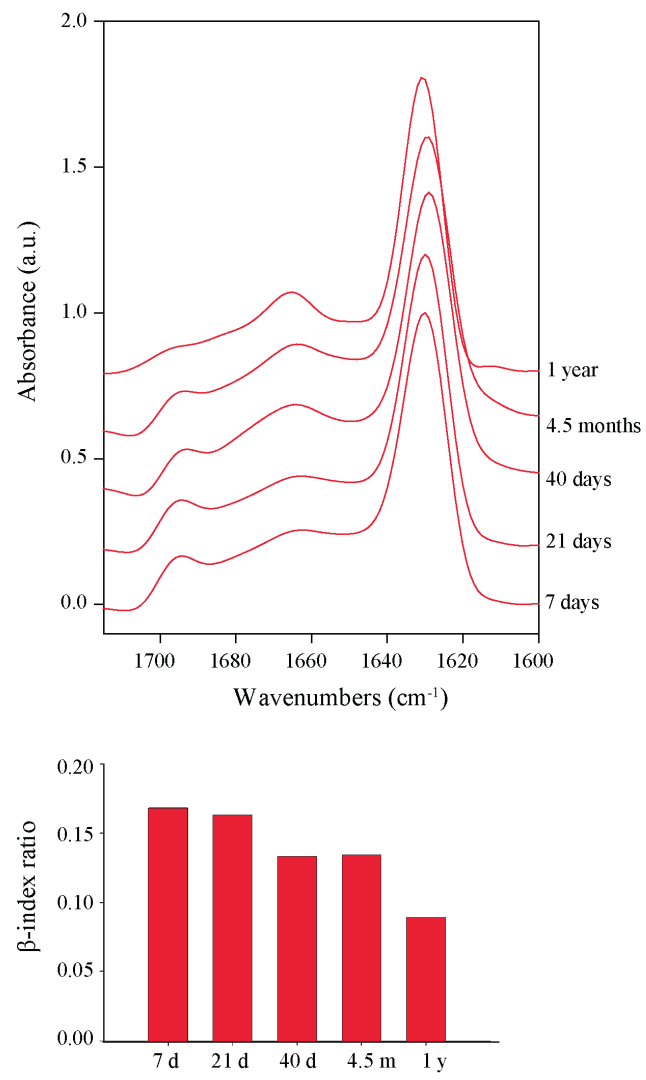

Figure S4: Evolution of $\boldsymbol{\beta}$-index ratios of $\mathrm{WT}$ and $\mathbf{E 2 2 K} \mathbf{A} \boldsymbol{\beta}_{1-42}$ fibrils. The structural properties of (A) WT and (B) E22K A $\beta_{1-42}$ fibrils were monitored using ATR-FTIR during 1 year. Spectral intensities were normalized to the intensity of the major contribution of $\beta$-structure around $1630 \mathrm{~cm}^{-1}$. Spectra were vertically offset for better visualization. Spectra depicted here were deconvolved using a Lorentzian deconvolution factor with a FWHH of $20 \mathrm{~cm}^{-1}$ and a Gaussian apodization factor with a FWHH of $16.67 \mathrm{~cm}^{-1}$, to obtain a resolution enhancement factor $\mathrm{K}=1.2$. The $\beta$-index ratio $\left(1695 / 1630 \mathrm{~cm}^{-1}\right.$ intensity ratio) was calculated on the basis of non-deconvolved ATR-FTIR spectra. 
A.

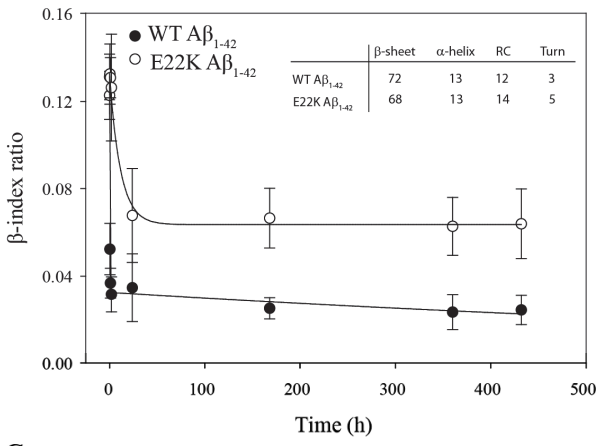

B.

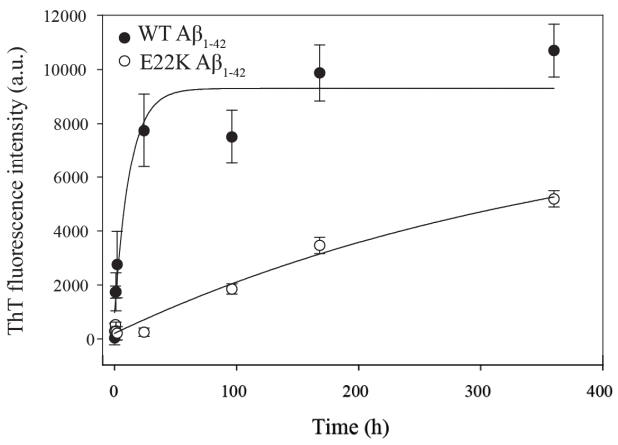

WT A $\beta_{1-42}$ fibrils in $10 \mathrm{mM} \mathrm{HCl} \mathrm{pH} 2.0$

$\mathrm{E} 22 \mathrm{~K} \mathrm{~A} \beta_{1-42}$ fibrils in $10 \mathrm{mM} \mathrm{HCl} \mathrm{pH} 2.0$
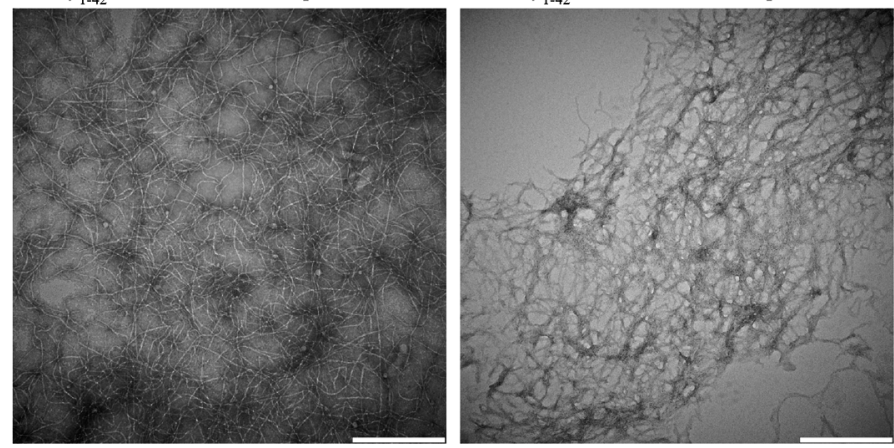

Figure S5: Aggregation of WT and E22K A $\boldsymbol{\beta}_{1-42}$ under acidic conditions. Aggregation of WT and E22K $\mathrm{A} \beta_{1-42}$ peptide was carried out in $10 \mathrm{mM} \mathrm{HCl} \mathrm{pH} 2.0$ at $37{ }^{\circ} \mathrm{C}$. (A) ATR-FTIR spectra were deconvolved using a Lorentzian deconvolution factor with a FWHH of $20 \mathrm{~cm}^{-1}$ and a Gaussian apodization factor with a FWHH of $16.67 \mathrm{~cm}^{-1}$, to obtain a resolution enhancement factor $\mathrm{K}=1.2$. The $\beta$-index ratio $\left(1695 / 1630 \mathrm{~cm}^{-1}\right.$ intensity ratio) was calculated on the basis of non-deconvolved ATR-FTIR spectra and $\beta$-index ratio values are representative of at least three independent experiments. (Inset) Secondary structure estimations based on ATR-FTIR analysis. (B) ThT fluorescence emission was measured during aggregation at $485 \mathrm{~nm}\left(\lambda_{\mathrm{ex}}=450 \mathrm{~nm}\right)$. Intensities were corrected for the ThT fluorescence background. Means and error bars have been calculated on basis of three independent experiments. (C) TEM revealed dense networks of negatively stained fibrils for both peptides. Scale bars represent $500 \mathrm{~nm}$. 


\section{Assessment of endotoxin levels of $A \beta$ peptide samples}

Prior to testing the inflammatory properties of $A \beta$ peptides, it was necessary to ensure samples were endotoxin-free, as endotoxin traces would interfere with the immune response assay. The EndoZyme ${ }^{\circledR}$ recombinant Factor $\mathrm{C}$ assay (Hyglos $\mathrm{GmbH}$, Germany) was used to quantify the LPS level of peptide samples. This assay is based on LPS-induced activation of recombinant Factor C, the LPS receptor of the blood clotting cascade of horseshoe crab. Addition of a fluorogenic substrate to the assay mix results in substrate cleavage by activated Factor $\mathrm{C}$ and an increase in fluorescence. LPS levels are expressed in EU units, with $1 \mathrm{EU}$ equalling approximately $100 \mathrm{pg} / \mathrm{ml}$ of LPS. In short, a serial dilution of LPS standards $(0.005$ $\mathrm{EU} / \mathrm{ml}$ to $5 \mathrm{EU} / \mathrm{ml}$ ) and $50 \mu \mathrm{M}$ solutions of monomeric WT and $\mathrm{E} 22 \mathrm{~K}$ A $\beta_{1-42}$ peptides were tested in duplicates in endotoxin-free water in a 96-well plate (100 $\mu \mathrm{l}$ sample/well). Subsequently, $100 \mu \mathrm{l}$ assay reagent (containing recombinant Factor $\mathrm{C}$ and the fluorogenic substrate) was added to each well, and the fluorescent signal was measured at the beginning of the incubation and after $90 \mathrm{~min}$ of incubation at $37^{\circ} \mathrm{C}$, using a FLUOstar Omega plate reader (BMG Labtech, Ortenberg, Germany). The excitation and emission wavelengths were set at 380 and $440 \mathrm{~nm}$, respectively, with bandwidths of 9 and $20 \mathrm{~nm}$, respectively. Plotting of the standard LPS curve (Fig. S6), and subsequent linear regression, allowed for the calculation of the endotoxin levels of both peptides (Equation S1). LPS levels of WT and $\mathrm{E} 22 \mathrm{~K} \mathrm{~A} \beta_{1-42}$ peptides equalled $0.003 \mathrm{EU} / \mathrm{ml}$ and $0.001 \mathrm{EU} / \mathrm{ml}$, respectively, and were lower than the permitted threshold for usage in an immune response assay.

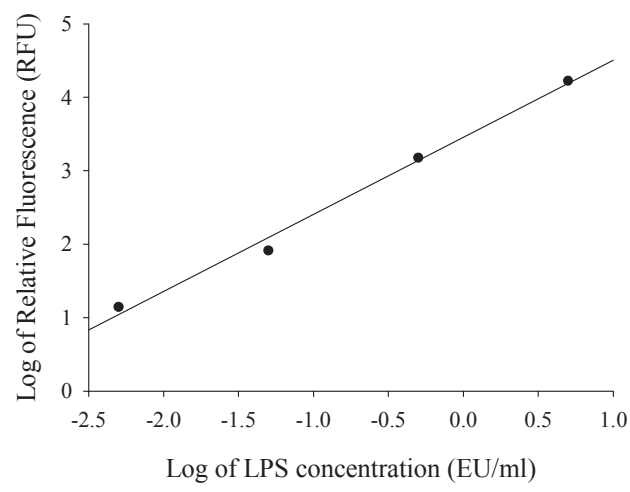

Figure S6: Standard curve of the EndoZyme® assay. LPS standard concentrations are plotted against their corresponding relative fluorescence signal. The logarithm of the fluorescence signal is proportional to the logarithm of the endotoxin concentration, and is linear in the 0.005-50 EU/ml range.

$$
\log (\mathrm{EU} / \mathrm{ml})=0.8593 \times \log (\mathrm{RFU})+3.4948
$$

with RFU $=$ Fluorescence averaged, $t=90 \min$ - Fluorescence averaged, $t=0$ min

$$
\begin{gathered}
\log (\mathrm{RFU})=\frac{\log \left(\frac{\mathrm{EU}}{\mathrm{ml}}\right)-3.4948}{0.8593} \\
\operatorname{RFU}=10 \frac{\left(\log \frac{(\mathrm{EU})}{\mathrm{mI}}\right)-3.4948}{0.8593} \text { (Eq. S1) }
\end{gathered}
$$




\subsection{References}

1. Eisenberg D \& Jucker M (2012) The amyloid state of proteins in human diseases. Cell 148(6):1188-1203.

2. Chiti F \& Dobson CM (2006) Protein misfolding, functional amyloid, and human disease. Annu Rev Biochem 75:333-366.

3. Greenwald J \& Riek R (2010) Biology of amyloid: structure, function, and regulation. Structure 18(10):1244-1260.

4. Nelson R, et al. (2005) Structure of the cross- $\beta$ spine of amyloid-like fibrils. Nature 435(7043):773-778.

5. Härd T (2014) Amyloid Fibrils: Formation, Polymorphism, and Inhibition. J Phys Chem Lett 5(3):607-614.

6. Tycko R \& Wickner RB (2013) Molecular Structures of Amyloid and Prion Fibrils: Consensus versus Controversy. Acc Chem Res 46(7):1487-1496.

7. Goldsbury CS, Frey P, Olivieri V, Aebi U, \& Müller SA (2005) Multiple assembly pathways underlie amyloid- $\beta$ fibril polymorphisms. $J$ Mol Biol 352(2):282-298.

8. Petkova AT, et al. (2002) A structural model for Alzheimer's $\beta$-amyloid fibrils based on experimental constraints from solid state NMR. Proc Natl Acad Sci U S A 99(26):1674216747.

9. Petkova AT, Yau WM, \& Tycko R (2006) Experimental constraints on quaternary structure in Alzheimer's $\beta$-amyloid fibrils. Biochemistry 45(2):498-512.

10. Zhang R, et al. (2009) Interprotofilament interactions between Alzheimer's Aß1-42 peptides in amyloid fibrils revealed by cryoEM. Proc Natl Acad Sci U S A 106(12):4653-4658.

11. Sachse C, Fändrich M, \& Grigorieff N (2008) Paired $\beta$-sheet structure of an A $\beta(1-40)$ amyloid fibril revealed by electron microscopy. Proc Natl Acad Sci U S A 105(21):7462-7466.

12. Jeong JS, Ansaloni A, Mezzenga R, Lashuel HA, \& Dietler G (2013) Novel mechanistic insight into the molecular basis of amyloid polymorphism and secondary nucleation during amyloid formation. $J$ Mol Biol 425(10):1765-1781.

13. Paravastu AK, Leapman RD, Yau WM, \& Tycko R (2008) Molecular structural basis for polymorphism in Alzheimer's $\beta$-amyloid fibrils. Proc Natl Acad Sci U S A 105(47):1834918354.

14. Petkova AT, et al. (2005) Self-propagating, molecular-level polymorphism in Alzheimer's $\beta$ amyloid fibrils. Science 307(5707):262-265.

15. Bousset L, et al. (2013) Structural and functional characterization of two alpha-synuclein strains. Nat Commun 4:2575.

16. Guo JL, et al. (2013) Distinct $\alpha$-synuclein strains differentially promote tau inclusions in neurons. Cell 154(1):103-117.

17. Lu JX, et al. (2013) Molecular Structure of $\beta$-Amyloid Fibrils in Alzheimer's Disease Brain Tissue. Cell 154(6):1257-1268.

18. Luhrs T, et al. (2005) 3D structure of Alzheimer's amyloid-ß(1-42) fibrils. Proc Natl Acad Sci US A 102(48):17342-17347.

19. Mocanu MM, et al. (2014) Polymorphism of hen egg white lysozyme amyloid fibrils influences the cytotoxicity in LLC-PK1 epithelial kidney cells. Int J Biol Macromol 65:176187.

20. Nekooki-Machida Y, et al. (2009) Distinct conformations of in vitro and in vivo amyloids of huntingtin-exon1 show different cytotoxicity. Proc Natl Acad Sci U S A 106(24):9679-9684.

21. Gath J, et al. (2014) Unlike twins: an NMR comparison of two $\alpha$-synuclein polymorphs featuring different toxicity. PLoS One 9(3):e90659.

22. Fukunaga S, et al. (2012) GM1 cluster mediates formation of toxic A $\beta$ fibrils by providing hydrophobic environments. Biochemistry 51(41):8125-8131.

23. Seilheimer B, et al. (1997) The toxicity of the Alzheimer's $\beta$-amyloid peptide correlates with a distinct fiber morphology. J Struct Biol 119(1):59-71.

24. Bergström J, et al. (2005) Amyloid deposits in transthyretin-derived amyloidosis: cleaved transthyretin is associated with distinct amyloid morphology. J Pathol 206(2):224-232. 
25. Fändrich M, Schmidt M, \& Grigorieff N (2011) Recent progress in understanding Alzheimer's $\beta$-amyloid structures. Trends Biochem Sci 36(6):338-345.

26. Glenner GG \& Wong CW (1984) Alzheimer's disease: initial report of the purification and characterization of a novel cerebrovascular amyloid protein. Biochem Biophys Res Commun 120:885-890.

27. Masters CL, et al. (1985) Amyloid plaque core protein in Alzheimer disease and Down syndrome. Proc Natl Acad Sci U S A 82(12):4245-4249.

28. Askanas V, Bornemann A, \& Engel WK (1990) Immunocytochemical localization of desmin at human neuromuscular junctions. Neurology 40(6):949-953.

29. Haltia M, et al. (1991) Gelsolin variant and beta-amyloid co-occur in a case of Alzheimer's with Lewy bodies. Neurobiol Aging 12(4):313-316.

30. Attems J, Lintner F, \& Jellinger KA (2004) Amyloid $\beta$ peptide 1-42 highly correlates with capillary cerebral amyloid angiopathy and Alzheimer disease pathology. Acta Neuropathol 107(4):283-291.

31. Prelli F, Castaño E, Glenner GG, \& Frangione B (1988) Differences between vascular and plaque core amyloid in Alzheimer's disease. J Neurochem 51(2):648-651.

32. Yamaguchi H, Hirai S, Morimatsu M, Shoji M, \& Ihara Y (1988) A variety of cerebral amyloid deposits in the brains of the Alzheimer-type dementia demonstrated by beta protein immunostaining. Acta Neuropathol 76(6):541-549.

33. Ellis RJ, et al. (1996) Cerebral amyloid angiopathy in the brains of patients with Alzheimer's disease: the CERAD experience, Part XV. Neurology 46(6):1592-1596.

34. Yamada M (2012) Predicting cerebral amyloid angiopathy-related intracerebral hemorrhages and other cerebrovascular disorders in Alzheimer's disease. Front Neurol 3:64.

35. Attar A, Meral D, Urbanc B, \& Bitan G (2014) Assembly of amyloid- $\beta$ protein variants containing familial Alzheimer's disease-linked amino acid substitutions. Bio-nanoimaging, eds Uversky VN \& Lyubchecnko YL (Academic Press, Boston), pp 429-442.

36. Tian J, Shi J, \& Mann DM (2004) Cerebral amyloid angiopathy and dementia. Panminerva Med 46(4):253-264.

37. Bugiani O, et al. (2010) Hereditary cerebral hemorrhage with amyloidosis associated with the E693K mutation of APP. Arch Neurol 67(8):987-995.

38. Eichner T \& Radford SE (2011) A diversity of assembly mechanisms of a generic amyloid fold. Mol Cell 43(1):8-18.

39. Qiang W, Yau WM, Luo Y, Mattson MP, \& Tycko R (2012) Antiparallel $\beta$-sheet architecture in Iowa-mutant $\beta$-amyloid fibrils. Proc Natl Acad Sci U S A 109(12):4443-4448.

40. LeVine H, 3rd (1999) Quantification of $\beta$-sheet amyloid fibril structures with thioflavin T. Methods Enzymol 309:274-284.

41. Morris KL \& Serpell LC (2012) X-ray fibre diffraction studies of amyloid fibrils. Methods Mol Biol 849:121-135.

42. Makin O, Sikorski P, \& Serpell L (2007) CLEARER: a new tool for the analysis of X-ray fibre diffraction patterns and diffraction simulation from atomic structural models. Appl. Cryst. 40:966-972.

43. Chan FT, et al. (2013) Protein amyloids develop an intrinsic fluorescence signature during aggregation. Analyst 138(7):2156-2162.

44. Pan J, Han J, Borchers CH, \& Konermann L (2011) Conformer-specific hydrogen exchange analysis of $A \beta(1-42)$ oligomers by top-down electron capture dissociation mass spectrometry. Anal Chem 83(13):5386-5393.

45. Kheterpal I, Wetzel R, \& Cook KD (2003) Enhanced correction methods for hydrogen exchange-mass spectrometric studies of amyloid fibrils. Protein Sci 12(3):635-643.

46. Zhang A, Qi W, Good TA, \& Fernandez EJ (2009) Structural differences between A $\beta(1-40)$ intermediate oligomers and fibrils elucidated by proteolytic fragmentation and hydrogen/deuterium exchange. Biophys $J$ 96(3):1091-1104.

47. Kheterpal I, Chen M, Cook KD, \& Wetzel R (2006) Structural differences in A $\beta$ amyloid protofibrils and fibrils mapped by hydrogen exchange - mass spectrometry with on-line proteolytic fragmentation. J Mol Biol 361(4):785-795. 
48. Schmittgen TD \& Livak KJ (2008) Analyzing real-time PCR data by the comparative C(T) method. Nat Protoc 3(6):1101-1108.

49. Olofsson A, Sauer-Eriksson AE, \& Ohman A (2006) The solvent protection of Alzheimer amyloid- $\beta-(1-42)$ fibrils as determined by solution NMR spectroscopy. $J$ Biol Chem 281(1):477-483.

50. Oberg KA, Ruysschaert JM, \& Goormaghtigh E (2004) The optimization of protein secondary structure determination with infrared and circular dichroism spectra. Eur $J$ Biochem 271(14):2937-2948.

51. Goormaghtigh E, Raussens V, \& Ruysschaert JM (1999) Attenuated total reflection infrared spectroscopy of proteins and lipids in biological membranes. Biochim Biophys Acta 1422(2):105-185.

52. Kubelka J \& Keiderling TA (2001) Differentiation of $\beta$-sheet-forming structures: Ab initiobased simulations of IR absorption and vibrational CD for model peptide and protein $\beta$-sheets. J Am Chem Soc 123(48):12048-12058.

53. Zandomeneghi G, Krebs MRH, Mccammon MG, \& Fandrich M (2004) FTIR reveals structural differences between native $\beta$-sheet proteins and amyloid fibrils. Protein Sci 13(12):3314-3321.

54. Moran SD \& Zanni MT (2014) How to Get Insight into Amyloid Structure and Formation from Infrared Spectroscopy. J Phys Chem Lett 5(11):1984-1993.

55. Chirgadze YN \& Nevskaya NA (1976) Infrared spectra and resonance interaction of amide-I vibration of the antiparallel-chain pleated sheet. Biopolymers 15(4):607-625.

56. Krimm S \& Bandekar J (1986) Vibrational spectroscopy and conformation of peptides, polypeptides, and proteins. Adv Protein Chem 38:181-364.

57. Miyazawa T \& Blout ER (1961) Infrared Spectra of Polypeptides in Various Conformations Amide I and II Bands. J Am Chem Soc 83(3):712-\&.

58. Celej MS, et al. (2012) Toxic prefibrillar $\alpha$-synuclein amyloid oligomers adopt a distinctive antiparallel $\beta$-sheet structure. Biochem J 443(3):719-726.

59. Cerf E, et al. (2009) Antiparallel $\beta$-sheet: a signature structure of the oligomeric amyloid $\beta$ peptide. Biochem J 421(3):415-423.

60. Sarroukh R, et al. (2011) Transformation of amyloid $\beta(1-40)$ oligomers into fibrils is characterized by a major change in secondary structure. Cell Mol Life Sci 68(8):1429-1438.

61. Sarroukh R, Goormaghtigh E, Ruysschaert JM, \& Raussens V (2013) ATR-FTIR: a "rejuvenated" tool to investigate amyloid proteins. Biochim Biophys Acta 1828(10):23282338.

62. Vandersteen A, et al. (2012) A comparative analysis of the aggregation behavior of amyloid- $\beta$ peptide variants. FEBS Lett 586(23):4088-4093.

63. Khurana R, et al. (2005) Mechanism of thioflavin T binding to amyloid fibrils. $J$ Struct Biol 151(3):229-238.

64. Cloe AL, Orgel JP, Sachleben JR, Tycko R, \& Meredith SC (2011) The Japanese mutant A $\beta$ $(\triangle \mathrm{E} 22-\mathrm{A} \beta(1-39))$ forms fibrils instantaneously, with low-thioflavin $\mathrm{T}$ fluorescence: seeding of wild-type $A \beta(1-40)$ into atypical fibrils by $\triangle \mathrm{E} 22-\mathrm{A} \beta(1-39)$. Biochemistry 50(12):2026-2039.

65. Chan FTS PD, Kaminski-Schierle GS, Kaminski CF (2014) Structure-Specific Intrinsic Fluorescence of Protein Amyloids Used to Study their Kinetics of Aggregation. Bionanoimaging: Protein Misfolding \& Aggregation, ed Uversky VN LY (Academic Press), pp pp. 147-155.

66. Sunde M, et al. (1997) Common core structure of amyloid fibrils by synchrotron X-ray diffraction. J Mol Biol 273(3):729-739.

67. Sikorski P, Atkins ED, \& Serpell LC (2003) Structure and texture of fibrous crystals formed by Alzheimer's A $\beta(11-25)$ peptide fragment. Structure 11(8):915-926.

68. Masuda Y, et al. (2005) Verification of the turn at positions 22 and 23 of the $\beta$-amyloid fibrils with Italian mutation using solid-state NMR. Bioorg Med Chem 13(24):6803-6809.

69. Rubio-Perez JM \& Morillas-Ruiz JM (2012) A review: inflammatory process in Alzheimer's disease, role of cytokines. ScientificWorldJournal 2012:756357.

70. Tsuchiya S, et al. (1980) Establishment and characterization of a human acute monocytic leukemia cell line (THP-1). Int J Cancer 26(2):171-176. 
71. Streltsov VA, Varghese JN, Masters CL, \& Nuttall SD (2011) Crystal structure of the amyloid- $\beta$ p3 fragment provides a model for oligomer formation in Alzheimer's disease. $J$ Neurosci 31(4):1419-1426.

72. Laganowsky A, et al. (2012) Atomic view of a toxic amyloid small oligomer. Science 335(6073):1228-1231.

73. Gu L, Liu C, \& Guo Z (2013) Structural Insights into A $\beta 42$ Oligomers Using Site-directed Spin Labeling. J Biol Chem 288(26):18673-18683.

74. Sandberg A, et al. (2010) Stabilization of neurotoxic Alzheimer amyloid- $\beta$ oligomers by protein engineering. Proc Natl Acad Sci U S A 107(35):15595-15600.

75. Zou Y, Li Y, Hao W, Hu X, \& Ma G (2013) Parallel $\beta$-sheet fibril and antiparallel $\beta$-sheet oligomer: new insights into amyloid formation of hen egg white lysozyme under heat and acidic condition from FTIR spectroscopy. J Phys Chem B 117(15):4003-4013.

76. Benilova I, Karran E, \& De Strooper B (2012) The toxic A $\beta$ oligomer and Alzheimer's disease: an emperor in need of clothes. Nat Neurosci 15(3):349-357.

77. Drachman DA (2014) The amyloid hypothesis, time to move on: Amyloid is the downstream result, not cause, of Alzheimer's disease. Alzheimers Dement 10(3):372-380.

78. LaFerla FM, Green KN, \& Oddo S (2007) Intracellular amyloid- $\beta$ in Alzheimer's disease. Nat Rev Neurosci 8(7):499-509.

79. Haass C \& Selkoe DJ (2007) Soluble protein oligomers in neurodegeneration: lessons from the Alzheimer's amyloid $\beta$-peptide. Nat Rev Mol Cell Biol 8(2):101-112.

80. Melchor JP, McVoy L, \& Van Nostrand WE (2000) Charge alterations of E22 enhance the pathogenic properties of the amyloid $\beta$-protein. J Neurochem 74(5):2209-2212.

81. Murakami K, et al. (2003) Neurotoxicity and physicochemical properties of A $\beta$ mutant peptides from cerebral amyloid angiopathy: implication for the pathogenesis of cerebral amyloid angiopathy and Alzheimer's disease. J Biol Chem 278(46):46179-46187.

82. Murakami K, et al. (2002) Synthesis, aggregation, neurotoxicity, and secondary structure of various A $\beta 1-42$ mutants of familial Alzheimer's disease at positions 21-23. Biochem Biophys Res Commun 294(1):5-10.

83. Doran TM, Anderson EA, Latchney SE, Opanashuk LA, \& Nilsson BL (2012) Turn nucleation perturbs amyloid $\beta$ self-assembly and cytotoxicity. $J$ Mol Biol 421(2-3):315-328.

84. Perálvarez-Marín A, et al. (2009) Influence of residue 22 on the folding, aggregation profile, and toxicity of the Alzheimer's amyloid $\beta$ peptide. Biophys $J$ 97(1):277-285.

85. Masuda Y, et al. (2009) Identification of physiological and toxic conformations in A $\beta 42$ aggregates. Chembiochem 10(2):287-295.

86. Lin YS \& Pande VS (2012) Effects of familial mutations on the monomer structure of A $\beta 42$. Biophys $J$ 103(12):L47-49.

87. Ahmed M, et al. (2010) Structural conversion of neurotoxic amyloid- $\beta(1-42)$ oligomers to fibrils. Nat Struct Mol Biol 17(5):561-567.

88. Qiang W, Kelley K, \& Tycko R (2013) Polymorph-specific kinetics and thermodynamics of $\beta$-amyloid fibril growth. $J$ Am Chem Soc 135(18):6860-6871.

89. Watts JC, et al. (2014) Serial propagation of distinct strains of A $\beta$ prions from Alzheimer's disease patients. Proc Natl Acad Sci U S A.

90. Donahue JE, et al. (2006) RAGE, LRP-1, and amyloid-beta protein in Alzheimer's disease. Acta Neuropathol 112(4):405-415.

91. Deane R, et al. (2003) RAGE mediates amyloid- $\beta$ peptide transport across the blood-brain barrier and accumulation in brain. Nat Med 9(7):907-913.

92. Fritz G (2011) RAGE: a single receptor fits multiple ligands. Trends Biochem Sci 36(12):625632.

93. Herz J \& Strickland DK (2001) LRP: a multifunctional scavenger and signaling receptor. $J$ Clin Invest 108(6):779-784.

94. Bu G, Cam J, \& Zerbinatti C (2006) LRP in amyloid- $\beta$ production and metabolism. Ann N Y Acad Sci 1086:35-53.

95. Takuma K, et al. (2009) RAGE-mediated signaling contributes to intraneuronal transport of amyloid- $\beta$ and neuronal dysfunction. Proc Natl Acad Sci U S A 106(47):20021-20026. 
96. Yan SD, et al. (1998) RAGE-A $\beta$ interactions in the pathophysiology of Alzheimer's disease. Restor Neurol Neurosci 12(2-3):167-173.

97. Yan SD, Bierhaus A, Nawroth PP, \& Stern DM (2009) RAGE and Alzheimer's disease: a progression factor for amyloid- $\beta$-induced cellular perturbation? J Alzheimers Dis 16(4):833843.

98. Zipp F \& Aktas O (2006) The brain as a target of inflammation: common pathways link inflammatory and neurodegenerative diseases. Trends Neurosci 29(9):518-527.

99. Ray WJ, Ashall F, \& Goate AM (1998) Molecular pathogenesis of sporadic and familial forms of Alzheimer's disease. Mol Med Today 4(4):151-157.

100. Lynch MA \& Mills KH (2012) Immunology meets neuroscience - opportunities for immune intervention in neurodegenerative diseases. Brain Behav Immun 26(1):1-10.

101. Amor S, Puentes F, Baker D, \& van der Valk P (2010) Inflammation in neurodegenerative diseases. Immunology 129(2):154-169.

102. Glass CK, Saijo K, Winner B, Marchetto MC, \& Gage FH (2010) Mechanisms underlying inflammation in neurodegeneration. Cell 140(6):918-934.

103. Huang Y \& Mucke L (2012) Alzheimer mechanisms and therapeutic strategies. Cell 148(6):1204-1222.

104. Noda M \& Suzumura A (2012) Sweepers in the CNS: Microglial Migration and Phagocytosis in the Alzheimer Disease Pathogenesis. Int J Alzheimers Dis 2012:891087.

105. Li C, et al. (2011) Astrocytes: implications for neuroinflammatory pathogenesis of Alzheimer's disease. Curr Alzheimer Res 8(1):67-80.

106. Wyss-Coray T, et al. (2003) Adult mouse astrocytes degrade amyloid- $\beta$ in vitro and in situ. Nat Med 9(4):453-457. 


\section{Chapter 4}

\section{ApoE associated with reconstituted HDL-like particles is protected from aggregation}

This chapter has been submitted to Biophysical Journal.

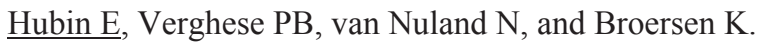

The $A P O E$ genotype determines $\mathrm{AD}$ susceptibility, with the $A P O E$ \&4 allele being an established risk factor for late-onset AD. This discovery resulted in the development of ApoEbased therapeutics for AD aimed at modulating the levels and lipidation status of ApoE. The ApoE lipidation status has been reported to impact $A \beta$ metabolism, in particular $A \beta$ aggregation and clearance. However, the details of how lipidation affects ApoE behaviour remain to be fully elucidated. In this study, we prepared lipid-free and lipid-bound ApoE particles, mimicking the high density lipoprotein (HDL) particles found in vivo, for all three isoforms (ApoE2, ApoE3, and ApoE4) and biophysically characterized them. We report that lipid-free ApoE in solution has the tendency to aggregate in vitro (ApoE4 > ApoE3 > ApoE2) under near-physiological conditions, and that aggregation is impeded by lipidation of ApoE. Although the latter has been suggested previously, to the best of our knowledge, this is the first study that provides experimental evidence for this hypothesis for all ApoE isoforms using physiological HDL-like particles. Moreover, previous studies have reported that ApoE4 in the CNS is less associated with lipids than the other ApoE isoforms, and that ApoE aggregates are toxic to neuronal cells. Therefore, these findings might explain the higher AD risk associated with ApoE4, and highlight the importance of the ApoE lipidation status in the context of $\mathrm{AD}$ pathology. 


\subsection{Introduction}

Lipids require specialized carriers that transport them through the body, known as apolipoproteins. Apolipoproteins facilitate lipid solubilization and serve as ligands for lipoprotein receptors that mediate cellular lipid uptake and play a role in cell signalling (1). ApoE is one of the most studied members of this protein family, as the APOE genotype has been linked to several neurological disorders, with a strong association to $\operatorname{AD}(2,3)$. ApoE is produced in abundance in the human brain by astrocytes, in less extent by macrophages and stressed neurons, and is the principal lipid transporter in the CSF (4).

ApoE exists as three isoforms: ApoE2, ApoE3, and ApoE4 (Table 4.1) (5). The APOE $\varepsilon 4$ allele is the most important genetic risk factor for development of late-onset AD. People carrying one or two copies of the $A P O E \& 4$ allele have respectively about three- and twelvefold more risk of acquiring $\mathrm{AD}$ than non- $A P O E \varepsilon 4$ carriers (6). In contrast, the $A P O E$ $\varepsilon 2$ allele is protective (7). ApoE was initially found to co-localize with $\mathrm{A} \beta$ plaques in the $\mathrm{AD}$ brain (8). Substantial evidence exists that ApoE contributes to AD pathogenesis by modulating $A \beta$ aggregation and clearance, and by regulating brain lipid metabolism and synaptic functioning through ApoE receptors such as those of the LDL receptor family (9-12). Proposed $\mathrm{A} \beta$-independent roles for ApoE4 in $\mathrm{AD}$ include generation of neurotoxic ApoE fragments, impairment of mitochondrial function, and disruption of the cytoskeleton through stimulation of tau phosphorylation (13).

Table 4.1: Prevalence of ApoE isoforms and their key differences, adapted from (14).

\begin{tabular}{|c|c|c|c|c|c|}
\hline \multirow[t]{2}{*}{$\begin{array}{l}\text { ApoE } \\
\text { isoform }\end{array}$} & \multirow{2}{*}{$\begin{array}{c}\text { Average } \\
\text { allelic } \\
\text { frequency } \\
(\%)\end{array}$} & \multicolumn{2}{|c|}{$\begin{array}{c}\text { Amino acid variation } \\
\text { (residues) }\end{array}$} & \multirow{2}{*}{$\begin{array}{l}\text { Lipoprotein- } \\
\text { binding } \\
\text { preferences }\end{array}$} & \multirow[t]{2}{*}{ Associated disorders } \\
\hline & & 112 & 158 & & \\
\hline ApoE2 & 7 & Cys & Cys & HDL & Type III hyperlipoproteinemia \\
\hline ApoE3 & 78 & Cys & Arg & HDL & Unknown \\
\hline ApoE4 & 15 & Arg & Arg & VLDL, LDL & $\begin{array}{l}\mathrm{AD} \text {, other neurological } \\
\text { disorders, atherosclerosis }\end{array}$ \\
\hline
\end{tabular}

Although the ApoE isoforms only differ by their amino acid compositions at positions 112 and 158 (15), these changes have profound effects on the structure and lipoprotein-binding preferences of the isoforms $(16,17)$. ApoE consists of two structural domains linked by a flexible hinge region (Fig. 4.1). Whereas the N- and C-terminal domains interact in ApoE4, this interaction does not occur to the same extent in ApoE2 and ApoE3 (14). The N-terminal receptor-binding domain is an extended four-helix bundle and is responsible for binding to the LDL and related receptors upon lipidation. The C-terminal domain of ApoE comprises several amphipathic $\alpha$-helices and contains the lipid-binding region that is capable of binding different types of lipids (e.g. cholesterol, phospholipids, fatty acids) and lipoproteins, including LDLs, very low density lipoproteins (VLDLs), and high density lipoproteins (HDLs).

ApoE in the human brain is mainly synthesized by and secreted from astrocytes to generate ApoE-containing HDL-like particles. It has been suggested that astrocyte-secreted HDL particles are discoidal in shape, but the conformation adopted by ApoE in the lipid complexes remains controversial (17). 


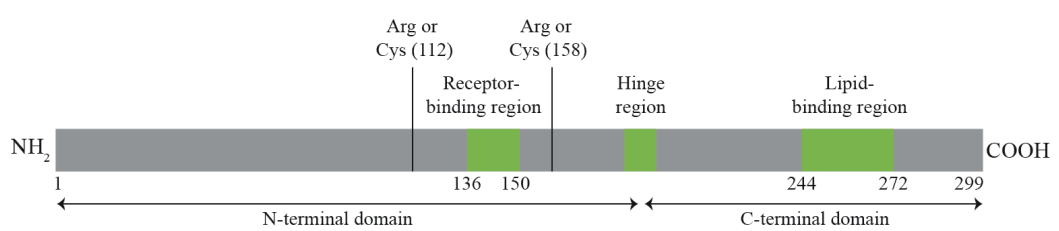

Figure 4.1: ApoE contains two domains connected by a flexible hinge region. The N-terminal domain comprises the receptor-binding region, whereas the C-terminal domain includes the major lipid-binding region. Adapted from (10).

The mechanistic link between ApoE and AD has been the subject of numerous studies and debates, but it has become clear that the lipidation status of ApoE plays an important role. For the most part, biologically active ApoE is associated with lipids and the ApoE lipidation status has been reported to impact $A \beta$ metabolism, i.e. $A \beta$ aggregation and deposition (18-21), and clearance (22-24). For example, enhanced expression of lipidated ApoE in AD mouse models, through activation of liver X receptors or through overexpression of the ATP-binding cassette $A$ that is responsible for ApoE lipidation, stimulates $A \beta$ clearance $(22,25)$. Therefore, modulators of ApoE secretion and lipidation are being explored as potential drugs for AD therapy $(21,26,27)$.

Studying ApoE behaviour in its lipid-free and lipid-bound state is thus of great importance to enhance our understanding of its functioning in the context of AD pathology. In this study, we therefore produced all three ApoE isoforms in their lipidated and non-lipidated forms, and systematically characterized and compared them by a range of biophysical techniques. The lipidation procedure was carefully selected to mimic in vivo discoidal HDL-like ApoE particles with a physiological lipid composition consisting of phospholipid and un-esterified cholesterol $(28,29)$. Our results confirm the previously reported tendency of lipid-free ApoE to self-assemble in solution (30-33) and provide experimental evidence that lipidation protects ApoE from aggregation.

\subsection{Experimental procedures}

\subsubsection{Preparation of HDL-like ApoE particles}

Preparation of reconstituted ApoE. Lyophilized recombinant human ApoE (Leinco Technologies, Inc., St Louis, USA) was resuspended to a concentration of $1 \mathrm{mg} / \mathrm{ml}$ in Dulbecco's phosphate-buffered saline (DPBS, Gibco) pH 7.4 containing $0.05 \mathrm{mM}$ dithiothreitol.

Liposome preparation. 1-palmitoyl-2-oleoyl-sn-glycero-3-phosphocholine (POPC, Avanti Lipids) and un-esterified cholesterol (Avanti Lipids) were mixed in a glass vial at a molar ratio of 90:5 and dried under a constant nitrogen gas stream. This ratio was selected to mimic the physiological lipid composition of HDL-like ApoE particles $(28,29)$. Lipids were resuspended in PBS at a concentration of $5 \mu \mathrm{g}$ lipids/ $\mu \mathrm{l}$ PBS. The solution was mixed thoroughly in a vortex mixer and intermittently for 5-10 min (with 1-2 min intervals) to generate liposomes. Complete hydration of liposomes was accomplished by incubating the solution at room temperature for $30 \mathrm{~min}$ and occasional vortex mixing.

ApoE lipidation. Lipids can be added directly to ApoE but lipidated particles will be more homogeneous when using the sodium cholate dialysis method (34). Therefore, sodium cholate $(50 \mathrm{mg} / \mathrm{ml}$, Sigma-Aldrich) was slowly titrated into the liposome solution (2-3 volumes of sodium cholate for 1 volume of lipids). The solution turbidity cleared after 5 min of gentle 
vortex mixing ( 1 min interval) and the preparation was kept at room temperature for 30-60 min. Reconstituted ApoE was then added to the liposome preparation (ApoE:POPC:cholesterol, molar ratio of 1:90:5) and mixed gently for 5-10 min (1-2 min interval). The solution was kept at room temperature for $1 \mathrm{~h}$ and dialysed (10 kDa cut-off membrane) against PBS for $4 \mathrm{~h}$ at room temperature (to promote removal of detergents), followed by $60-72 \mathrm{~h}$ at $4{ }^{\circ} \mathrm{C}$. After dialysis, samples were analysed by gel filtration chromatography (Superdex 200 10/300 GL) and non-denaturing (native) polyacrylamide gel electrophoresis (PAGE). ApoE concentrations were determined by absorbance measurements at $280 \mathrm{~nm}$ using an extinction coefficient of $44460 \mathrm{M}^{-1} \mathrm{~cm}^{-1}$ (35). Samples were diluted in PBS to $0.1 \mathrm{mg} / \mathrm{ml}$ prior to further analysis. All lipoprotein samples were prepared using the same lipid-cholesterol suspension and the procedure was performed in parallel. Samples were stored at $4{ }^{\circ} \mathrm{C}$.

\subsubsection{TEM imaging of lipid-free and lipid-bound ApoE}

A staining procedure was adapted to assess the formation of HDL-like ApoE particles with TEM (36). Briefly, grids (carbon-coated Formvar 400-mesh copper grids, AgarScientific) were glow discharged prior to sample application. Lipidated ApoE $(2 \mu 1$ of a $0.1 \mathrm{mg} / \mathrm{ml}$ sample) was spotted and incubated on the grids for $2 \mathrm{~min}$ at room temperature. The grids were subsequently blotted, washed ( $3 \times 2 \mathrm{~s}$, in ultrapure water), and stained with $1 \%$ (w/v) uranyl acetate $(2 \times 2 \mathrm{~min})$. For imaging of lipid-free ApoE, samples were spotted and incubated on grids for $30 \mathrm{~s}$, blotted, washed $(1 \times 5 \mathrm{~s})$, and stained with $1 \%$ uranyl acetate $(1 \times 30 \mathrm{~s})$. Samples were studied with a JEM-1400 microscope (JEOL Ltd., Tokyo, Japan) at $80 \mathrm{kV}$.

\subsubsection{Native PAGE}

Lipoprotein particle formation was assessed by native PAGE. Equal amounts of ApoE isoforms $(3 \mu \mathrm{g})$ were mixed with the Novex ${ }^{\circledR}$ Tris-Glycine Native Sample Buffer $(1: 1)$ to obtain a final volume of $15 \mu 1$, and loaded on a 4-20\% Tris-glycine gel (Invitrogen). The gel was run at $100 \mathrm{~V}$ for $16 \mathrm{~h}$ at $4{ }^{\circ} \mathrm{C}$. Sample migration was assessed using the NativeMark ${ }^{\mathrm{TM}}$ Unstained protein standard (Life Technologies).

\subsubsection{FFF-MALS}

For each fractionation, a volume of $10 \mu \mathrm{l}$ ApoE $(0.1 \mathrm{mg} / \mathrm{ml})$ was injected in an Eclipse asymmetrical flow field flow fractionation (FFF) system (Wyatt Technology), and the flow rate out of the channel was maintained at $1 \mathrm{ml} / \mathrm{min}$. Fractionated samples were analysed with multi-angle light scattering (MALS) using the DAWN HELEOS system (Wyatt Technology), an ultraviolet (UV) detector, and an Optilab rEX refractive index detector (Wyatt Technology) connected to the Eclipse system. The MALS system was equipped with a laser operating at $658 \mathrm{~nm}$ and measurements were taken at $14.4^{\circ}, 25.9^{\circ}, 34.8^{\circ}, 42.8^{\circ}, 51.5^{\circ}$, $60.0^{\circ}, 69.3^{\circ}, 79.7^{\circ}, 90.0^{\circ}, 100.3^{\circ}, 110.7^{\circ}, 121.2^{\circ}, 132.2^{\circ}, 142.5^{\circ}, 152.5^{\circ}$, and $163.3^{\circ}$, with reference to the axis of the incident beam. Astra V software (version 5.3.4.14) was used for data acquisition and correction for inter-detector delay and band broadening.

\subsubsection{Dynamic light scattering}

Lipid-free and lipid-bound ApoE $(0.1 \mathrm{mg} / \mathrm{ml}$ in PBS) were analysed using dynamic light scattering (DLS). DLS experiments were conducted with a DynaPro DLS plate reader (Wyatt Technology) at $25^{\circ} \mathrm{C}$ and at a scattering angle of $158^{\circ}$. Data were analysed using 
Dynamics ${ }^{\circledR}$ software (Wyatt Technology) and represent the averages of 15 acquisitions (10 s/acquisition).

\subsubsection{Circular dichroism}

ApoE isoforms $(0.1 \mathrm{mg} / \mathrm{ml}$ in PBS $)$ in the absence and presence of lipids were placed in a quartz cuvette with an optical path of $0.1 \mathrm{~cm}$. Far-UV circular dichroism (CD) spectra were recorded in a Jasco J-715 spectropolarimeter at $25{ }^{\circ} \mathrm{C}$. The wavelength range was set from 260 to $190 \mathrm{~nm}$ with $0.2 \mathrm{~nm}$ resolution, $8.0 \mathrm{~s}$ response time, and $1.0 \mathrm{~nm}$ bandwidth. Data were collected as averages of 8 scans at a scanning speed of $50 \mathrm{~nm} / \mathrm{min}$. Spectra were corrected by subtracting the buffer baseline. Measurements were performed as independent duplicates. Data are presented as the mean residue ellipticity (MRE, in $\operatorname{deg} \mathrm{cm}^{2} \mathrm{dmol}^{-1}$ ). Secondary structure content was estimated using CDSSTR software and the normalized root meansquare deviation (NRMSD) is displayed as a measure of correspondence between the experimental and calculated reference spectra $(37,38)$.

\subsubsection{Intrinsic tryptophan fluorescence}

Emission fluorescence spectra of lipidated and non-lipidated ApoE isoforms $(0.1 \mathrm{mg} / \mathrm{ml}$ in PBS) were measured using a LS 55 spectrometer (PerkinElmer) at $25{ }^{\circ} \mathrm{C}$. The excitation wavelength was set to $280 \mathrm{~nm}$ ( $5 \mathrm{~nm}$ bandwidth) and the emission intensity was scanned from 300 to $450 \mathrm{~nm}$ ( $5 \mathrm{~nm}$ bandwidth) at a scan speed of $100 \mathrm{~nm} / \mathrm{min}$. Spectra were corrected for buffer and represent averages of 8 scans. Measurements were performed as independent duplicates.

\subsection{Results}

Astrocyte-secreted ApoE in the brain is predominantly associated with cholesterol and phospholipid-rich HDL-like complexes $(28,29)$. Therefore, HDL-like ApoE particles were prepared using POPC and un-esterified cholesterol, in a 1:90:5 molar ratio (ApoE:POPC:cholesterol), using the sodium cholate dialysis method described previously (34). The lipidation procedure was assessed by TEM and revealed discoidal lipidated ApoE particles (Fig. 4.2).

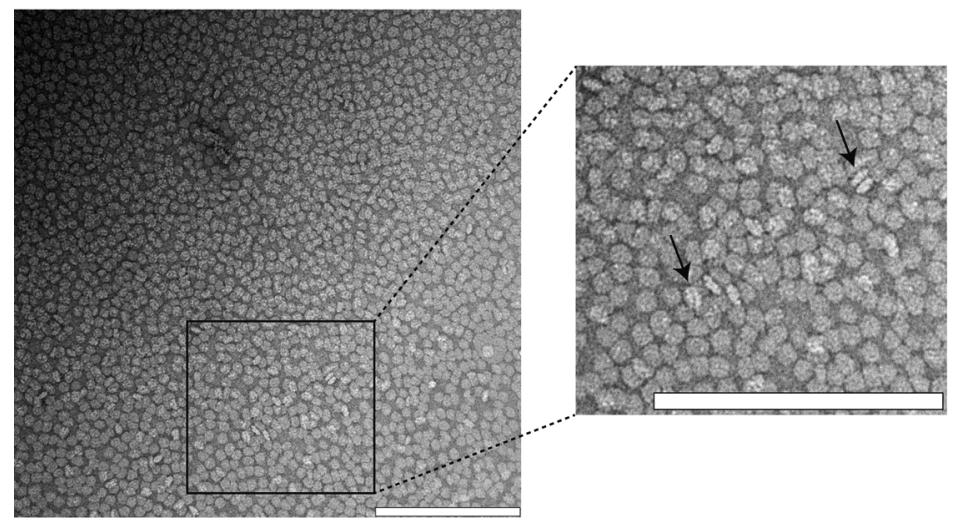

Figure 4.2: Assessment of the formation of HDL-like discoidal ApoE particles with TEM. The majority of the discoidal ApoE particles are visualized from their top/bottom, but some can also be seen from a lateral perspective (indicated by arrows). The scale bars represent $200 \mathrm{~nm}$. 
The sodium cholate procedure resulted in a heterogeneous population of lipid-bound ApoE particles consisting of three fractions, as shown by FFF-MALS (Fig. 4.3). FFF is a high resolution separation technique that consists of a velocity gradient inside a channel that separates particles based on their size. Smaller particles will be more rapidly transported through the channel than larger ones and will elute first, as opposed to size exclusion chromatography. This heterogeneity detected for lipidated ApoE particles is consistent with previous studies reporting different sizes for ApoE-containing lipoproteins secreted by astrocytes from transgenic mice expressing human ApoE, and in CSF of human subjects (29, $39,40)$.

Next, ApoE isoforms in their lipid-free and lipid-bound state were characterized using FFFMALS, native PAGE, and DLS. The first particles to elute from the FFF channel were the HDL-like ApoE particles, and not the lipid-free ApoE isoforms, as detected by differential refractive index analysis (Fig. 4.3A), MALS (Fig. 4.3B), and UV absorbance (Fig. 4.3C). Whereas lipid-free ApoE was eluted around $15 \mathrm{~min}$, lipidated ApoE particles displayed shorter retention times, i.e. between 12-14 min. This result indicates that the size of lipidated ApoE, and more specific the hydrodynamic radius, is smaller than that of lipid-free ApoE.

A.
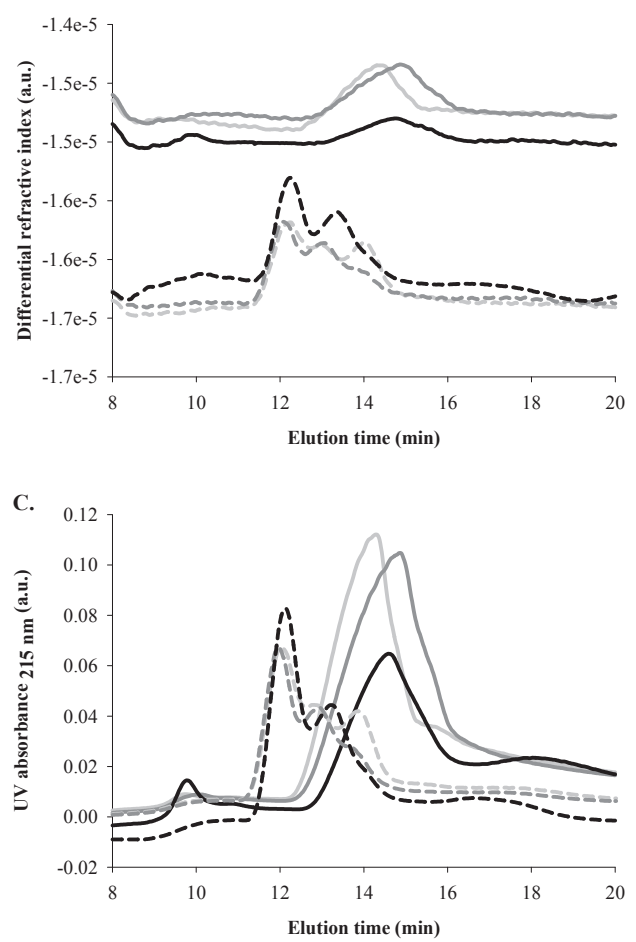

B.

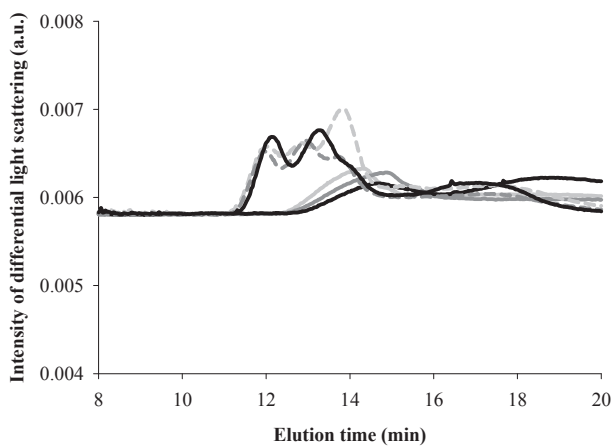

Figure 4.3: The heterogeneous composition of HDL-like ApoE particles. Lipid-free and HDL-like ApoE particles $(0.1 \mathrm{mg} / \mathrm{ml}$ in PBS) were separated by FFF and their composition was compared by their (A) differential refractive index, (B) intensity of differential light scattering, and (C) UV absorbance at $215 \mathrm{~nm}$.

Accordingly, native PAGE revealed that lipid-bound ApoE migrated further in the 4-20\% Tris-glycine gel than lipid-free ApoE (Fig. 4.4A). Moreover, estimations of the hydrodynamic radii by DLS confirmed that lipidated ApoE, regardless of the ApoE isoform, was smaller 
than lipid-free ApoE (Fig. 4.4B). Together, these results suggest that lipid-free ApoE has the tendency to aggregate in solution, whereas lipidation is capable of impeding this behaviour. This tendency is isoform-dependent, with the most pronounced aggregation for ApoE4, followed by ApoE3 and ApoE2 (Fig. 4.4).

A.

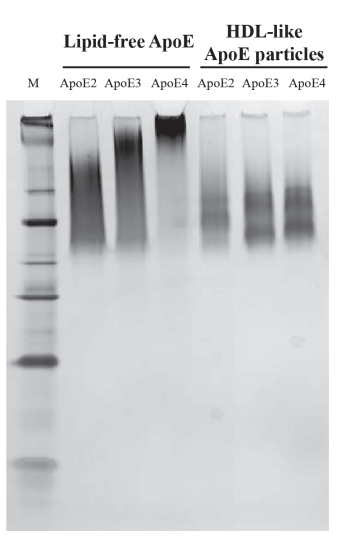

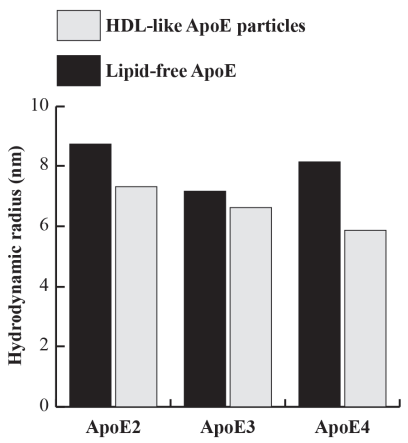

Figure 4.4: Lipidation impedes aggregation of ApoE. Migration patterns and size distributions of lipid-free and HDL-like ApoE particles $(0.1 \mathrm{mg} / \mathrm{ml}$ in PBS) were obtained by native PAGE and DLS, respectively. (A) Lipidated ApoE migrates further in a 4-20\% Tris-glycine gel compared to lipid-free ApoE (M: NativeMark ${ }^{\mathrm{TM}}$ Unstained protein standard). (B) The hydrodynamic radius of lipidated ApoE is smaller than that of lipid-free ApoE.

The aggregation of lipid-free ApoE was visualized by TEM and revealed amorphous aggregates (Fig. 4.5).

A.

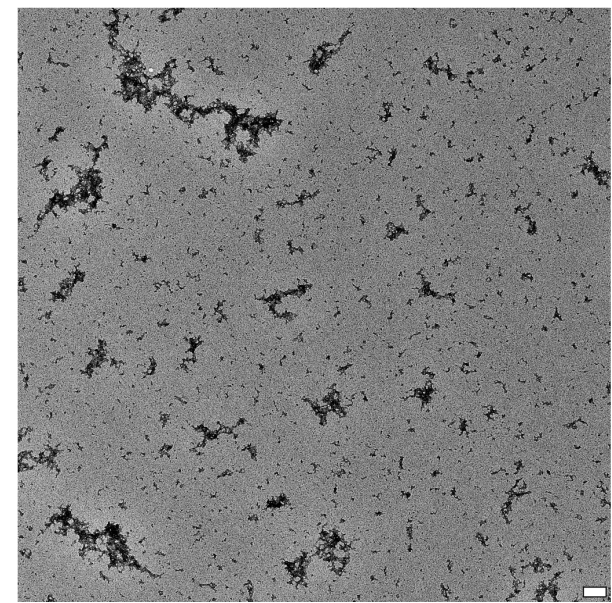

B.

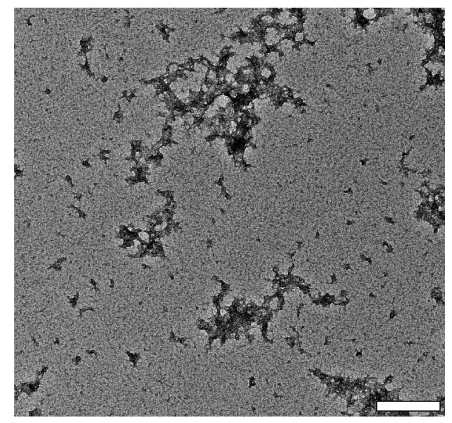

Figure 4.5: Lipid-free ApoE self-assembles into amorphous aggregates. Lipid-free ApoE aggregates displayed an amorphous morphology, similar for all three isoforms, as assessed by TEM. Lipid-free ApoE4 aggregates are depicted. (B) An enlarged image of lipid-free ApoE4 aggregates. The scale bars represent 200 nm. 
To assess the effect of lipidation on secondary structure content of ApoE, CD measurements were performed. Lipid-free as well as lipid-bound ApoE displayed a predominant $\alpha$-helical structural signature, characterized by two minima around $208 \mathrm{~nm}$ and $222 \mathrm{~nm}$. Lipid-free and lipidated ApoE displayed approximately $60 \% \alpha$-helicity (Fig. 4.6), which corresponds to values reported previously (41). The mean residue ellipticity was however slightly increased in the lipidated ApoE state with a small gain of $\alpha$-helicity and loss of $\beta$-sheet structure (Fig. 4.6). However, taken into account an approximate error of $5 \%$ in the measurements, the overall effect of lipidation on the secondary structure of ApoE was minor.

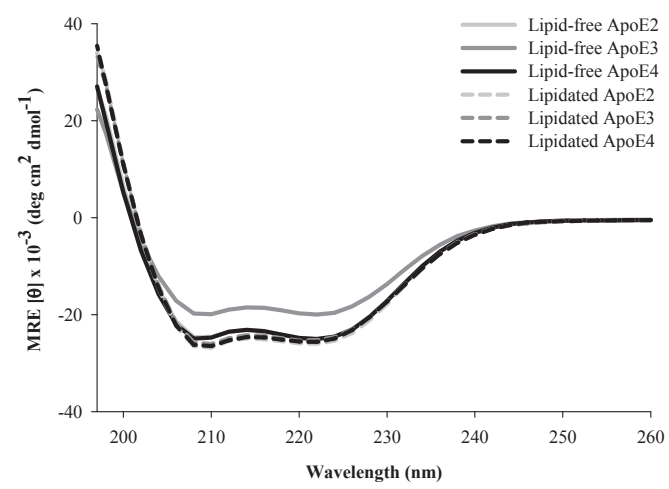

\begin{tabular}{lccccc}
\hline \hline Peptide & \multicolumn{3}{c}{ Secondary structure element (\%) } & & \multirow{2}{*}{ NRMSD } \\
& a-helix & $\boldsymbol{\beta}$-sheet & Random coil & Turn & \\
\hline \hline Lipid-free ApoE2 & 57 & 22 & 14 & 8 & 0.002 \\
Lipidated ApoE2 & 61 & 15 & 16 & 7 & 0.002 \\
Lipid-free ApoE3 & 56 & 20 & 16 & 8 & 0.003 \\
Lipidated ApoE3 & 64 & 14 & 11 & 10 & 0.002 \\
Lipid-free ApoE4 & 60 & 14 & 19 & 8 & 0.002 \\
Lipidated ApoE4 & 63 & 16 & 14 & 6 & 0.002 \\
\hline \hline
\end{tabular}

Figure 4.6: Effect of lipidation on the secondary structure of ApoE. The secondary structure content of lipidfree and HDL-like ApoE particles $(0.1 \mathrm{mg} / \mathrm{ml}$ in PBS) was studied by CD. CD reveals a predominant $\alpha$-helical structural signature for all samples characterized by double minima around $208 \mathrm{~nm}$ and $222 \mathrm{~nm}$. Secondary structure content of each sample was estimated using CDSSTR software $(40,41)$. The goodness of fit of the experimental CD data with the reference data is indicated by the NRMSD value.

In contrast, more pronounced differences could be observed in terms of tertiary structure, when lipid-free and lipid-bound ApoE were compared by their intrinsic Trp fluorescence. ApoE has seven Trp residues: four are located in the $\mathrm{N}$-terminal domain and three are situated in the C-terminal lipid-binding domain. ApoE particles displayed a marked blue shift in their fluorescence maximum upon lipidation (Fig. 4.7). We attribute this blue shift to tertiary structural alterations in the vicinity of the Trp residues resulting in an increased hydrophobic environment. 
A.

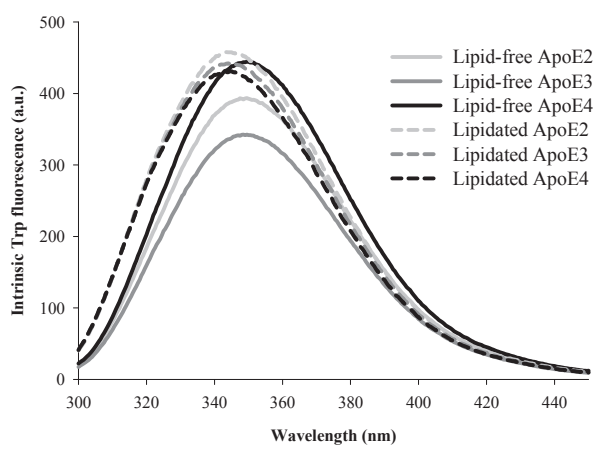

B.

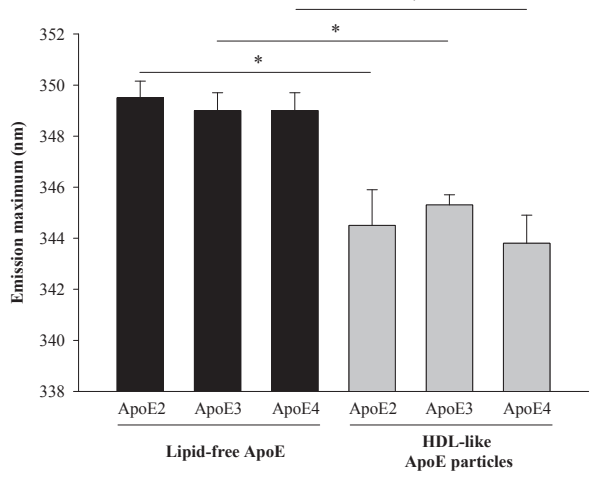

Figure 4.7: Effect of lipidation on the tertiary structure of ApoE. (A) Intrinsic Trp fluorescence emission spectra $\left(\lambda_{\mathrm{ex}}=280 \mathrm{~nm}\right)$ corresponding to lipid-free and HDL-like ApoE particles $(0.1 \mathrm{mg} / \mathrm{ml} \mathrm{in}$ PBS $)$. (B) The maximum of the Trp fluorescence emission spectrum of lipidated ApoE is blue-shifted compared to that of lipidfree ApoE. Statistical significance of the results was established by P-values using unpaired two-tailed t-tests, with * $\mathrm{P}<0.05$.

\subsection{Discussion}

ApoE has been reported to self-assemble (30-33) and the hypothesis has been raised that the amphipathic $\alpha$-helical structure of ApoE is stabilized upon lipid binding, which may protect it from amyloidogenic folding pathways (33). We provide experimental evidence that lipidation indeed impedes aggregation of ApoE, by comparing lipid-free ApoE and HDL-like discoidal ApoE particles of all three ApoE isoforms using a biophysical approach.

Our results show that lipid-free ApoE has the tendency to self-assemble, with ApoE4 having the highest aggregation propensity, followed by ApoE3 and ApoE2 (Fig. 4.3 to 4.5). This is in accordance with previous observations that provide evidence that ApoE oligomerizes through a monomer-dimer-tetramer association process (31), and can aggregate further from tetramers to higher molecular weight aggregates $(30,32)$. These aggregates displayed an $\alpha$-helical structure (33), in accordance with our results (Fig. 4.6). Moreover, the ApoE aggregation rate was previously shown to be isoform-dependent (ApoE4 $>$ ApoE3 $>$ ApoE2), which was attributed to differences in conformational stability of the ApoE N-terminal region, with a decreased stability resulting in a higher aggregation rate (33). Not only ApoE, but also other apolipoproteins including ApoA-I, ApoA-II, and ApoB100 display low conformational stability and have the tendency to self-assemble (42).

Despite the importance of the stability of the N-terminus, several studies have appointed the C-terminus as the main determinant of ApoE self-assembly (32, 43-46). The C-terminus of ApoE comprises amphipathic $\alpha$-helices and exposes a large, hydrophobic surface (14). Moreover, the C-terminal fragment $\mathrm{ApoE}_{216-299}$ forms aggregates in vitro (46). Fan and coworkers showed that mutations of hydrophobic residues in this region completely abolished self-assembly and rendered ApoE into its monomeric form (45). Furthermore, CD and sedimentation equilibrium analysis of the lipid-free ApoE C-terminal domain revealed an intermolecular coiled-coil helix formation that promotes ApoE dimerization and subsequent tetramerization (47).

As the lipid-binding region of ApoE is situated in the C-terminal region of ApoE, it was hypothesized that there might be a link between ApoE self-assembly and its lipid-binding 
properties $(48,49)$. This was confirmed by the observation that mutations abolishing aggregation resulted in increased formation of lipoprotein particles (48). Furthermore, high affinity binding to phospholipid vesicles required dissociation of ApoE oligomers to monomers (49).

Accordingly, we provide experimental evidence that lipidation impedes ApoE self-assembly into amorphous aggregates, as ApoE bound to lipids is smaller than when alone in solution, based on its hydrodynamic radius and migration properties (Fig. 4.3 to 4.5). Lipidation has minor effects on the secondary structure of ApoE, with the main contribution still arising from $\alpha$-helices (Fig. 4.6), but elicits tertiary structural alterations in the vicinity of Trp residues (Fig. 4.7). This observation is consistent with the general consensus that ApoE undergoes a lipid binding-induced conformational rearrangement (17). It has been suggested that lipidation might stabilize the amphipathic $\alpha$-helical structure of ApoE and protect it against aggregation (33). This is not a property solely applicable to ApoE, but also to other apolipoproteins that contain a large proportion of amphipathic $\alpha$-helices and display low conformational stability in the absence of lipids (42).

Although ApoE mostly occurs in its lipid-bound form in plasma and CSF, there are lipid-poor reservoirs that are vulnerable to aggregation: e.g. ApoE synthesized by macrophages and neurons in stress conditions (33). In particular, ApoE4 appears to be less lipidated than ApoE2 and ApoE3 (50). The higher propensity of lipid-free ApoE4 in solution to aggregate compared to other ApoE isoforms as shown by our data, and its ability to form aggregates that are toxic to neuronal cells (33), might therefore underlie its association with AD. 


\subsection{References}

1. Dieckmann M, Dietrich MF, \& Herz J (2010) Lipoprotein receptors - an evolutionarily ancient multifunctional receptor family. Biol Chem 391(11):1341-1363.

2. Mahley RW, Weisgraber KH, \& Huang Y (2009) Apolipoprotein E: structure determines function, from atherosclerosis to Alzheimer's disease to AIDS. J Lipid Res 50 Suppl:S183188 .

3. Verghese PB, Castellano JM, \& Holtzman DM (2011) Apolipoprotein E in Alzheimer's disease and other neurological disorders. Lancet Neurol 10(3):241-252.

4. Mahley RW (1988) Apolipoprotein E: cholesterol transport protein with expanding role in cell biology. Science 240(4852):622-630.

5. Zannis VI \& Breslow JL (1981) Human very low density lipoprotein apolipoprotein E isoprotein polymorphism is explained by genetic variation and posttranslational modification. Biochemistry 20(4):1033-1041.

6. Strittmatter WJ, et al. (1993) Apolipoprotein E: high-avidity binding to $\beta$-amyloid and increased frequency of type 4 allele in late-onset familial Alzheimer disease. Proc Natl Acad Sci U S A 90(5):1977-1981.

7. Farrer LA, et al. (1997) Effects of age, sex, and ethnicity on the association between apolipoprotein E genotype and Alzheimer disease. A meta-analysis. APOE and Alzheimer Disease Meta Analysis Consortium. JAMA 278(16):1349-1356.

8. Namba Y, Tomonaga M, Kawasaki H, Otomo E, \& Ikeda K (1991) Apolipoprotein E immunoreactivity in cerebral amyloid deposits and neurofibrillary tangles in Alzheimer's disease and kuru plaque amyloid in Creutzfeldt-Jakob disease. Brain Res 541(1):163-166.

9. Mahley RW, Weisgraber KH, \& Huang Y (2006) Apolipoprotein E4: a causative factor and therapeutic target in neuropathology, including Alzheimer's disease. Proc Natl Acad Sci U S A 103(15):5644-5651.

10. $\mathrm{Bu} \mathrm{G}$ (2009) Apolipoprotein $\mathrm{E}$ and its receptors in Alzheimer's disease: pathways, pathogenesis and therapy. Nat Rev Neurosci 10(5):333-344.

11. Iurescia S, Fioretti D, Mangialasche F, \& Rinaldi M (2010) The pathological cross talk between apolipoprotein E and amyloid- $\beta$ peptide in Alzheimer's disease: emerging gene-based therapeutic approaches. J Alzheimers Dis 21(1):35-48.

12. Liu CC, Kanekiyo T, Xu H, \& Bu G (2013) Apolipoprotein E and Alzheimer disease: risk, mechanisms and therapy. Nat Rev Neurol 9(2):106-118.

13. Huang Y (2010) A $\beta$-independent roles of apolipoprotein E4 in the pathogenesis of Alzheimer's disease. Trends Mol Med 16(6):287-294.

14. Hatters DM, Peters-Libeu CA, \& Weisgraber KH (2006) Apolipoprotein E structure: insights into function. Trends Biochem Sci 31(8):445-454.

15. Weisgraber KH, Rall SC, \& Mahley RW (1981) Human E apoprotein heterogeneity. Cysteinearginine interchanges in the amino acid sequence of the apo-E isoforms. $J$ Biol Chem 256(17):9077-9083.

16. Zhong N \& Weisgraber KH (2009) Understanding the association of apolipoprotein E4 with Alzheimer disease: clues from its structure. J Biol Chem 284(10):6027-6031.

17. Hauser PS, Narayanaswami V, \& Ryan RO (2011) Apolipoprotein E: from lipid transport to neurobiology. Prog Lipid Res 50(1):62-74.

18. Carter DB (2005) The interaction of amyloid- $\beta$ with ApoE. Subcell Biochem 38:255-272.

19. Tokuda T, et al. (2000) Lipidation of apolipoprotein E influences its isoform-specific interaction with Alzheimer's amyloid beta peptides. Biochem J 348 Pt 2:359-365.

20. Stratman NC, et al. (2005) Isoform-specific interactions of human apolipoprotein E to an intermediate conformation of human Alzheimer amyloid- $\beta$ peptide. Chem Phys Lipids 137(12):52-61.

21. Cramer PE, et al. (2012) ApoE-directed therapeutics rapidly clear $\beta$-amyloid and reverse deficits in AD mouse models. Science 335(6075):1503-1506.

22. Jiang Q, et al. (2008) ApoE promotes the proteolytic degradation of A $\beta$. Neuron 58(5):681693. 
23. Deane R, et al. (2008) ApoE isoform-specific disruption of amyloid $\beta$ peptide clearance from mouse brain. J Clin Invest 118(12):4002-4013.

24. Wildsmith KR, Holley M, Savage JC, Skerrett R, \& Landreth GE (2013) Evidence for impaired amyloid $\beta$ clearance in Alzheimer's disease. Alzheimers Res Ther 5(4):33.

25. Wahrle SE, et al. (2008) Overexpression of ABCA1 reduces amyloid deposition in the PDAPP mouse model of Alzheimer disease. J Clin Invest 118(2):671-682.

26. Yu JT, Tan L, \& Hardy J (2014) Apolipoprotein E in Alzheimer's Disease: An Update. Annu Rev Neurosci. Doi: 10.1146/annurev-neuro-071013-014300.

27. Liao F, et al. (2014) Anti-ApoE Antibody Given after Plaque Onset Decreases A $\beta$ Accumulation and Improves Brain Function in a Mouse Model of A $\beta$ Amyloidosis. $J$ Neurosci 34(21):7281-7292.

28. LaDu MJ, et al. (1998) Nascent astrocyte particles differ from lipoproteins in CSF. $J$ Neurochem 70(5):2070-2081.

29. DeMattos RB, et al. (2001) Purification and characterization of astrocyte-secreted apolipoprotein $\mathrm{E}$ and J-containing lipoproteins from wild-type and human apoE transgenic mice. Neurochem Int 39(5-6):415-425.

30. Perugini MA, Schuck P, \& Howlett GJ (2000) Self-association of human apolipoprotein E3 and E4 in the presence and absence of phospholipid. J Biol Chem 275(47):36758-36765.

31. Garai K \& Frieden C (2010) The association-dissociation behavior of the ApoE proteins: kinetic and equilibrium studies. Biochemistry 49(44):9533-9541.

32. Chou CY, et al. (2005) Structural variation in human apolipoprotein E3 and E4: secondary structure, tertiary structure, and size distribution. Biophys $J$ 88(1):455-466.

33. Hatters DM, Zhong N, Rutenber E, \& Weisgraber KH (2006) Amino-terminal domain stability mediates apolipoprotein E aggregation into neurotoxic fibrils. $J$ Mol Biol 361(5):932944.

34. Jonas A, Sweeny SA, \& Herbert PN (1984) Discoidal complexes of A and C apolipoproteins with lipids and their reactions with lecithin: cholesterol acyltransferase. $J$ Biol Chem 259(10):6369-6375.

35. Wilkins MR, et al. (1999) Protein identification and analysis tools in the ExPASy server. Methods Mol Biol 112:531-552.

36. Zhang L, et al. (2010) An optimized negative-staining protocol of electron microscopy for apoE4 POPC lipoprotein. J Lipid Res 51(5):1228-1236.

37. Sreerama N \& Woody RW (2000) Estimation of protein secondary structure from circular dichroism spectra: comparison of CONTIN, SELCON, and CDSSTR methods with an expanded reference set. Anal Biochem 287(2):252-260.

38. Whitmore L \& Wallace BA (2008) Protein secondary structure analyses from circular dichroism spectroscopy: methods and reference databases. Biopolymers 89(5):392-400.

39. Fagan AM, et al. (1999) Unique lipoproteins secreted by primary astrocytes from wild type, apoE (-/-), and human apoE transgenic mice. J Biol Chem 274(42):30001-30007.

40. Yamauchi K, et al. (1999) Apolipoprotein E in cerebrospinal fluid: relation to phenotype and plasma apolipoprotein E concentrations. Clin Chem 45(4):497-504.

41. Morrow JA, et al. (2000) Differences in stability among the human apolipoprotein E isoforms determined by the amino-terminal domain. Biochemistry 39(38):11657-11666.

42. Hatters DM \& Howlett GJ (2002) The structural basis for amyloid formation by plasma apolipoproteins: a review. Eur Biophys $J$ 31(1):2-8.

43. Aggerbeck LP, Wetterau JR, Weisgraber KH, Wu CS, \& Lindgren FT (1988) Human apolipoprotein E3 in aqueous solution. II. Properties of the amino- and carboxyl-terminal domains. J Biol Chem 263(13):6249-6258.

44. Westerlund JA \& Weisgraber KH (1993) Discrete carboxyl-terminal segments of apolipoprotein E mediate lipoprotein association and protein oligomerization. $J$ Biol Chem 268(21):15745-15750.

45. Fan D, Li Q, Korando L, Jerome WG, \& Wang J (2004) A monomeric human apolipoprotein E carboxyl-terminal domain. Biochemistry 43(17):5055-5064.

46. Wisniewski T, Lalowski M, Golabek A, Vogel T, \& Frangione B (1995) Is Alzheimer's disease an apolipoprotein E amyloidosis? Lancet 345(8955):956-958. 
47. Choy N, Raussens V, \& Narayanaswami V (2003) Inter-molecular coiled-coil formation in human apolipoprotein E C-terminal domain. J Mol Biol 334(3):527-539.

48. Zhang Y, et al. (2007) A monomeric, biologically active, full-length human apolipoprotein E. Biochemistry 46(37):10722-10732.

49. Garai K, Baban B, \& Frieden C (2011) Dissociation of apolipoprotein E oligomers to monomer is required for high-affinity binding to phospholipid vesicles. Biochemistry 50(13):2550-2558.

50. Tai LM, et al. (2014) Soluble apoE/A $\beta$ complex: mechanism and therapeutic target for APOE4-induced AD risk. Mol Neurodegener 9:2. 


\section{Chapter 5}

\section{Insights into insulin-degrading enzyme-mediated cleavage of the A $\beta$ peptide}

This chapter has been submitted to FEBS Letters.

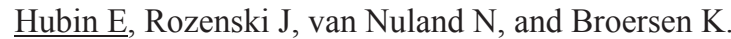

An impairment of $A \beta$ clearance can underlie the accumulation of the $A \beta$ peptide in amyloid plaques in the brain and result in AD. One major pathway involved in removal of $A \beta$ in the brain is proteolytic degradation by enzymes such as IDE. Upregulating the activity of IDE by small-molecule activators is currently being assessed as a potential therapeutic strategy for AD. However, a full understanding of the degrading capacity of IDE is required to unravel the possible therapeutic potential of IDE in AD treatment. It is generally accepted that IDE degrades the monomeric $\mathrm{A} \beta$ peptide, but little is known about the capability of IDE to cleave $A \beta$ aggregates, in particular $A \beta$ oligomers that have been suggested to be the primary toxic agents in $\mathrm{AD}$. Using a biophysical approach, we studied IDE-mediated degradation of different $A \beta$ aggregation states in vitro. Our findings show that $A \beta_{1-40}$ and $A \beta_{1-42}$ monomers are cleaved at multiple and similar sites by IDE, and that the efficiency of IDE-mediated A $\beta$ degradation decreases with prolonged $A \beta$ aggregation. We identify $\mathrm{Met}_{35}-\mathrm{Val}_{36}$ as a novel IDE cleavage site in the $A \beta$ sequence and show that $A \beta$ fragments resulting from IDEmediated cleavage are aggregation-prone. The aggregative and potentially toxic behaviour of $\mathrm{A} \beta$ fragments generated upon cleavage by IDE must be taken into account in the design of IDE-based therapeutic strategies for AD. 


\subsection{Introduction}

AD patients generally show a decreased clearance of the $\mathrm{A} \beta$ peptide compared to healthy control subjects (1). The impairment of $A \beta$ clearance, in some cases combined with an increased $A \beta$ production, results in assembly of $A \beta$ into aggregated forms (2). Therefore, lowering the $A \beta$ burden by increasing $A \beta$ clearance provides a promising avenue for $A D$ treatment.

Clearance of $A \beta$ in the human brain is predominantly mediated by two pathways: receptormediated $\mathrm{A} \beta$ transport across the $\mathrm{BBB}$, and cleavage by $\mathrm{A} \beta$-degrading enzymes (3). Many proteases have been reported to cleave $A \beta$ in vivo or in vitro, including insulin-degrading enzyme (IDE), neprilysin (NEP), endothelin-converting enzyme, angiotensin-converting enzyme, and matrix metallo-endopeptidase-9 (MMP-9) (4-7).

In this chapter, we will focus on IDE, a $\mathrm{Zn}^{2+}$-metalloendopeptidase, for which a link with AD has been proven through numerous studies. First, Bertram and co-workers identified a genetic linkage of $\mathrm{AD}$ to chromosome 10 in the region to which $I D E$ is mapped (8), and several single nucleotide polymorphisms within the IDE gene are associated with AD (9). Second, IDE effectively degrades synthetic $A \beta$ in vitro $(10,11)$ and overexpression of IDE in cultured cells resulted in a marked reduction in $A \beta$ levels (12). Third, rat and mouse models deficient for IDE displayed increased levels of $\mathrm{A} \beta(13,14)$, whereas IDE overexpression improved AD pathology and resulted in significant reduction of total amyloid burden and an improved survival rate (15).

In addition to the $\mathrm{A} \beta$ peptide, IDE degrades a wide range of other substrates including insulin, amylin, glucagon, insulin-like growth factors, and transforming growth factor-alpha. Amino acid sequence comparisons of these substrates revealed no significant similarity between them. However, they share the ability to form amyloid fibrils under physiological conditions and it has been suggested that IDE selects its substrates on their ability to adopt a $\beta$-sheet conformation upon interaction $(16,17)$.

In view of the development of IDE-based therapies for $\mathrm{AD}$, a full comprehension of the $\mathrm{A} \beta$ degrading capacity of IDE is required. It has previously been reported that IDE is capable of degrading monomeric $A \beta(10,18-20)$, but the ability of IDE to cleave $A \beta$ aggregates such as oligomers, suggested to be the primary toxic species in AD (21), and fibrils, is less welldocumented in the literature. To extend our understanding of IDE activity, we therefore monitored and characterized IDE-mediated cleavage of $\mathrm{A} \beta$ in vitro using biophysical techniques, at different time points during the $A \beta$ aggregation process.

\subsection{Experimental procedures}

\subsubsection{A $\beta$ peptide solubilization}

$A \beta_{1-40}, A \beta_{1-42}$, and ${ }^{15} \mathrm{~N}$-labeled $A \beta$ peptides (RPeptide) were dissolved according to the standard procedure developed and validated in our laboratory (22). In short, A $\beta$ peptides were dissolved in HFIP. HFIP was evaporated using nitrogen gas and the peptide film was redissolved using DMSO. The peptide was separated from DMSO by elution from a HiTrap $^{\mathrm{TM}}$ desalting column (GE Healthcare) into the appropriate filtered buffer (ThT fluorescence measurements: PBS pH 7.4, ESI-MS: $100 \mathrm{mM} \mathrm{NH}_{4} \mathrm{HCO}_{3} \mathrm{pH}$ 7.4, NMR: $50 \mathrm{mM}$ phosphate buffer $\mathrm{pH} 6.8$ containing $50 \mathrm{mM} \mathrm{NaCl}$ ). The resulting samples were kept on ice until experiments started with a maximum lag time of 30 min. Peptide concentration was determined using the Coomassie (Bradford) Protein Assay kit and diluted to the required final 
concentration: $10 \mu \mathrm{M}$ for ThT/ESI-MS measurements and $45 \mu \mathrm{M}$ for NMR experiments. Aggregation of $\mathrm{A} \beta$ peptides occurred at $37^{\circ} \mathrm{C}$ under quiescent conditions.

\subsubsection{IDE-mediated $A \beta$ degradation}

IDE (R\&D Systems) was added to $A \beta$ samples at a final concentration of $36 \mathrm{nM}$ at the beginning of the aggregation process, after $3 \mathrm{~h}$, and after $21 \mathrm{~h}$ and later. Under these conditions but in the absence of IDE, samples comprise mainly A $\beta$ monomers $(0 \mathrm{~h})$, oligomers $(3 \mathrm{~h})$, and (proto)fibrils ( $21 \mathrm{~h}$ and later), as demonstrated in (22). IDE-mediated cleavage of $\mathrm{A} \beta$ was monitored by ThT fluorescence, ESI-MS, and solution NMR.

\subsubsection{ThT fluorescence to monitor IDE-mediated cleavage of the A $\beta$ peptide}

The fibrillization kinetics of $\mathrm{A} \beta$ preparations were monitored in situ by measuring fluorescence of ThT $(12 \mu \mathrm{M})$ at $37^{\circ} \mathrm{C}$ in a Greiner 96-well plate using a FLUOstar OPTIMA fluorescence plate reader (BMG LABTECH GmbH, Germany) at an excitation wavelength of $440 \mathrm{~nm}$ (9 nm bandwidth) and an emission wavelength of $480 \mathrm{~nm}$ (20 nm bandwidth). Fluorescence readings were recorded every $5 \mathrm{~min}$ for a period of $46 \mathrm{~h}$. Recorded values were averaged and background measurements (buffer containing ThT with or without IDE) were subtracted.

\subsubsection{Identification of generated A $\beta$ fragments upon IDE cleavage using ESI-MS}

ESI-MS was used to identify A $\beta$ fragments generated by IDE (23). Positive-ion mass spectra were recorded on an orthogonal acceleration quadrupole time-of-flight mass spectrometer (Synapt G2 HDMS, Waters, Milford, MA) equipped with a standard electrospray probe (Zspray) and controlled by a datasystem running MassLynx 3.4 (Micromass, Manchester, UK), which was also used for spectra analysis and peptide fragment identification. Samples were diluted 1:10 in acetonitrile:water (1:1) prior to immediate infusion using a syringe pump with a flow rate of $5 \mu \mathrm{l} / \mathrm{min}$. Cone voltage was set to $30 \mathrm{~V}$, capillary voltage was $3 \mathrm{kV}$. Scan time was set to $4.9 \mathrm{~s}$ with an inter-scan time of $0.1 \mathrm{~s}$. At least ten spectra were acquired and averaged.

\subsubsection{Solution NMR spectroscopy as a tool to monitor A $\beta$ aggregation and IDE- mediated degradation}

Prior to incubation, $50 \mu 1 \mathrm{D}_{2} \mathrm{O}$ was added to ${ }^{15} \mathrm{~N}$-labeled $\mathrm{A} \beta$ (45 $\mu \mathrm{M}$ final concentration) to reach a final volume of $550 \mu \mathrm{l}$. The $2 \mathrm{D}{ }^{1} \mathrm{H}_{-}{ }^{15} \mathrm{~N}$ heteronuclear single quantum correlation spectroscopy (HSQC) experiments were conducted at $37^{\circ} \mathrm{C}$ with a Varian NMR Direct-Drive System $800 \mathrm{MHz}$ spectrometer equipped with a salt tolerance triple-resonance PFG-Z cold probe. Data were processed using NMRPipe (24) and analysed using NMRView (25).

\subsection{Results}

\subsubsection{A $\beta$ aggregation state determines susceptibility for degradation by IDE}

The ability of IDE to cleave different aggregation states of $A \beta_{1-40}$ and $A \beta_{1-42}$ was assessed by ThT fluorescence (Fig. 5.1). In the absence of IDE, $A \beta_{1-40}$ aggregation was marked by a strong increase in ThT fluorescence, indicative for fibril formation. In contrast, addition of IDE to monomeric $A \beta_{1-40}$ prevented fibril formation, as the ThT background signal did not increase, showing that IDE is capable of degrading $A \beta_{1-40}$ monomers into fragments that do not form ThT-positive aggregates upon prolonged incubation (Fig. 5.1A). IDE addition at 
later $A \beta$ aggregation time points, enriched in oligomers $(3 \mathrm{~h})$ or (proto)fibrils $(21 \mathrm{~h})(22)$, induced a partial decrease in ThT fluorescence. This partial decrease suggests (i) degradation of ThT-positive $A \beta_{1-40}$ aggregates by IDE, or (ii) degradation of monomers in solution that are in dynamic equilibrium with ThT-positive aggregates, causing dissociation of ThT-positive aggregates to restore this equilibrium. The cleavage of $A \beta_{1-42}$ by IDE showed many similarities with the observations for $A \beta_{1-40}$ and was characterized by a strong inhibition of $A \beta_{1-42}$ fibril formation when IDE was added at the beginning of the aggregation process, and by a drop in ThT fluorescence when IDE was added at later aggregation time points (Fig. $5.1 \mathrm{~B})$. However, the decrease in ThT fluorescence upon addition of IDE to the aggregated $A \beta_{1-42}$ sample was less pronounced than for $A \beta_{1-40}$. These results suggest that ThT-positive aggregates, both of $A \beta_{1-40}$ and $A \beta_{1-42}$, are at least partially resistant to IDE-induced cleavage.

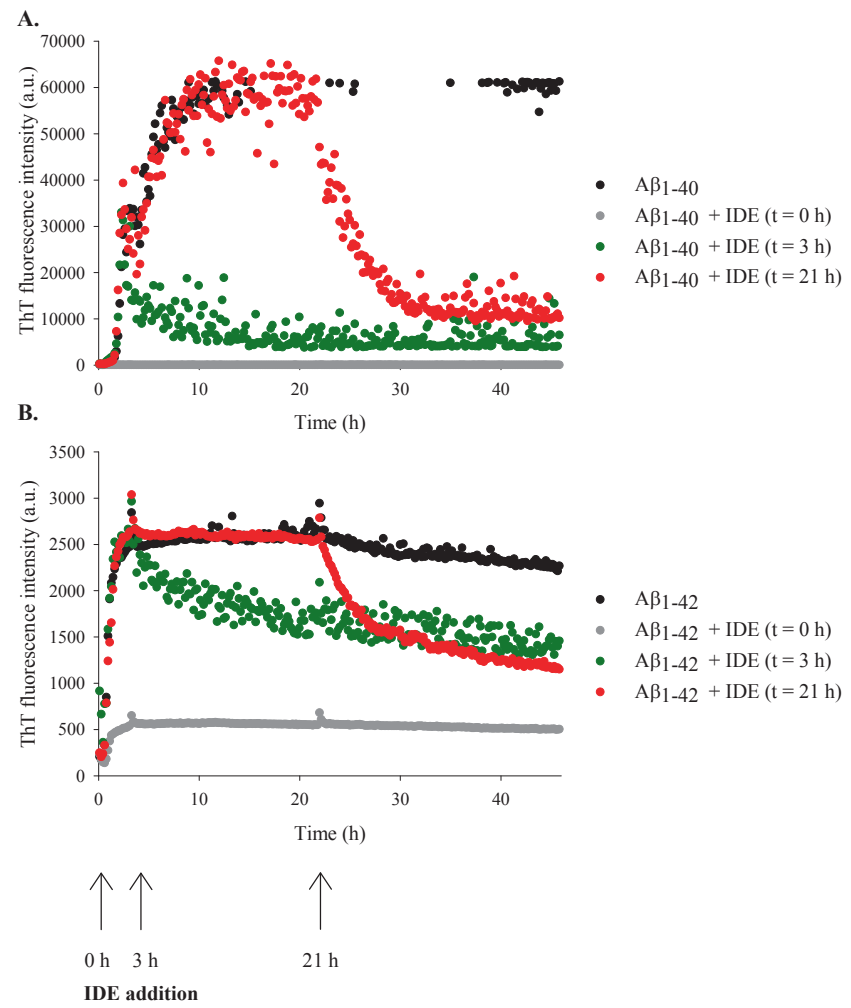

Figure 5.1: A $\beta$ aggregation state determines susceptibility for IDE-mediated degradation. Aggregation of $10 \mu \mathrm{M}$ (A) $\mathrm{A} \beta_{1-40}$ and (B) $A \beta_{1-42}$ was monitored by ThT fluorescence. IDE (36 nM) was added to the $A \beta$ sample at the beginning of the $A \beta$ aggregation process (sample comprising mainly $A \beta$ monomers), after $3 \mathrm{~h}$ (enriched in oligomers), and after $21 \mathrm{~h}$ (enriched in (proto)fibrils).

\subsubsection{A $\beta$ degradation by IDE results in multiple fragments}

To investigate which fragments are formed upon IDE-mediated cleavage of $A \beta$, the cleavage patterns of $A \beta_{1-40}$ and $A \beta_{1-42}$ by IDE were determined using ESI-MS. First, our results show that monomeric $A \beta_{1-40}$ and $A \beta_{1-42}$ are cleaved at multiple and similar sites (Fig. 5.2 and Fig. $\mathrm{S} 1$ in section 5.5). Moreover, one $\mathrm{A} \beta$ peptide can be cleaved by IDE at least twice, since fragments $A \beta_{14-28}, A \beta_{15-28}$, and $A \beta_{20-28}$ were detected. 


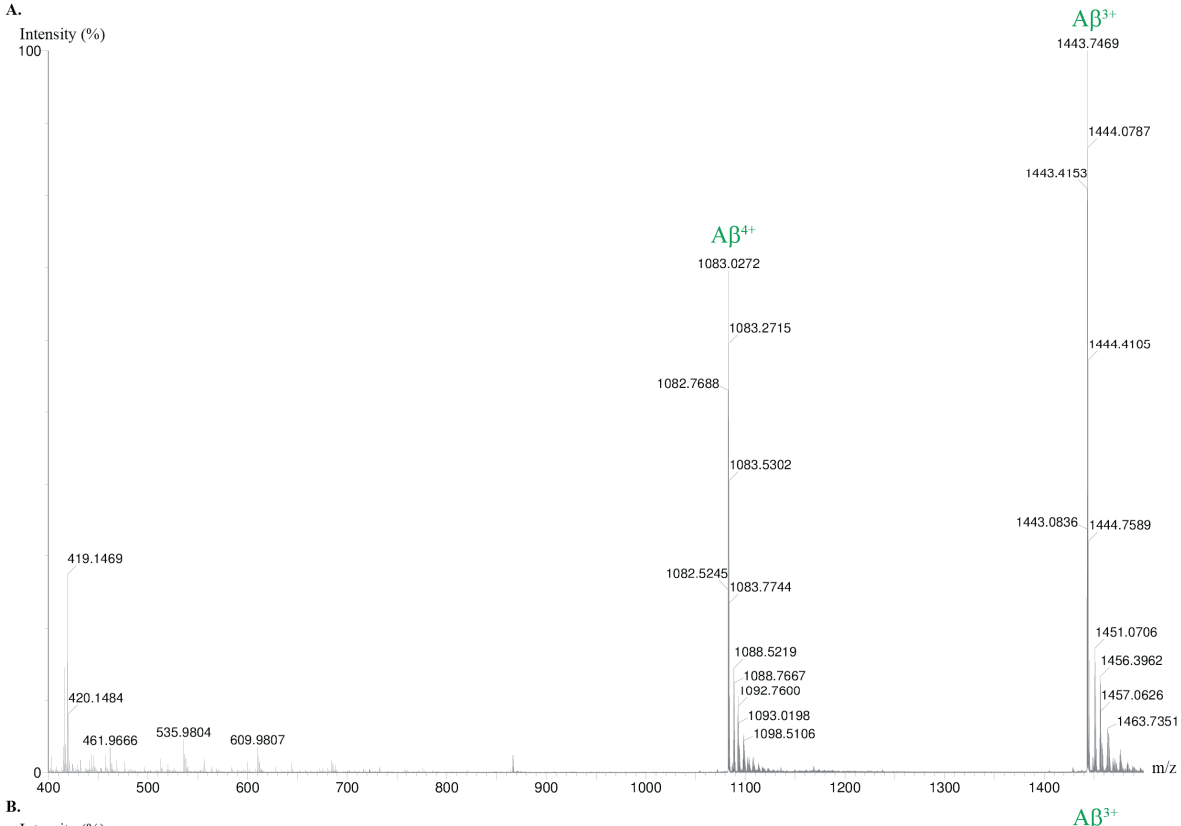

B. ntensity (\%)

100

419.1469

1444.0787

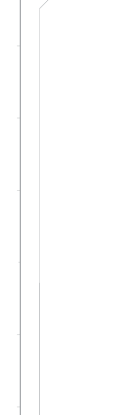

(1)

420.1484
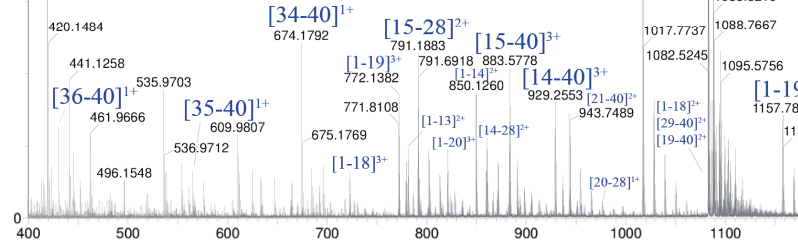

700

C.
90

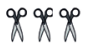
xo
$2 x$
$\left.\mathrm{D}_{1} \mathrm{~A}_{2} \mathrm{E}_{3} \mathrm{~F}_{4} \mathrm{R}_{5} \mathrm{H}_{6} \mathrm{D}_{7} \mathrm{~S}_{8} \mathrm{G}_{9} \mathrm{Y}_{10} \mathrm{E}_{11} \mathrm{~V}_{12} \mathrm{H}_{13} \mathrm{H}_{14} \mathrm{Q}_{15} \mathrm{~K}_{16} \mathrm{~L}_{17} \mathrm{~V}_{18} \mathrm{~F}_{19} \mathrm{~F}_{20} \mathrm{~A}_{21} \mathrm{E}_{22} \mathrm{D}_{23} \mathrm{~V}_{24} \mathrm{G}_{25} \mathrm{~S}_{26} \mathrm{~N}_{27} \mathrm{~K}_{28} \mathrm{G}_{28} \mathrm{~A}_{30} \mathrm{I}_{31} \mathrm{I}_{32} \mathrm{G}_{33} \mathrm{~L}_{34} \mathrm{M}_{35} \mathrm{~V}_{36} \mathrm{G}_{37} \mathrm{G}_{38} \mathrm{~V}_{39} \mathrm{~V}_{40} \mathrm{I}_{41} \mathrm{~A}_{42}\right)$

Figure 5.2: IDE-mediated cleavage of monomeric $A \beta$ results in multiple fragments. Assignment of ion peaks detected by ESI-MS associated with monomeric $\mathrm{A} \beta_{1-40}(10 \mu \mathrm{M})$ in $\mathbf{( A )}$ absence and (B) presence of $36 \mathrm{nM}$ IDE, after 15 min of incubation at $37{ }^{\circ} \mathrm{C}$. (C) Overview of the detected $A \beta_{1-40}$ and $A \beta_{1-42}$ sites susceptible to IDE proteolysis. 
Second, and consistent with ThT fluorescence data, IDE addition to aggregated A $\beta$ resulted in similar fragments compared to addition of IDE to monomeric $A \beta$, but there was a considerable amount of non-degraded $\mathrm{A} \beta$ peptide left in the sample (Fig. 5.3).

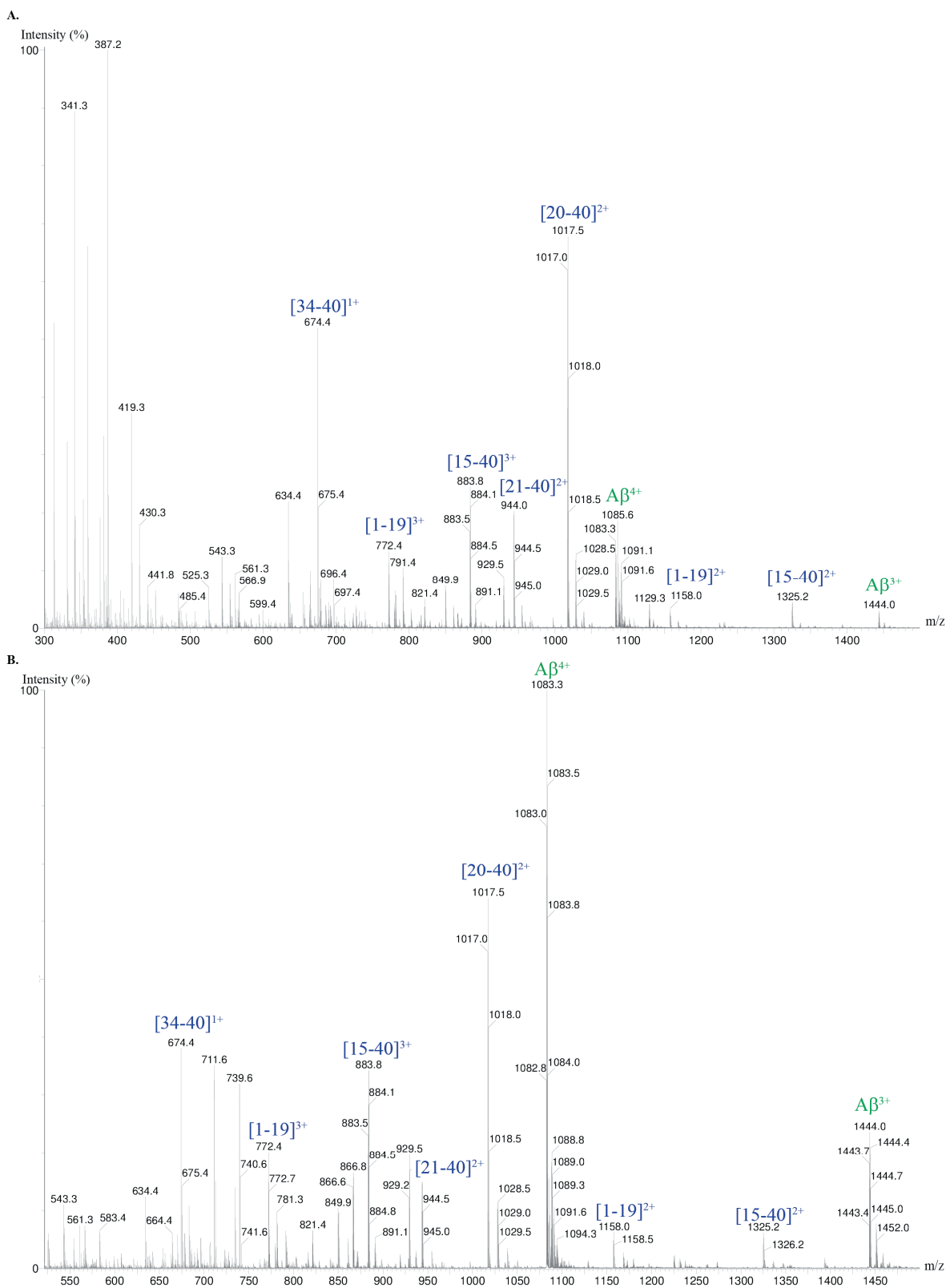

Figure 5.3: Longer incubation times of A $\beta$ prior to IDE addition result in a decrease in susceptibility of $A \beta$ for IDE-mediated cleavage. Assignment of $\mathrm{A} \beta_{1-40}$ fragments detected by ESI-MS. IDE $(36 \mathrm{nM})$ was added to an $\mathrm{A} \beta_{1-40}(10 \mu \mathrm{M})$ buffered solution at $(\mathbf{A}) \mathrm{t}=0 \mathrm{~h}$ and $(\mathbf{B}) \mathrm{t}=24 \mathrm{~h}$ of the aggregation process, and incubated for 1 $\mathrm{h}$ at $37^{\circ} \mathrm{C}$. Samples were centrifuged for $15 \mathrm{~min}$ at $13200 \mathrm{rpm}$ prior to ESI-MS analysis and the data depicted here correspond to the soluble fractions. 
This can be seen in fig. 5.3B by the higher intensities of the ion peaks corresponding to fulllength $\mathrm{A} \beta\left(\mathrm{A} \beta^{3+}\right.$ at $m / z$ 1443.0, $\mathrm{A} \beta^{4+}$ at $m / z$ 1083.3) compared to the most intense generated fragment $\mathrm{A} \beta_{20-40}\left(\mathrm{~A} \beta_{20-40}{ }^{2+}\right.$ at $m / z$ 1017.5).

\subsubsection{Generated $A \beta$ fragments are aggregation-prone}

The properties of the obtained fragments upon IDE-mediated cleavage of $\mathrm{A} \beta$ have not yet been explored. ThT fluorescence data indicated that no ThT-positive aggregates were formed from the $A \beta$ fragments obtained upon IDE-induced cleavage of monomeric A $\beta$ (Fig. 5.1). However, ThT fluorescence intensity may not provide the most sensitive read-out to detect small quantities of aggregation, possibly formed only by a specific subset of fragments. Hence, to further characterize IDE-mediated $A \beta$ cleavage and to reveal whether $A \beta$ fragments resulting from IDE action were prone to aggregation, the IDE-mediated degradation of ${ }^{15} \mathrm{~N}$ labeled $\mathrm{A} \beta$ was monitored by solution NMR spectroscopy, and ${ }^{1} \mathrm{H}-{ }^{15} \mathrm{~N}$ HSQC spectra were acquired at $37^{\circ} \mathrm{C}$.

Fig. 5.4 shows that ${ }^{15} \mathrm{~N}$-labeled $\mathrm{A} \beta_{1-40}$ aggregation was accompanied by a systematic decrease of all peak intensities in time as only early $A \beta$ aggregation states are detectable by solution NMR, whereas the resonances broaden and signal intensities decrease due to long rotational correlation times when aggregation ensues (26). However, after $40 \mathrm{~h}$ of incubation of $\mathrm{A} \beta_{1-40}$ at $37{ }^{\circ} \mathrm{C}$, some residual signal intensity was still present. This is in agreement with previous studies showing a decrease in intensity for the backbone amides until a dynamic equilibrium is established between monomers and higher ordered aggregates $(27,28)$.

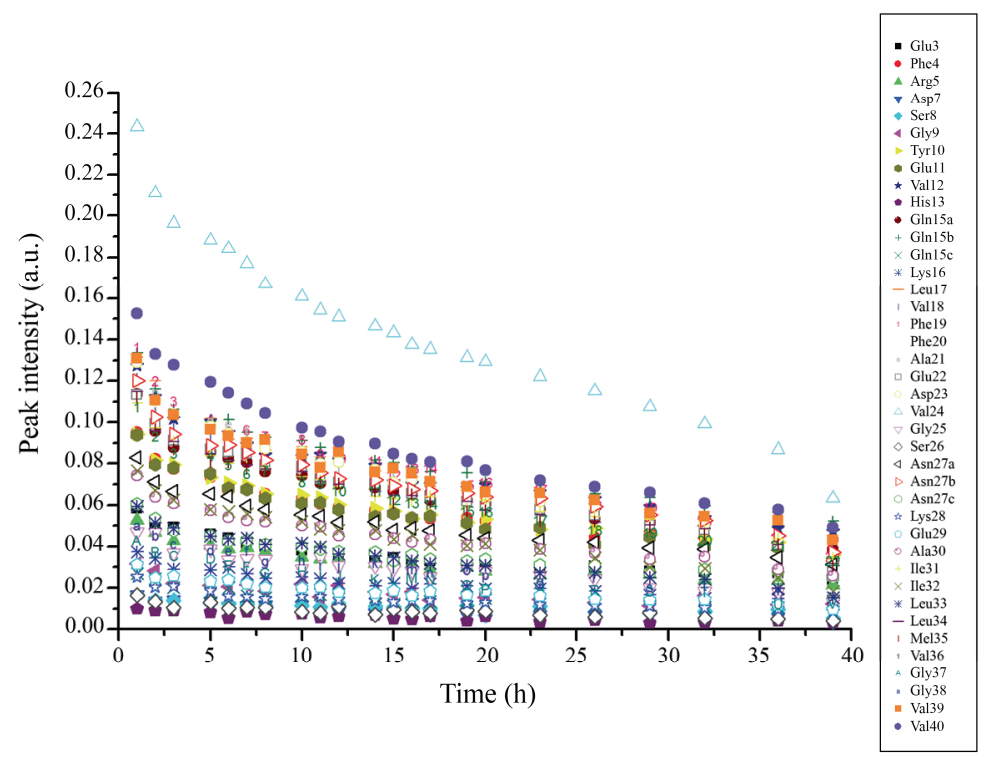

Figure 5.4: Decrease in ${ }^{1} \mathbf{H}^{15}{ }^{15}$ HSQC signal intensity upon aggregation of $\mathbf{A} \boldsymbol{\beta}_{1-40}$. Peak assignments of the ${ }^{1} \mathrm{H}-{ }^{15} \mathrm{~N}$ HSQC spectrum of $\mathrm{A} \beta_{1-40}$ were transferred from previous studies (28-30).

Next, addition of IDE to the aggregated A $\beta$ sample resulted in reappearance of the peak intensities and changes in chemical shifts of some peaks (Fig. 5.5 and S2). Several new peaks emerged, and other peaks were shifted or split in comparison with the original spectrum. These findings reflect changes in the local environment of certain amino acids, most likely because different $A \beta$ fragments were generated by IDE. However, it should be noted that 
longer pre-incubation of the $A \beta$ peptide, resulting in maturation of fibrils, was not accompanied by reappearance of the spectrum after addition of IDE (Fig. S3).

The NMR signal in fig. 5.5 eventually disappeared in time, as seen by comparing the peak intensities after $30 \mathrm{~h}, 36 \mathrm{~h}$, and $72 \mathrm{~h}$ of incubation of the sample with IDE. This suggests that the generated $\mathrm{A} \beta$ fragments aggregate themselves or stick to larger remaining aggregates in the sample. This hypothesis is in accordance with ESI-MS results that revealed the presence of $A \beta$ fragments in the sample pellet after prolonged incubation, demonstrating their tendency to aggregate (Fig. 5.6).

In vivo, several $A \beta$-degrading enzymes with different $A \beta$-degrading capacities exist. It is thus possible that $A \beta$ aggregates that have not or only partially been degraded by IDE are sensitive to yet other known enzymes with $A \beta$-degrading activity. We tested this hypothesis by adding a second $A \beta$-degrading enzyme, i.e. NEP, to the aggregated $A \beta$ sample that had first been subjected to IDE. We found that NEP addition resulted in the appearance of new peaks and shifting/splitting of other peaks (Fig. S2).

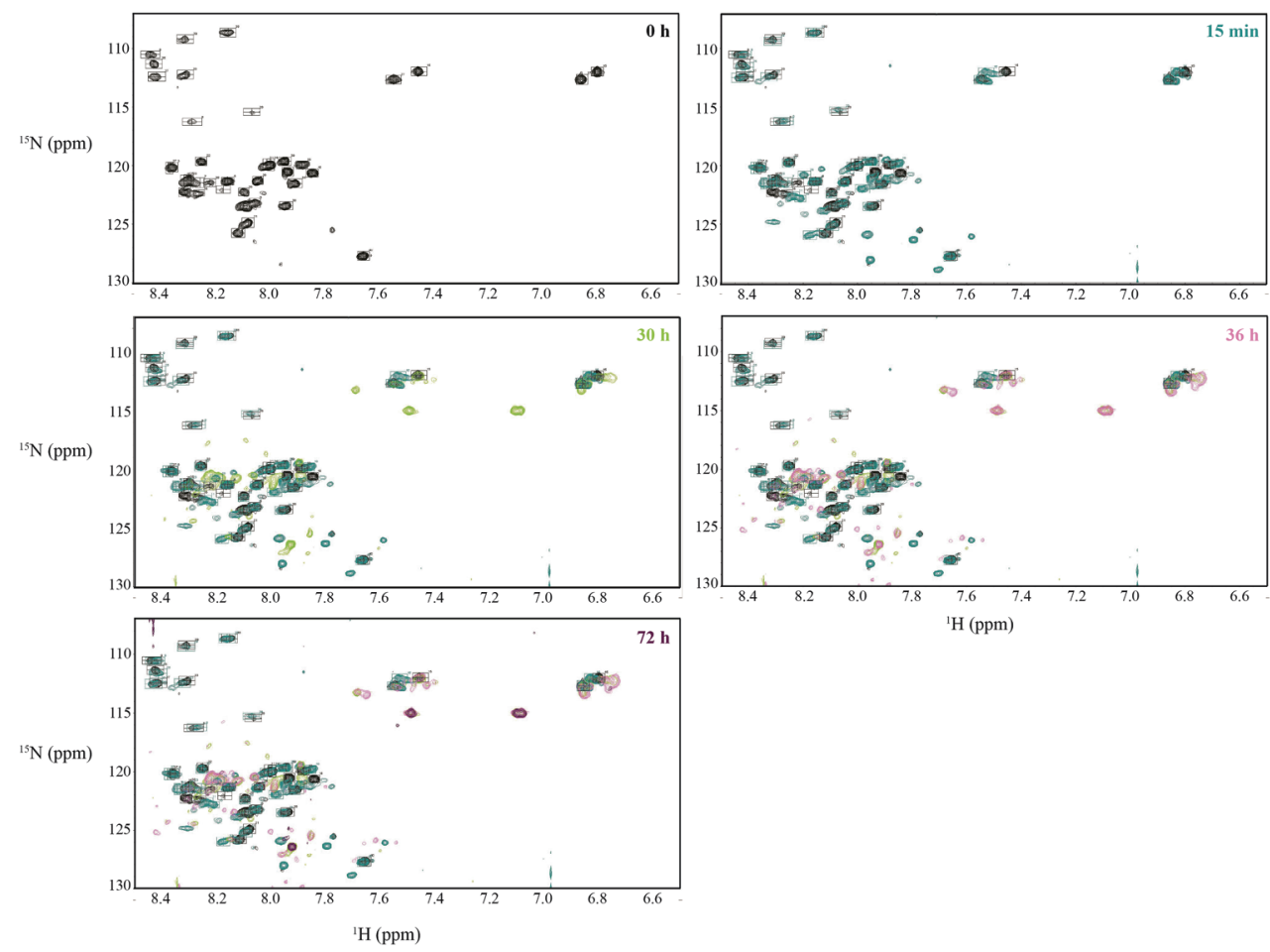

Figure 5.5: Aggregation and cleavage of $\mathbf{A} \boldsymbol{\beta}_{1-40}$ monitored by solution NMR spectroscopy. The ${ }^{1} \mathrm{H}_{-}{ }^{15} \mathrm{~N}$ HSQC signal of aggregated $\mathrm{A} \beta_{1-40}\left(45 \mu \mathrm{M}, 20 \mathrm{~h}\right.$ at $37^{\circ} \mathrm{C}$, depicted in black) is altered upon addition of IDE (36 $\mathrm{nM})$ and reveals new peaks, and shifting and splitting of original peaks. However, the signal intensity decays in time, indicating that the generated fragments also aggregate, or stick to larger aggregates still present in the sample. 
A.

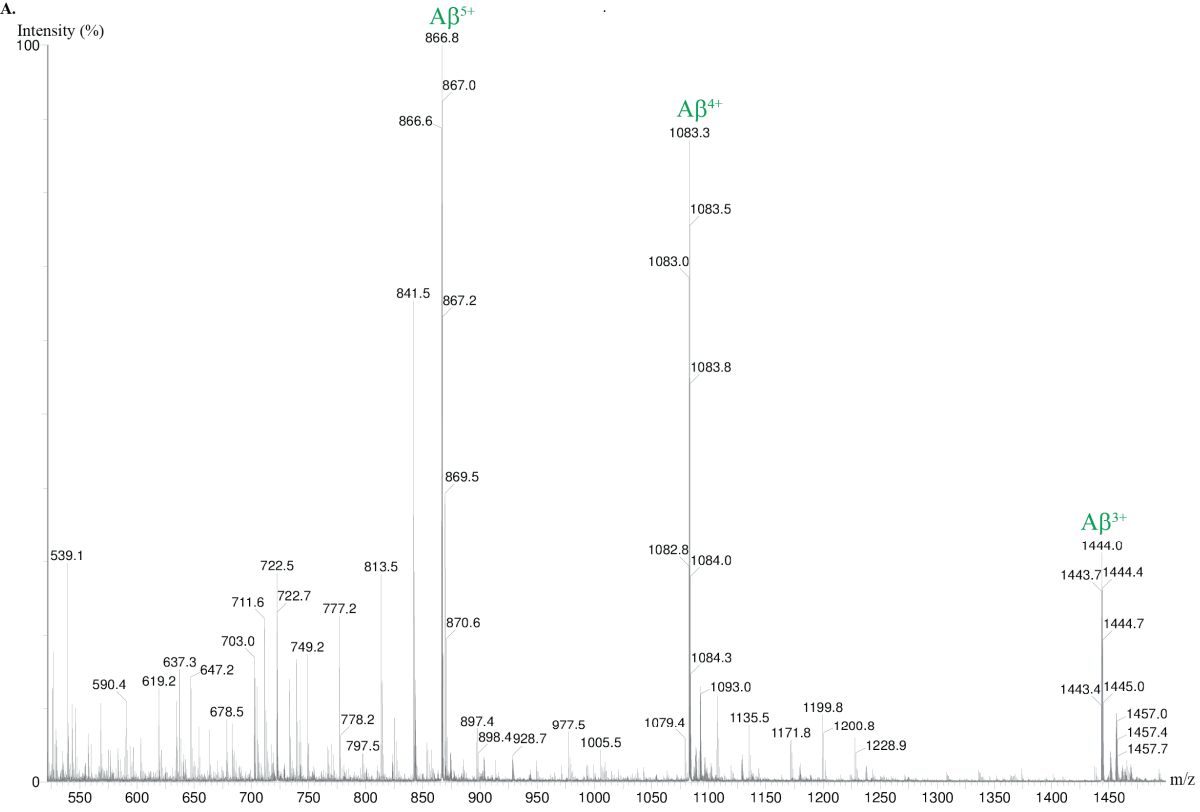

B.

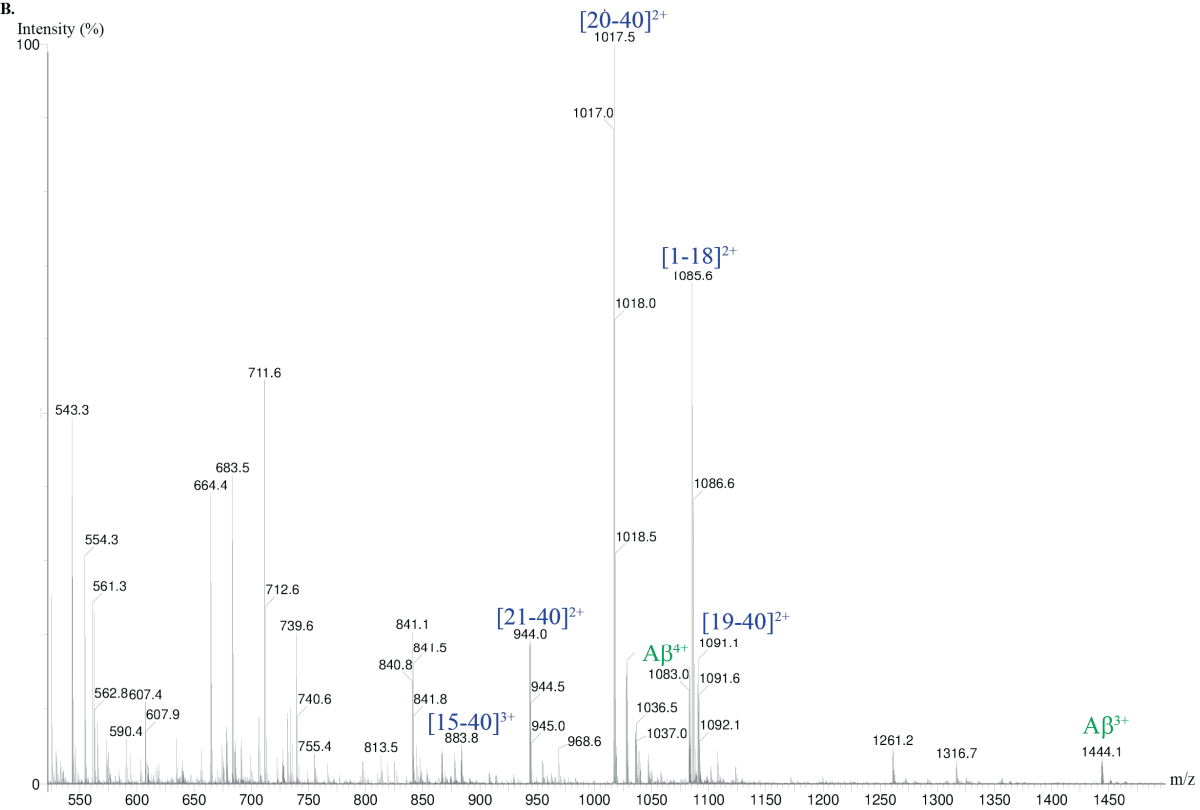

Figure 5.6: $\mathbf{A} \beta$ fragments aggregate in time and are detected in the pellet of the $\mathbf{A} \boldsymbol{\beta}_{1-40}$-IDE sample. IDE $(36 \mathrm{nM})$ was added to aggregated $\mathrm{A} \beta_{1-40}(10 \mu \mathrm{M})$, that was pre-incubated for $24 \mathrm{~h}$ at $37^{\circ} \mathrm{C}$, and ESI-MS spectra of the pellet fractions (obtained after $15 \mathrm{~min}$ of centrifugation at $13200 \mathrm{rpm}$ ) were obtained after (A) $1 \mathrm{~h}$ and (B) $24 \mathrm{~h}$ of incubation with IDE. Whereas the pellet fraction only displayed ion peaks corresponding to full-length $\mathrm{A} \beta_{1-40}$ after $1 \mathrm{~h}$ of IDE incubation, cleavage fragments were observed in the pellet after $48 \mathrm{~h}$ of incubation, indicating that generated $A \beta$ fragments aggregate in time. 


\subsection{Discussion}

IDE has the ability to cleave $A \beta$ intra- and extracellularly and may prove valuable as a target to upregulate $A \beta$ clearance in impaired AD patients (31-33). Therefore, drug compounds are under development that can modulate IDE activity to enhance $\mathrm{A} \beta$ degradation in AD patients (34-36). However, to fully comprehend the therapeutic potential of IDE, it is necessary to have insight into its degrading capacity. IDE cleaves monomeric $A \beta(6)$, but the ability of IDE to cleave $\mathrm{A} \beta$ oligomers, considered the main toxic species in $\mathrm{AD}(21)$, or fibrils, is not wellknown. In this study, we therefore monitored IDE-mediated cleavage of $\mathrm{A} \beta$ in vitro, at different time points during its aggregation, to gain more insight into the potential therapeutic utility of IDE in AD.

Degradation of various $A \beta$ aggregated species was initially assessed by monitoring changes in ThT fluorescence, as this is a commonly used reporter dye for fibril formation (37). Fig. 5.1 shows that A $\beta$ monomers are efficiently cleaved by IDE, and that IDE prevents formation of ThT-positive aggregates within the time frame of the measurements. This is in agreement with previous studies demonstrating IDE-mediated cleavage of $\mathrm{A} \beta$ monomers $(10,18-20)$. Moreover, cleavage fragments were identified by ESI-MS and demonstrated that $A \beta_{1-40}$ and $A \beta_{1-42}$ monomers are cleaved at similar sites (Fig. 5.2). As one of the roles of IDE is to completely inactivate hormones (38), this could explain why it cleaves its substrates at multiple sites, to ensure elimination of any residual activity by fragments. Several cleavage sites within the $A \beta$ sequence were previously reported by others, whereas our data confirm the recently discovered cleavage sites $\mathrm{Gly}_{33}-\mathrm{Leu}_{34}$ and $\mathrm{Leu}_{34}-\mathrm{Met}_{35}(18,20,39)$. Moreover, we report $\mathrm{Met}_{35}-\mathrm{Val}_{36}$ to be a novel cleavage site that has not yet been identified. As $\mathrm{A} \beta$ fragments are aggregation-prone (Fig. 5.5 and 5.6) and may have neurotoxic effects $(20,40)$, the properties of these newly identified cleavage fragments $\left(A \beta_{1-35}, A \beta_{36-40 / 42}\right)$ must be further elucidated, as they may have consequences for protease-based $\mathrm{AD}$ therapies.

Second, ThT fluorescence data suggest that not only A $\beta$ monomers are being cleaved, but also larger ThT-positive aggregates (Fig. 5.1) although cleavage is less pronounced with prolonged $\mathrm{A} \beta$ aggregation (Fig. 5.3). Thus, it can be speculated that increasing fibril maturity correlates with a decreased propensity to IDE-induced cleavage. The crystal structure of IDE resembles a clamshell, with a large internal chamber formed from two bowl-shaped halves connected by a flexible linker. IDE engulfs and degrades its substrates within this catalytic chamber whose size is limited to accommodate only relatively small peptides, i.e. consisting of maximally 70 amino acids (41-43). Therefore, IDE has been suggested to exclusively degrade monomeric $\mathrm{A} \beta$, because oligomeric and fibrillar forms of $\mathrm{A} \beta$ are too large to completely fit into this catalytic chamber $(17,41-43)$. Binding of monomeric $A \beta$ to a $\beta$-strand of IDE, located at the "door" of the chamber, results in formation of an intermolecular antiparallel $\beta$-sheet and stabilization of the internal chamber, and subsequent cleavage (42). This might explain the selectivity of IDE for amyloidogenic substrates.

To gain more insight into our findings with ThT fluorescence, we assessed $A \beta$ degradation using solution NMR spectroscopy, which has the advantage that only small species, i.e. A $\beta$ monomers and early oligomers, are NMR detectable. Accordingly, aggregation of ${ }^{15} \mathrm{~N}$-labeled $\mathrm{A} \beta$ was accompanied by a decrease in the signal intensity of the ${ }^{1} \mathrm{H}^{15} \mathrm{~N}$ HSQC spectrum (Fig. 5.4). Subsequent addition of IDE to aggregated $A \beta$ resulted in reappearance and alteration of the spectrum, indicating that $A \beta$ cleavage occurred and that fragments were formed (Fig. 5.5). However, in light of the findings derived from the structural IDE studies mentioned above, the species that were cleaved by IDE are most likely $\mathrm{A} \beta$ monomers in dynamic equilibrium 
with NMR-invisible aggregates, and not the aggregates themselves. Previous studies using solution NMR demonstrated that $\mathrm{A} \beta$ monomers are constantly binding to and being released from oligomers (27) and protofibrils (28). Accordingly, the monotonic decrease in ThT fluorescence depicted in fig. 5.1 upon addition of IDE to ThT-positive A $\beta$ aggregates may be explained by the degradation of residual $A \beta$ monomers in solution that exist in equilibrium with ThT-positive aggregates. A $\beta$ monomer cleavage by IDE would disturb this dynamic equilibrium, forcing ThT-positive A $\beta$ aggregates to dissociate to restore the equilibrium. This hypothesis is however highly speculative, and should be validated by future experiments. Furthermore, although HDX-MS revealed that A $\beta$ molecules making up fibrils are also continuously recycled (44), peak intensities did not reappear after IDE addition to mature fibrils (Fig. S3). However, combining proteases capable of degrading different A $\beta$ aggregation species at distinct cellular locations, such as IDE, NEP, and MMP-9, might hold therapeutic potential for AD treatment (Fig. S2).

In summary, we show that $\mathrm{A} \beta$ monomers are cleaved at multiple sites by IDE, and we report a new $A \beta$ cleavage site: $\mathrm{Met}_{35}-\mathrm{Val}_{36}$. The generated $\mathrm{A} \beta$ fragments, that are aggregation-prone, must be further investigated to unravel their aggregation properties in more detail, and to reveal if they possess neurotoxic properties, as this will have consequences for IDE-based therapeutic strategies for AD.

\subsection{Supplementary information}

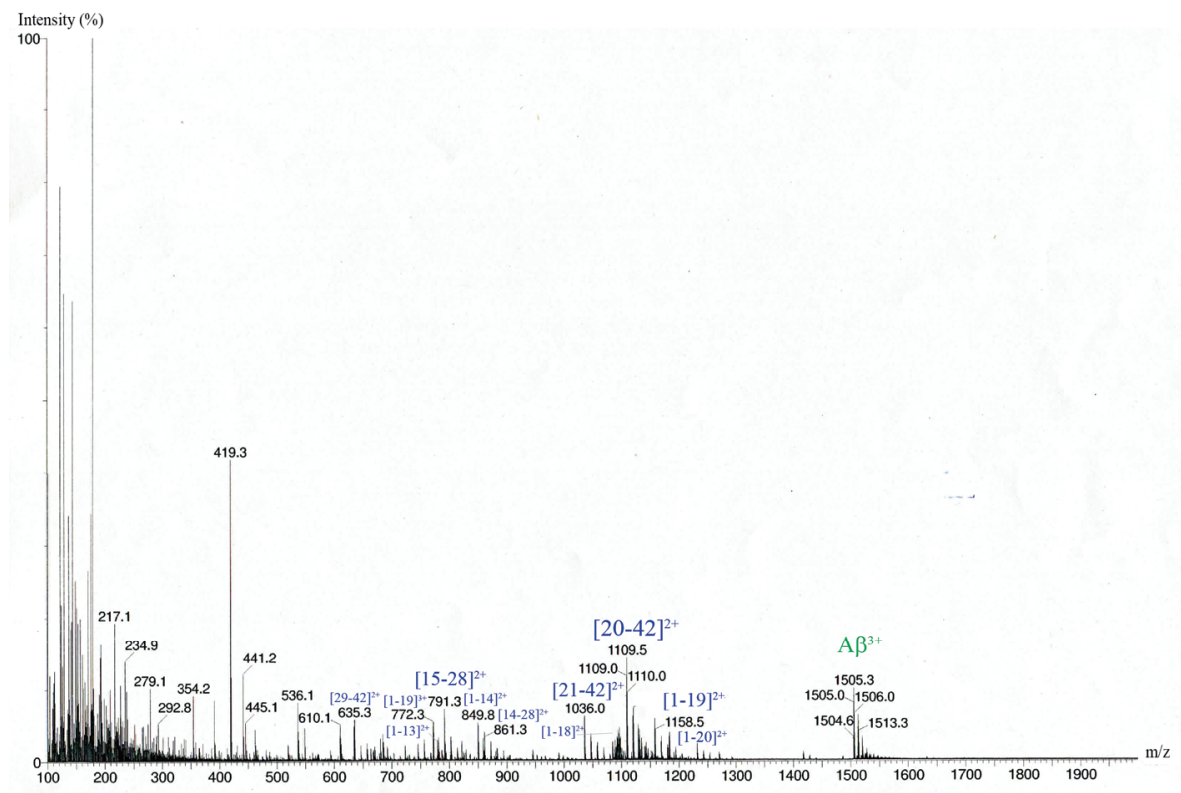

Figure S1: IDE-mediated cleavage of monomeric $\mathbf{A} \boldsymbol{\beta}_{1-42}$ results in multiple fragments. Assignment of ion peaks detected by ESI-MS associated with monomeric $\mathrm{A} \beta_{1-42}(10 \mu \mathrm{M})$ in the presence of $36 \mathrm{nM}$ IDE, after $1 \mathrm{~h}$ of incubation at $37^{\circ} \mathrm{C}$. 

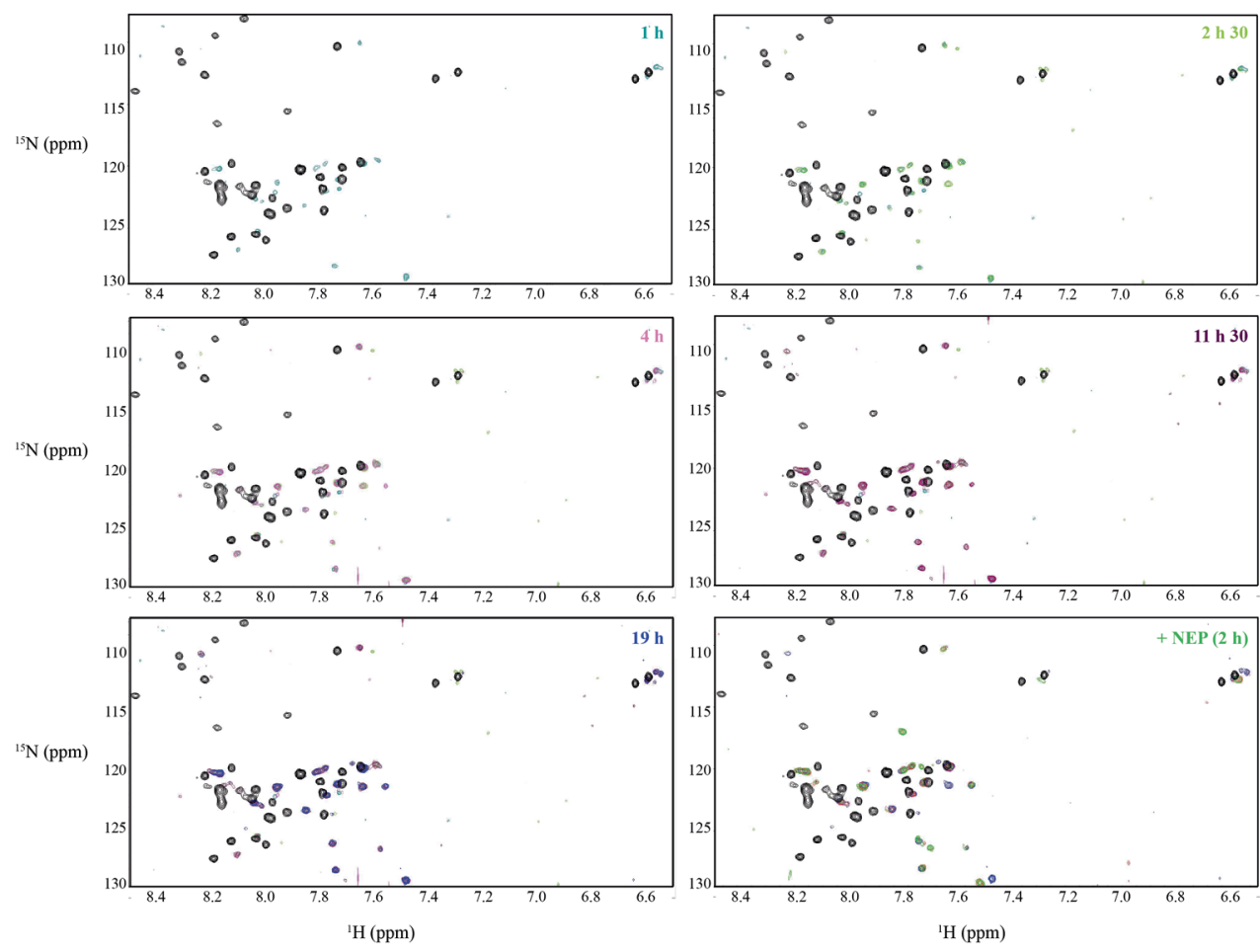

Figure S2: $\mathbf{A} \boldsymbol{\beta}_{1-42}$ cleavage by IDE and NEP monitored by solution NMR. Addition of IDE (36 $\left.\mathrm{nM}\right)$ to aggregated $\mathrm{A} \beta_{1-42}\left(45 \mu \mathrm{M}, 6 \mathrm{~h}\right.$ at $\left.37^{\circ} \mathrm{C}\right)$ reveals new peaks in the ${ }^{1} \mathrm{H}-{ }^{15} \mathrm{~N}$ HSQC spectrum, and shifting and splitting of original peaks (corresponding to monomeric $A \beta_{1-42}$, depicted in black). Subsequent addition of NEP (36 nM), another well-known $A \beta$-degrading enzyme capable of degrading $A \beta$ monomers and oligomers (6), resulted in additional peak shifting and emergence of new peaks. This observation indicates that combination therapy, based on the distinct degrading capacities of different proteases, might have therapeutic utility.

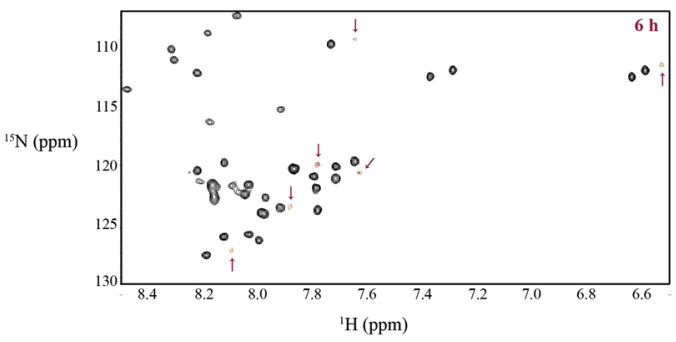

Figure S3: Addition of IDE to $24 \mathrm{~h}$ pre-incubated $A \beta_{1-42}$ does not result in NMR-detectable $A \beta_{1-42}$ cleavage. The ${ }^{1} \mathrm{H}-{ }^{15} \mathrm{~N}$ HSQC signal intensity of monomeric $\mathrm{A} \beta_{1-42}(45 \mu \mathrm{M})$ decreased and disappeared during aggregation at $37^{\circ} \mathrm{C}$. The spectrum corresponding to the $6 \mathrm{~h} \mathrm{~A} \beta$ aggregation time point is displayed as a reference (residual peaks are indicated by arrows). IDE addition ( $36 \mathrm{nM}$ ) after $24 \mathrm{~h}$ of pre-incubation of $\mathrm{A} \beta_{1-42}$ did not result in reappearance of the spectrum. 


\subsection{References}

1. Mawuenyega KG, et al. (2010) Decreased clearance of CNS $\beta$-amyloid in Alzheimer's disease. Science 330(6012):1774.

2. Wildsmith KR, Holley M, Savage JC, Skerrett R, \& Landreth GE (2013) Evidence for impaired amyloid $\beta$ clearance in Alzheimer's disease. Alzheimers Res Ther 5(4):33.

3. Tanzi RE, Moir RD, \& Wagner SL (2004) Clearance of Alzheimer's A $\beta$ peptide: the many roads to perdition. Neuron 43(5):605-608

4. Wang DS, Dickson DW, \& Malter JS (2006) $\beta$-Amyloid degradation and Alzheimer's disease. $J$ Biomed Biotechnol 2006(3):58406.

5. Miners JS, et al. (2008) A $\beta$-degrading enzymes in Alzheimer's disease. Brain Pathol 18(2):240-252.

6. De Strooper B (2010) Proteases and proteolysis in Alzheimer disease: a multifactorial view on the disease process. Physiol Rev 90(2):465-494.

7. Saido T \& Leissring MA (2012) Proteolytic degradation of amyloid $\beta$-protein. Cold Spring Harb Perspect Med 2(6):a006379.

8. Bertram L, et al. (2000) Evidence for genetic linkage of Alzheimer's disease to chromosome 10q. Science 290(5500):2302-2303.

9. Bartl J, et al. (2011) Disorder-specific effects of polymorphisms at opposing ends of the Insulin Degrading Enzyme gene. BMC Med Genet 12:151.

10. Kurochkin IV \& Goto S (1994) Alzheimer's $\beta$-amyloid peptide specifically interacts with and is degraded by insulin degrading enzyme. FEBS Lett 345(1):33-37.

11. Qiu WQ, et al. (1998) Insulin-degrading enzyme regulates extracellular levels of amyloid $\beta$ protein by degradation. $J$ Biol Chem 273(49):32730-32738.

12. Vekrellis K, et al. (2000) Neurons regulate extracellular levels of amyloid $\beta$-protein via proteolysis by insulin-degrading enzyme. J Neurosci 20(5):1657-1665.

13. Farris W, et al. (2003) Insulin-degrading enzyme regulates the levels of insulin, amyloid $\beta$ protein, and the $\beta$-amyloid precursor protein intracellular domain in vivo. Proc Natl Acad Sci US A 100(7):4162-4167.

14. Farris W, et al. (2004) Partial loss-of-function mutations in insulin-degrading enzyme that induce diabetes also impair degradation of amyloid $\beta$-protein. Am J Pathol 164(4):1425-1434.

15. Leissring MA, et al. (2003) Enhanced proteolysis of $\beta$-amyloid in APP transgenic mice prevents plaque formation, secondary pathology, and premature death. Neuron 40(6):10871093.

16. Kurochkin IV (2001) Insulin-degrading enzyme: embarking on amyloid destruction. Trends Biochem Sci 26(7):421-425.

17. Malito E, Hulse RE, \& Tang WJ (2008) Amyloid $\beta$-degrading cryptidases: insulin degrading enzyme, presequence peptidase, and neprilysin. Cell Mol Life Sci 65(16):2574-2585.

18. Chesneau V, Vekrellis K, Rosner MR, \& Selkoe DJ (2000) Purified recombinant insulindegrading enzyme degrades amyloid $\beta$-protein but does not promote its oligomerization. Biochem J 351 Pt 2:509-516.

19. Morelli L, et al. (2003) Differential degradation of amyloid $\beta$ genetic variants associated with hereditary dementia or stroke by insulin-degrading enzyme. J Biol Chem 278(26):2322123226.

20. Mukherjee A, et al. (2000) Insulysin hydrolyzes amyloid $\beta$ peptides to products that are neither neurotoxic nor deposit on amyloid plaques. $J$ Neurosci 20(23):8745-8749.

21. Haass C \& Selkoe DJ (2007) Soluble protein oligomers in neurodegeneration: lessons from the Alzheimer's amyloid $\beta$-peptide. Nat Rev Mol Cell Biol 8(2):101-112.

22. Broersen K, et al. (2011) A standardized and biocompatible preparation of aggregate-free amyloid beta peptide for biophysical and biological studies of Alzheimer's disease. Protein Eng Des Sel 24(9):743-750.

23. Grasso G (2011) The use of mass spectrometry to study amyloid- $\beta$ peptides. Mass Spectrom Rev 30(3):347-365.

24. Delaglio F, et al. (1995) NMRPipe: a multidimensional spectral processing system based on UNIX pipes. $J$ Biomol NMR 6(3):277-293. 
25. Johnson BA (2004) Using NMRView to visualize and analyze the NMR spectra of macromolecules. Methods Mol Biol 278:313-352.

26. Zeeb M \& Balbach J (2004) Protein folding studied by real-time NMR spectroscopy. Methods 34(1):65-74.

27. Fawzi NL, Ying J, Torchia DA, \& Clore GM (2010) Kinetics of amyloid $\beta$ monomer-tooligomer exchange by NMR relaxation. J Am Chem Soc 132(29):9948-9951.

28. Fawzi NL, Ying J, Ghirlando R, Torchia DA, \& Clore GM (2011) Atomic-resolution dynamics on the surface of amyloid- $\beta$ protofibrils probed by solution NMR. Nature 480(7376):268-272.

29. Hou L, et al. (2004) Solution NMR studies of the $A \beta(1-40)$ and $A \beta(1-42)$ peptides establish that the Met35 oxidation state affects the mechanism of amyloid formation. J Am Chem Soc 126(7):1992-2005.

30. Scheidt HA, Morgado I, Rothemund S, Huster D, \& Fändrich M (2011) Solid-state NMR spectroscopic investigation of $A \beta$ protofibrils: implication of a $\beta$-sheet remodeling upon maturation into terminal amyloid fibrils. Angew Chem Int Ed Engl 50(12):2837-2840.

31. Eckman EA \& Eckman CB (2005) A $\beta$-degrading enzymes: modulators of Alzheimer's disease pathogenesis and targets for therapeutic intervention. Biochem Soc Trans 33(Pt 5):1101-1105.

32. Song ES \& Hersh LB (2005) Insulysin: an allosteric enzyme as a target for Alzheimer's disease. J Mol Neurosci 25(3):201-206.

33. Selkoe DJ (2001) Clearing the brain's amyloid cobwebs. Neuron 32(2):177-180.

34. Kukday SS, et al. (2012) Cell-permeable, small-molecule activators of the insulin-degrading enzyme. J Biomol Screen 17(10):1348-1361.

35. Cabrol C, et al. (2009) Small-molecule activators of insulin-degrading enzyme discovered through high-throughput compound screening. PloS one 4(4):e5274.

36. Çakir B, et al. (2012) Structure based discovery of small molecules to regulate the activity of human insulin degrading enzyme. PloS one 7(2):e31787.

37. Biancalana M \& Koide S (2010) Molecular mechanism of Thioflavin-T binding to amyloid fibrils. Biochim Biophys Acta 1804(7):1405-1412.

38. Maianti JP, et al. (2014) Anti-diabetic activity of insulin-degrading enzyme inhibitors mediated by multiple hormones. Nature 511:94-98.

39. Grasso G, Mineo P, Rizzarelli E, \& Spoto G (2009) MALDI, AP/MALDI and ESI techniques for the MS detection of amyloid $\beta$-peptides. International Journal of Mass Spectrometry 282(1):50-55.

40. Misiti F, et al. (2005) A $\beta(31-35)$ peptide induce apoptosis in PC 12 cells: contrast with $\mathrm{A} \beta(25-$ 35) peptide and examination of underlying mechanisms. Neurochem Int 46(7):575-583.

41. Shen Y, Joachimiak A, Rosner MR, \& Tang WJ (2006) Structures of human insulin-degrading enzyme reveal a new substrate recognition mechanism. Nature 443(7113):870-874.

42. McCord LA, et al. (2013) Conformational states and recognition of amyloidogenic peptides of human insulin-degrading enzyme. Proc Natl Acad Sci U S A 110(34):13827-13832.

43. Malito E, et al. (2008) Molecular bases for the recognition of short peptide substrates and cysteine-directed modifications of human insulin-degrading enzyme. Biochemistry 47(48):12822-12834.

44. Sánchez L, et al. (2011) A 440 and A 342 amyloid fibrils exhibit distinct molecular recycling properties. J Am Chem Soc 133(17):6505-6508. 


\title{
Chapter 6
}

\section{New peptidomimetic inhibitors of $A \beta$ aggregation: molecular guidance for rational drug design}

This chapter has been submitted to European Journal of Medicinal Chemistry.

\author{
Barrera E, Andujar S.A., Hubin E, Broersen K, Méndez L, \\ Delpiccolo C, Masman M.F., Rodriguez A.M., and Enriz D.R.
}

The incidence of $\mathrm{AD}$ is expected to nearly triple by 2050 if no effective therapy becomes available. A primary role in $\mathrm{AD}$ pathology has been assigned to the $\mathrm{A} \beta$ peptide, which aggregates from what appears to be a harmless intrinsically disordered monomer into higher ordered and toxic aggregates. Therefore, several drug development strategies aim to interfere with the self-assembly of $A \beta$. In this study, a new series of low molecular weight peptidomimetics was designed, possessing a significant $\mathrm{A} \beta$ anti-aggregation effect. These potential $\beta$-sheet breakers were designed by structure-based virtual screening based on a previously reported lead structure resembling the central region of the $\mathrm{A} \beta$ sequence. Potential binding sites of the compounds to an $A \beta_{1-42}$ pentamer model were obtained by docking analysis, and extensive MD simulations in explicit water provided insights into the dynamic behaviour of these complexes. Alterations in the structure of the $A \beta_{1-42}$ pentamer in presence of the potential $\beta$-sheet breakers were identified, including: (i) destruction of the regular helical twist, and (ii) loss of a stabilizing hydrophobic interaction in the $\beta_{1}$ region $\left(\mathrm{Val}_{18^{-}}\right.$ $\mathrm{Ser}_{26}$ ) of the $\mathrm{A} \beta$ peptide. The predicted inhibitory effect of the newly designed compounds on oligomer and fibril formation was validated using a range of biophysical assays. In conclusion, we report novel compounds that interfere with $\mathrm{A} \beta$ aggregation and highlight that combining docking and MD simulations can serve as a guiding principle in the design of new anti-aggregation compounds and in the elucidation of the mechanistic details of their mode of action.

\section{Author contributions:}

This chapter is part of a more extensive study designed by Enriz D.R. and co-workers, who chemically synthesized a range of compounds with potential A $\beta$ anti-aggregation properties. Masman M.F. designed the molecular modelling study and executed the computational simulations. Hubin E and Broersen K performed the biophysical experiments (presented in section 6.3.2: Biophysical assessment of compound activities). 


\subsection{Introduction}

Current AD drugs only alleviate disease symptoms with limited therapeutic effect. In the absence of effective drugs and with the ageing global population, the incidence of AD is expected to rise rapidly over the coming years. The discovery of disease-modifying therapeutics that can halt or ultimately reverse AD progression is thus vital. The most widely accepted theory regarding the aetiology of $\mathrm{AD}$ is known as the amyloid cascade hypothesis, which features the $A \beta$ peptide as the central pathological agent (1). Although the characteristic lesions of $\mathrm{AD}$ are plaques consisting of fibrillar $\mathrm{A} \beta$, the most toxic forms of $\mathrm{A} \beta$ are generally believed to be soluble oligomers (2). Therefore, several therapeutic approaches targeting $A \beta$ are under development which include reducing $A \beta$ levels by modulating $\beta$ - and $\gamma$-secretase activities $(3,4)$, increasing the $A \beta$ clearance rate $(5)$, and inhibiting the selfassembly of $A \beta(6)$.

Numerous studies exploring the mechanism of $A \beta$ aggregation have been ongoing for several decades, leading to the identification of a variety of inhibitors targeting the self-assembly of $\mathrm{A} \beta$. These compounds include short peptides, proteins, and small chemical compounds (6). With respect to peptide inhibitors, a pioneering effort by Ghanta and co-workers demonstrated the possibility to use short peptides related to protein self-recognition regions as a viable strategy for the development of new $\mathrm{A} \beta$ anti-aggregation ligands (7). Tjernberg and coworkers synthesized a series of short peptides derived from $A \beta$ and identified the $A \beta_{16-20}$ core region (KLVFF) as one of the nucleation sites in $A \beta$ (8). They observed that the KLVFF peptide could bind to full-length $A \beta$ and prevent its self-assembly into $\beta$-sheet amyloid fibrils. These results indicated that peptide-based self-recognition regions have potential to inhibit the aggregation of amyloidogenic proteins by acting as $\beta$-sheet breakers. Several studies expanded upon these original findings $(9,10)$. Soto and co-workers designed and synthesized three $\beta$-sheet breaker peptides based on the central region $A \beta_{17-20}$. These peptides inhibited aggregation and disassembled amyloid fibrils in vitro, and prevented $A \beta$-induced neurotoxicity in cells $(11,12)$. Moreover, treatment with these peptides inhibited neuronal cell death, brain inflammation, and memory impairment in transgenic AD mouse models, and displayed low toxicity, low immunogenicity, high solubility, and reasonably high BBB permeability (13). Unfortunately, their bioavailability was poor as they were rapidly degraded by proteolytic enzymes due to their peptidic nature, imposing serious limitations for their therapeutic use (14). Next, Chen and co-workers reported small peptidomimetics (based on the LPFFD sequence) with similar abilities to inhibit and reverse A $\beta$ aggregation, but with potentially better drug-like properties in terms of biological stability and membrane permeability (15). These compounds were selected for high solubility and low molecular weight. Among these molecules, BSBM6 (referred to as compound 1 in this chapter) possessed a significant anti-aggregation effect and appeared as one of the best candidates for further studies (Fig. 6.1). This compound has been suggested to interfere with electrostatic interactions during aggregation and to destabilize the $\mathrm{A} \beta$ fibril $\mathrm{H}$-bonding network (15). However, several questions remain regarding the molecular mechanism of the inhibitory mode of action of this compound.

\section{Computational studies}

A growing number of theoretical molecular simulation studies have been conducted to analyse the interactions of $\mathrm{A} \beta$ with anti-aggregation molecules, including docking analysis and MD simulations (16-18). All these efforts have revealed several strengths and limitations of the current techniques (19). The main limitations in using docking analysis to identify 
binding modes of compounds against a receptor structure are the requirements for a high quality receptor structure and minimal structural changes upon ligand binding. This makes docking challenging in the context of $A \beta$ aggregation, as the nature of $A \beta$ is highly dynamic, which makes the choice of the right target structure or set of structures difficult. Moreover, these structures have not yet been fully unravelled. Another challenge associated with docking in general is the scoring and refinement of docked conformations (20). In contrast, MD simulations provide a molecular-level view of a system as it evolves over time, making them particularly useful in studying $A \beta$ and its interactions with small molecules (19). Since $A \beta$ adopts a variety of structures along the aggregation pathway (21), MD simulations can be used to examine how these different structures may interact with therapeutic anti-aggregation compounds. MD simulations however require considerably more computational expense compared to docking analysis (19). Lemkul and Bevan reported a comprehensive review about the role of molecular simulations in the development of inhibitors of A $\beta$ peptide aggregation and indicated that "combining docking and MD provides the most efficient and informative means of assessment of candidate molecules" (19). Limitations imposed by docking (target rigidity and sampling) are overcome by MD, whereas limitations associated with MD (computational expense) are complemented by docking.

In this study, we report a possible mechanism of action for the peptidomimetic compound 1 (BSBM6), previously reported to be a potent inhibitor of $A \beta$ aggregation (15). Mechanistic insights were obtained by combining docking and MD simulations of the interactions between this compound and a structural model of an $A \beta_{1-42}$ penta-oligomer designed by Masman and co-workers (22). In a second step, these insights were used to design new compounds with inhibitory effects on A $\beta$ self-assembly by a structure-based virtual screening. Predicted antiaggregation activities of these compounds were assessed in vitro using a range of biophysical techniques.

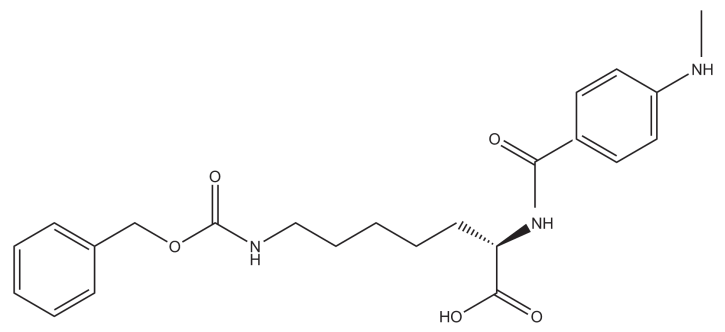

Figure 6.1: Chemical structure of the $\beta$-sheet breaker peptidomimetic B6MS6 (compound 1), developed by Chen and co-workers based on the Lipinski rules (15).

\subsection{Experimental procedures}

\subsubsection{Chemical compounds}

Compounds 3 ( $N \alpha$-Boc- $N \varepsilon$-Cbz-L-lysine N-hydroxysuccinimide ester), 4 ( $N \alpha$-Fmoc- $N \varepsilon$-Z-Llysine), 5 ( $N \alpha, N \varepsilon$-Di-Z-L-lysine), and $6(N \alpha, N \varepsilon$-Di-Z-L-lysine hydroxysuccinimide ester) were purchased at Sigma-Aldrich with a minimal purity of $98 \%$. All compounds were dissolved in DMSO prior to experiments.

\subsubsection{Preparation of $A \beta$ peptide and compounds}

$\mathrm{A} \beta_{1-42}$ (rPeptide) was dissolved according to the standard procedure developed and validated in our laboratory (23). In short, $A \beta_{1-42}$ was dissolved in HFIP. HFIP was evaporated using 
nitrogen gas and the peptide film was redissolved using DMSO. The peptide was separated from DMSO by elution from a HiTrap ${ }^{\mathrm{TM}}$ desalting column (GE Healthcare) into a PBS buffer. The resulting samples were kept on ice until experiments started with a maximum lag time of $30 \mathrm{~min}$. Peptide concentration was determined using absorbance at $280 \mathrm{~nm}$ and an extinction coefficient of $1490 \mathrm{M}^{-1} \mathrm{~cm}^{-1}$, and corrected to $25 \mu \mathrm{M}$ in PBS. A $\beta$ peptides were incubated under quiescent conditions at $37{ }^{\circ} \mathrm{C}$, in the absence or presence of a compound. The compound concentrations ranged from 0 to $100 \mu \mathrm{M}$ in DMSO (final DMSO concentration in the samples was $5 \%$ ).

\subsubsection{ThT fluorescence}

After 7 days of incubation, a volume of $50 \mu \mathrm{l}$ incubated $A \beta /$ compound sample was mixed with $12 \mu \mathrm{M}$ ThT and incubated for $10 \mathrm{~min}$ at room temperature. The extent of aggregation was determined using a Varian Cary Eclipse fluorimeter upon excitation at a wavelength of $450 \mathrm{~nm}$, while recording the emission spectrum at a wavelength range from 470 to $560 \mathrm{~nm}$ (bandwidths of $9 \mathrm{~nm}$ and $20 \mathrm{~nm}$, respectively). Measurements were performed as independent triplicates. Recorded values were averaged and background measurements (buffer containing $12 \mu \mathrm{M}$ ThT with or without compound) were subtracted.

\subsubsection{TEM}

After 7 days of incubation, samples $(5 \mu \mathrm{l})$ were adsorbed to carbon-coated Formvar 400-mesh copper grids (Agar Scientific) for $1 \mathrm{~min}$. The grids were blotted, washed, and stained with 2 $\%(w / v)$ phosphatidic acid. Grids were imaged with a JEM-1400 microscope (JEOL Ltd., Tokyo, Japan) at $80 \mathrm{kV}$. TEM images are representative of three independently prepared sample solutions.

\subsubsection{Dot blotting with Aß oligomer-specific A11 antibody}

After $1.5 \mathrm{~h}$ of incubation, a volume of $5 \mu \mathrm{l}$ sample was spotted onto a nitrocellulose membrane. Membranes were blocked in phosphate-buffered saline containing $0.2 \%$ Tween$20\left(1 \mathrm{~h}, 25{ }^{\circ} \mathrm{C}\right)$, and incubated overnight at $4{ }^{\circ} \mathrm{C}$ with the primary oligomer-recognizing A11 antibody (Invitrogen), diluted 1:4000 in $100 \mathrm{mM}$ Hepes, $\mathrm{pH} 7.0$ (24). After incubation (0.5 h, $25{ }^{\circ} \mathrm{C}$ ) with a secondary anti-rabbit-HRP-tagged antibody (Promega), diluted 1:8000 in phosphate-buffered saline containing $0.05 \%$ Tween-20, membranes were visualized using the Immobilon ${ }^{\mathrm{TM}}$ Western chemiluminescent HRP substrate system. The procedure was repeated to detect total $A \beta$ present in the samples using anti-amyloid precursor protein mouse monoclonal antibody DE2B4 (Abcam) by first blocking the membrane for $1 \mathrm{~h}$ at $25{ }^{\circ} \mathrm{C}$ in phosphate-buffered saline containing $0.05 \%$ Tween-20 and $5 \%$ milk, followed by overnight incubation at $4^{\circ} \mathrm{C}$ in 1:20000 diluted DE2B4 in phosphate-buffered saline containing $0.05 \%$ Tween-20 and $5 \%$ milk. Goat anti-mouse-HRP-tagged antibody was used as secondary antibody and membranes were visualized using the Immobilon ${ }^{\mathrm{TM}}$ Western chemiluminescent HRP substrate.

\subsubsection{Docking analysis and MD simulations}

The full-length pentameric aggregate $A \beta_{1-42}$ model developed by Masman and co-workers was used as a target system (22). The simulations presented in this chapter were designed and performed by Masman M.F. In short, Gasteiger charges were assigned for all compounds, and nonpolar hydrogen atoms were merged. All torsions were allowed to rotate during docking. 
The grid dimensions were 50x50x50 points along the $\mathrm{x}-, \mathrm{y}-$, and $\mathrm{z}$-axes, with points separated by $1 \AA$. The grid was chosen to be sufficiently large to cover the whole system (blind docking method). The value of exhaustiveness of search was 400 and the number of poses collected was 10. All graphic manipulations and visualizations were performed by means of AutoDock Tools 1.5.4 (25) and ligand docking with Autodock Vina 1.1.1 (26). A total of ten different binding modes were obtained in every docking calculation and these were ranked according to their binding free energies $\Delta \mathrm{G}$ (expressed in $\mathrm{kcal} \mathrm{mol}^{-1}$ ). The best binding modes obtained for each compound in the docking calculations were used as initial complexes of a $10 \mathrm{~ns} \mathrm{MD}$ simulation. The purpose of this procedure was to generate side chain relaxation and improve the ligand-protein interactions. The coordinates were saved every 2 ps. MD simulations were performed using the GROMACS 4.5.3 package of programs (27), with the GROMOS $9653 \mathrm{a} 6$ force field (28). The N-terminus of each peptide was protonated and the C-terminus was deprotonated and given zwitterionic conditions. All other amino acids were assigned their canonical state at physiological $\mathrm{pH}$. The system was placed in a dodecahedric box of simple point charge water, including neutralizing counter-ions. The simulations were run under normal temperature and pressure (NPT) conditions, using the V-rescale coupling algorithm for keeping the temperature constant $(\mathrm{T}=310 \mathrm{~K}, \tau \mathrm{T}=0.1 \mathrm{ps})$ and the Parrinello-Rahman barostate to isotropically regulate pressure $(\mathrm{P}=1 \mathrm{bar}, \tau \mathrm{P}=2.0 \mathrm{ps})$. The LINCS algorithm was used to constrain the lengths of $\mathrm{H}$-containing bonds, the waters were restrained using the SETTLE algorithm. The time step for the simulations was $0.002 \mathrm{ps}$ and the compressibility was $4.5 \times 10^{-5} \mathrm{bar}^{-1}$. Van der Waals forces were treated using a $1.4 \mathrm{~nm}$ cut-off. Long-range electrostatic forces were treated using the particle mesh Ewald method. For the molecular mechanics/generalized born surface area (MM-GBSA) methodology, snapshots were taken at 10 ps time intervals from the corresponding last 1000 ps MD trajectories, and the explicit water molecules were removed from the snapshots. Once the binding site was determined, longer MD simulations reaching 200 ns overall simulation time were carried out. Post MD analysis was also carried out using the GROMACS 4.5.3 package of programs.

\subsection{Results}

\subsubsection{Mechanistic insights into the anti-aggregation activity of peptidomimetic B6MS6 using molecular simulations}

Despite experimental observations of B6MS6 (compound 1) activity described previously (15), many questions remained concerning the interactions between $A \beta$ and compound 1 on a molecular level: (i) what is the A $\beta$-binding site of compound 1, (ii) which physicochemical factors control its binding, and (iii) does compound binding induce changes in the A $\beta$ peptide structure? Answering these questions will be important to broaden our mechanistic understanding of how this compound might prevent $A \beta$ fibril formation and will help in the design of new anti-aggregation agents.

Computer simulations, such as $\mathrm{MD}$, are well suited to provide molecular-level details of binding interactions. For MD simulations, the $A \beta_{1-42}$ pentamer model reported previously was used (22). Compound 1 was docked into the $A \beta_{1-42}$ pentamer using the program Autodock Vina. Calculations were performed using the blind docking strategy, where the possible binding sites were obtained by scanning the entire surface of the pentameric peptide target (29). Four distinct binding sites were identified (indicated as I-IV in fig. 6.2). Site I was located in the polar, disordered and highly flexible region of the $A \beta_{1-42}$ peptide, site II corresponded to the top site of the pentamer, where an incoming monomer may take position 
during oligomerization, whereas sites III and IV were located at the $\beta_{1}$ site of the A $\beta$ peptide, consisting of residues $\mathrm{Val}_{18}-\mathrm{Ser}_{26}$.

To determine the most likely site of attachment for compound 1, at first relatively short MD simulations (10 ns sampling time) were performed to calculate the relative binding free energies $\Delta \mathrm{G}$ of each complex, using the MM/GBSA method. Structural snapshots collected throughout the short MD simulations were used to estimate the $\Delta \mathrm{G}$ values of compound 1$\mathrm{A} \beta_{1-42}$ pentamer interactions. The type III complex revealed the lowest $\Delta \mathrm{G}$, indicating that this is the strongest binding mode compared to the other three detected binding sites (Fig. 6.2). Taken into account these initial results, a central role for the type III arrangement was identified. However, a more detailed analysis of potential structural alterations elicited in the $\mathrm{A} \beta_{1-42}$ pentamer upon interaction with compound 1 was required, as these insights would be useful in the design of new inhibiting compounds. All further evaluations were therefore restricted to type III complexes, characterized by binding of compound 1 to the central hydrophobic core of the $A \beta_{1-42}$ pentamer.

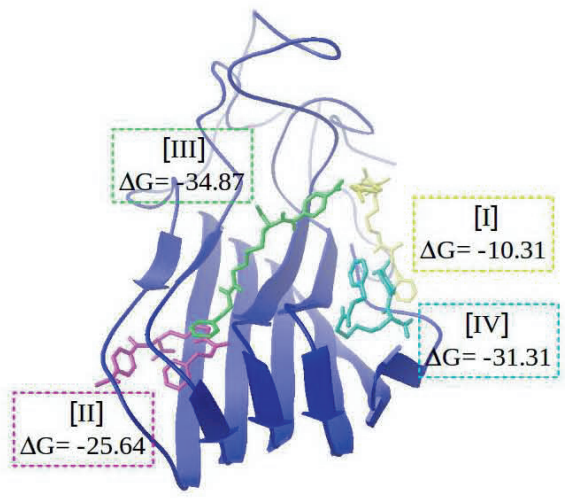

Figure 6.2: Potential binding modes of drug compound 1 to the $A \beta_{1-42}$ pentamer model described previously (22), and the corresponding calculated binding free energies $\Delta \mathbf{G}$. The blind docking strategy identified four potential binding pockets of compound 1 in the $A \beta_{1-42}$ pentamer model, depicted as [I-IV]. Binding free energies $\Delta \mathrm{G}$ (expressed in units of $\mathrm{kcal} \mathrm{mol}^{-1}$ ) were estimated using the $\mathrm{MM} / \mathrm{GBSA}$ method.

To explore the dynamic behaviour of the type III complex, more extensive MD simulations were carried out in explicit water (200 ns sampling time). Initial and final structures obtained from the MD simulations were compared for the $A \beta_{1-42}$ pentamer in absence and presence of compound 1. Results indicated that only minor changes occurred within the time frame of 200 $\mathrm{ns}$ in the $\mathrm{A} \beta_{1-42}$ pentameric structure in the absence of compound 1, with the pentameric structure being slightly more compact or "tight" in comparison to its initial structure (Fig. 6.3A). In contrast, significant changes occurred for the complex with compound 1, mainly in the plane-parallel organization of individual $\beta$-sheets and a trend towards the formation of a more twisted arrangement became apparent (Fig. 6.3B). This distortion in structure might perturb fibril formation (22).

Compound 1 disrupts the $\beta$-sheet structure of the $A \beta_{1-42}$ pentamer by altering key stabilizing interactions

Hence, to further decipher the effect of compound 1 on the structure of the $A \beta_{1-42}$ pentamer, attention was focused on the $\beta$-helix motif that was suggested previously to be present in the $\beta_{2}$ region (residues $\mathrm{Ile}_{31}-\mathrm{Ala}_{42}$ ) of the $\mathrm{A} \beta_{1-42}$ pentamer model. Masman and co-workers identified this $\beta$-helix motif as a crucial stabilizing element in the aggregation process and a 
potential target for anti-amyloid drug design (22). The $\beta$-helix is a plausible structural motif for amyloid fibrils, as it is predominantly composed of $\beta$-sheet structure with the proper cross$\beta$ orientation (30). This type of structure enables the H-bonding between the $\beta$-strands to be extended over the total length of the amyloid fibrils, thereby accounting for their characteristic rigidity and stability. The twist of the $\beta$-helix motif can be quantified by the dihedral angle $\delta$, defined by residues Ala42x, Val36 $\mathrm{x}$ and Val36 $6_{X-1}$, Ala42 ${ }_{X-1}$, where $\mathrm{x}$ stands for the number of the peptide chain (Fig. 6.4A).
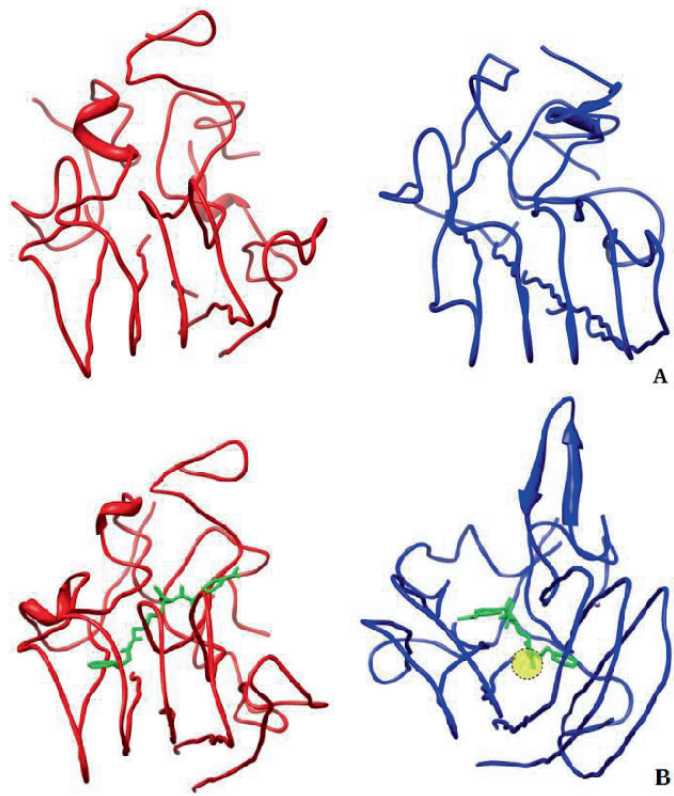

Figure 6.3: Assessment of the dynamic behaviour of the type III complex of compound 1 with pentameric $\mathbf{A} \boldsymbol{\beta}_{1-42}$ using MD simulations. Initial (red) and final (blue) structural snapshots (side view) were obtained using MD simulations (200 ns sampling time, in explicit water) for pentameric $A \beta_{1-42}$ in (A) absence and (B) presence of compound 1. Compound 1 inserts in the pentamer core and distorts the pentamer structure. The carboxyl group of compound 1 is marked as a yellow circle.

Positions of the $\mathrm{C} \alpha$ atoms of these residues (depicted as spheres in fig. 6.4A) determine the value of $\delta$, which was estimated previously to be in the order of $-10^{\circ}(22)$. Dihedral angles $\delta$ were computed for the $A \beta_{1-42}$ pentamer in absence and presence of compound 1 . The $\delta$-value for $A \beta_{1-42}$ alone appeared to be slightly above the $-10^{\circ}$ base line, with a rather homogeneous trend for all various pairs of peptide chains A-E (Fig. 6.4B). However, the complex with compound 1 showed significant deviations with respect to $\delta$, defined between chains $\mathrm{D}$ and $\mathrm{E}$ (Fig. 6.4C). The sudden change to a value of about $-100 /-110^{\circ}$ occurring after approximately $60 \mathrm{~ns}$ of MD simulations is indicative of the disruption of the $\beta$-helix structure.

In a next step, the impact of compound 1 on the inter-strand salt bridge formation between residues Asp23 $3_{X}$ - Lys $28_{X+1}$ was analysed (Fig. 6.5), as this has been suggested to be an important stabilizing interaction in fibril formation (31). After approximately $150 \mathrm{~ns}$ of sampling time, the distance between the charged moieties of chains $\mathrm{B}$ and $\mathrm{C}$ increased to approximately $1.5 \AA$ in the presence of compound 1 (Fig. 6.5B). The increased distance between both chains persisted for much of the remaining simulation time, in comparison with the results obtained for the $A \beta_{1-42}$ pentamer alone, where the salt bridge distance persisted at a 
distance of approximately $1 \AA$ throughout the MD simulations (Fig. 6.5A). However, the distance of $1.5 \AA$ is still small enough to accommodate the formation of a salt bridge between residues Asp $23_{X}$ and Lys $28_{X+1}$, indicating that compound 1 most likely does not prevent this interaction.
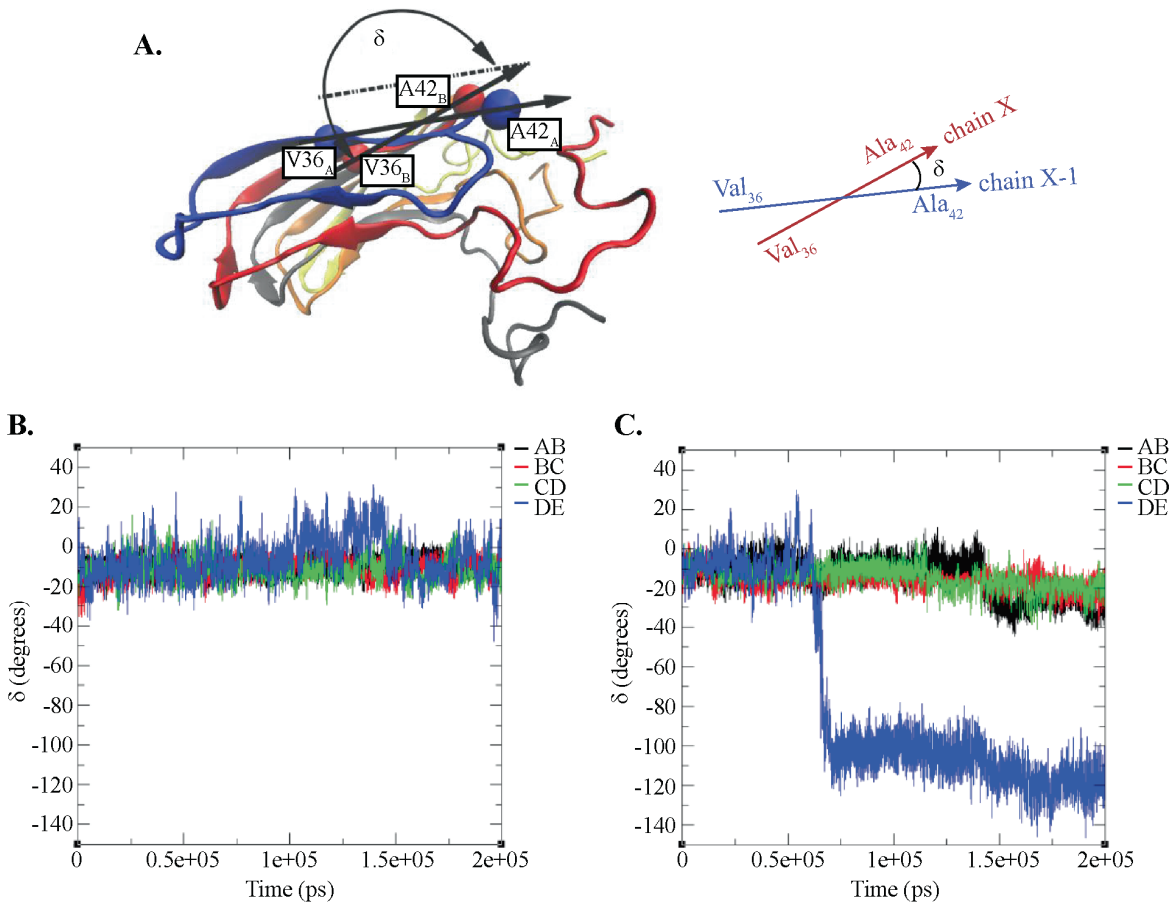

Figure 6.4: Effect of compound 1 on the dihedral angle $\delta$, a parameter used to quantify the twist of the $\beta$ helix motif. (A) Schematic of the dihedral angle $\delta$, introduced by Masman and co-workers (22), to describe the anticipated $\beta$-helix structure found in the $\mathrm{A} \beta_{1-42}$ pentamer (top view along the axis of the $\beta$-helix). The value of $\delta$ is defined by the position of four $\mathrm{C} \alpha$ atoms of residues Ala42, Val36, Val36 $6_{x-1}$ and $\mathrm{Ala}_{x} 2_{x-1}$ (depicted as spheres), on two adjacent chains of the $A \beta_{1-42}$ pentamer (with x comprising chains $A$ to E). Dihedral angles $\delta$ are displayed for $(\mathbf{B})$ the $A \beta_{1-42}$ pentamer alone, and $(\mathbf{C})$ in presence of compound 1 as a function of MD simulation time.

A.

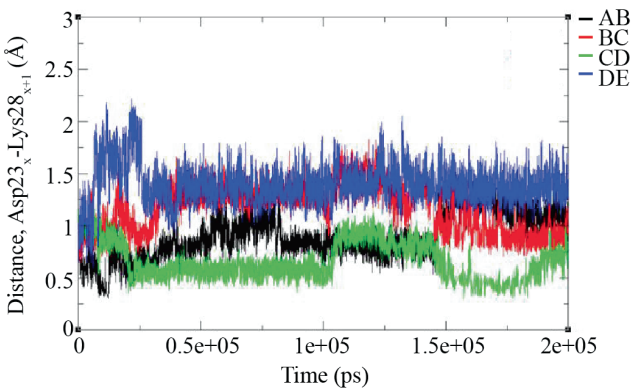

B.

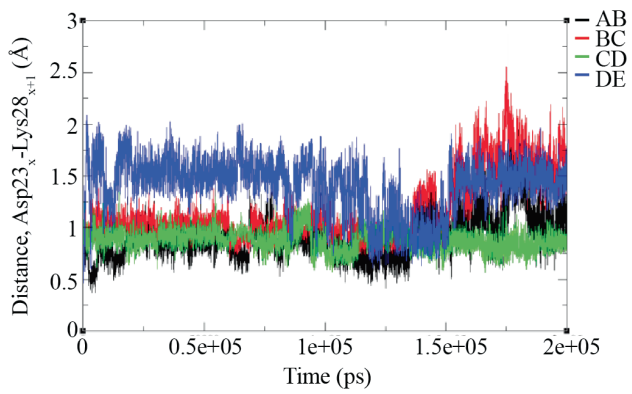

Figure 6.5: Effect of compound 1 on inter-strand salt bridge formation. (A) The inter-chain salt bridge distance between residues Asp $23_{x}$ and Lys $28_{x+1}$, as observed during $200 \mathrm{~ns}$ of MD simulations of the A $\beta_{1-42}$ pentamer in the absence of compound 1. (B) The inter-chain salt bridge distance between residues Asp23 and Lys $28_{x+1}$ of the $\mathrm{A} \beta_{1-42}$ pentamer in presence of compound 1, as observed during $200 \mathrm{~ns}$ of MD simulations. 
The effect of compound 1 on the structure of the $A \beta_{1-42}$ pentamer in close proximity of its binding site was evaluated by measuring the distances between the different chains in the $\beta_{1}$ region $\left(\mathrm{Val}_{18}-\mathrm{Ser}_{26}\right)$. The distance between chains $\mathrm{B}$ and $\mathrm{C}$ was significantly increased after $150 \mathrm{~ns}$ of simulation in presence of compound 1 (Fig. 6.6A and B). Next, the distances between the different chains in areas remote from the binding site were evaluated. The presence of compound 1 induced a significant increase in the distance between the two outer chains (D and $E$ ) in the $\beta_{2}$ region ( Ile $_{31}-\mathrm{Ala}_{42}$ ) (Fig. 6.6D), while the remainder of the distances between the chains were similar to those observed for the $A \beta_{42}$ pentamer alone (Fig. 6.6C).

A.

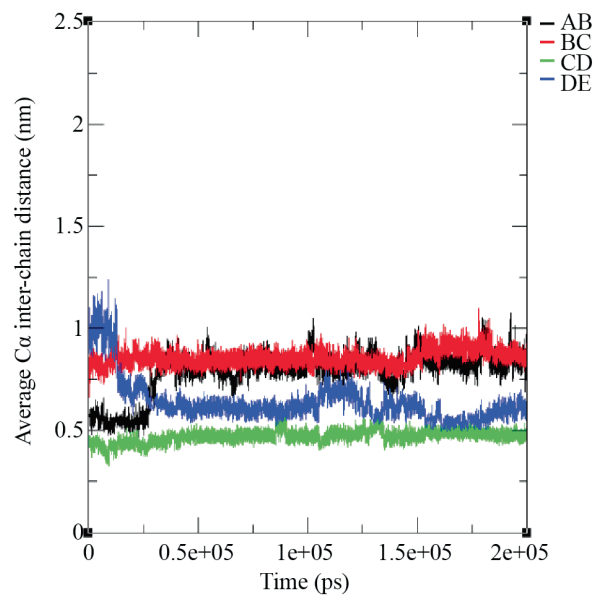

C.

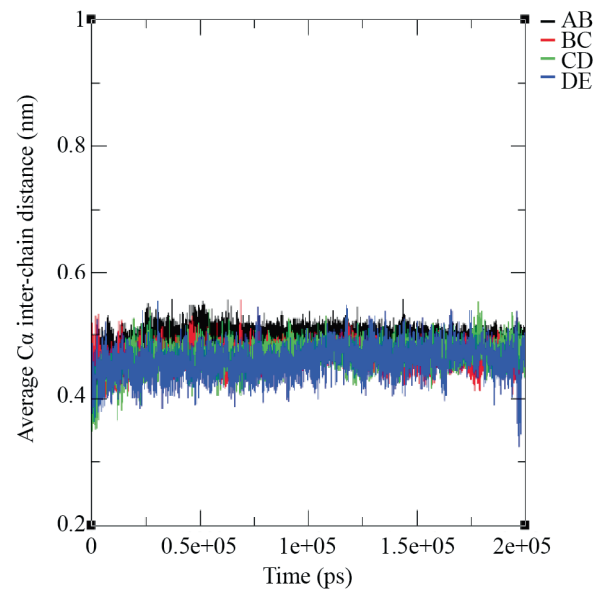

B.

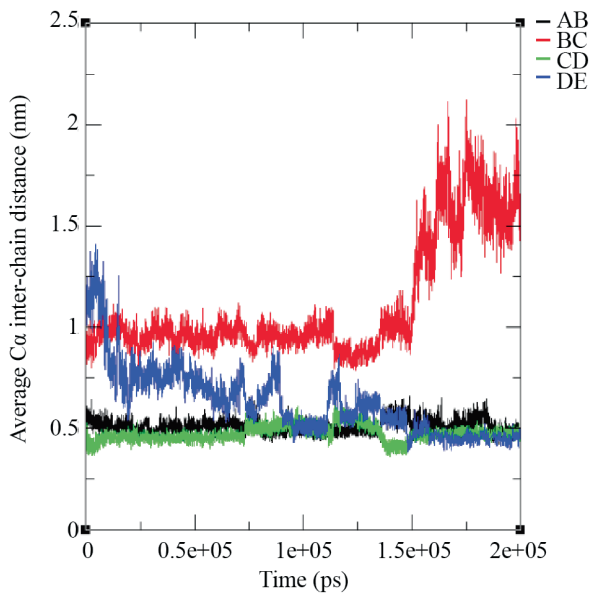

D.

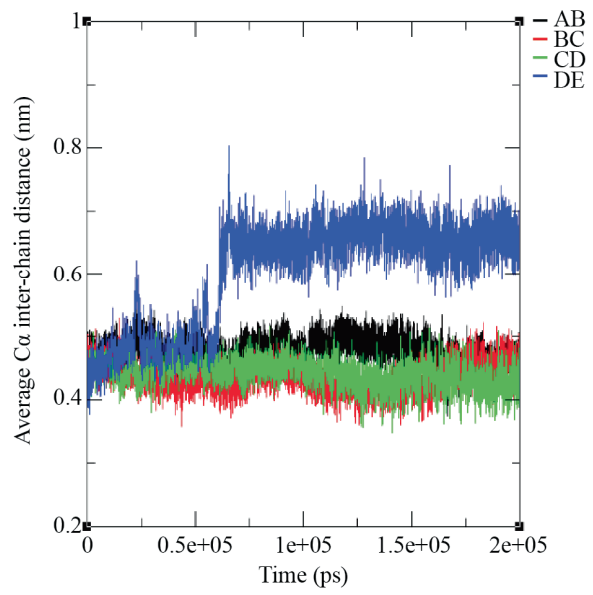

Figure 6.6: Compound 1 affects $A \beta_{1-42}$ pentamer structure in proximity of its binding site $\left(\beta_{1}\right.$ region) and in areas more remote $\left(\boldsymbol{\beta}_{2}\right.$ region). (A-B) Average inter-chain distances of the mass centres of the $\mathrm{C} \alpha$ atoms in the $\beta_{1}$ region of the $A \beta_{1-42}$ pentamer in the $(\mathbf{A})$ absence and (B) presence of compound 1, in function of MD simulation time. (C-D) Average inter-chain distances of the mass centres of the $\mathrm{C} \alpha$ atoms in the $\beta_{2}$ region of the $\mathrm{A} \beta_{1-42}$ pentamer in the $(\mathbf{C})$ absence and $(\mathbf{D})$ presence of compound 1, in function of MD simulation time. 


\subsubsection{Design and experimental testing of new anti-aggregation peptidomimetics}

Structure-based virtual screening of new compounds with potential inhibitory activity on A $\beta$ aggregation

In a next step, we aimed to identify new compounds, structurally similar to compound 1 . A structure-based virtual screening was performed using the NCI database to select the best candidate structures that were then purchased or chemically synthesized (Fig. 6.7). Next, we experimentally assessed their inhibitory effect on $\mathrm{A} \beta$ aggregation using a biophysical approach.

\begin{tabular}{cllll}
\hline \hline Compound & $\mathrm{R}_{1}$ & $\mathrm{R}_{2}$ & $\mathrm{R}_{3}$ & $\mathrm{n}$ \\
\hline 1 & - & $4-\mathrm{NHMe}-\mathrm{Bz}$ & $\mathrm{Cbz}$ & 2 \\
2 & $\mathrm{Su}$ & $\mathrm{Boc}$ & $\mathrm{Boc}$ & 1 \\
3 & $\mathrm{Su}$ & $\mathrm{Boc}$ & $\mathrm{Cbz}$ & 1 \\
4 & - & $\mathrm{Fmoc}$ & $\mathrm{Cbz}$ & 1 \\
5 & - & $\mathrm{Cbz}$ & $\mathrm{Cbz}$ & 1 \\
6 & $\mathrm{Su}$ & $\mathrm{Cbz}$ & $\mathrm{Cbz}$ & 1 \\
7 & $\mathrm{Su}$ & $\mathrm{Fmoc}$ & $\mathrm{Cbz}$ & 1 \\
8 & $\mathrm{Su}$ & $\mathrm{Cbz}$ & $\mathrm{Boc}$ & 1 \\
9 & $\mathrm{Su}$ & $\mathrm{Fmoc}$ & $\mathrm{Fmoc}$ & 1 \\
10 & $\mathrm{Su}$ & $\mathrm{Boc}$ & $\mathrm{Fmoc}$ & 1 \\
11 & $\mathrm{Su}$ & $\mathrm{Cbz}$ & $\mathrm{Fmoc}$ & 1 \\
\hline \hline
\end{tabular}<smiles>[R3]NCCCC(C)C[C@@H](N[R])C(=O)O[R]</smiles><smiles>CN1C(=O)CCC1=O</smiles><smiles>C[SH](C)(=O)OCC1c2ccccc2-c2ccccc21</smiles><smiles>CC(C)(OC(=O)OCc1ccccc1)C(=O)OCc1ccccc1</smiles><smiles>CC(C)(C)OC(=O)OC(C)(C)C</smiles>

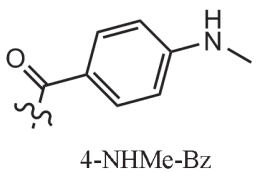

Figure 6.7: Structural features of the synthesized peptidomimetics, designed by structure-based virtual selection to possess $\mathbf{A} \boldsymbol{\beta}$ anti-aggregation activity. Abbreviations: $\mathrm{Su}$, succinimide; Fmoc, fluorenylmethyloxycarbonyl; $\mathrm{Cbz}$, carbonylbenzynoxy; Boc, ter-butyloxycarbonyl; 4-NHMe-Bz, 4methylaminobenzoyl.

The selected compounds possessed a lysine backbone, in contrast to compound 1 which has a homolysine core. These compounds showed additional variation in three parts of the molecule as depicted in fig. 6.7: (i) the $\alpha$-amino group, (ii) the $\alpha$-carboxyl group, and (iii) the $\varepsilon$-amino group. Simulations suggested that insertion of compounds in the A $\beta$ pentamer core was a crucial event for anti-aggregation activity, and this appeared to be associated with the presence of a hydroxysuccinimide ester. 
The binding mode of these compounds was investigated using docking analysis, with the same procedure as described previously. Only compounds that showed the $\beta_{1}$ portion as the preferential zone to form the complex with the $A \beta_{1-42}$ pentamer (type III complexation) were taken into account. The simulations for the new compounds showed different behaviours ranging from similar to compound 1 (noticeably affecting the pentameric structure of $A \beta_{1-42}$ ), to intermediate or no significant effect on $\mathrm{A} \beta$ structure. In the following section, only the MD simulations results obtained for four compounds are discussed, which are representative of the entire series: two compounds that induced the most noticeable structural changes (compounds 3 and 6), and two compounds that did not affect the pentameric $A \beta_{1-42}$ structure (compounds 4 and 5).

The MD results obtained for compounds 3 and 6 were comparable to those observed for compound 1. Both peptidomimetics deeply inserted in the core of the $A \beta_{1-42}$ pentamer (Fig. $6.8 \mathrm{~A}$ and $\mathrm{B})$. In contrast, compounds 4 and 5 were excluded from the core of the $\mathrm{A} \beta_{1-42}$ pentamer at the end of the $200 \mathrm{~ns}$ simulation (Fig. 6.8C and D). One of the main differences between both compound types is that compounds 3 and 6 contain a hydroxysuccinimide ester, whereas compounds 4 and 5 do not (Fig. 6.7). We suggest that the presence of this ester might facilitate the insertion process of the compound in the $\mathrm{A} \beta_{1-42}$ pentamer structure.

A.
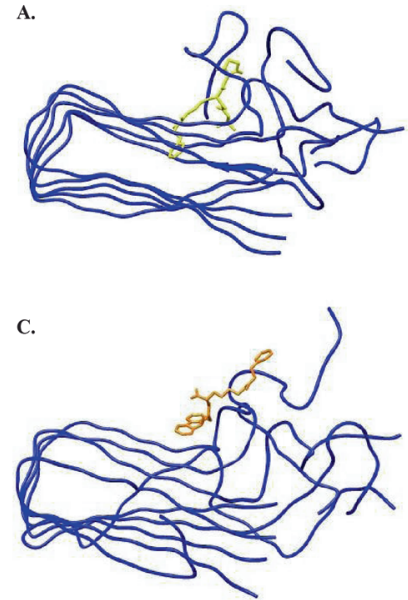

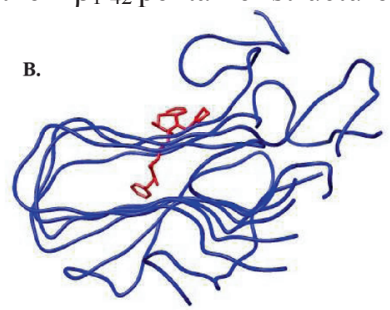

D.

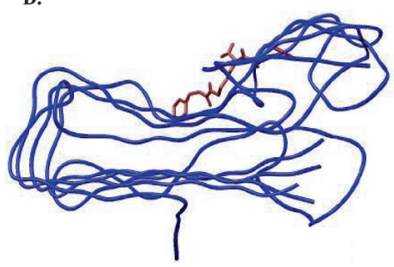

Figure 6.8: Compounds 3 and 6 insert in the $A \beta_{1-42}$ pentamer core, in comparison with the expelled compounds 4 and 5. Lateral spatial view of complexes between the $A \beta_{1-42}$ pentamer and (A) compound 3, (B) compound 6, (C) compound 4, and (D) compound 5, after 200 ns of MD simulations.

From these simulations, it was hypothesized that compounds 4 and 5 would be marginally effective in modulating aggregation behaviour of $A \beta_{1-42}$, whereas compounds 3 and 6 were expected to inhibit $\mathrm{A} \beta_{1-42}$ aggregation.

\section{Biophysical assessment of compound activities}

To experimentally address the computational results, the activities of these four compounds, representative of the entire series, were determined using a range of biophysical assays. To assess the $A \beta$ anti-aggregation activities of the representative compounds, $A \beta_{1-42}$ fibril formation $\left(25 \mu \mathrm{M} \mathrm{A} \beta\right.$ concentration) after 7 days of incubation at $37{ }^{\circ} \mathrm{C}$, in the presence and absence of different compound concentrations, was measured using ThT fluorescence. ThT is 
a dye commonly used to detect fibril formation, as its fluorescence emission is largely enhanced upon binding to amyloid fibrils (32). A $\beta_{1-42}$ fibril formation was significantly inhibited in a dose-dependent manner by compounds 3 and 6 , as seen by decreased ThT fluorescence intensities with increasing compound concentration (Fig. 6.9A and B). Compounds 3 and 6 were maximally active at a concentration of $100 \mu \mathrm{M}$. In contrast, the presence of compound 5, which is also representative for compound 4, did not affect ThTreactivity of $\mathrm{A} \beta_{1-42}$ (Fig. 6.9C).
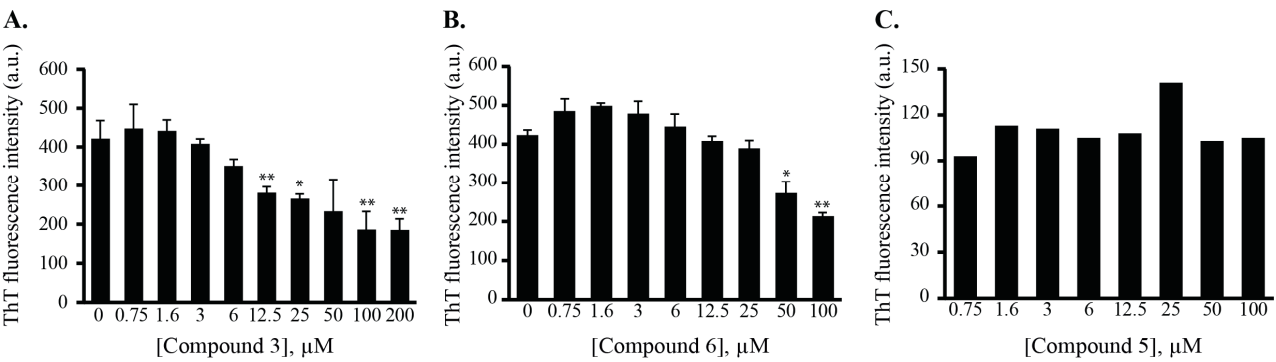

Figure 6.9: $A \beta_{1-42}$ fibril formation is affected in a dose-dependent manner by compounds 3 and 6 . Fibril formation of $25 \mu \mathrm{MA} \beta_{1-42}$, incubated in the absence and presence of compounds at $37{ }^{\circ} \mathrm{C}$ for $7 \mathrm{~d}$, was monitored using ThT fluorescence intensity at $485 \mathrm{~nm}\left(\lambda_{\mathrm{ex}}=450 \mathrm{~nm}\right)$ : (A) compound 3, (B) compound 6, and (C) compound 5 (which is representative for compound 4). Values represent results of three independent replicates for active compounds 3 and 6. Statistical significance of the results in (A) and (B) was established using paired two-tailed t-tests. Statistical significance levels were $* \mathrm{P}<0.05$, and $* * \mathrm{P}<0.005$.

Accordingly, TEM revealed networks of intertwined and negatively stained fibrils for samples containing $A \beta_{1-42}$ and one of the non-inhibitory compounds 4 and 5 (Fig. 6.10). For $A \beta_{1-42}$ incubated in presence of compound 3, less fibrils were detected compared to $A \beta_{1-42}$ alone, and no fibrils were seen for $A \beta_{1-42}$ incubated in presence of $100 \mu \mathrm{M}$ of compound 6 , indicating its anti-aggregating effect (Fig. 6.10). However, it should be taken into consideration that TEM cannot be exclusively used as a quantitative method for fibril formation.

As a final assessment, the effect of compounds on the formation of oligomeric $A \beta_{1-42}$ was determined. Soluble oligomeric $A \beta$ has been suggested previously to be the main responsible for the neurotoxic response and cognitive defects observed in AD patients (2). Therefore, dot blot analysis was performed with the anti-amyloid precursor protein antibody DE2B4, for detection of the total amount of A $\beta$ present, and with the oligomer-specific A11 antibody, developed by Glabe and co-workers (24). Samples were blotted after $1.5 \mathrm{~h}$ of incubation at 37 ${ }^{\circ} \mathrm{C}$. In the absence of anti-aggregation compounds, a high A11 response is expected at this time point as it has been shown previously that this corresponds to a toxic A $\beta$ oligomerenriched fraction (23). Consistently, high dot blot intensities (and thus high reactivity with DE2B4 and A11 antibodies) were recorded for $A \beta_{1-42}$ in presence of the inactive compounds 4 and 5. Compounds 3 and 6 however inhibited oligomerization from $100 \mu \mathrm{M}$ and higher, as demonstrated by the lack of reactivity with DE2B4 and A11 antibodies at these concentrations (Fig. 6.11). 


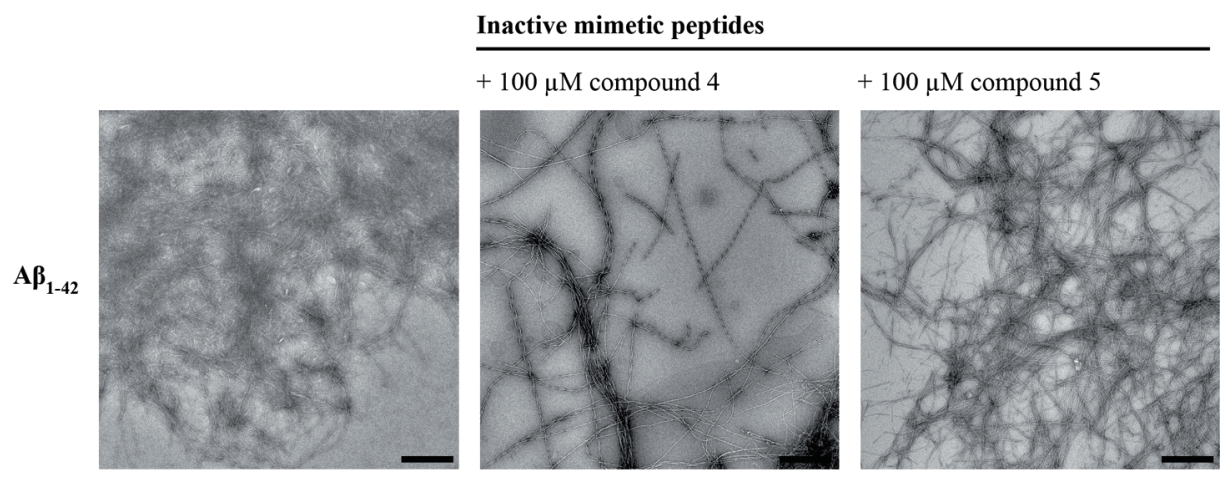

\section{A $\beta$ aggregation inhibitors}

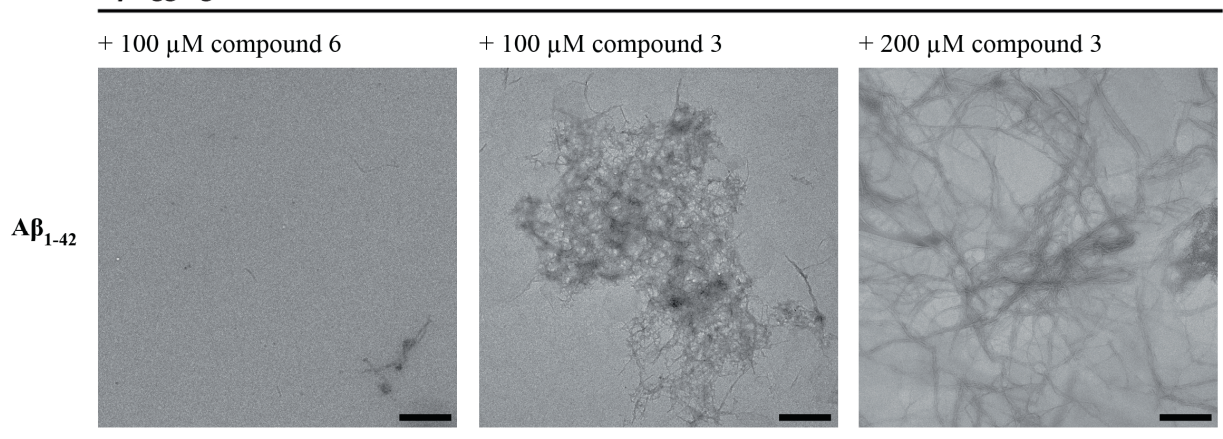

Figure 6.10: TEM visualization of the effect of compounds on $\mathbf{A} \boldsymbol{\beta}_{1-42}$ fibril formation. Images were obtained from $25 \mu \mathrm{M} \mathrm{A} \beta_{42}$ incubated in the absence or presence of compounds 3 to 6 at $37{ }^{\circ} \mathrm{C}$ for $7 \mathrm{~d}$. Scale bars represent $500 \mathrm{~nm}$.

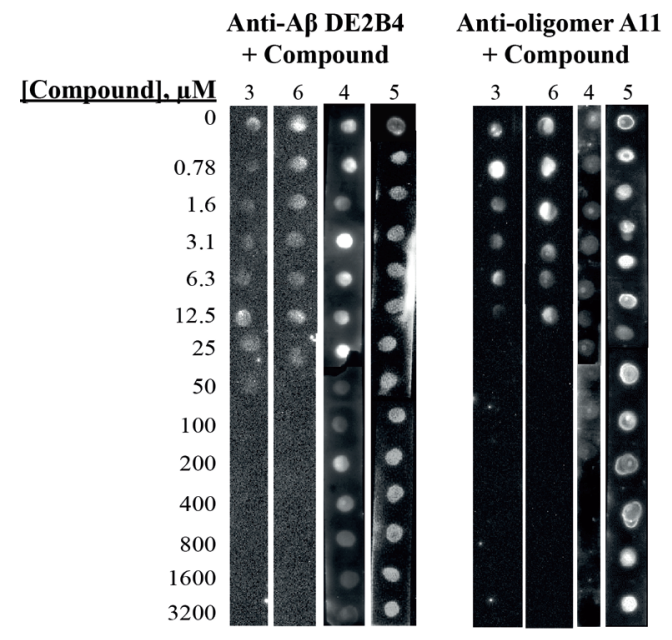

Figure 6.11: Dot blot analysis of the effect of compounds on $A \boldsymbol{\beta}_{1-42}$ oligomer formation. Images were obtained from $25 \mu \mathrm{M} \mathrm{A} \beta_{1-42}$ incubated in presence of compounds 3 to 6 at $37{ }^{\circ} \mathrm{C}$ for $1.5 \mathrm{~h}$. Dot blot analysis was performed with the anti-amyloid precursor protein antibody DE2B4, for detection of the total amount of A $\beta_{1-42}$ present, and with the oligomer-specific A11 antibody. 


\subsection{Discussion}

We report a new series of peptidomimetics capable of interfering with $\mathrm{A} \beta$ aggregation and/or $\mathrm{A} \beta$ oligomerization. Among the new compounds tested, compounds 3 and 6 displayed the strongest activities, both in MD simulations and docking studies, as well as in biophysical assays. These compounds were obtained through a molecular modelling study which allowed a structure-based virtual selection of the most promising compounds. By combining docking analysis with MD simulations, we report a generally applicable procedure to evaluate the binding process of ligands interacting with an $\mathrm{A} \beta_{1-42}$ pentameric model, while providing a detailed picture for the binding mechanism of these ligands at the molecular level and their potential anti-aggregating mechanistic mode of action. Alterations in the structure of the $\mathrm{A} \beta_{1-42}$ pentamer model elicited by compound 1 have been identified by computational simulations. These include: (i) destruction of the regular $\beta$-helical twist, and (ii) loss of a stabilizing hydrophobic interaction in the $\beta_{1}$ region of the $A \beta$ peptide. Moreover, insertion of the compound in the core of the $A \beta$ pentamer is required for exerting its $A \beta$ anti-aggregation effect and this depends on the chemical composition of the compound, in particular on the presence of a hydroxysuccinimide ester group.

Monitoring $A \beta_{1-42}$ aggregation by ThT fluorescence and TEM revealed that fibril formation was significantly decreased in presence of compounds 3 and 6, whereas dot blot analysis demonstrated a decrease of the formation of soluble oligomers, suggested previously to be the primary pathological species causing cognitive decline in $\mathrm{AD}(2)$.

Taking this into account, our results provide information which may be helpful in obtaining a better understanding of the mode of action of these ligands, and of their potential to disrupt $\mathrm{A} \beta_{1-42}$ aggregation at a molecular level. It should however be emphasized that $\mathrm{MD}$ simulations performed here treat only a very short time span and therefore only take into account the beginning of the interaction of the peptidomimetics with the A $\beta$ pentamer. In contrast, the biophysical assays used in this study measure pronounced continuous changes and alterations that may involve conformational changes that are not yet visible with MD simulations. However, changes in the degrees of freedom of both partners (drug compound and $\mathrm{A} \beta$ pentamer) during the earliest binding events can thus potentially have a large impact on the overall aggregation process.

In conclusion, our results show that the combination of docking and MD simulations is a valuable approach to identify molecules with potent $\mathrm{A} \beta$ anti-aggregation activity, and to understand the minimum structural requirements for their binding. We suggest that this combined methodology can serve as a guide in the design of new A $\beta$ self-assembly inhibitors. 


\subsection{References}

1. Hardy J \& Allsop D (1991) Amyloid deposition as the central event in the aetiology of Alzheimer's disease. Trends Pharmacol Sci 12(10):383-388.

2. Haass C \& Selkoe DJ (2007) Soluble protein oligomers in neurodegeneration: lessons from the Alzheimer's amyloid $\beta$-peptide. Nat Rev Mol Cell Biol 8(2):101-112.

3. Yan R \& Vassar R (2014) Targeting the $\beta$ secretase BACE1 for Alzheimer's disease therapy. Lancet Neurol 13(3):319-329.

4. Pettersson M, Stepan AF, Kauffman GW, \& Johnson DS (2013) Novel $\gamma$-secretase modulators for the treatment of Alzheimer's disease: a review focusing on patents from 2010 to 2012. Expert Opin Ther Pat 23(10):1349-1366.

5. Lannfelt L, Relkin NR, \& Siemers ER (2014) Amyloid- $\beta$-directed immunotherapy for Alzheimer's disease. J Intern Med 275(3):284-295.

6. Cheng B, et al. (2013) Inhibiting toxic aggregation of amyloidogenic proteins: a therapeutic strategy for protein misfolding diseases. Biochim Biophys Acta 1830(10):4860-4871.

7. Ghanta J, Shen CL, Kiessling LL, \& Murphy RM (1996) A strategy for designing inhibitors of $\beta$-amyloid toxicity. J Biol Chem 271(47):29525-29528.

8. Tjernberg LO, et al. (1996) Arrest of $\beta$-amyloid fibril formation by a pentapeptide ligand. $J$ Biol Chem 271(15):8545-8548.

9. Lowe TL, Strzelec A, Kiessling LL, \& Murphy RM (2001) Structure-function relationships for inhibitors of $\beta$-amyloid toxicity containing the recognition sequence KLVFF. Biochemistry 40(26):7882-7889.

10. Gibson TJ \& Murphy RM (2005) Design of peptidyl compounds that affect $\beta$-amyloid aggregation: importance of surface tension and context. Biochemistry 44(24):8898-8907.

11. Soto C, Kindy MS, Baumann M, \& Frangione B (1996) Inhibition of Alzheimer's amyloidosis by peptides that prevent $\beta$-sheet conformation. Biochem Biophys Res Commun 226(3):672680.

12. Soto C, et al. (1998) $\beta$-sheet breaker peptides inhibit fibrillogenesis in a rat brain model of amyloidosis: implications for Alzheimer's therapy. Nat Med 4(7):822-826.

13. Permanne B, et al. (2002) Reduction of amyloid load and cerebral damage in a transgenic mouse model of Alzheimer's disease by treatment with a $\beta$-sheet breaker peptide. FASEB $J$ 16(8):860-862.

14. Adessi C, et al. (2003) Pharmacological profiles of peptide drug candidates for the treatment of Alzheimer's disease. J Biol Chem 278(16):13905-13911.

15. Chen D, Martin ZS, Soto C, \& Schein CH (2009) Computational selection of inhibitors of Abeta aggregation and neuronal toxicity. Bioorg Med Chem 17(14):5189-5197.

16. Liu FF, Dong XY, He L, Middelberg AP, \& Sun Y (2011) Molecular insight into conformational transition of amyloid $\beta$-peptide 42 inhibited by (-)-epigallocatechin-3-gallate probed by molecular simulations. J Phys Chem B 115(41):11879-11887.

17. Raman EP, Takeda T, \& Klimov DK (2009) Molecular dynamics simulations of Ibuprofen binding to A $\beta$ peptides. Biophys $J$ 97(7):2070-2079.

18. Lemkul JA \& Bevan DR (2012) Morin inhibits the early stages of amyloid $\beta$-peptide aggregation by altering tertiary and quaternary interactions to produce "off-pathway" structures. Biochemistry 51(30):5990-6009.

19. Lemkul JA \& Bevan DR (2012) The role of molecular simulations in the development of inhibitors of amyloid $\beta$-peptide aggregation for the treatment of Alzheimer's disease. ACS Chem Neurosci 3(11):845-856.

20. Moitessier N, Englebienne P, Lee D, Lawandi J, \& Corbeil CR (2008) Towards the development of universal, fast and highly accurate docking/scoring methods: a long way to go. Br J Pharmacol 153 Suppl 1:S7-26.

21. Roychaudhuri R, Yang M, Hoshi MM, \& Teplow DB (2009) Amyloid $\beta$-protein assembly and Alzheimer disease. $J$ Biol Chem 284(8):4749-4753.

22. Masman MF, et al. (2009) In silico study of full-length amyloid $\beta$ 1-42 tri- and pentaoligomers in solution. J Phys Chem B 113(34):11710-11719. 
23. Broersen K, et al. (2011) A standardized and biocompatible preparation of aggregate-free amyloid beta peptide for biophysical and biological studies of Alzheimer's disease. Protein Eng Des Sel 24(9):743-750.

24. Kayed R, et al. (2003) Common Structure of Soluble Amyloid Oligomers Implies Common Mechanism of Pathogenesis. Science 300(5618):486-489.

25. Sanner MF (1999) Python: a programming language for software integration and development. J Mol Graph Model 17(1):57-61.

26. Trott O \& Olson AJ (2010) AutoDock Vina: improving the speed and accuracy of docking with a new scoring function, efficient optimization, and multithreading. $J$ Comput Chem 31(2):455-461.

27. Hess B, Kutzner C, van der Spoel D, \& Lindahl E (2008) GROMACS 4: Algorithms for Highly Efficient, Load-Balanced, and Scalable Molecular Simulation. J. Chem Theory Comput 4(3):435-447.

28. Oostenbrink C, Villa A, Mark AE, \& van Gunsteren WF (2004) A biomolecular force field based on the free enthalpy of hydration and solvation: the GROMOS force-field parameter sets 53A5 and 53A6. J Comput Chem 25(13):1656-1676.

29. Hetényi C \& van der Spoel D (2006) Blind docking of drug-sized compounds to proteins with up to a thousand residues. FEBS Lett 580(5):1447-1450.

30. Ferguson N, et al. (2006) General structural motifs of amyloid protofilaments. Proc Natl Acad Sci U S A 103(44):16248-16253.

31. Lemkul JA \& Bevan DR (2010) Assessing the stability of Alzheimer's amyloid protofibrils using molecular dynamics. $J$ Phys Chem B 114(4):1652-1660.

32. LeVine H, 3rd (1999) Quantification of $\beta$-sheet amyloid fibril structures with thioflavin T. Methods Enzymol 309:274-284. 


\title{
Chapter 7
}

\section{Can ecosystem management provide a framework for Alzheimer's disease therapy?}

This chapter has been submitted to Trends in Molecular Medicine.

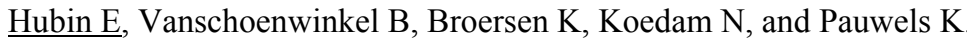

\begin{abstract}
$\mathrm{AD}$ is a progressive neurodegenerative brain disorder that involves a plethora of molecular pathways. In the context of therapeutic treatment, the $A \beta$ peptide constitutes an interesting research avenue as $A \beta$ has been suggested to be a primary driver of $A D$ pathology. The highly dynamic and complex nature of the $A \beta$ network inspired us to think about $A \beta$ in $A D$ in terms of the complexity of an ecosystem. Here, we explore the potential merits of an ecosystem paradigm as a novel way to consider $\mathrm{AD}$ and $\mathrm{A} \beta$ dynamics in particular. In addition to stimulating cross-disciplinary thinking by comparing the $\mathrm{A} \beta$ network to an ecosystem, the approach presented here may be valuable for educational purposes as it offers a more convenient and tangible way to illustrate and understand the molecular phenomena that occur in the brain. Moreover, as ecosystem management relies on the total analysis of relationships between elements in an ecosystem, it can be opportune to implement lessons that can be learned from successful ecosystem management with the aim to prevent or remediate AD. We therefore propose that combining network medicine with general ecosystem management principles is a new and holistic approach to unravel $\mathrm{AD}$ mechanisms and design successful therapies.
\end{abstract}




\subsection{AD complexity imposes a challenge for therapy development}

$\mathrm{AD}$, the most common form of dementia, affects the brain and causes severe memory loss and behavioural changes. The main hallmarks of the disease are the formation of amyloid plaques and the generation of neurofibrillary tangles, which ultimately result in neuronal dysfunction and neuronal cell death (1). This phenomenon of protein aggregation is a feature shared by many neurodegenerative diseases.

It has been suggested that aggregation of the $A \beta$ peptide into insoluble fibrils plays a role in the development and pathogenesis of AD (2). Post-mortem brain analysis of AD patients typically shows accumulation of $A \beta$ plaques in the brain extracellular space. However, no clear correlation was found between plaque load and disease severity, shifting the attention to soluble $A \beta$ oligomeric species (3) and the ongoing aggregation process (4) as the main culprits for toxicity in $\mathrm{AD}$.

Several drug discovery strategies have therefore been directed at interfering with $A \beta$ production, aggregation, clearance, and toxicity (5). Despite some promising drug candidates, clinical trials have been unsuccessful due to a lack of efficacy or safety issues $(6,7)$. Current treatment is still limited to the alleviation of disease symptoms without the arrest or reversion of the underlying disorder. This lack of success reflects the general failure to fully comprehend amyloid deposition and its dynamics. As various biochemical pathways are affected in $\mathrm{AD}$, it is conceivable that targeting one disease pathway might overall have a negligible effect as other disease mechanisms and pathways could still play a dominant role.

In most $\mathrm{AD}$ cases, $\mathrm{A} \beta$ accumulation is the result of the interplay between certain susceptibility genes, environmental factors, and lifestyle contributors (8). Moreover, the in vivo A $\beta$ peptide pool is highly diverse with multiple $A \beta$ variants (alloforms) interacting and influencing each other's behaviour, and as such it can influence disease outcome (Box 1). In addition to the imbalance between $\mathrm{A} \beta$ production and clearance, $\mathrm{AD}$ pathology also includes neuronal degeneration, an impaired microvasculature, a dysfunctional BBB, neuroinflammation, mitochondrial deterioration, oxidative stress, cytoskeletal disintegration, and epigenetic changes (9). Although the amyloid cascade hypothesis is still influential to explain the pathophysiology of $\mathrm{AD}$, alternative views consider tau as the main driving force of $\mathrm{AD}(10)$ or deem that several pathogenic features of $\mathrm{AD}$ can be interpreted as amyloid-independent alterations of synaptic plasticity, endolysosomal trafficking, cell cycle regulation, and neuronal survival (11). Another hypothesis suggests that AD results from accelerated neural damage and cognitive decline in the vulnerable, aged brain due to microvascular failure and decreased angiogenesis (12). Therefore, it is essential that drug development strategies fully address the multifactorial nature of $\mathrm{AD}$ and the complexity of the behaviour of $\mathrm{A} \beta$ in this disease (13). Developing these new therapeutic strategies is indispensable as AD incidence has been predicted to nearly triple by 2050 if no cure becomes available (14).

In an effort to approach the behaviour of $\mathrm{A} \beta$ in $\mathrm{AD}$ from a different angle, and considering the complexity and involvement (but not exclusively) of $\mathrm{A} \beta$ in $\mathrm{AD}$, we postulate that a similar complexity can be observed in ecosystems ${ }^{1}$, which can be defined as networks of interactions among species and their environment (15). In ecosystems, the relative abundance of the component species is continuously moulded by environmental conditions affecting the

\footnotetext{
${ }^{1}$ Ecosystem: a dynamic and complex system comprising plant, animal, and microorganism communities with their nonliving environment interacting as a functional unit (15).
} 
relative population growth of species, priority effects ${ }^{2}$, i.e. order of emergence or arrival of species (16), as well as biotic interactions among species (17). As a result, community structure may change over time and the resulting trajectories may lead to different equilibria or oscillations which, in turn, will determine the functions and services provided by the system (e.g. in terms of productivity ${ }^{3}$, efficiency of biochemical cycles, resistance against invasive species) (18). Similarly, the temporal dynamics in the composition of $A \beta$ species may also be governed by inter- and intra-species interactions and changes in environmental conditions, and priority effects (e.g. shifts in the $A \beta_{1-42}: A \beta_{1-40}$ ratio or in the occurrence of other alloforms). (19). The endpoint of the evolution of a complex system may be deterministic (e.g. the formation of plaques in $\mathrm{AD}$, eutrophication of a lake), but the route to get there may not be. For instance, not all patients with amyloid plaques have similar symptoms (20). There could also be different endpoints, some of which may be preferable over others, e.g. clear versus turbid water states in shallow lakes (Fig. 7.1). Finally, the stochastic nature of community trajectories should be investigated as order of arrival (priority effects) or small initial deviations followed by positive feedbacks could reduce the predictability of responses (18). Based on these insights from ecosystem ecology, we postulate that a better knowledge of the interplay between the drivers that determine variation in the temporal trajectories of $\mathrm{A} \beta$ species, minimizing or avoiding trajectories that are associated with toxicity, may render AD treatment more effective.

\section{Box 1: Use of the term 'A $\beta$ alloform'.}

An $A \beta$ alloform is defined as a distinct form of the $\mathrm{A} \beta$ peptide that is commonly treated as a single kind of peptide species. This includes the different $\mathrm{A} \beta$ peptide length variants and posttranslational side chain modifications. First, heterogeneous $\gamma$-secretase cleavage results in A $\beta$ peptides of various lengths ranging from 37 to 49 amino acids (21). Second, A $\beta$ peptides can undergo post-translational side chain modifications including racemization, isomerization, phosphorylation, oxidation, non-enzymatic glycation, and pyroglutamylation (19). Mass spectrometry (in combination with immunoprecipitation) is the most frequently used method to gain insight into the composition of the $A \beta$ peptide pool in the brain. As $A \beta$ alloform mixtures behave in a more complex manner than when studied in isolation in terms of aggregation behaviour, dynamics, and toxic properties (22-25), interactions among $A \beta$ alloforms should be considered when designing new therapeutic AD strategies.

We showcase some of the commonalities between $\mathrm{A} \beta$ in $\mathrm{AD}$ and ecological principles (Fig. 7.2, Table 7.1). This chapter explores the parallel that exists between the complexity of the molecular interactions of $\mathrm{A} \beta$ within $\mathrm{AD}$ and the complex architecture of direct and indirect interactions in ecosystems. We propose that insights from ecology, community assembly theory, and ecosystem management principles in particular (Box 2), might provide us with novel insights into AD pathogenesis and could serve as a guiding principle for innovative therapy design.

\footnotetext{
${ }^{2}$ Priority effect: this phenomenon occurs when species that arrive first in a community significantly affect the establishment, growth, or reproduction of species arriving later, and thus affect community functioning. Hence, the future development of the community may depend on its past recruitment history and on the persistence of established residents (16).

${ }^{3}$ Productivity: rate of conversion of resources into biomass, usually expressed in units of mass per unit area (volume) per unit time.
} 
Moreover, the framework presented here provides an additional opportunity to establish a dialogue between researchers, industrial partners, and the lay public (patients and caretakers) by using observable and familiar macroscopic events in ecosystems as proxies for molecular and cellular events in AD.

\section{A. Shallow lake}

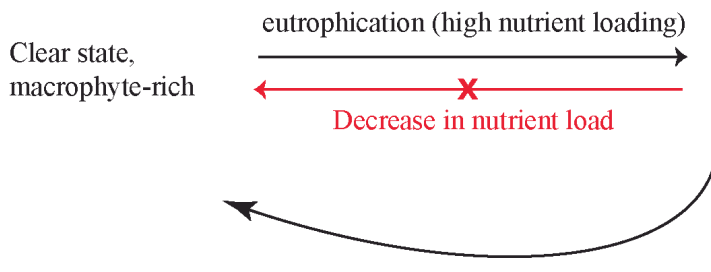

Turbid, undesirable state,

phytoplankton-rich

Multiple measures required:

Decrease in nutrient load (e.g. P, N)

Sediment removal

Biomanipulation

Alteration of water level

\section{B. Brain environment}

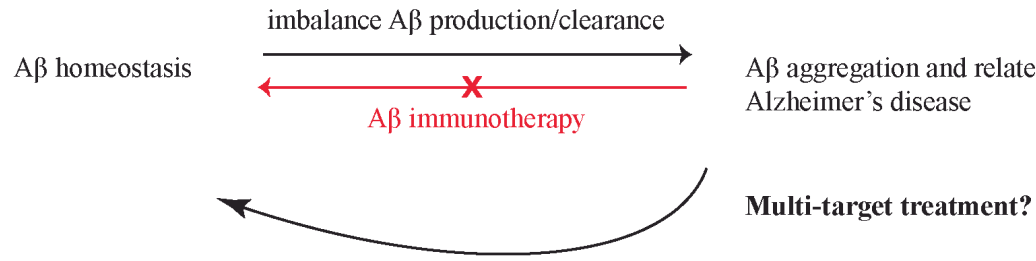

Figure 7.1: Ecosystem management principles may be useful to develop novel AD therapies. (A) Shallow lakes can typically be in one of two contrasting equilibrium states: a clear state with submerged macrophytes or a turbid state dominated by phytoplankton. If the nutrient loading (e.g. P, N) of the lake exceeds a critical value, eutrophication may cause a switch from the clear to the turbid state that is generally considered as undesirable, because plant communities and rich fish fauna disappear and biodiversity decreases. In many cases, nutrient reduction, i.e. decreasing the nutrient load, is unsufficient to restore a non-vegetated turbid shallow lake to a clear vegetated state. Additional measures are then required for restoration, such as food web management, i.e. removal/alteration of a part of the fish stock (biomanipulation), alteration of the water level, and sediment removal. Various models have been designed that simulate the behaviour of shallow lakes and can be useful for ecosystem management, as they indicate which measures are required to improve lake transparency (26). (B) A $\beta$ immunotherapy has not yet proven successful in the treatment of AD. Anti-amyloid treatment only after dementia develops may be too little and too late to affect the clinical course of the disease. Similar to successful ecosystem management, multiple measures may be required to prevent or remediate $\mathrm{AD}$.

\section{Box 2: Use of the term 'Ecosystem management'.}

We define ecosystem management as the management of abiotic factors and/or biotic interactions in a natural environment of interacting species to maximize ecosystem services. Ecosystem services are the direct and indirect contributions of ecosystems to human wellbeing (27). When natural resource management is applied to the whole ecosystem, rather than to a single species, it is termed ecosystem management (Fig. 7.1A). The fundamental objective of ecosystem management is long-term stability. In this context, manipulative experiments that aim to push an ecosystem into another state and ecological models that incorporate multiple stable states and alternative trajectories to capture the complex dynamics of ecosystems, play an important role (15). 


\subsection{Comparison of $A \beta$ behaviour in $A D$ with general ecosystem principles}

Ecosystems can be perceived at different levels in the context of $\mathrm{AD}$ : the brain, the extracellular space, or specific subcellular compartments (e.g. mitochondria). The choice of ecosystem boundaries will define the subset of "species" and interactions to include in our analysis. Here, we consider the human brain as an ecosystem (Fig. 7.2, Table 7.1).

Biogeochemical cycles that move chemical substances (e.g. water, carbon-rich compounds, etc.) through the biotic and abiotic compartments of an ecosystem, are critical for life. These molecules may be recycled or accumulated in a sink/reservoir, such as different ecosystem compartments species, tissues, or biomass (15). Similarly, there is a flow of $A \beta$ throughout the lifespan of an individual. The production of $A \beta$ is a physiological process that occurs mainly in neuronal cells and has been suggested to be essential for normal synaptic activity (28). There is a tight regulation of $A \beta$ production with its clearance that occurs via receptormediated transfer across the BBB or via enzymatic proteolysis (29). Whereas aberrations in biogeochemical cycles can alter the structure and functioning of natural and managed ecosystems (30), an imbalance between $\mathrm{A} \beta$ production and clearance can result in $\mathrm{A} \beta$ accumulation in plaques throughout the brain (31).

An ecosystem can contain many different species communities. Similarly, the A $\beta$ monomeric peptide pool in the brain contains multiple $A \beta$ variants, including different peptide lengths and post-translational side chain modifications. We collectively refer to all these $A \beta$ variants as $A \beta$ alloforms (Box 1). In addition to the diversity of $A \beta$ species described above, several $\mathrm{A} \beta$ mutants have been linked to the familial type of $\mathrm{AD}$ that occurs at early age, defined as before the age of 65 (32). Taking A $\beta$ peptide pool diversity into account, a parallel can thus be seen with variation in the relative abundance of species in ecological communities or in the relative abundance of genotypes in populations. In both cases, interactions occur between entities that differ in the effects they have on overall ecosystem functioning.

Similar to the interactions that occur between species in an ecosystem (15), the in vivo A $\beta$ peptide pool is a complex mixture of $A \beta$ species influencing one another. It has now been recognized that the composition of this pool, rather than the absolute $A \beta$ quantity, plays a prominent role in disease outcome as different $A \beta$ alloforms can influence each other's aggregation behaviour and toxic properties (22-25). For example, shifts in the $A \beta_{1-42}: A \beta_{1-40}$ ratio can modulate the formation of neurotoxic oligomers (22). Minor traces of $A \beta_{1-38}$ can render $A \beta_{1-40}$ toxic to a neuroblastoma cell line, whilst exerting a cytoprotective effect on $A \beta_{1-42}$ (24). Moreover, the interplay between different $A \beta$ aggregation states must also be considered, as they exist in a dynamic equilibrium, and it has been suggested that the ongoing aggregation, rather than a specific toxic entity, is responsible for A $\beta$-related toxicity (4). Moreover, the inherently dynamic character of the A $\beta$ network (19) is in agreement with the observation that ecosystems are dynamic entities (15).

Not only interactions among species are defined as part of an ecosystem, but also interactions with the abiotic environment (15). Environmental stressors can change the temporal trajectories of ecosystems resulting in unfavourable ecosystem states such as turbid ponds (Fig. 7.1A), bleached coral reefs, or nutrient-exhausted soils (33). 


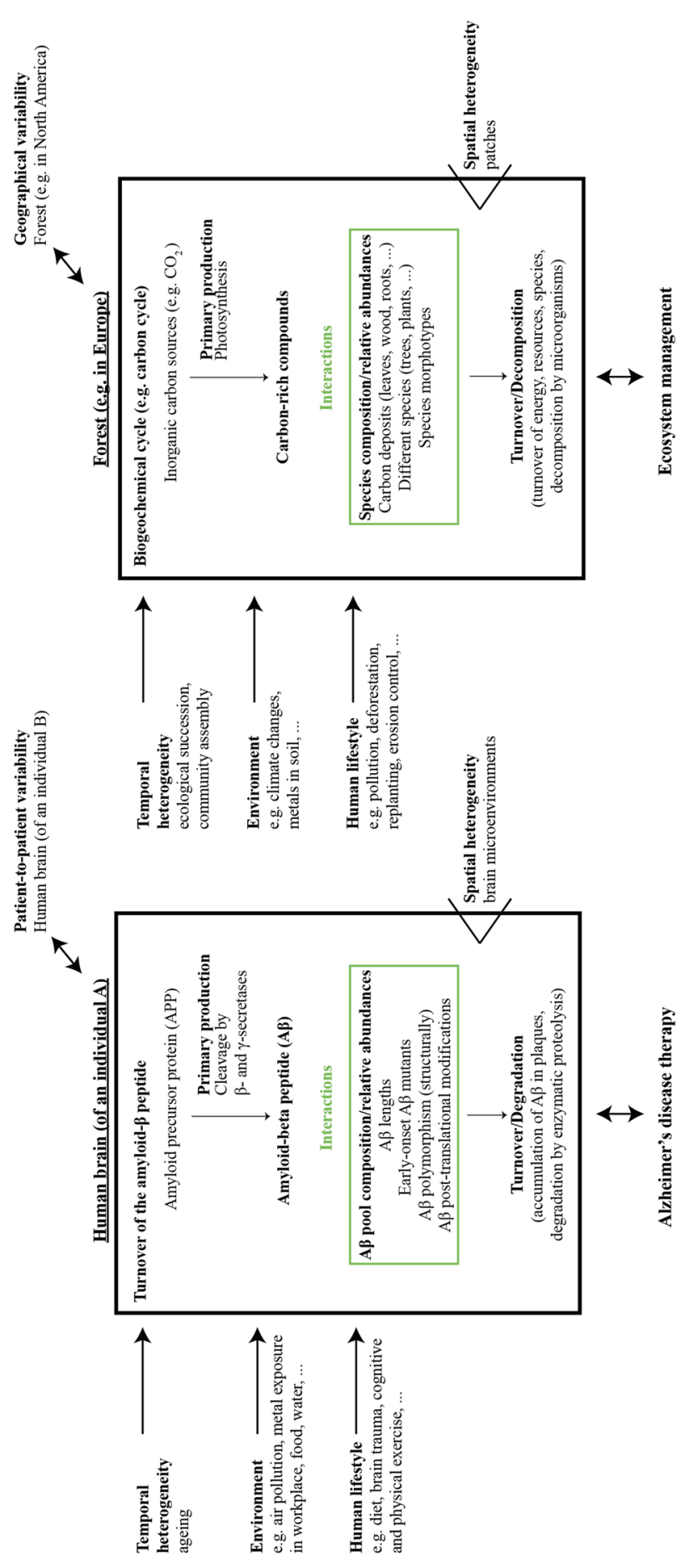

용

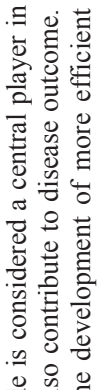

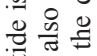

훙등ㅇ

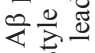

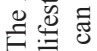

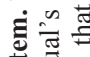

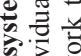

这

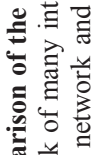

ํㅡㄹ 
Moreover, in response to environmental stimuli, epigenetic ${ }^{4}$ changes may occur that can affect ecologically important traits (34). Similarly, mounting evidence shows that environmental factors influence $\mathrm{AD}$ and $\mathrm{A} \beta$ properties. Air pollution has been shown to accelerate $A \beta$ accumulation and induce oxidative stress (35). Metals $(\mathrm{Cu}, \mathrm{Zn}, \mathrm{Fe}, \mathrm{Al})$ colocalize with $A \beta$ plaques and induce $A \beta$ toxicity through enhanced $A \beta$ aggregation and production of ROS (36). Stress or exposure to environmental toxins can also induce epigenetic changes related to memory and learning. In this regard, exposure to lead $(\mathrm{Pb})$ early in life has been demonstrated to upregulate genes involved in AD late in life in primates, through mechanisms involving DNA methylation and histone acetylation (37). Overexposure to metals, either via drinking water, food, or the environment, can thus potentially have profound effects. Furthermore, as epigenetic changes are potentially reversible, they may provide targets for the development of new therapies (38).

Another important driver of ecosystem dynamics is the human impact (15). The behaviour of humans can affect ecosystems in numerous ways, e.g. by pollution, deforestation and overfishery, but also by replanting and sustainable energy usage. Likewise, human lifestyle has been suggested to be associated with $\mathrm{AD}$ development and $\mathrm{A} \beta$ properties. Several food components have been suggested to be potent inhibitors of $A \beta$ aggregation or to act as antiinflammatory molecules or antioxidants (39). Moreover, prolonged cognitive and physical exercise have been shown to have a positive effect on the rate of cognitive decline (40). In contrast, severe brain injury (41) and diabetes (42) are important risk factors for AD development. Certain discrepancies should however be noted. In the case of AD, lifestyle affects the state of the individual itself, whereas in the case of an ecosystem, humans impact the whole system around them, which however ultimately may also translate into an altered state of the individual (e.g. air pollution may cause asthma).

Ecosystems are often not stable over time and may evolve from one equilibrium to another or experience regular cycles. This process is driven by birth and death rates (demography), colonization dynamics, extinction, and priority effects. Likewise, temporal changes in the brain associated with ageing are the most important risk factor for AD development (temporal heterogeneity). Ageing is associated with translational errors leading to defective protein synthesis, with less efficient protein quality control machineries, and with cumulative oxidative damage to proteins and membranes. However, the contribution of ageing to $\mathrm{AD}$ is highly complex and still not yet fully understood (43).

Furthermore, spatial heterogeneity and associated variation in the exchange of energy, species, and genotypes among habitat patches ${ }^{5}$ or among ecosystem sub-compartments is central to the functioning of ecosystems (44). The arrival of particular species can have disproportionately negative impacts on ecosystem functioning, which is referred to as the invasive species concept (45).

\footnotetext{
${ }^{4}$ Epigenetics: the acquired and heritable modifications on DNA that regulate the expression and function of genes without affecting the DNA nucleotide sequence, including DNA (hydroxyl)methylation and histone modifications. Epigenetic changes are considered as a mechanism by which the environment can interact with the genome (34).

${ }^{5}$ Patch: a relatively homogeneous subunit of an ecosystem or a spatially defined unit delineating a single ecosystem (e.g. a lake). Some ecosystems can be viewed as a mosaic of different patches, illustrating their spatial heterogeneity. Other ecosystems exist as discrete patches that may interact with the surrounding landscape matrix as well as with distant patches via dispersal and exchange of energy and matter (44).
} 
Likewise, spatial heterogeneity exists in the $\mathrm{A} \beta$ network as different brain microenvironments can be identified in an $\mathrm{AD}$ patient. $\mathrm{AD}$ affects some brain regions more than others and different brain regions can accumulate different amounts of $\mathrm{A} \beta$ (46). The invasive species concept in ecology can be compared to the effects related to particularly damaging variants of molecules in certain brain compartments (e.g. due to an increased $A \beta_{1-42}: A \beta_{1-40}$ ratio).

Finally, there is evidence that thresholds occur in ecosystems and have important effects on ecosystem services (47). An ecological threshold is the point where abrupt changes in an ecosystem property or in an environmental driver produce large responses in the ecosystem. It has been suggested that ecosystems can exist in alternative stable states (48), but given enough disturbance can be pushed over the hill (threshold) to another state. Similarly, an asymptomatic phase in AD takes place in which the first pathological events occur without affecting the cognitive ability of the patient. At a critical point in time (threshold), a conversion takes place to mild cognitive impairment and later to AD (49).

\subsection{Ecosystem management as a guiding principle for AD therapy design}

In the past decades, significant progress has been made in understanding $\mathrm{AD}$ mechanisms. However, numerous clinical trials have not yet resulted in an effective AD treatment. Hence, there is an urgent need for innovative approaches to $\mathrm{AD}$ drug design and it is crucial to understand the complex relationship between different molecular compounds and events that are involved in $\mathrm{AD}$.

As AD is complex and multifactorial, we should not focus on one disease component or pathway, but rather approach the disease from a broader perspective. Network medicine ${ }^{6}$ has been suggested earlier to offer a platform for studying both disease complexity (identifying disease factors and pathways) and the interdependencies between the different players (50), and multi-target drug ligands are being developed that target multiple key components in AD (51). Future research and implementation of these compounds in clinical trials will reveal their potential success in the fight against AD.

We have highlighted here that the behaviour of $\mathrm{A} \beta$ in $\mathrm{AD}$ shows many similarities with a complex ecosystem (Fig. 7.2, Table 7.1). Other disease contributing factors (e.g. tau) have been left out for simplicity, but need to be taken into account in this paradigm in the future. We want to raise the awareness that ecosystem management principles may pave the way for new insights into disease mechanisms and $\mathrm{AD}$ remediation and/or prevention.

A number of ecosystem management principles and paradigms may be useful to develop novel therapies. Promising paradigms include the notion that complex systems can exist in alternative stable states, stabilized by feedback mechanisms, and the fact that management can help to stimulate that certain favourable equilibria can be reached (Fig. 7.1). Additional information about temporal dynamics and alternative trajectories in complex systems can be generated by models. For instance, age-structured population models (52) developed in ecology may help to understand the development of molecules from precursors and how this can be modified by changing environmental conditions. Time series data combined with trials that alternate the order of treatments/introduction of interactors in a complex system, can help

\footnotetext{
${ }^{6}$ Network medicine: an integrated study of genomics, transcriptomics, proteomics, metabolomics, phenomics, and environmental perturbations, such as pharmacological intervention or pathogenic infection, for the purpose of understanding human disease and how to cure it (50).
} 
to assess to what extent history matters in determining the deterministic outcome of species or molecule interactions (53).

Moreover, all risk factors of $\mathrm{AD}$ that can potentially be modified must be identified, so that interventions can take place before the pathologic burden and accumulated neurodegeneration is irreversible. In ecosystems, early warning signs for regime shifts provide a tool for the improvement of ecosystem management and serve as an indicator for the implementation of preventive actions to avoid undesirable transitions in ecosystems $(54,55)$. For example, microbial-based monitoring programmes have been applied in the Neuse River Estuary in the USA to formulate and validate water quality models aimed at predicting nutrient-productivity and algal bloom thresholds. In this context, there are indications that an impending regime shift is often announced by rapid fluctuations between the current state and a potential future stable state. For instance, clear shallow lakes may first become turbid for brief periods of time before they shift to a permanent turbid state. Likewise, we need to identify thresholds and monitor the "flickering" of AD biomarkers in time-lapse experiments. The currently used CSF biomarkers reflect the core pathological features of $\mathrm{AD}$ and include total tau, hyperphosphorylated tau, and $A \beta_{1-42}$. Since the pathologic processes of $A D$ start decades before the first symptoms, these biomarkers may provide means of early disease detection or identification of the risk for developing AD. In addition, biomarkers might prove valuable in monitoring the effect of anti-AD drugs (56). In this way, the biochemical trajectories via which the disease manifests itself could be monitored, and controlled interventions can be made possible. This strategy is similar to how ecosystem management has been successfully applied in e.g. shallow lake restoration, where the status and nutrient loading of the lake is continuously monitored (26).

In summary, we would like to stimulate out-of-the-box thinking and propose that combining network medicine with general ecosystem management principles could be a new and holistic approach to better understand AD pathology and design successful therapies. In-depth studies by combining the expertise of both researchers in the AD field and ecologists, and openminded cross-disciplinary dialogues, may provide insight into the success potential of this ecosystem-based approach and its translation into concrete solutions in the clinical setting. In addition to the potential of our proposed approach to the AD field, we hypothesize that this may also impact treatment perspectives of other multifactorial neurodegenerative diseases, such as Parkinson's disease.

\section{Box 3: Outstanding questions and future perspectives}

1. Since ecosystem management relies on the total analysis of relationships between various elements in an ecosystem, lessons learned from successful ecosystem management might improve strategies to prevent or remediate AD. Similar to the combined set of measures necessary for the successful restoration of shallow lakes (Fig. 7.1A), remediation/prevention of $\mathrm{AD}$ may require interventions at the level of multiple disease pathways and factors (Fig. 7.1B). A recent study describes the design of a small molecule compound that targets and modulates various pathological facets of $\mathrm{AD}$, by integrating elements for $\mathrm{A} \beta$ aggregation control, metal chelation, ROS regulation, and antioxidant activity (57). This work is an important step towards multi-target treatment of $\mathrm{AD}$, and further optimization and clinical testing of multi-target ligands will reveal their efficacy in the future. 


\section{Box 3 (continued): Outstanding questions and future perspectives}

2. An evaluation is required to determine to what extent our analogy holds true for all aspects of disease and ecosystem management, as certain fundamental differences should not be overlooked. For example, contrary to species, molecules (such as A $\beta$ ) are typically not selfreplicating entities. Their dynamics and turnover are determined by the surrounding tissue that produces them, rather than by differential reproductive success, migration, and mortality, as would be the case for species in an ecosystem.

3. The diagnostic guidelines of $\mathrm{AD}$ have recently been updated to include CSF biomarkers. Biomarkers however cannot only be used for early detection of disease development and tracking of disease progression, but also hold promise for more effective therapeutic interventions before amyloid pathology is already widespread. Ultimately, the use of biomarkers might allow for interventions tailored to the individual, i.e. personalized medicine (56). Hence, the search for new biomarkers continues, in particular blood biomarkers, as blood samples are easier and cheaper to collect than performing a lumbar puncture procedure. Recently, a small scale study identified a biomarker panel consisting of ten lipids from peripheral blood with an $\mathrm{AD}$ prediction accuracy of $90 \%$ in the preclinical stage (58).

4. Multiple disease-associated mutations have been identified in the past (59) and much can be learned from individuals who possess genetic risk factor(s) and develop AD at an early age. Genome-wide association studies can also identify potential protective factors. Recently, the coding mutation A673T in the APP gene has been reported to protect against AD and cognitive decline in the elderly without $\mathrm{AD}$, by reducing $\mathrm{A} \beta$ deposition and pathology (60). Further research into this and other potential protective factors is required to fully comprehend their implications for therapy development.

Table 7.1: Approaching A $\beta$ in AD from an ecological point of view.

\begin{tabular}{|c|c|}
\hline General ecosystem descriptors, adapted from (15) & The $A \beta$ peptide as a central player in $A D$ \\
\hline $\begin{array}{l}\text { Ecosystems can be defined by the network of } \\
\text { interactions among organisms, and between organisms } \\
\text { and their environment. }\end{array}$ & We consider the $A \beta$ network in the context of $A D$. \\
\hline $\begin{array}{l}\text { The scale of an ecosystem depends on the question } \\
\text { being asked. }\end{array}$ & $\begin{array}{l}\text { In } \mathrm{AD} \text {, several ecosystems can be considered: the } \\
\text { brain, but also the extracellular or intracellular space, } \\
\text { or specific subcellular compartments (e.g. } \\
\text { mitochondria). }\end{array}$ \\
\hline $\begin{array}{l}\text { The overall ecosystem structure is controlled by } \\
\text { external factors (e.g. climate, time, biota) that are not } \\
\text { themselves influenced by the ecosystem. }\end{array}$ & $\begin{array}{l}\text { Examples of external factors that regulate } A \beta \\
\text { properties include ageing (the major risk factor for } \\
\text { AD), exposure to certain substances (e.g. metals) and a } \\
\text { patient's lifestyle. }\end{array}$ \\
\hline Ecosystems are dynamic entities. & $\begin{array}{l}\text { The } \mathrm{A} \beta \text { network is highly dynamic. Intramolecular } \\
\text { dynamics of } \mathrm{A} \beta \text { comprise the intrinsic disorder and } \\
\text { polypeptide backbone flexibility present in isolated } \mathrm{A} \beta \\
\text { monomeric peptides and aggregation states. The } \\
\text { interplay between different } \mathrm{A} \beta \text { alloforms in the in vivo } \\
\mathrm{A} \beta \text { peptide pool and the dynamic equilibrium that } \\
\text { exists between different } \mathrm{A} \beta \text { species are referred to as } \\
\text { intermolecular } \mathrm{A} \beta \text { dynamics. }\end{array}$ \\
\hline
\end{tabular}


Table 7.1 (continued): Approaching A $\beta$ in AD from an ecological point of view.

\begin{tabular}{l} 
General ecosystem descriptors, adapted from (15) \\
\hline Ecosystems in similar environments that are located in \\
different parts of the world can have very different \\
characteristics simply because they contain different \\
species. \\
The introduction of non-native species to the \\
ecosystem can cause substantial shifts in ecosystem \\
function. \\
Human activities have an increasing impact on \\
virtually all the processes that govern ecosystem \\
properties.
\end{tabular}

Ecosystem processes are driven by the number of species in an ecosystem, the exact nature of each individual species, and their relative abundances. Many effects of species on ecosystems are indirect and not easily predicted.

Classifying ecosystems into ecologically homogeneous units is an important step towards effective ecosystem management.

\section{The $\mathrm{A} \beta$ peptide as a central player in $\mathrm{AD}$}

The brain consists of microenvironments that do not all contain the same amount of $A \beta$. There is also considerable patient-to-patient variability.

A shift in $A \beta_{1-42}: A \beta_{1-40}$ ratio or occurrence of other alloforms can have profound effects on $A \beta$-related toxicity. This knowledge can be useful for drug development strategies.

Human lifestyle (e.g. diet, cognitive and physical exercise) or intervention (therapy) can modulate $\mathrm{AD}$ development and progression.

The $\mathrm{A} \beta$ peptide pool in the brain is highly diverse and influences the disease outcome. Additional heterogeneity results from the intrinsic structural flexibility of $A \beta$ (e.g. fibril polymorphism). $A \beta$ species influence each other's aggregation, dynamics, and toxic properties, either direct or indirect.

Neuropathological characterization of AD severity and disease progression (using Braak staging, positron emission tomography, magnetic resonance imaging, genotyping, and biomarkers) can enhance the care for $\mathrm{AD}$ patients and allow for an optimized therapy.

Primary production is the production of organic matter The primary production of $\mathrm{A} \beta$ originates from the from inorganic carbon sources (e.g. $\mathrm{CO}_{2}$ ) through transmembrane amyloid precursor protein APP by $\beta$ photosynthesis. The carbon-rich compounds and and $\gamma$-secretase proteolysis. A major route of $\mathrm{A} \beta$ nutrients in dead organic matter are broken down by a degradation is via proteases (e.g. IDE, NEP). group of processes known as decomposition.

Daily and seasonal variations in the environment can influence the ecosystem.

Diurnal $\mathrm{A} \beta$ fluctuations depend on the sleep-wake cycle.

Ecological theory suggests that in most cases, in order to coexist, species must have some level of limiting similarity: they must be different from one another in some fundamental way, otherwise one species would competitively exclude the other. Despite this, the cumulative effect of additional species in an ecosystem is not linear. The arrival of particular species can have disproportionately negative impacts on ecosystem functioning, as illustrated by the invasive species concept.

Ecosystems are typically subject to disturbances that can change ecosystem properties and alter subsequent dynamics. A disturbance can be defined as "a relatively discrete event in time and space that alters the structure of populations, communities, and ecosystems, and causes changes in resources availability or the physical environment".
$A \beta_{1-40}$ and $A \beta_{1-42}$ coexist under pathophysiological conditions, but their coexistence does not result in a linear manifestation: their cumulative effect is exemplified in more complex mixtures composed of $A \beta_{1-40}$ and $A \beta_{1-42}$ whereby a relatively small increase in $A \beta_{1-42}$ (e.g. $30 \%$ ) confers properties (both biophysical and cytotoxic traits) that are markedly more similar to pure $A \beta_{1-42}(100 \%)$ samples.

One example of such a disturbance is a traumatic brain injury, which increases the risk of developing AD. 
Table 7.1 (continued): Approaching A $\beta$ in AD from an ecological point of view.

\begin{tabular}{l|l}
\hline \hline General ecosystem descriptors, adapted from (15) & \multicolumn{1}{c}{ The A $\boldsymbol{\beta}$ peptide as a central player in AD } \\
\hline \hline $\begin{array}{l}\text { Ecosystems can exist in alternative stable states. } \\
\text { Management of abiotic factors and/or biotic } \\
\text { interactions in a natural environment of interacting } \\
\text { species can push an ecosystem to an alternative state to } \\
\text { maximize ecosystem services. }\end{array}$ & $\begin{array}{l}\text { novel insights into the multifactorial nature of AD and } \\
\text { the dynamic character of A } \beta \text {. Network medicine and } \\
\text { design of multi-target drugs are therefore promising } \\
\text { therapeutic avenues for AD. A better knowledge of the } \\
\text { interplay between the drivers that determine variation } \\
\text { in the temporal trajectories of A } \beta \text { species, minimizing } \\
\text { or avoiding trajectories associated with toxicity, could } \\
\text { help improve AD treatment. }\end{array}$ \\
\hline \hline
\end{tabular}




\subsection{References}

1. $\quad$ Mucke L (2009) Neuroscience: Alzheimer's disease. Nature 461(7266):895-897.

2. Hardy J \& Allsop D (1991) Amyloid deposition as the central event in the aetiology of Alzheimer's disease. Trends Pharmacol Sci 12(10):383-388.

3. Haass C \& Selkoe DJ (2007) Soluble protein oligomers in neurodegeneration: lessons from the Alzheimer's amyloid $\beta$-peptide. Nat Rev Mol Cell Biol 8(2):101-112.

4. Jan A, et al. (2011) A $\beta 42$ neurotoxicity is mediated by ongoing nucleated polymerization process rather than by discrete A 342 species. J Biol Chem 286(10):8585-8596.

5. Karran E, Mercken M, \& De Strooper B (2011) The amyloid cascade hypothesis for Alzheimer's disease: an appraisal for the development of therapeutics. Nat Rev Drug Discov 10(9):698-712.

6. Salloway S, et al. (2014) Two phase 3 trials of bapineuzumab in mild-to-moderate Alzheimer's disease. N Engl J Med 370(4):322-333.

7. Doody RS, et al. (2014) Phase 3 trials of solanezumab for mild-to-moderate Alzheimer's disease. $N$ Engl J Med 370(4):311-321.

8. Mayeux R \& Stern Y (2012) Epidemiology of Alzheimer disease. Cold Spring Harb Perspect Med 2(8):a006239.

9. Huang Y \& Mucke L (2012) Alzheimer mechanisms and therapeutic strategies. Cell 148(6):1204-1222.

10. Medina M \& Avila $\mathrm{J}$ (2014) New perspectives on the role of tau in Alzheimer's disease. Implications for therapy. Biochem Pharmacol 88(4):540-547.

11. Sorrentino P, Iuliano A, Polverino A, Jacini F, \& Sorrentino G (2014) The dark sides of amyloid in Alzheimer's disease pathogenesis. FEBS Lett 588(5):641-652.

12. Drachman DA (2014) The amyloid hypothesis, time to move on: Amyloid is the downstream result, not cause, of Alzheimer's disease. Alzheimers Dement 10(3):372-380.

13. Carreiras MC, Mendes E, Perry MJ, Francisco AP, \& Marco-Contelles J (2013) The multifactorial nature of Alzheimer's disease for developing potential therapeutics. Curr Top Med Chem 13(15):1745-1770.

14. Thies W, Bleiler L, \& Association As (2013) 2013 Alzheimer's disease facts and figures. Alzheimers Dement 9(2):208-245.

15. Chapin III FS, Chapin MC, Matson PA, \& Vitousek P (2011) Principles of terrestrial ecosystem ecology (Springer).

16. De Meester L, Gómez A, Okamura B, \& Schwenk K (2002) The Monopolization Hypothesis and the dispersal-gene flow paradox in aquatic organisms. Acta Oecologica 23(3):121-135.

17. Vellend M (2010) Conceptual synthesis in community ecology. Q Rev Biol 85(2):183-206.

18. Chase JM (2003) Community assembly: when should history matter? Oecologia 136(4):489498.

19. Hubin E, van Nuland NA, Broersen K, \& Pauwels K (2014) Transient dynamics of A $\beta$ contribute to toxicity in Alzheimer's disease. Cell Mol Life Sci. 71(18), 3507-3521.

20. Erten-Lyons D, et al. (2009) Factors associated with resistance to dementia despite high Alzheimer disease pathology. Neurology 72(4):354-360.

21. Acx H, et al. (2013) Signature A $\beta$ Profiles Are Produced by Different $\gamma$-Secretase Complexes. J Biol Chem 289(7):4346-4455.

22. Kuperstein I, et al. (2010) Neurotoxicity of Alzheimer's disease A $\beta$ peptides is induced by small changes in the A $\beta 42$ to A $\beta 40$ ratio. The EMBO journal 29(19):3408-3420.

23. Pauwels K, et al. (2012) Structural basis for increased toxicity of pathological $A \beta 42: A \beta 40$ ratios in Alzheimer disease. J Biol Chem 287(8):5650-5660.

24. Vandersteen A, et al. (2012) Molecular plasticity regulates oligomerization and cytotoxicity of the multipeptide-length amyloid- $\beta$ peptide pool. J Biol Chem 287(44):36732-36743.

25. Yoshiike Y, Chui DH, Akagi T, Tanaka N, \& Takashima A (2003) Specific compositions of amyloid- $\beta$ peptides as the determinant of toxic $\beta$-aggregation. $J$ Biol Chem 278(26):2364823655 . 
26. Janse J, et al. (2008) Critical phosphorus loading of different types of shallow lakes and the consequences for management estimated with the ecosystem model PCLake. Limnologica Ecology and Management of Inland Waters 38(3-4):203-219.

27. Mace GM, Norris K, \& Fitter AH (2012) Biodiversity and ecosystem services: a multilayered relationship. Trends Ecol Evol 27(1):19-26.

28. Giuffrida ML, et al. (2010) The monomer state of $\beta$-amyloid: where the Alzheimer's disease protein meets physiology. Rev Neurosci 21(2):83-93.

29. Tanzi RE, Moir RD, \& Wagner SL (2004) Clearance of Alzheimer's A $\beta$ peptide: the many roads to perdition. Neuron 43(5):605-608.

30. Peñuelas J, et al. (2013) Human-induced nitrogen-phosphorus imbalances alter natural and managed ecosystems across the globe. Nat Commun 4:2934.

31. Haass C, Kaether C, Thinakaran G, \& Sisodia S (2012) Trafficking and proteolytic processing of APP. Cold Spring Harb Perspect Med 2(5):a006270.

32. Wu L, et al. (2012) Early-onset familial Alzheimer's disease (EOFAD). Can J Neurol Sci 39(4):436-445.

33. Scheffer \& Marten (2009) Critical Transitions in Nature and Society (Princeton University Press).

34. Kilvitis HJ, et al. (2014) Ecological epigenetics. Adv Exp Med Biol 781:191-210.

35. Moulton PV \& Yang W (2012) Air pollution, oxidative stress, and Alzheimer's disease. $J$ Environ Public Health 2012:472751.

36. Tiiman A, Palumaa P, \& Tõugu V (2013) The missing link in the amyloid cascade of Alzheimer's disease - metal ions. Neurochem Int 62(4):367-378.

37. Bihaqi SW, Huang $\mathrm{H}, \mathrm{Wu} J, \&$ Zawia NH (2011) Infant exposure to lead (Pb) and epigenetic modifications in the aging primate brain: implications for Alzheimer's disease. $J$ Alzheimers Dis 27(4):819-833.

38. Adwan L \& Zawia NH (2013) Epigenetics: a novel therapeutic approach for the treatment of Alzheimer's disease. Pharmacol Ther 139(1):41-50.

39. Ramesh BN, Rao TS, Prakasam A, Sambamurti K, \& Rao KS (2010) Neuronutrition and Alzheimer's disease. J Alzheimers Dis 19(4):1123-1139.

40. Li S, et al. (2013) Environmental novelty activates $\beta 2$-adrenergic signaling to prevent the impairment of hippocampal LTP by A $\beta$ oligomers. Neuron 77(5):929-941.

41. Lye TC \& Shores EA (2000) Traumatic brain injury as a risk factor for Alzheimer's disease: a review. Neuropsychol Rev 10(2):115-129.

42. Yang Y \& Song W (2013) Molecular links between Alzheimer's disease and diabetes mellitus. Neuroscience 250:140-150.

43. Fjell AM, et al. (2014) What is normal in normal aging? Effects of aging, amyloid and Alzheimer's disease on the cerebral cortex and the hippocampus. Prog Neurobiol 117:20-40.

44. Holyoak M, Leibold MA, \& Holt RD (2005) Metacommunities. Spatial dynamics and ecological communities. (University of Chicago Press).

45. Ehrenfeld JG (2010) Ecosystem Consequences of Biological Invasions. Annual Review of Ecology, Evolution, and Systematics 41(1):59-80.

46. Benzinger TL, et al. (2013) Regional variability of imaging biomarkers in autosomal dominant Alzheimer's disease. Proc Natl Acad Sci U S A 110(47):E4502-4509.

47. Groffman PM, et al. (2006) Ecological thresholds: the key to successful environmental management or an important concept with no practical application? Ecosystems 9(1):1-13.

48. Beisner BE, Haydon DT, \& Cuddington K (2003) Alternative stable states in ecology. Frontiers in Ecology and the Environment 1(7):376-382.

49. Trzepacz PT, et al. (2014) Comparison of neuroimaging modalities for the prediction of conversion from mild cognitive impairment to Alzheimer's dementia. Neurobiol Aging 35(1):143-151.

50. Barabási AL, Gulbahce N, \& Loscalzo J (2011) Network medicine: a network-based approach to human disease. Nat Rev Genet 12(1):56-68.

51. Zheng H, Fridkin M, \& Youdim M (2014) From Single Target to Multitarget/Network Therapeutics in Alzheimer's Therapy. Pharmaceuticals 7(2):113-135.

52. Caswell H (2001) Matrix Population Models, 2nd Edition (Sinauer Associates). 
53. Mergeay J, De Meester L, Eggermont H, \& Verschuren D (2011) Priority effects and species sorting in a long paleoecological record of repeated community assembly through time. Ecology 92(12):2267-2275.

54. Carpenter SR, et al. (2011) Early warnings of regime shifts: a whole-ecosystem experiment. Science 332(6033):1079-1082.

55. Fort H, Mazzeo N, Scheffer M, \& van Nes E (2010) Catastrophic shifts in ecosystems: spatial early warnings and management procedures (Inspired in the physics of phase transitions) Journal of Physics: Conference Series 246:012035.

56. Hampel H, et al. (2014) Perspective on future role of biological markers in clinical therapy trials of Alzheimer's disease: A long-range point of view beyond 2020. Biochem Pharmacol 88(4):426-449.

57. Lee S, et al. (2014) Rational design of a structural framework with potential use to develop chemical reagents that target and modulate multiple facets of Alzheimer's disease. $J$ Am Chem Soc 136(1):299-310.

58. Mapstone M, et al. (2014) Plasma phospholipids identify antecedent memory impairment in older adults. Nat Med 20(4):415-418.

59. Tanzi RE (2013) A brief history of Alzheimer's disease gene discovery. J Alzheimers Dis 33 Suppl 1:S5-13.

60. Hashimoto Y \& Matsuoka M (2014) A mutation protective against Alzheimer's disease renders amyloid $\beta$ precursor protein incapable of mediating neurotoxicity. $J$ Neurochem. Doi: $10.1111 / \mathrm{jnc} / 12717$. 


\section{Concluding remarks and perspectives}

\section{Alzheimer's disease in the twenty-first century}

More than a century has passed since Alois Alzheimer first identified the disease now named after him (1). What was described in 1906 as a syndrome wherein elderly people became forgetful and child-like, is now recognized as the most common form of dementia affecting millions of people worldwide. The increasing number of AD patients and the lack of a cure, combined with the global economic burden, have risen the awareness that $\mathrm{AD}$, and dementia in general, must be considered as a public health priority (2).

Although it is increasingly evident that $\mathrm{AD}$ is a multifactorial disease, extensive research in the past decades has pointed in the direction of amyloid pathology as a primary driver of AD. The transition of the intrinsically disordered monomeric $A \beta$ peptide into more structured aggregates is the crucial conversion from what appears to be a harmless polypeptide into malignant forms that cause synaptotoxicity and neuronal cell death, which result in the diagnostic and pathological signs of $\mathrm{AD}(3,4)$.

Due to this central role in $\mathrm{AD}$ pathogenesis, $\mathrm{A} \beta$ has been the main target of $\mathrm{AD}$ drug development studies. However, although significant progress has been made to gain insight into disease mechanisms, it is clear that the picture is still incomplete. To date, the A $\beta$-based drugs tested in advanced-stage clinical trials in humans have been unsuccessful, mainly due to a lack of efficacy or intolerable side-effects.

\section{$\underline{\text { 2. The dynamic nature of the } A \beta \text { peptide: a disease-contributing factor }}$}

It is striking to observe that many proteins involved in human disease are classified as IDPs, such as $A \beta$, but also $\alpha$-synuclein, tau, and multiple prions (5). This raises the question as to whether their dynamic nature may act as a disease-contributing factor, as opposed to or in addition to the generally accepted idea that specific sizes or conformations of oligomeric forms of these proteins induce pathogenesis.

The aim of this doctoral thesis was thus to gain more insight into the dynamic nature of $A \beta$, as a better understanding of $\mathrm{A} \beta$ dynamics will likely benefit therapeutic strategies for tackling $\mathrm{AD}$.

The $\mathrm{A} \beta$ peptide pool in the brain is highly heterogeneous and dynamic (Chapter 1 ). Therefore, it is indispensable that the aggregation and toxic properties of the in vivo occurring $A \beta$ peptide variants are studied in detail, to assure that rational decisions are made in AD therapy design. One avenue for fighting $\mathrm{AD}$ consists of the upregulation of the non-amyloidogenic pathway at the expense of the amyloidogenic A $\beta$-producing pathway (6). Our results however indicate that the products of the proteolytic activities of $\alpha$ - and $\gamma$-secretase, the p3 peptides, are also aggregation-prone and form fibrils (Chapter 2). Upregulation of the "non-amyloidogenic" pathway might thus not be the best course to follow. Modulating $\gamma$-secretase processing to shift the balance between different $A \beta$ alloforms (e.g. decreased $A \beta_{1-42}: A \beta_{1-40}$ ratio) has also been proposed as a therapeutic strategy (7). This requires an in-depth understanding of the A $\beta$ peptide pool and the aggregation (Chapter 2) and toxic behaviour of its composing alloforms. In addition to studying the properties of the different peptides in isolation, it is however also crucial to study mixtures of different $A \beta$ alloforms to mimic the in vivo situation. Several studies have reported that mixtures of $A \beta$ alloforms behave in a more complex manner in 
vitro than anticipated from their behaviour in isolation, in terms of aggregation properties and toxicity $(8-12)$.

Another contributing factor to $A \beta$ heterogeneity is genetic variability within the $A \beta$-coding region of the $A P P$ gene, resulting in $\mathrm{A} \beta$ mutants associated with early-onset FAD (Chapter 1). FAD mutations not only affect $A \beta$ aggregation properties (Chapter 2), but can also result in structural alterations. The data presented in chapter 3 show that the Italian E22K A $\beta$ mutant forms fibrils composed of antiparallel $\beta$-sheets, as opposed to parallel $\beta$-sheet wild type fibrils. Moreover, both fibril types give rise to different inflammatory responses in THP-1 monocytes in culture. These results suggest that the observed $A \beta$ fibril polymorphism might be related to in vivo differences between wild type and Italian-mutant $A \beta$ : late-onset $A D$ associated mainly with plaques versus early-onset $\mathrm{AD}$ associated with $\mathrm{CAA}$. The antiparallel $\beta$-sheet structure might predispose the Italian $\mathrm{A} \beta$ mutant to cross the BBB and mainly deposit in the blood vessels. Although this hypothesis is speculative and requires further investigation, the CAA-associated Iowa D $23 \mathrm{~N}$ A $\beta$ mutant has recently also been shown to form antiparallel $\beta$-sheet fibrils (13).

The dynamic nature of $\mathrm{A} \beta$ allows it to interact with various cellular components, such as membranes, lipids, and metals, but also ApoE and $A \beta$-degrading enzymes (Chapter 1). Understanding the interplay of these components with $\mathrm{A} \beta$ has implications for potential AD treatments. First, modulating the secretion or lipidation status of ApoE isoforms is currently being explored as a potential treatment, as this can influence the functionality of ApoE and its effect on $\mathrm{A} \beta$ metabolism (14). The data in chapter 4 demonstrate that lipid-free ApoE has the tendency to aggregate in solution (ApoE4 $>$ ApoE3 $>$ ApoE2), and that ApoE associated with reconstituted HDL particles is protected from this self-assembly behaviour. The high AD risk associated with the ApoE4 isoform might arise from its higher propensity to aggregate, in comparison with ApoE2 and ApoE3, and its capability to form aggregates that are toxic to neuronal cells (15). Second, another therapeutic strategy under investigation is the upregulation of $A \beta$-degrading enzymes such as IDE (16). This requires a full comprehension of the degrading capabilities of these enzymes and the identification of all their potential substrates. Our findings show that the capacity of IDE to degrade $A \beta$ is dependent on the A $\beta$ aggregation state and the dynamic equilibrium between the different $A \beta$ aggregation species (Chapter 5). IDE contains an internal catalytic chamber spatially limited to the engulfment of small peptides (17) and cleavage of $A \beta$ is therefore limited to monomers. The $A \beta$ degradation detected by our analysis at later $\mathrm{A} \beta$ aggregation time points must therefore arise from cleavage of $A \beta$ monomers that are in dynamic equilibrium with higher aggregation species, forcing these aggregates to dissociate to some extent, to restore this equilibrium.

In conclusion, the dynamic interplay between various components that influence the heterogeneous $A \beta$ system is a complicating factor and must be taken into account in search for a more effective $A D$ therapy. The dynamic nature of $A \beta$ and its ability to undergo conformational changes and aggregation has hampered its study, but promising new experimental approaches and chemical tools are being developed to address $A \beta$ dynamics (18). These tools have the major advantage that they can be used directly without the need for modification of $\mathrm{A} \beta$ with additional amino acids, tags, or fluorophores $(19,20)$, as this can alter its aggregation properties as demonstrated for biotinylation of $\mathrm{A} \beta$ (Chapter 2). Finally, the research in this thesis was limited to an in vitro approach, but validating the importance of $\mathrm{A} \beta$ dynamics for $\mathrm{AD}$ in the in vivo setting should be explored in future work. 


\section{Where to go next in $\mathrm{AD}$ research?}

In addition to the dynamic nature of $A \beta$, the multifactorial character of $\mathrm{AD}$ imposes a major challenge for $\mathrm{AD}$ drug development. Most $\mathrm{AD}$ cases are sporadic and are due to a combination of genetic, environmental, and lifestyle factors. Finding a selective therapeutic agent has proven challenging as there are so many disease pathways involved.

Gradually, the attention in the AD field is shifting from single-target drugs, such as the mimetic peptide compounds presented in chapter 6, towards the development of multi-target ligands and combination therapies. Multi-target drugs not only target A $\beta$, but simultaneously address various aspects of $\mathrm{AD}$ pathology including neuroinflammation and oxidative stress $(18,21-23)$. This approach requires understanding and managing the "big picture", rather than focusing on one disease pathway. Multi-target ligands may then serve as leads for further development as network medicines. Network medicine offers a platform to understand the complexity of a disease and all the molecular pathways involved, their interconnections, and identify potential treatment strategies $(24,25)$.

In chapter 7 , we demonstrate that the complexity of the $\mathrm{A} \beta$ network in $\mathrm{AD}$ shows many similarities to an ecosystem or society, where minor perturbations might have profound effects that can result in cataclysmic events. We suggest that the dynamic A $\beta$ "ecosystem" can be used as a framework to gain more insight into disease mechanisms and support the development of new and more effective AD treatment. Combining the expertise of $\mathrm{AD}$ researchers (network medicine) and biologists (ecosystem management) may reveal the success potential of this approach.

Future AD research will however not only seek to hit the right targets with the right drug, but also to use that drug at the right disease stage (26). A growing body of evidence suggests that the underlying pathology precedes the onset of clinically detectable AD by a decade or more (27). By the time a patient is diagnosed and treated, or included in a clinical trial, massive neuronal loss and widespread pathology is usually already at hand, and this might explain failure of tested $A \beta$-based drugs. Therapies need to be applied earlier and be targeted at the disease mechanisms occurring in the brain at early disease stages (28). Hence, drugs that failed in clinical trials when tested on mild-to-moderate AD patients, such as Solanezumab (Eli Lilly) and Gantenerumab (Roche), both passive immunotherapies, are now being initiated in early mild-to-mild AD patients. If this approach turns out successful, it will however require better biomarkers that can monitor changes in the brain or blood associated with disease progression and standardization of diagnostic measurements. Whereas combined measurements of $\mathrm{A} \beta$ and total and phosphorylated tau levels remain the most promising CSF biomarkers, the search for accurate blood biomarkers continues, as blood samples are easier and cheaper to collect than performing a lumbar puncture procedure. Recently, a small-scale study identified a biomarker panel consisting of ten lipids from peripheral blood with an AD prediction accuracy of $90 \%$ in the preclinical stage (29). Further validation of biomarkers on large scale is however needed to (i) identify individuals who are most likely to respond to certain treatments by determining their disease stage and predicting their disease progress, and to (ii) monitor drug safety and treatment effectiveness. On the long run, the use of biomarkers could then set the path for personalized medicine in the field of AD.

Finally, if we want to win the fight against $\mathrm{AD}$, the interaction and open dialogue between researchers in academia, pharmaceutical companies, regulatory organizations, and patients will be of the utmost importance. Collaboration between these different stakeholders must 
expand further in light of their common goal of bringing new preventive and therapeutic solutions to $\mathrm{AD}$ patients. 


\section{References}

1. Maurer K, Volk S, \& Gerbaldo H (1997) Auguste D and Alzheimer's disease. Lancet 349(9064):1546-1549.

2. Wortmann M (2012) Dementia: a global health priority - highlights from an ADI and World Health Organization report. Alzheimers Res Ther 4(5):40.

3. Hardy J \& Allsop D (1991) Amyloid deposition as the central event in the aetiology of Alzheimer's disease. Trends Pharmacol Sci 12(10):383-388.

4. Hardy J \& Selkoe DJ (2002) The amyloid hypothesis of Alzheimer's disease: progress and problems on the road to therapeutics. Science 297(5580):353-356.

5. Uversky VN (2014) The triple power of $\mathrm{D}^{3}$ : Protein intrinsic disorder in degenerative diseases. Front Biosci (Landmark Ed) 19:181-258.

6. Endres K \& Fahrenholz F (2010) Upregulation of the $\alpha$-secretase ADAM10 - risk or reason for hope? FEBS J 277(7):1585-1596.

7. De Strooper B, Vassar R, \& Golde T (2010) The secretases: enzymes with therapeutic potential in Alzheimer disease. Nat Rev Neurol 6(2):99-107.

8. Vandersteen A, et al. (2012) Molecular plasticity regulates oligomerization and cytotoxicity of the multipeptide-length amyloid- $\beta$ peptide pool. J Biol Chem 287(44):36732-36743.

9. Pauwels K, et al. (2012) Structural basis for increased toxicity of pathological A $\beta 42: A \beta 40$ ratios in Alzheimer disease. $J$ Biol Chem 287(8):5650-5660.

10. Kuperstein I, et al. (2010) Neurotoxicity of Alzheimer's disease A $\beta$ peptides is induced by small changes in the $\mathrm{A} \beta 42$ to $\mathrm{A} \beta 40$ ratio. The EMBO journal 29(19):3408-3420.

11. Snyder SW, et al. (1994) Amyloid- $\beta$ aggregation: selective inhibition of aggregation in mixtures of amyloid with different chain lengths. Biophys $J$ 67(3):1216-1228.

12. Yoshiike Y, Chui DH, Akagi T, Tanaka N, \& Takashima A (2003) Specific compositions of amyloid-beta peptides as the determinant of toxic beta-aggregation. $J$ Biol Chem 278(26):23648-23655.

13. Qiang W, Yau WM, Luo Y, Mattson MP, \& Tycko R (2012) Antiparallel $\beta$-sheet architecture in Iowa-mutant $\beta$-amyloid fibrils. Proc Natl Acad Sci U S A 109(12):4443-4448.

14. Liu CC, Kanekiyo T, Xu H, \& Bu G (2013) Apolipoprotein E and Alzheimer disease: risk, mechanisms and therapy. Nat Rev Neurol 9(2):106-118.

15. Hatters DM, Zhong N, Rutenber E, \& Weisgraber KH (2006) Amino-terminal domain stability mediates apolipoprotein E aggregation into neurotoxic fibrils. $J$ Mol Biol 361(5):932944.

16. Malito E, Hulse RE, \& Tang WJ (2008) Amyloid $\beta$-degrading cryptidases: insulin degrading enzyme, presequence peptidase, and neprilysin. Cell Mol Life Sci 65(16):2574-2585.

17. Shen Y, Joachimiak A, Rosner MR, \& Tang WJ (2006) Structures of human insulin-degrading enzyme reveal a new substrate recognition mechanism. Nature 443(7113):870-874.

18. Lee S, et al. (2014) Rational design of a structural framework with potential use to develop chemical reagents that target and modulate multiple facets of Alzheimer's disease. J Am Chem Soc 136(1):299-310.

19. Zhang Y, et al. (2013) Pulsed hydrogen-deuterium exchange mass spectrometry probes conformational changes in amyloid beta (A $\beta)$ peptide aggregation. Proc Natl Acad Sci U S A 110(36):14604-14609.

20. Santi S, et al. (2013) Real-time amyloid aggregation monitoring with a photonic crystal-based approach. Chemphyschem 14(15):3476-3482.

21. Zheng H, Fridkin M, \& Youdim M (2014) From Single Target to Multitarget/Network Therapeutics in Alzheimer's Therapy. Pharmaceuticals 7(2):113-135.

22. Carreiras MC, Mendes E, Perry MJ, Francisco AP, \& Marco-Contelles J (2013) The multifactorial nature of Alzheimer's disease for developing potential therapeutics. Curr Top Med Chem 13(15):1745-1770.

23. Calzà L, et al. (2013) From the multifactorial nature of Alzheimer`s disease to multitarget therapy: the contribution of the translational approach. Curr Top Med Chem 13(15):18431852 . 
24. Barabási AL, Gulbahce N, \& Loscalzo J (2011) Network medicine: a network-based approach to human disease. Nat Rev Genet 12(1):56-68.

25. Jacunski A \& Tatonetti NP (2013) Connecting the dots: applications of network medicine in pharmacology and disease. Clin Pharmacol Ther 94(6):659-669.

26. Sperling RA, Jack CR, \& Aisen PS (2011) Testing the right target and right drug at the right stage. Sci Transl Med 3(111):111 cm133.

27. Braak H \& Braak E (1997) Frequency of stages of Alzheimer-related lesions in different age categories. Neurobiol Aging 18(4):351-357.

28. Gandy S (2011) Perspective: prevention is better than cure. Nature 475(7355):S15.

29. Mapstone M, et al. (2014) Plasma phospholipids identify antecedent memory impairment in older adults. Nat Med 20(4):415-418. 


\section{$\underline{\text { Summary }}$}

Protein aggregation has been associated with a wide range of highly debilitating and increasingly prevalent human diseases, ranging from neurodegenerative disorders to nonneuropathic amyloidoises. One of the most widespread neurodegenerative diseases is Alzheimer's disease (AD), which is the leading cause of dementia, affecting millions of people worldwide and imposing an enormous economic burden in terms of health and hospice care. $\mathrm{AD}$ disrupts the communication between nerve cells in the brain, which becomes apparent as a gradual loss of memory from the age of 65 years and older in the majority of $\mathrm{AD}$ cases. As $\mathrm{AD}$ pathology spreads throughout the brain causing cell death and brain atrophy, $\mathrm{AD}$ patients experience a decline in thinking skills, behavioural problems, and eventually lose their personal identity and ability to communicate, depending entirely on others for care.

More than a century has passed since Alois Alzheimer first described the disease now named after him and significant progress has been made to understand the cellular and molecular events that are responsible for the progressive dysfunction and death of nerve cells. Despite extensive testing of numerous drug compounds in clinical trials, there is unfortunately still no means of halting or reverting $\mathrm{AD}$ progression, and current treatment is limited to the alleviation of disease symptoms. As the number of $\mathrm{AD}$ cases has been predicted to nearly triple by 2050 in the ageing global population, there is a growing and urgent need to find an effective AD therapy.

Substantial evidence points to the amyloid-beta $(A \beta)$ peptide as a major causative factor in $\mathrm{AD}$. The $\mathrm{A} \beta$ peptide is cleaved from the transmembrane amyloid precursor protein by $\beta$ - and $\gamma$-secretase. This apparently harmless intrinsically disordered monomeric peptide converts into higher ordered and toxic aggregates, and eventually into amyloid fibrils that deposit into extracellular plaques in the brain. A $\beta$ aggregation initiates a cascade of molecular events culminating in widespread neurodegeneration. The amyloid cascade hypothesis suggests that synapto- and neurotoxicity in $\mathrm{AD}$ is mediated by soluble $\mathrm{A} \beta$ oligomers. However, it has proven difficult to study these aggregates in vivo with the currently available technology, due to the dynamic nature of the A $\beta$ peptide. The dynamics, stability, and transient lifetime of potentially toxic species hamper the possibility to precisely pinpoint the structural aspects of toxic A $\beta$ aggregates. Moreover, the dynamic behaviour of aggregation intermediates may actually be an important driver of $A \beta$ toxicity as the ongoing aggregation process has also been suggested to be a culprit for toxicity.

We postulate that the dynamic nature of the $A \beta$ peptide is a complicating factor that contributes to $\mathrm{AD}$ pathogenesis and should be taken into account in therapeutic AD strategies. The research presented in this doctoral thesis aims to provide more insight into $A \beta$ dynamics. The influence of genetic variability and external regulating factors on $A \beta$ dynamics, in particular on the aggregation and structural properties of $\mathrm{A} \beta$, is investigated in vitro using a biophysical approach complemented with cell culture studies.

The first part of this thesis extensively reviews what has been reported in the literature on $A \beta$ dynamics, including intra- and intermolecular dynamics (Chapter 1). Intramolecular $A \beta$ dynamics encompass the intrinsically disordered nature of $A \beta$ and the inherent flexibility of the polypeptide backbone present in every $\mathrm{A} \beta$ aggregation state. Intermolecular $A \beta$ dynamics 
are illustrated by (i) the highly transient and interconverting forms of $A \beta$, and by (ii) the variability and interactions within the pool of different $A \beta$ peptide variants in the brain. Furthermore, the dynamic nature of $\mathrm{A} \beta$ allows it to interact with many other molecules that can modulate $\mathrm{A} \beta$ properties. Variability in terms of space (different brain compartments and patient-to-patient differences) and time (ageing, lifestyle, and circadian rhythm) imposes an additional facet to the complex and dynamic "A $\beta$ network".

The second part of this thesis focuses on certain aspects of $A \beta$ dynamics and discusses their potential impact on AD pathology.

First, the heterogeneity within the in vivo $\mathrm{A} \beta$ peptide pool was investigated (Chapter 2 ). We monitored the in vitro aggregation of (i) $\mathrm{N}$ - and $\mathrm{C}$-terminal varying $\mathrm{A} \beta$ peptides, (ii) $\mathrm{A} \beta$ mutants associated with the hereditary familial type of $\mathrm{AD}$ (FAD), and (iii) biotinylated $\mathrm{A} \beta$, as this modified variant is often used in in vitro studies. We demonstrate that minor sequential variations in the $A \beta$ peptide sequence have profound effects on $A \beta$ aggregation. These findings are of interest in light of secretase activity-modifying AD therapeutic strategies that aim to lower $\mathrm{A} \beta$ production or alter the ratios between the generated $\mathrm{A} \beta$ peptide variants.

In chapter 3, we present the aggregation, structural, and inflammatory properties of the Italian E22K A $\beta$ mutant that is causative of early-onset FAD associated with cerebral amyloid angiopathy (CAA). Our findings show that the Italian $A \beta$ mutant forms fibrils containing an antiparallel $\beta$-sheet structure, in comparison to wild type fibrils that consist of parallel $\beta$ sheets, as do most amyloid fibrils reported in the literature. We suggest that this unique antiparallel structural signature might explain the clinical differences between the Italian mutant and wild type $A \beta$. We suggest that it predisposes the mutant to deposit mainly in the walls of the brain blood vessels causing CAA, rather than accumulating in amyloid plaques in the brain parenchyma.

Next, two interaction partners of $\mathrm{A} \beta$ were the subject of study: (i) Apolipoprotein $\mathrm{E}$ (ApoE) that exists as three isoforms (ApoE2, ApoE3, and ApoE4) with ApoE4 being an important risk factor for late-onset $\mathrm{AD}$, and (ii) insulin-degrading enzyme (IDE), one of the proteases in the brain that is capable of cleaving A $\beta$. First, we show that lipid-free ApoE in solution aggregates in vitro, in particular ApoE4, whereas lipidation of ApoE impedes this behaviour (Chapter 4). Although ApoE is mainly lipidated in the brain, lipid-poor ApoE reservoirs exist that could lead to the formation of ApoE aggregates. As ApoE4 aggregates have been reported to be neurotoxic, this might explain the higher AD risk associated with ApoE4, in comparison with other ApoE isoforms. Second, we provide evidence that the ability of IDE to degrade $\mathrm{A} \beta$ decreases with $\mathrm{A} \beta$ aggregation and we identify $\mathrm{Met}_{35}-\mathrm{Val}_{36}$ as a novel IDE cleavage site within the $A \beta$ sequence (Chapter 5). As IDE-induced $A \beta$ fragments are aggregation-prone, these findings must be considered in therapies that aim to increase $A \beta$ clearance by upregulating the activity of proteases such as IDE.

Therapeutic strategies capable of interfering with $\mathrm{A} \beta$-induced pathology in $\mathrm{AD}$ are the main focus of the third part of this thesis. The combination of docking analysis and molecular dynamics simulations allowed for the design of a series of new mimetic peptides possessing A $\beta$ anti-aggregation properties (Chapter 6). Computer simulations provided mechanistic insights into their potential mode of action. We demonstrate that insertion of drug compounds in the core of an $\mathrm{A} \beta$ pentamer distorts $\mathrm{A} \beta$ structure by destabilizing several molecular interactions that play a key role in fibril formation. Moreover, we experimentally confirm the predicted inhibitory effect of these compounds on $A \beta$ aggregation. Finally, as there is a shift 
in attention from single-target drugs to combination therapies that address the multifactorial nature of $\mathrm{AD}$, we present a novel way of evaluating the complexity of $\mathrm{A} \beta$ in $\mathrm{AD}$ in chapter 7 . We demonstrate that the dynamic $\mathrm{A} \beta$ network displays many similarities with an ecosystem and suggest that combining network medicine with general ecosystem management principles is a new and holistic approach to unravel $\mathrm{AD}$ mechanisms and potentially design more successful therapies.

To conclude, the research presented in this doctoral thesis illustrates the dynamic nature of $A \beta$ and demonstrates that $A \beta$ dynamics add an additional degree of complexity to the role of $A \beta$ in $\mathrm{AD}$. Fully understanding $\mathrm{A} \beta$ dynamics will most likely benefit the development of more effective AD therapies that can ultimately stop this devastating and widespread disease. 


\section{Samenvatting}

Eiwitaggregatie kan gepaard gaan met uiteenlopende en slopende ziekten in de mens, gaande van neurodegeneratieve ziekten tot lokale en systemische amyloïdoses. Een van de meest wijdverspreide neurodegeneratieve ziekten is de ziekte van Alzheimer, de belangrijkste oorzaak van dementie. Deze ziekte treft wereldwijd miljoenen personen en draagt enorme economische gevolgen met zich mee op vlak van gezondheidszorg en opvang. De ziekte van Alzheimer verstoort de communicatie tussen zenuwcellen in de hersenen en komt tot uiting als een gradueel verlies van het geheugenvermogen, in de meeste gevallen vanaf de leeftijd van 65 jaar of ouder. Verspreiding van de ziekte van Alzheimer doorheen de hersenen leidt tot celdood en hersenatrofie. Patiënten ervaren daardoor verminderde denkvaardigheden, gedragsproblemen en verliezen uiteindelijk hun persoonlijke identiteit en het vermogen om te communiceren, waardoor ze volledig afhankelijk worden van de zorg van anderen.

Het is meer dan een eeuw geleden dat Alois Alzheimer voor het eerst de ziekte beschreef die later naar hem is vernoemd. Sindsdien is aanzienlijke vooruitgang geboekt in het begrijpen van de cellulaire en moleculaire gebeurtenissen die verantwoordelijk zijn voor de geleidelijke disfunctie en dood van zenuwcellen. Er is echter nog geen middel gevonden om de progressie van de ziekte van Alzheimer te stoppen of terug te draaien, ondanks het uitgebreid testen van talrijke medicijnen. Aangezien de huidige behandelingswijze enkel ziektesymptomen verlicht, is er een groeiende en dringende behoefte aan een meer doeltreffende therapie. De wereldbevolking vergrijst en voorspellingen geven aan dat het aantal gevallen van de ziekte van Alzheimer bijna zal verdrievoudigen tegen 2050.

Substantieel bewijs wijst het amyloïde-beta $(\mathrm{A} \beta)$ peptide aan als een belangrijke oorzaak van de ziekte van Alzheimer. De enzymen $\beta$ - en $\gamma$-secretase knippen het A $\beta$ peptide uit het transmembranaire amyloïde precursor eiwit. Dit ogenschijnlijk onschuldige intrinsiek ongeordend monomere $\mathrm{A} \beta$ peptide converteert naar meer geordende en toxische aggregaten, en uiteindelijk naar amyloïde fibrillen die zich afzetten in extracellulaire plaques in de hersenen. $A \beta$ aggregatie initieert daarbij een cascade van moleculaire gebeurtenissen die culmineren in wijdverspreide neurodegeneratie. De amyloïde cascade hypothese suggereert dat oplosbare $A \beta$ oligomeren verantwoordelijk zijn voor de synapto- en neurotoxiciteit in de ziekte van Alzheimer. Het dynamische karakter van $\mathrm{A} \beta$ maakt het echter moeilijk om deze aggregaten in vivo te bestuderen met de huidige technologie. De dynamiek, stabiliteit en beperkte levensduur van potentieel toxische vormen van het peptide belemmeren de precieze bepaling van de structuur van toxische $A \beta$ aggregaten. Bovendien werd het dynamische aggregatieproces zelf ook al aangewezen als bron van toxiciteit, in plaats van specifieke vormen van $A \beta$.

Wij postuleren dat het dynamische karakter van het $\mathrm{A} \beta$ peptide een complicerende factor is die bijdraagt tot de pathogenese van de ziekte van Alzheimer en die in rekening moet gebracht worden in therapeutische strategieën. Deze doctoraatsthesis heeft als doel meer inzicht te bieden in de $A \beta$ dynamiek. De invloed van genetische variabiliteit en extern regulerende factoren op $A \beta$ dynamiek, in het bijzonder op de aggregatie en structurele eigenschappen van $\mathrm{A} \beta$, werd in vitro onderzocht met behulp van biofysische technieken en celcultuurstudies.

Het eerste deel van dit proefschrift geeft een uitgebreid overzicht van wat reeds gerapporteerd is in de literatuur over $\mathrm{A} \beta$ dynamiek, met inbegrip van intra- en intermoleculair dynamiek (Hoofdstuk 1). Intramoleculaire dynamiek omvat de intrinsiek ongeordende aard van $A \beta$ en 
de inherente flexibiliteit van het peptide. Intermoleculaire $A \beta$ dynamiek wordt geillustreerd door (i) de transiënte en interconverterende vormen van $A \beta$, en door (ii) de variabiliteit en interacties binnen de pool van verschillende $\mathrm{A} \beta$ peptide varianten in de hersenen. Bovendien laat het dynamische karakter $A \beta$ toe om te interageren met andere moleculen die het gedrag van $A \beta$ kunnen moduleren. Variabiliteit in ruimte (verschillende hersencompartimenten, verschillen tussen patiënten) en in de tijd (veroudering, levensstijl, circadiaans ritme) geeft een extra dimensie aan het complexe en dynamische "A $\beta$ netwerk".

Het tweede deel van dit proefschrift richt zich specifiek op bepaalde aspecten van de $A \beta$ dynamiek en bespreekt hun potentiële effect op de pathogenese van de ziekte van Alzheimer.

Eerst werd de heterogeniteit binnen de in vivo $\mathrm{A} \beta$ peptide pool onderzocht door het bepalen van het in vitro aggregatiegedrag van (i) $\mathrm{N}$ - en $\mathrm{C}$-terminaal variërende $\mathrm{A} \beta$ peptiden, van (ii) $\mathrm{A} \beta$ mutanten geassocieerd met de familiale vorm van de ziekte van Alzheimer die op jonge leeftijd voorkomt, en van (iii) gebiotinyleerd $A \beta$ aangezien deze gemodificeerde variant vaak gebruikt wordt in in vitro studies (Hoofdstuk 2). We tonen aan dat kleine variaties in de A $\beta$ sequentie verregaande gevolgen hebben voor $A \beta$ aggregatie. Deze bevindingen zijn van belang voor therapieën die als doel hebben de activiteit van secretasen te moduleren om $A \beta$ productie te verlagen of de ratio tussen verschillende gegenereerde $A \beta$ peptide varianten te wijzigen.

In hoofdstuk 3 presenteren we de aggregatie, structurele en inflammatorische eigenschappen van de Italiaanse E22K A $\beta$ mutant die de ziekte van Alzheimer veroorzaakt op jonge leeftijd en gepaard gaat met cerebrale amyloïde angiopathie. De resultaten tonen aan dat de Italiaanse $\mathrm{A} \beta$ mutant fibrillen vormt met een antiparallelle $\beta$-sheet structuur, in vergelijking met wild type fibrillen die opgebouwd zijn uit parallelle $\beta$-sheets zoals de meeste amyloïde fibrillen. We suggereren dat dit unieke structurele kenmerk de mutant aanzet om zich voornamelijk af te zetten in de wanden van de hersenbloedvaten, in plaats van zich op te hopen in amyloïde plaques in de hersenparenchym, en dus aan de grondslag ligt van de klinische verschillen tussen de Italiaanse mutant en wild type $\mathrm{A} \beta$.

Vervolgens waren twee interactiepartners van $A \beta$ het onderwerp van studie: (i) Apolipoproteïne E (ApoE) dat voorkomt als drie isovormen (ApoE2, ApoE3 en ApoE4) en waarvan ApoE4 een belangrijke risicofactor is voor de ziekte van Alzheimer op late leeftijd, en het (ii) insuline-degraderende enzym (IDE), één van de proteasen in de hersenen dat $A \beta$ knipt. De bevindingen in hoofdstuk 4 tonen aan dat lipide-vrij ApoE in oplossing aggregeert in vitro, in het bijzonder ApoE4, en dat lipidatie van ApoE dit gedrag belemmert. Ook al is ApoE voornamelijk gelipideerd in de hersenen, er bestaan lipide-arme ApoE reservoirs die zouden kunnen leiden tot de vorming van ApoE aggregaten. Aangezien ApoE4 aggregaten neurotoxisch zijn, kan dit het hoger risico op de ziekte van Alzheimer verklaren dat gepaard gaat met ApoE4, in vergelijking met andere ApoE isovormen. In hoofdstuk 5 leveren we bewijs dat het vermogen van IDE om $A \beta$ te degraderen afneemt met $A \beta$ aggregatie. We identificeren bovendien $\mathrm{Met}_{35}-\mathrm{Val}_{36}$ als een nieuwe IDE-knippingssite in de A $\beta$ sequentie. Aangezien IDE-geïnduceerde $A \beta$ fragmenten zelf ook aggregeren, moeten deze bevindingen in beschouwing genomen worden in therapieën die de hoeveelheid $A \beta$ in de hersenen trachten te verlagen door een toename in activiteit van $A \beta$ proteasen zoals IDE.

Het derde deel van deze thesis legt zich toe op therapeutische strategieën die interfereren met A $\beta$-geïnduceerde pathologie in de ziekte van Alzheimer. Eerst werd een reeks van nieuwe peptiden met $\mathrm{A} \beta$ anti-aggregatie eigenschappen ontworpen door het combineren van docking 
analyse en simulaties van de moleculaire dynamiek (Hoofdstuk 6). Computersimulaties brachten mechanistisch inzicht in het potentieel werkingsmechanisme van deze peptiden. De resultaten tonen aan dat de insertie van deze actieve componenten in de kern van een $\mathrm{A} \beta$ pentameer de structuur van $A \beta$ ontwricht door het destabiliseren van verschillende moleculaire interacties die een voorname rol spelen in fibrilvorming. We bevestigen bovendien experimenteel het voorspelde inhiberende effect van deze componenten op A $\beta$ aggregatie. Tenslotte, aangezien er een verschuiving is van medicijnen die één enkel doel voor ogen hebben naar combinatietherapieën en medicijnen die het multifactoriële karakter van de ziekte van Alzheimer aanpakken, presenteren we een nieuwe manier om de complexiteit van $\mathrm{A} \beta$ in de ziekte van Alzheimer te evalueren. We tonen aan dat het dynamische $A \beta$ netwerk vele gelijkenissen vertoont met een ecosysteem en suggereren dat de het combineren van netwerk medicijnen en algemene principes uit ecosysteem management een nieuwe en integrale benadering is om ziektemechanismen van Alzheimer te ontrafelen en meer succesvolle therapieën te ontwikkelen.

Tot slot, dit proefschrift illustreert het dynamische karakter van $A \beta$ en toont aan dat de $A \beta$ dynamiek een graad van complexiteit toevoegt aan de rol van $A \beta$ in de ziekte van Alzheimer. Het volledig begrijpen van deze $A \beta$ dynamiek zal hoogstwaarschijnlijk de ontwikkeling van meer effectieve therapieën voor de ziekte van Alzheimer ten goede komen, zodat deze slopende en wijdverspreide ziekte eindelijk tot halt kan geroepen worden. 


\section{Publication list}

\section{Journal articles}

Vandersteen A*, Hubin $E^{*}$, Sarroukh R, De Baets G, Schymkowitz J, Rousseau F, Subramaniam V, Raussens V, Wenschuh H, Wildemann D, and Broersen K. A comparative analysis of the aggregation behavior of amyloid- $\beta$ peptide variants (2012). FEBS Letters 586(23), 4088-4093.

* joint first authors

$\underline{\text { Hubin E}}$, van Nuland N, Broersen K, and Pauwels K. Transient dynamics of A $\beta$ contribute to toxicity in Alzheimer's disease. Cellular and Molecular Life Sciences 71(18), 3507-3521.

Hubin E, Deroo S, Kamniski Schierle G, Kamniski C, Serpell L, Subramaniam V, van Nuland N, Broersen K, Raussens V, and Sarroukh R. Distinct $\beta$-sheet structures in wild type and Italian-mutant A $\beta$ fibrils: a possible link to different clinical phenotypes. Proceedings of the National Academy of Sciences of the United States of America, under submission.

Hubin E, Verghese PB, van Nuland N, and Broersen K. ApoE associated with HDL-like particles is protected from self-aggregation. Biophysical Journal, under submission.

Hubin E, Rozenski J, van Nuland N, and Broersen K. Insights into insulin-degrading enzymemediated cleavage of the A $\beta$ peptide. FEBS Letters, under submission.

Barrera E, Andujar SA, Hubin E, Broersen K, Méndez L, Delpiccolo C, Masman MF, Rodriguez AM, and Enriz DR. New mimetic peptide inhibitors of A $\beta$ aggregation: molecular guidance for rational drug design. European Journal of Medicinal Chemistry, under submission.

Hubin E, Vanschoenwinkel B, Broersen K, Koedam N, and Pauwels K. Can ecosystem management provide a framework for Alzheimer's disease therapy? Trends in Molecular Medicine, under submission.

Deroo S, Stengel F, Mohammadi A, Henry N, Hubin E, Krammer E, Prévost M, Aebersold R, and Raussens V. Chemical crosslinking/mass spectrometry maps the amyloid $\beta$ peptide binding region on both apolipoprotein E domains. ACS Chemical Biology, under submission.

\section{Conference contributions (oral presentation)}

Hubin E, Sarroukh R, Deroo S, Kaminski Schierle G, Kaminski C, Serpell L, Subramaniam $\mathrm{V}$, van Nuland $\mathrm{N}$, Raussens $\mathrm{V}$, and Broersen $\mathrm{K}$. Antiparallel $\beta$-sheet architecture of Italianmutant amyloid- $\beta$ fibrils and their effect on inflammation. VIB seminar, April 2014, Blankenberge, Belgium.

Hubin E. Brain cells under attack - Alzheimer's disease (PechaKucha talk). Campustalks \#20 International Women's day, March 2014, Brussels, Belgium. 
Hubin E, Sarroukh R, Deroo S, Serpell L, Subramaniam V, Raussens V, van Nuland N, and Broersen K. Antiparallel $\beta$-sheet architecture of Italian-mutant amyloid- $\beta$ fibrils. TN2 conference on Alzheimer's disease and related disorders, October 2013, Amsterdam, The Netherlands

Hubin E, Rozenski J, Subramaniam V, van Nuland N, and Broersen K. Effect of ApoE isoform and lipidation status on proteolytic clearance of the amyloid-beta peptide. NVMSBSMS International Congress on Mass Spectrometry, March 2012, Rolduc, The Netherlands.

\section{Conference contributions (poster presentation)}

Antiparallel $\beta$-sheet architecture of Italian-mutant amyloid- $\beta$ fibrils. Hubin E, Sarroukh R, Deroo S, Serpell L, Subramaniam V, van Nuland N, Raussens V, and Broersen, K.

TN2 conference on Alzheimer's disease and related disorders

October 2013, Amsterdam, The Netherlands

Spetsai Summer School on Protein interactions, assemblies and human disease September 2013, Spetses, Greece

Elucidation of the proteolytic clearance mechanism of the amyloid-beta peptide by insulindegrading enzyme. Hubin E, Rozenski J, Subramaniam V, Broersen K, and van Nuland N.

Young Belgian Magnetic Resonance Scientist meeting

November 2012, Spa, Belgium

Effect of ApoE isoform and lipidation status on proteolytic clearance of the amyloid-beta peptide. Hubin E, Rozenski J, Subramaniam V, van Nuland N, and Broersen K.

VIB seminar 2012

April 2012, Blankenberge, Belgium

NVMS-BSMS International Congress on Mass Spectrometry

March 2012, Rolduc, The Netherlands

ApoE, Alzheimer's disease and Lipoprotein Biology, Keystone symposia

March 2012, Colorado, USA

Annual Dutch meeting on Molecular and Cellular Biophysics

October 2011, Veldhoven, The Netherlands

8th European Biophysics Congress (EBSA)

August 2011, Budapest, Hungary 

